\title{
IN SITU HYDRODYNAMIC AND MORPHODYNAMIC MEASUREMENTS DURING EXTREME STORM EVENTS
}

by

Stanford James Borrell

A thesis submitted to the Faculty of the University of Delaware in partial

fulfillment of the requirements for the degree of Master of Applied Sciences in Civil Engineering

Fall 2019

(C) 2019 Stanford James Borrell

All Rights Reserved 


\section{IN SITU HYDRODYNAMIC AND MORPHODYNAMIC MEASUREMENTS DURING EXTREME STORM EVENTS}

by
Stanford James Borrell

Approved:

Jack A. Puleo, Ph.D.

Professor in charge of thesis on behalf of the Advisory Committee

Approved:

Sue McNeil, Ph.D.

Chair of the Department of Civil \& Environmental Engineering

Approved:

Levi T. Thompson, Ph.D.

Dean of the College of Engineering

Approved:

Douglas J. Doren, Ph.D.

Interim Vice Provost for Graduate and Professional Education and Dean of the Graduate College 


\section{ACKNOWLEDGMENTS}

This work was supported by Delaware Sea Grant (NA18OAR4170086), the United States Coastal Research Program (W912H18P0124) and the University of Delaware (UD). A special thanks to Cliff Graviet and John Apple of Bethany Beach for site access and logistics support as well as the following students at the Center for Applied Coastal Research at UD for their assistance in field deployment and data collection efforts in unfavorable conditions: Demetra Cristaudo, Ben Gross, Michael Larner, Sravani Mallavarapu, Rory O'Boyle, Yashar Rafati, Rachael Schaefer, Liangyi Yue, and Tingting Zhu.

I would like to thank my parents, Clyde and Sarah, and significant other, Nicole, for their love and support throughout my life, as without this I would not be the person I am today. I would also like to thank my pet cat, Castor, for his emotional support and unwavering companionship.

Lastly, I would like to thank my advisor and mentor Dr. Jack A. Puleo for the opportunity to pursue a Master of Applied Sciences degree at UD in coastal engineering. Without this unforgettable experience, I would not have developed such an interest in coastal processes, an appreciation for field scientists, and a love for MATLAB. 


\section{TABLE OF CONTENTS}

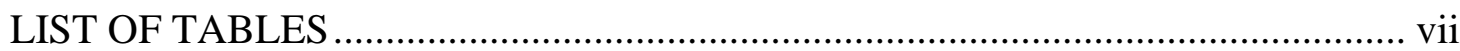

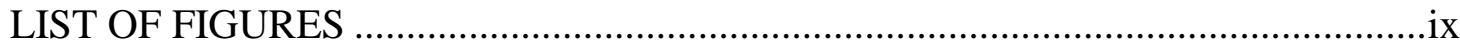

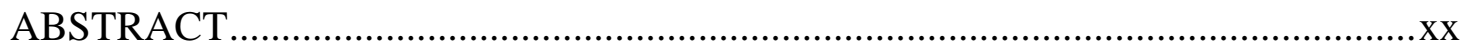

Chapter

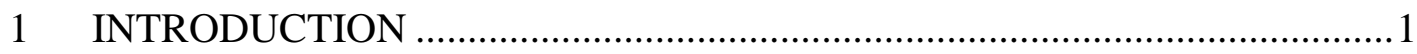

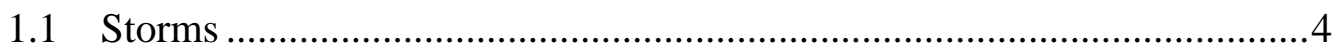

1.1.1 Nor'easter Riley \& Nor'easter Toby..........................................4

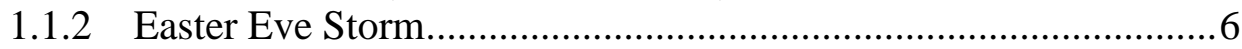

1.1.3 Storm Intensity Quantification...........................................

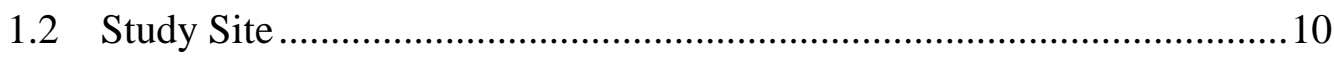

2 DEPLOYMENT TECHNIQUE........................................................ 13

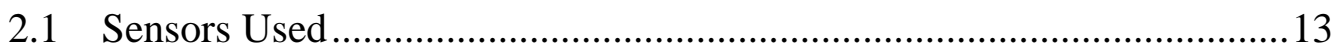

2.1.1 Acoustic Distance Meter (ADM) ...........................................14

2.1.2 Electro-magnetic Current Meter (JFE) ...................................16

2.1.3 RBR Pressure Sensor (RBR) .................................................17

2.1.4 Real-Time Kinematic Global Positioning System (RTK

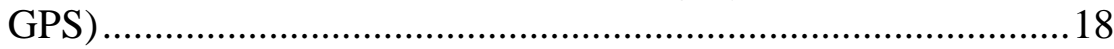

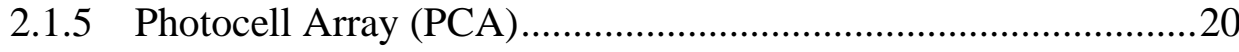

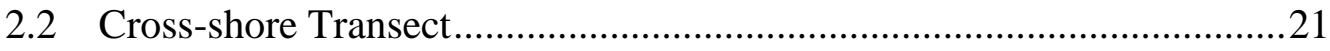

2.3 Deployment Logistics .......................................................... 24

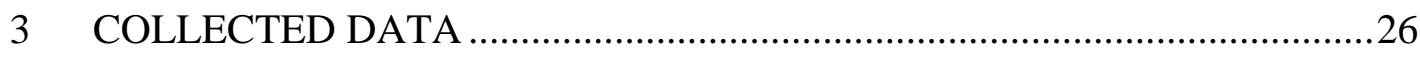

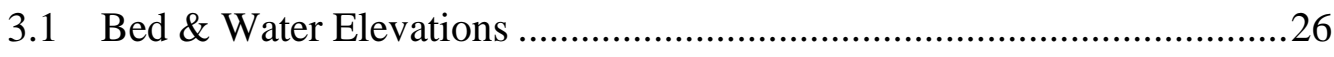

3.1.1 Converting ADM Voltage to Elevation ...................................26

3.1.2 Measuring Bed Elevations ................................................28 


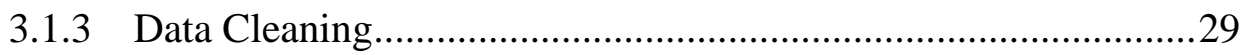

3.1.4 Data During Storm Events ...........................................................37

3.1.4.1 Nor'easter Riley .............................................................

3.1.4.2 Easter Eve Storm..........................................................41

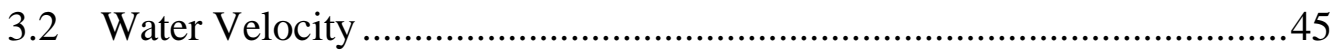

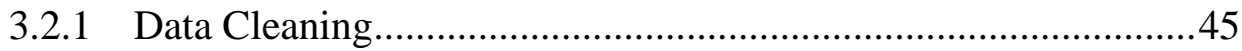

3.2.2 Data During Storm Events .........................................................47

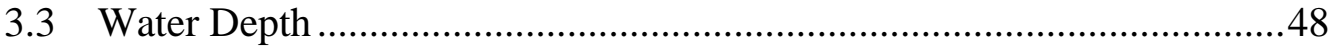

3.3.1 Depth Data Adjustments ............................................................48

3.3.2 Data Cleaning...........................................................................49

3.3.3 Calculated Water Depth from CLFF...........................................50

3.3.4 Data During Storm Events ........................................................52

3.3.4.1 Nor'easter Riley ............................................................53

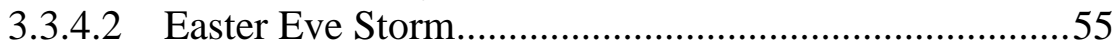

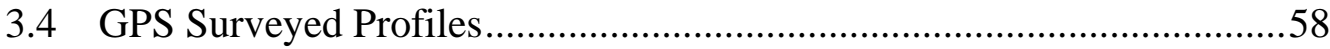

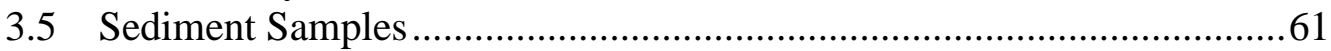

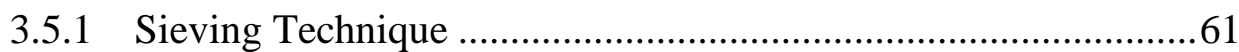

3.5.2 Grain Diameter Statistics ........................................................63

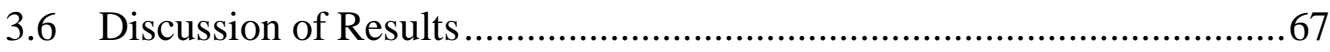

4 DATA ANALYSIS .................................................................................

4.1 Dimensionless Numbers …………………….....................................71

4.1.1 Iribarren Number .....................................................................71

4.1.1.1 Iribarren Number Background ......................................71

4.1.1.2 Measured Wave Data.......................................................73

4.1.1.3 Iribarren Number During Storm Events ........................75

4.1.2 Surf Scaling Parameter ..............................................................78

4.1.2.1 Surf Scaling Parameter Background ..............................78

4.1.2.2 Estimation of Wave Breaking Height ............................78 
4.1.2.3 Surf Scaling Parameter During Storm Events

4.1.3 Dimensionless Sediment Fall Velocity .81

4.1.3.1 Dimensionless Sediment Fall Velocity

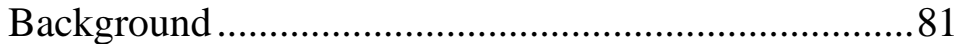

4.1.3.2 Estimation of Sediment Fall Velocity .........................82

4.1.3.3 Dimensionless Sediment Fall Velocity During Storm Events .............................................................83

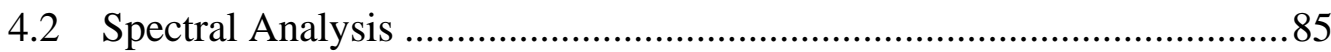

4.2.1 Spectral Energy During Storm Events ....................................86

4.2.1.1 Spectral Energy During Nor'easter Riley ...................87

4.2.1.2 Spectral Energy During Easter Eve Storm..................92

4.2.2 Spectral Energy and Offshore Wave Conditions .......................98

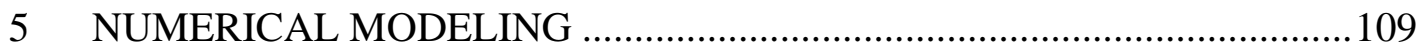

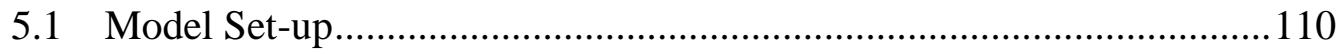

5.1.1 Bathymetry and Grid...................................................... 110

5.1.2 Environmental Conditions .................................................111

5.1.3 Input Parameters ............................................................. 113

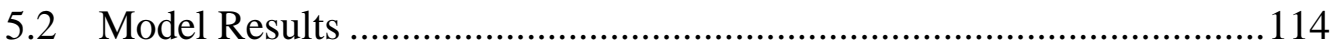

5.2.1 Input Parameter Sensitivity .................................................114

5.2.2 Model Calibration ..............................................................119

5.2.3 Discussion of Model Results .............................................122

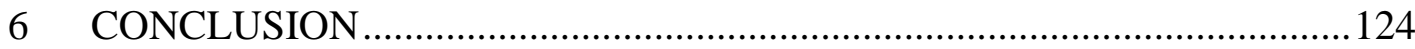

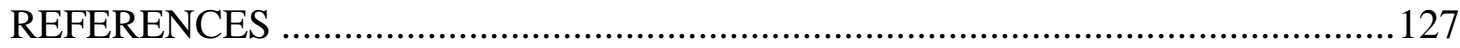




\section{LIST OF TABLES}

Table 1.1: $\quad$ Storm intensity quantification......................................................... 10

Table 3.1: $\quad$ Sigma Filter Values - Nor'easter Riley...............................................32

Table 3.2: $\quad$ Sigma Filter Values - Easter Eve Storm. .......................................... 33

Table 3.3: $\quad$ CLFF Filter Values - Nor'easter Riley............................................ 35

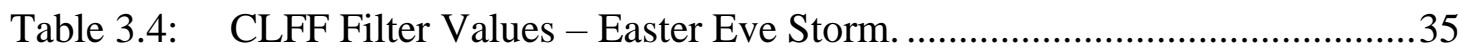

Table 3.5: Wave forcing conditions during Nor'easter Riley for each tidal cycle. Brackets $(<>)$ denote time averaged values. Parentheses denote the difference relative to previous tidal cycle. $H_{1 / 3}, H_{\max }$, and $T_{p}$ are from NBDC 44009, storm surge and maximum storm tide data are from NOAA tide gauge 8557380.

Table 3.6: Wave forcing conditions during the Easter Eve Storm for each tidal cycle. Brackets $(<>)$ denote time averaged values.

Parentheses denote the difference relative to previous tidal cycle. $H_{1 / 3}, H_{\text {max }}$, and $T_{p}$ are from NBDC 44009 , storm surge and maximum storm tide data are from NOAA tide gauge 8557380 .

Table 3.7: Wentworth Scale (adopted from (Dean \& Dalrymple, 2004)) for sand.

Table 3.8: $\quad$ Pre-storm sediment sample statistics during the Easter Eve Storm........66

Table 3.9: Mid-storm sediment sample statistics during the Easter Eve Storm .66

Table 3.10: Post-storm sediment sample statistics during the Easter Eve Storm

Table 4.1: Wave breaking types and morphodynamic beach states for ranges of $\xi$. 
Table 4.2: Wave breaking types and morphodynamic beach states for ranges of $\epsilon$. .78

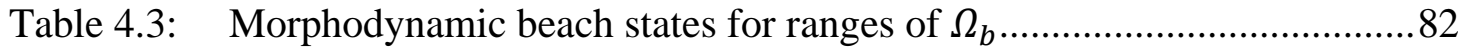

Table 4.4: Linear regression coefficients of significant water elevation $\left(\eta_{S}\right.$, $\left.\eta_{S, I G}, \eta_{S, I N C}\right)$ vs. $\gamma_{1}$ during Nor'easter Riley

Table 4.5: Linear regression coefficients of significant water elevation $\left(\eta_{S}\right.$, $\left.\eta_{S, I G}, \eta_{S, I N C}\right)$ vs. $\gamma_{2}$ during Nor'easter Riley. 103

Table 4.6: Linear regression coefficients of significant water elevation $\left(\eta_{S}\right.$, $\left.\eta_{S, I G}, \eta_{S, I N C}\right)$ vs. $\gamma_{1}$ during the Easter Eve Storm

Table 4.7: Linear regression coefficients of significant water elevation $\left(\eta_{S}\right.$, $\left.\eta_{S, I G}, \eta_{S, I N C}\right)$ vs. $\gamma_{2}$ during the Easter Eve Storm

Table 4.8: Linear regression coefficients of normalized significant water elevation $\left(\eta_{S} / H_{o}^{\prime}, \eta_{S, I G} / H_{o}^{\prime}, \eta_{S, I N C} / H_{o}^{\prime}\right)$ vs. $\xi$ during Nor'easter Riley.....

Table 4.9: Linear regression coefficients of normalized significant water elevation $\left(\eta_{S} / H_{o}^{\prime}, \eta_{S, I G} / H_{o}^{\prime}, \eta_{S, I N C} / H_{o}^{\prime}\right)$ vs. $\xi$ during the Easter Eve Storm

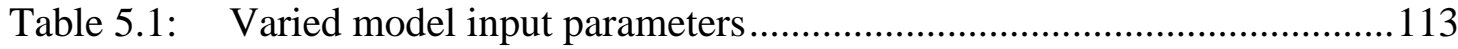

Table 5.2: Qualification of model performance ................................................. 120

Table 5.3: Model simulation input parameters yielding the highest BSS value $(0.83)$ 


\section{LIST OF FIGURES}

Figure 1.1: Satellite image of Nor'easter Riley from GOES-16 weather satellite (A). Satellite image of Nor'easter Toby from GOES-16 weather satellite (B)

Figure 1.2: Wave climate data from storms Nor'easter Riley (blue), Nor'easter Toby (red), and the Easter Eve Storm (black) obtained from NDBC 44009 (A - C) and NOAA tide gauge 8557380 (D). Significant wave height (A), Peak wave period (B), Wave direction relative to North (C), Water elevation (solid) and storm surge (broken) (D)

Figure 1.3: Geographical locations of field study site (Bethany Beach, DE), NOAA tide gauge 8557380 (Lewes, DE), and NDBC wave buoy 44009.

Figure 1.4: Cross-shore bathymetry measured in February 2018, subaerial beach profile, tidal datums, and deployment station locations at the field study site before Nor'easter Riley.

Figure 1.5: Cross-shore bathymetry measured in March 2018, subaerial beach profile, tidal datums, and station locations at the field study site before Nor'easter Toby.

Figure 1.6: Cross-shore bathymetry measured in March 2019, subaerial beach profile, tidal datums, and deployment station locations at the field study site before the Easter Eve Storm.

Figure 2.1: Schematic of deployed sensors and deployment station during field studies.

Figure 2.2: Self-contained waterproof box housing the ADM, Turnigy LIPO battery, and MadgeTech data logger.

Figure 2.3: Photo of deployment station showing the Atmosphere RBR, JFE sensing unit, and JFE temperature probe. 
Figure 2.4: Photos of Leica RTK GPS and push-cart to obtain cross-shore elevation profiles.

Figure 2.5: Photo of PCA during Easter Eve Storm deployment

Figure 2.6: Cross-shore transect of monopole deployment stations (with identification labels) installed during Nor'easter Toby. Same installation technique was used during Nor'easter Riley....

Figure 2.7: Photos of monopole deployment station structural failure during Nor'easter Riley (A) and Nor'easter Toby (B).

Figure 2.8: Photo of framed deployment stations during the Easter Eve Storm. 24

Figure 3.1: Example of an ADM calibration plot. Calibration equation was used to convert ADM output voltage to units of distance.

Figure 3.2: Example of ADM distance (blue) and elevation (orange) values at deployment Station C during Nor'easter Riley.... 28

Figure 3.3: Water elevation (blue) and raw identified bed elevation (red) data at deployment Station C during Nor'easter Riley.....

Figure 3.4: Water elevation (blue) and identified bed elevation (red) data at deployment Station C during Nor'easter Riley. Bed elevation data was cleaned using the RBR Filter.

Figure 3.5: Water elevation (blue) and identified bed elevation (red) data at deployment Station C during Nor'easter Riley. Bed elevation data was cleaned using the Sigma Filter.....

Figure 3.6: Water elevation (blue), identified bed elevation (red), and CLFF Filter tolerance values (green and magenta) at deployment Station C during Nor'easter Riley.

Figure 3.7: Water elevation (blue) and identified bed elevation (red) data at deployment Station C during Nor'easter Riley. Bed elevation data was cleaned using the CLFF Filter.

Figure 3.8: Water elevation (blue), bed elevation (red), and continuous low frequency fit (CLFF, black) at all deployment stations during Nor'easter Riley. 
Figure 3.9: Water elevation (blue), bed elevation (red), and continuous low frequency fit (CLFF, black) at all deployment stations during the Easter Eve Storm.

Figure 3.10: Wave forcing ( $A$ and $B$ ), relative bed elevation change $(C)$, and beach face slope measured from Station $C$ and Station F (D) during Nor'easter Riley. The significant wave height (A, blue) and peak wave period (B) are from NDBC Buoy 44009. The tidal and storm surge data (A, black and grey) are from NOAA tide gauge 8557380 .

Figure 3.11: Wave forcing (A and B), relative bed elevation change (C), and beach face slope measured from Station A and Station F (D) during the Easter Eve Storm. The significant wave height (A, blue) and peak wave period (B) are from NDBC Buoy 44009. The tidal and storm surge data (A, black and grey) are from NOAA tide gauge 8557380 .

Figure 3.12: 1:1 comparison plot of elevation data measured by the ADM vs. elevation data surveyed by the GPS at each day-time low tide during Nor'easter Riley. The root-mean-square error (RMSE) was calculated at each station and averaged to obtain a final $R M S E$ value.

Figure 3.13: 1:1 comparison plot of elevation data measured by the ADM vs. elevation data surveyed by the GPS at each day-time low tide during the Easter Eve Storm. The root-mean-square error (RMSE) was calculated at each station and averaged to obtain a final $R M S E$ value

Figure 3.14: Elevation data recorded by the $\operatorname{ADM}(\mathrm{A}$, blue and tan), adjusted JFE elevation (A, magenta), water and bed elevation tolerance values (A, black), and velocity data recorded by the JFE (B and C) during Nor'easter Riley at deployment Station C. Velocity data was cleaned using Equation 3.7.

Figure 3.15: Cross-shore velocity measurements during Nor'easter Riley.....

Figure 3.16: Cross-shore velocity measurements during Nor'easter Riley. .48 
Figure 3.17: Depth data (raw and adjusted) measured by the RBR pressure sensor from deployment Station C during Nor'easter Riley. Raw depth (blue) data is directly off the RBR before adjustments were applied (red and black).

Figure 3.18: Elevation data recorded by the ADM (A, blue and tan), adjusted RBR elevation (A, solid black), bed elevation tolerance values (A, broken black), and depth data recorded by the RBR (B) during Nor'easter Riley at deployment Station C. Depth data was cleaned using Equation 3.8.

Figure 3.19: Measured water elevation (A, blue) and bed elevation CLFF (A, $\tan )$ used to calculate water depth (B) during Nor'easter Riley at deployment Station C

Figure 3.20: Wave forcing (A and B), measured water depth (C), and calculated water depth (D) during Nor'easter Riley. The significant wave height (A, blue) and peak wave period (B) are from NDBC Buoy 44009. The tidal and storm surge data (A, black and grey) are from NOAA tide gauge 8557380

Figure 3.21: Mean measured (A), mean calculated (B), maximum measured (C), maximum calculated (D) water depths per tidal cycle at each deployment station during Nor'easter Riley.

Figure 3.22: Wave forcing (A and B), measured water depth (C), and calculated water depth (D) during the Easter Eve Storm. The significant wave height (A, blue) and peak wave period (B) are from NDBC Buoy 44009. The tidal and storm surge data (A, black and grey) are from NOAA tide gauge 8557380 .

Figure 3.23: Mean measured (A), mean calculated (B), maximum measured (C), maximum calculated (D) water depths per tidal cycle at each deployment station during the Easter Eve Storm 58

Figure 3.24: GPS surveyed profiles of the beach face during Nor'easter Riley. .59

Figure 3.25: GPS surveyed profiles of the beach face during the Easter Eve Storm. 60

Figure 3.26: GPS surveyed profiles of the beach face during Nor'easter Toby. 60 
Figure 3.27: Various sized sieves (A) and stack of sieves in descending size on a machine used for shaking sediment samples (B).

Figure 3.28: Cumulative grain size distribution at each deployment station during the Easter Eve Storm.

Figure 4.1: Measured significant wave height (blue), deep water wave height (red) and equivalent deep water wave height (black) during Nor'easter Riley (A) and the Easter Eve Storm (B).

Figure 4.2: Equivalent deep water wave height (A), peak wave period (B), beach face slope (C), and Iribarren number values (D) during Nor'easter Riley. .76

Figure 4.3: Equivalent deep water wave height (A), peak wave period (B), beach face slope $(C)$, and Iribarren number values (D) during the Easter Eve Storm.

Figure 4.4: Equivalent deep water and breaking wave height (A), wave peak period (B), beach face slope (C), and surf scaling parameter (D) during Nor'easter Riley.

Figure 4.5: Equivalent deep water and breaking wave height (A), wave peak period (B), beach face slope (C), and surf scaling parameter (D) during the Easter Eve Storm. 80

Figure 4.6: Breaking wave height (A), wave peak period (B), and dimensionless sediment fall velocity (C) during Nor' easter Riley

Figure 4.7: Breaking wave height (A), wave peak period (B), and dimensionless sediment fall velocity (C) during the Easter Eve Storm 84

Figure 4.8: Spectral energy time stack during Nor'easter Riley at deployment Station B.

Figure 4.9: Spectral energy time stack during Nor'easter Riley at deployment Station C.

Figure 4.10: Spectral energy time stack during Nor'easter Riley at deployment Station E. 88 
Figure 4.11: Time series of water elevation (A) with denoted 20-minute time segment (solid magenta), demeaned water elevation during 20minute time segment (B), and power spectral density (C) during tidal cycle 2 of Nor'easter Riley at Station B.

Figure 4.12: Time series of water elevation (A) with denoted 20-minute time segment (solid magenta), demeaned water elevation during 20minute time segment (B), and power spectral density (C) during tidal cycle 3 of Nor'easter Riley at Station C.

Figure 4.13: Time series of the total (blue), incident (black), and infragravity (red) band energy during Nor'easter Riley.

Figure 4.14: Percent of total spectral energy time series of the incident (black) and infragravity (red) band during Nor'easter Riley. The 50\% threshold (magenta) is shown.

Figure 4.15: Spectral energy time stack during the Easter Eve Storm at deployment Station A.

Figure 4.16: Spectral energy time stack during the Easter Eve Storm at deployment Station B

Figure 4.17: Spectral energy time stack during the Easter Eve Storm at deployment Station C

Figure 4.18: Time series of water elevation (A) with denoted 20-minute time segment (solid magenta), demeaned water elevation during 20minute time segment (B), and power spectral density (C) during tidal cycle 2 of Easer Eve Storm at Station A.

Figure 4.19: Time series of water elevation (A) with denoted 20-minute time segment (solid magenta), demeaned water elevation during 20minute time segment (B), and power spectral density (C) during tidal cycle 2 of Easer Eve Storm at Station B

Figure 4.20: Time series of water elevation (A) with denoted 20-minute time segment (solid magenta), demeaned water elevation during 20minute time segment (B), and power spectral density (C) during tidal cycle 3 of Easer Eve Storm at Station C

Figure 4.21: Time series of the total (blue), incident (black), and infragravity (red) band energy during the Easter Eve Storm. 
Figure 4.22: Percent of total spectral energy time series of the incident (black) and infragravity (red) band during the Easter Eve Storm. The 50\% threshold (magenta) is shown.

Figure 4.23: Timeseries of demeaned significant water elevation at each crossshore deployment station during Nor'easter Riley. The total (blue), incident band (black) and infragravity band (red) significant water elevations are shown.

Figure 4.24: Timeseries of demeaned significant water elevation at each crossshore deployment station during the Easter Eve Storm. The total (blue), incident band (black) and infragravity band (red) significant water elevations are shown.

Figure 4.25: Total (top), infragravity band (middle), and incident band (bottom) significant water elevation (circles) correlated using linear regression (solid lines) with $\gamma_{1}$ parameter proposed by Stockdon (2006) at each cross-shore deployment station during Nor'easter Riley.

Figure 4.26: Total (top), infragravity band (middle), and incident band (bottom) significant water elevation (circles) correlated using linear regression (solid lines) with $\gamma_{2}$ parameter proposed by Stockdon (2006) at each cross-shore deployment station during Nor'easter Riley

Figure 4.27: Total (top), infragravity band (middle), and incident band (bottom) significant water elevation (circles) correlated using linear regression (solid lines) with $\gamma_{1}$ parameter proposed by Stockdon (2006) at each cross-shore deployment station during the Easter Eve Storm.

Figure 4.28: Total (top), infragravity band (middle), and incident band (bottom) significant water elevation (circles) correlated using linear regression (solid lines) with $\gamma_{2}$ parameter proposed by Stockdon (2006) at each cross-shore deployment station during the Easter Eve Storm.

Figure 4.29: Total (top), infragravity band (middle), and incident band (bottom) significant water elevation (circles) correlated using linear regression (solid lines) with $\xi$ at each cross-shore deployment station during Nor'easter Riley. 105 
Figure 4.30: Total (top), infragravity band (middle), and incident band (bottom) significant water elevation (circles) correlated using linear regression (solid lines) with $\xi$ at each cross-shore deployment station during the Easter Eve Storm.

Figure 5.1: Pre-simulation cross-shore bathymetry and beach face profile with variable grid spacing.

Figure 5.2: Environmental (wave, tidal, and wind) forcing conditions used in XBeach model simulations. Wave height (A, blue), water elevation (A, black), wave period (B), and wave direction (D, red) were obtained from USACE DE003 buoy. Wind speed (C) and wind direction (D, blue) were obtained from the Bethany Beach Boardwalk Station of DEOS.

Figure 5.3: XBeach model simulations evaluating the sensitivity of the facAs (A) and $f a c S k$ (B) parameters. The parameters wetslp, bedfriction, and bedfriccoef had values of 0.1, manning, and 0.02, respectively, for all model simulations.

Figure 5.4: XBeach model simulations evaluating the sensitivity of the wetslp parameter. The parameters facAs, facSk, bedfriction, and bedfriccoef had values of 0.1, 0.4, manning, and 0.02, respectively, for all model simulations.

Figure 5.5: XBeach model simulations evaluating the sensitivity of the bedfriction (manning, A and white-colebrook, B) and bedfriccoef parameters. The parameters facAs, facSk, and wetslp had values of $0.1,0.4$, and 0.1 , respectively, for all model simulations.

Figure 5.6: XBeach model results (broken lines) yielding the highest BSS (0.83) compared to collected GPS surveys (solid lines). Deployment stations (grey circles) are shown for reference.

Figure 5.7: XBeach model results (tan) and collected in situ field data (magenta) time series of bed elevation at each cross-shore deployment station.

Figure 5.8: XBeach model results (red) and collected in situ field data (blue) time series of water elevation at each cross-shore deployment station. 


\section{LIST OF SYMBOLS}

$<\ldots>$ Time-averaged value

[...] Spatially-averaged value

$A \quad$ Archimedes buoyancy index

$A_{s} \quad$ Wave asymmetry

BSS Brier Skill Score

C Speed of sound in air

$c_{f} \quad$ Dimensionless bed friction coefficient

$D \quad$ Sensor-to-target distance

$d \quad$ Sediment grain diameter

$d_{50} \quad$ Median sediment grain diameter

$d_{90} \quad$ Sediment grain diameter $90 \%$ finer by weight

$d_{J F E}^{b} \quad$ JFE bed elevation tolerance distance

$d_{J F E}^{\eta} \quad$ JFE water elevation tolerance distance

$d_{R B R}^{b} \quad$ RBR bed elevation tolerance distance

$d f \quad$ Frequency bin resolution

$d t \quad$ Sampling rate

$d x \quad$ Cross-shore grid spacing

$\left(\frac{d z}{d t}\right)_{c} \quad$ Critical rate of elevation change

$f \quad$ Spectral frequency

$f_{A S} \quad$ facAs parameter

$f_{s} \quad$ Sampling frequency

$f_{S k} \quad$ facSk parameter

$g$ Gravitational acceleration

$h \quad$ Water depth

$h_{b} \quad$ Wave breaking depth

$H_{1 / 3} \quad$ Significant wave height

$H_{b} \quad$ Wave breaking height

$H_{\max }$ Maximum significant wave height

$H_{o} \quad$ Deep water wave height

$H_{o}^{\prime} \quad$ Equivalent deep water wave height

I Nor'easter risk index

$k \quad$ Wave number

$k_{b} \quad$ Wave breaking empirical coefficient

$k_{s} \quad$ Nikuradse grain roughness

$K_{r} \quad$ Refraction coefficient

$K_{S} \quad$ Shoaling coefficient

$L_{o} \quad$ Deep water wave length

$M_{d} \quad$ Mean grain diameter 


$\begin{array}{ll}m & \text { Slope of linear regression } \\ N & \text { Number of data points } \\ P & \text { Hydrostatic pressure } \\ P_{a t m} & \text { Atmospheric pressure } \\ P S D & \text { Energy spectra } \\ R e & \text { Particle Reynolds number } \\ R M S E & \text { Root-mean-square error } \\ r^{2} & \text { Coefficient of determination } \\ S & \text { Storm surge } \\ S_{k} & \text { Wave skewness } \\ S_{m a x} & \text { Maximum storm surge } \\ S_{2 S D} & \text { Storm surge values greater than two standard deviations } \\ S E P I & \text { Storm erosion potential index } \\ S P & \text { Storm power } \\ S & \text { Sediment-to-fluid density ratio } \\ t & \text { Time } \\ t_{A D M} & \text { Transit time of emitted acoustic energy } \\ t_{c} & \text { Minimum time } \\ t_{i n t} & \text { Time interval } \\ T_{C} & \text { Temperature in units of Celsius } \\ T_{D} & \text { Storm duration } \\ T_{p} & \text { Peak wave period } \\ \text { tan } \theta & \text { Beach face slope } \\ u & \text { Cross-shore velocity measured in situ } \\ u_{a} & \text { Sediment advection velocity } \\ u_{E} & \text { X-component of the Eulerian flow velocity } \\ u_{r m s} & \text { Root-mean square velocity } \\ v_{E} & \text { Y-component of the Eulerian flow velocity } \\ W & \text { Filter weight } \\ W_{B L} & \text { Bed elevation lower filter weight } \\ W_{B U} & \text { Bed elevation upper filter weight } \\ W_{W} & \text { Water elevation filter weight } \\ w_{S} & \text { Sediment fall velocity } \\ Z_{D T L T} & \text { ADM measured bed elevation during day-time low tide } \\ Z_{G P S} & \text { GPS surveyed bed elevation during day-time low tide } \\ Z^{\prime} & \text { Bed elevation segment } \\ \bar{Z} & \text { Mean of bed elevation segment } \\ Z_{\sigma} & \text { Standard deviation of bed elevation segment } \\ Z_{C L F F}^{\prime} & \text { CLFF segment } \\ Z & \text { Elevation measurement } \\ & \end{array}$


$z_{c} \quad$ Computed bed elevation

$z_{o} \quad$ Initial bed elevation

$z_{C L F F} \quad$ Bed elevation CLFF

$Z_{J F E} \quad$ JFE sensing unit elevation

$Z_{R B R} \quad$ RBR elevation

$\alpha \quad$ Sediment skewness

$\beta \quad$ Sediment kurtosis

$\gamma_{1} \quad$ Offshore wave parameter (Stockdon, 2006)

$\gamma_{2} \quad$ Offshore wave parameter with beach slope (Stockdon, 2006)

$\gamma_{b} \quad$ Breaker index

$\Delta t \quad$ Time interval between measurement values

$\frac{\partial z_{b}}{\partial x} \quad$ Underwater bed slope

$\epsilon \quad$ Surf scaling parameter

$\eta \quad$ Water elevation

$\eta_{M H H W}$ Water elevation greater than the mean higher high water

$\eta_{S} \quad$ Significant water elevation

$\eta_{S, I G} \quad$ Significant water elevation within infragravity band

$\eta_{S, I N C}$ Significant water elevation within incident band

$\eta^{\prime} \quad$ Water elevation segment

$\eta_{\sigma^{2}}^{\prime} \quad$ Variance of water elevation segment

$\theta \quad$ Post-refraction wave direction relative to shore-normal

$\theta_{o} \quad$ Wave direction relative to shore-normal

$\theta_{N} \quad$ Wave direction relative to North

$\Theta \quad$ Shields parameter

$v \quad$ Kinematic fluid viscosity

$\xi \quad$ Iribarren number

$\rho \quad$ Density of sea water

$\sigma \quad$ Sediment sorting

$\tau_{b x}^{E} \quad \mathrm{X}$-component of bed shear stress

$\tau_{b y}^{E} \quad$ Y-component of bed shear stress

$\tau_{b} \quad$ Bed shear stress calculated from quadratic drag law

$\varphi \quad$ Sediment phi units

$\Omega_{b} \quad$ Dimensionless sediment fall velocity using $H_{b}$

$\Omega_{o} \quad$ Dimensionless sediment fall velocity using $H_{o}$

$\omega \quad$ Wave radian frequency 


\begin{abstract}
Wave forcing from hurricanes, nor'easters, and energetic storms can cause erosion of the berm and beach face resulting in increased vulnerability of dunes and coastal infrastructure. LIDAR or other surveying techniques have quantified post-event morphology, but there is a lack of in situ hydrodynamic and morphodynamic measurements during extreme storm events. Two successful field studies were conducted in March 2018 and April 2019 at Bethany Beach, Delaware where in situ hydrodynamic and morphodynamic measurements were made during a nor' easter (Nor'easter Riley) and an energetic storm (Easter Eve Storm). An array of sensors to measure water velocity, water depth, water elevation and bed elevation were mounted to scaffold pipes and deployed in a single cross-shore transect. GPS profiles of the beach face were measured during every day-time low tide throughout the storm events. Calibration of the popular numerical model, XBeach, was performed using the collected in situ field data during Nor'easter Riley.
\end{abstract}




\section{Chapter 1}

\section{INTRODUCTION}

The East Coast of the United States of America is heavily impacted by extreme storm events, hurricanes and nor'easters, which result in property damage, reduced ecosystem function, and the loss of life. Two of the most recent hurricanes to make landfall in the mid-Atlantic region are Hurricane Florence (2018) and Hurricane Sandy (2012). The total estimated cost and casualties of these storms were $\$ 24$ billion with 53 deaths and \$65 billion with 159 deaths, respectively (Smith et al., 2019). One of the most infamous nor'easters in history, The Great Ash Wednesday Storm of 1962, had a total estimated cost of \$7.7 billion (adjusted for inflation) with 40 estimated casualties (Davis \& Dolan, 1993; Savadove \& Buchholz, 1997). An extremely energetic nor'easter, commonly referred to as Nor'Ida, occurred from November $12^{\text {th }}-14^{\text {th }}, 2009$ when the remnants of Hurricane Ida collided with a nor'easter. Nor'Ida severely impacted the northeastern US coast, especially the state of New Jersey where initial damage estimates were \$180 million (New Jersey Office of Emergency Management, 2014). The effects of climate change may alter the risk associated with future storms through sea level rise and the possible increase in storm frequency and intensity (Bender et al., 2010).

The state of Delaware is especially vulnerable to the impacts of coastal storms due to low elevation and that no geographical location in the state is 
farther than $12.9 \mathrm{~km}$ (8 miles) from tidal waters (Runkle et al., 2017). The Delmarva coast was found to be the most vulnerable area on the U.S. East Coast to storm-induced erosion (Zhang et al., 2001). Land subsidence exacerbates the problem resulting in local sea level rise almost double the global sea level rise rate (Bason et al., 2009). These issues, along with the fact that Delaware can be affected by both hurricanes and nor'easters, establish a need to understand the impact of these storms to improve

coastal planning and resilience. Coast-related activities have be shown to be critical to the state economy with respect to total industry production, jobs, and tax revenue (Latham \& Lewis, 2012).

The meteorological behavior and resulting impact vary between the two storm types, as hurricanes tend to cause more damage than nor'easters but for a shorter duration. The duration of intense forcing for a hurricane is typically on the time scale of hours, while the duration of a nor'easter can last for days. Nor'easters usually occur over many tidal cycles and the associated storm surge can be especially destructive during spring tides. The erosion potential for a nor'easter can be similar, if not greater, compared to a hurricane due to the longer duration of intense forcing (Davis \& Dolan, 1993; Zhang et al., 2001).

The Delaware coastline is often void of offshore sandbars (Roberts et al., 2013), causing initial wave breaking close to shore. Therefore, the beach face acts as a 'first line of defense' against storms while dunes act as a 'last line of defense' to protect coastal infrastructure. In general, the erosional vulnerability of a beach is dependent on the morphological geometry (Aagaard et al., 2005; Wright, 1980). For example, reflective (steep) beaches are more vulnerable to erosion due to 
subharmonic resonance which can lead to berm overtopping, while dissipative (flat) beaches require strong infragravity (low frequency) oscillations that penetrate to the backbeach (Wright, 1980). The coupling of increased water levels and increased offshore wave heights can drastically change the geometry of the beach during a storm event, often steepening the beach face and depositing sediment offshore in the form of a sandbar. This resultant profile is commonly referred to as a bar-type (or storm) profile, whereas a pre-storm berm-type (or swell) profile has a wide subaerial beach face and no evident offshore sandbar (Komar, 1998) as shown in. Bar and berm-type profiles are also referred to as winter and summer profiles, respectively, due to their seasonal occurrence (Bascom, 1953; Shepard, 1950). However, the common lack of sandbars at Delaware beaches results in an almost evenly distributed planar nearshore deposit (Roberts et al., 2013). Storm-induced berm erosion and the absence of protective sandbars can lead to an increased vulnerability to the backbeach and dunes along the Delaware coastline. Therefore, it is necessary to understand the hydrodynamic forcing and resulting morphodynamic beach response during storm events to properly assess the risk posed to coastal infrastructure. Various in situ sensors were deployed to quantify the hydrodynamic forcing and resulting beach response during extreme storm events at Bethany Beach, Delaware. The sensors were deployed from seaward of the prestorm berm to the dune toe. Various past efforts (Aagaard et al., 2005; Almeida et al., 2013; Harley et al., 2017; Senechal et al., 2011; Stockdon et al., 2006; Vousdoukas et al., 2012) have used remote sensing (e.g. LIDAR and video cameras) or real-time kinematic global positioning units (RTK-GPS) to measure 
the hydrodynamics and morphodynamics during storms. However, the amount of in situ data collected during a storm across the beach is limited due to the challenging environment. Sensors can become buried or lost, the structures which the sensors are deployed (i.e. scaffold pipes) can fail, and the short time notice of an approaching storm can make logistics difficult. Despite these difficulties, in situ data collection during storm events is needed to understand important physical processes that occur during storm events and thus improve predictive modeling capabilities (Elko et al., 2014).

\subsection{Storms}

\subsubsection{Nor'easter Riley \& Nor'easter Toby}

The Delmarva Peninsula was affected by a month-long (March 2018) winter event dubbed "The Four'easters", as there were four nor'easter storm events. Field deployments to collect in situ data were conducted during the first (Nor'easter Riley, Figure 1.1A) and fourth (Nor'easter Toby, Figure 1.1B) of these four nor'easters. 


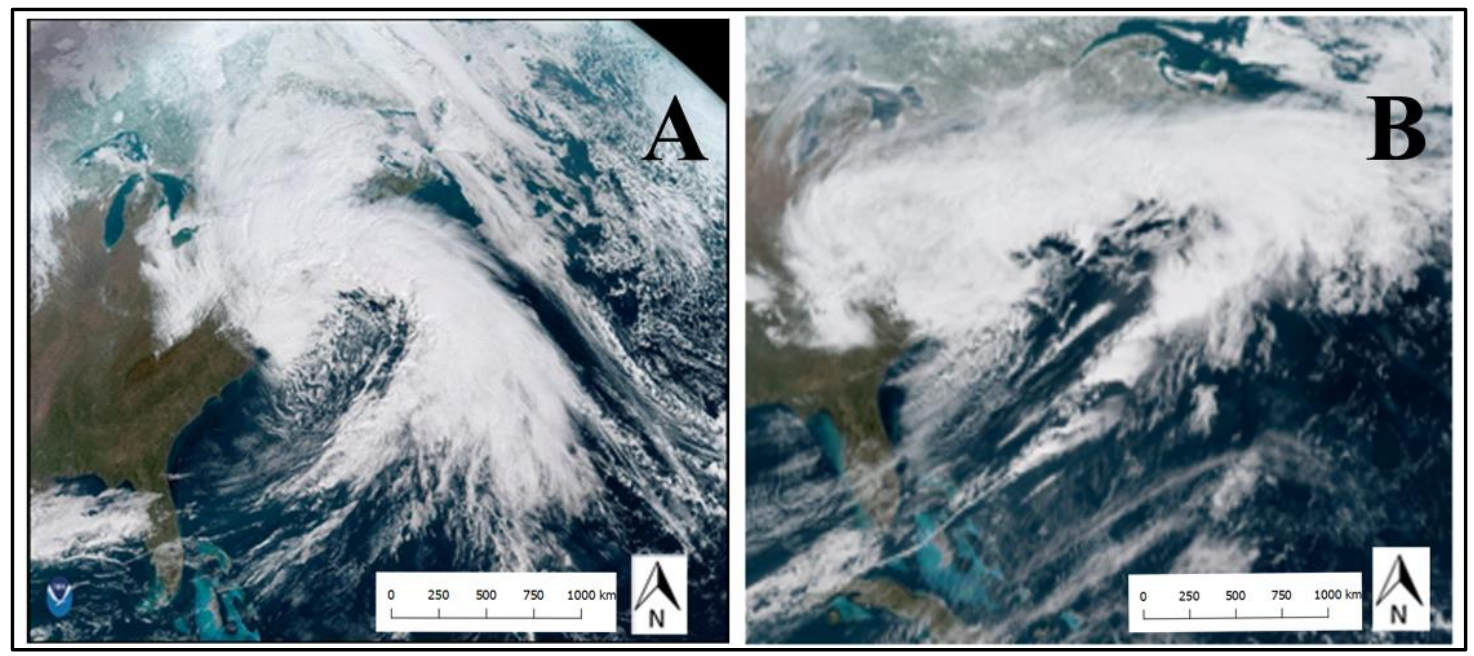

Figure 1.1: Satellite image of Nor'easter Riley from GOES-16 weather satellite (A). Satellite image of Nor'easter Toby from GOES-16 weather satellite $(\mathrm{B})$.

Nor'easter Riley underwent bombogenesis where the central pressure of the low-pressure system dropped more than 24 mbars in 24 hours (Masters, 2018). The storm continued through March 05, 2018, lasting over multiple high tides and occured during spring tides. Coastal New England was most heavily impacted by Nor'easter Riley as winds of over $40 \mathrm{~m} / \mathrm{s}(90 \mathrm{mph})$ were recorded at multiple locations, roads were inundated during high tides, a peak storm surge of $1.28 \mathrm{~m}$ was recorded at NOAA tide gauge 8443970 in Boston, Massachusetts and 240,000 homes lost power in Massachusetts (LeComte, 2019). The Delaware coast did not experience as intense of an impact, but flooding did occur in coastal towns during high tides and coastal erosion was observed. A maximum significant wave height of $4.16 \mathrm{~m}$ (Figure 1.2A), wave periods ranging from $5.3 \mathrm{~s}-16 \mathrm{~s}$ (Figure 1.2B), and wave direction ranging from $26^{\circ}-358^{\circ}$ relative to north 
(Figure 1.2C) were measured from National Buoy Data Center (NBDC) Station 44009 (Figure 1.3) during the time where the significant wave height maintained a value greater than $1.5 \mathrm{~m}$ for at least 3 consecutive hours. The peak storm surge during Nor'easter Riley measured at NOAA tide gauge 8557380 in nearby Lewes, Delaware (Figure 1.3) was $0.92 \mathrm{~m}$ (Figure 1.2C).

Nor'easter Toby occurred from March 20, 2018 - March 22, 2018 and was a less severe threat to erosion and coastal infrastructure as compared to Nor'easter Riley (Table 1.1), likely due to the shorter duration. Despite being less of a coastal threat, Nor'easter Toby caused massive snowstorms along the U.S. East Coast resulting in thousands of flight cancelations and over 100,000 homes to lose power in the mid-Atlantic and Northeast (Breslin \& Carr, 2018). Long Island, New York received the largest amount of snow fall, reporting totals over $0.51 \mathrm{~m}$ (20 in.) while wind speed magnitudes of $35 \mathrm{~m} / \mathrm{s}(79 \mathrm{mph})$ were reported in Topsfield, Massachusetts (LeComte, 2019). A maximum significant wave height of $4.41 \mathrm{~m}$ (Figure 1.2A), wave periods ranging from $5.6 \mathrm{~s}-10.8 \mathrm{~s}$ (Figure 1.2B), and wave direction ranging from $45^{\circ}-91^{\circ}$ relative to north (Figure 1.2C) were measured from NBDC Station 44009. The peak storm surge during Nor'easter Toby measured at NOAA tide gauge 8557380 was $0.87 \mathrm{~m}$ (Figure 1.2C).

\subsubsection{Easter Eve Storm}

A less extreme storm affected the Delaware coast on April 20, 2019, the day prior to the Christian holiday Easter (herein referred to as the "Easter Eve Storm"). While not a nor' easter, this brief energetic storm event occurred during spring tides, caused coastal erosion, and allowed testing an alternative sensor 
deployment technique. A maximum significant wave height of $2.46 \mathrm{~m}$ (Figure 1.2A), wave periods ranging from $7.1 \mathrm{~s}-11.4 \mathrm{~s}$ (Figure 1.2B), and wave direction ranging from $104^{\circ}-165^{\circ}$ relative to north (Figure $1.2 \mathrm{C}$ ) were measured from NBDC Station 44009. The peak storm surge during the Easter Eve Storm measured at NOAA tide gauge 8557380 was $0.23 \mathrm{~m}$ (Figure 1.2C).

\subsubsection{Storm Intensity Quantification}

The need to quantify the potential impacts of storms is important for public and coastal management interests. Accurate and timely storm impact predictions can be used to inform residents of coastal communities to make the necessary preparations for a storm event or to evacuate their homes entirely. The most well-known storm impact scale is the Saffir-Simpson scale used for hurricanes (Saffir, 1977; Simpson, 1971). The Saffir-Simpson scale ranks hurricanes from Category 1 (minor) to Category 5 (major) depending on the wind speed magnitude. 


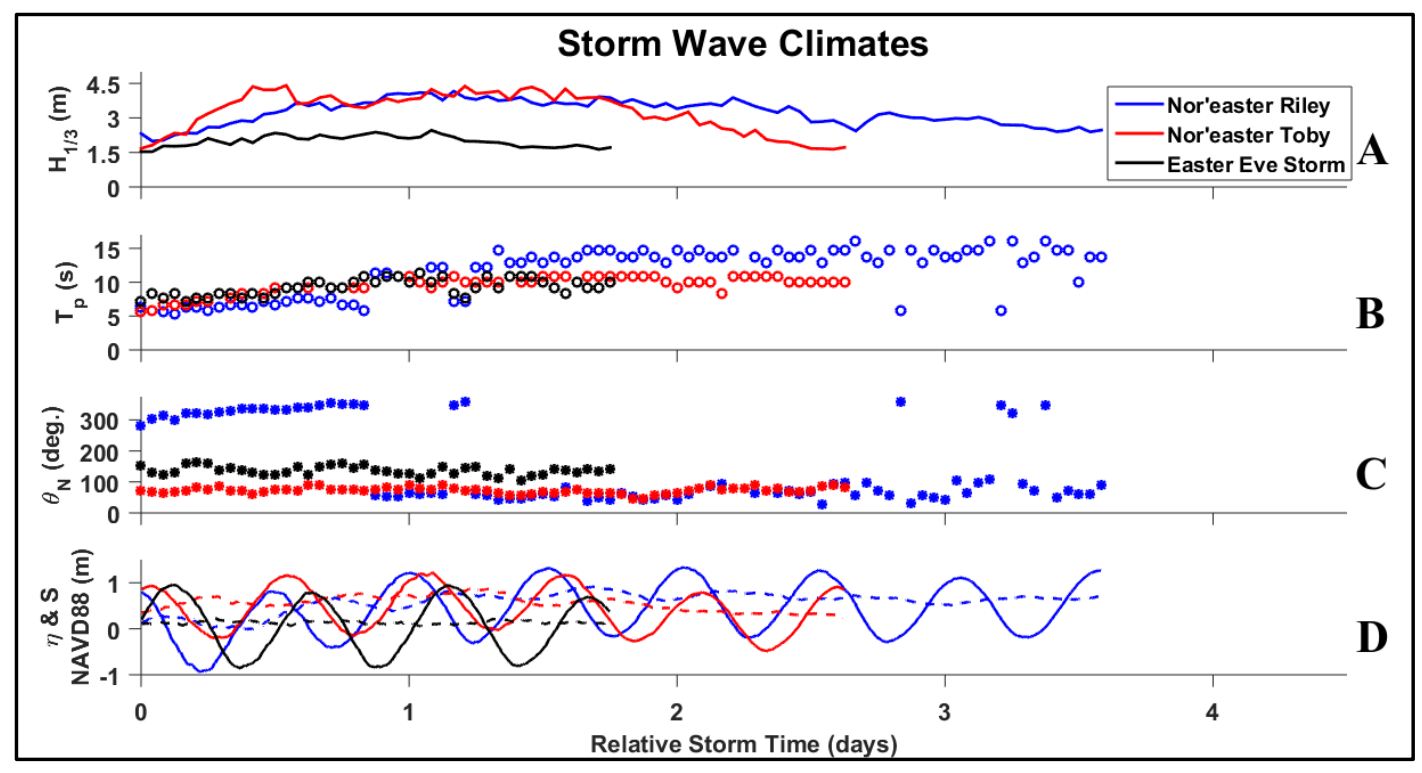

Figure 1.2: Wave climate data from storms Nor'easter Riley (blue), Nor'easter Toby (red), and the Easter Eve Storm (black) obtained from NDBC 44009 (A - C) and NOAA tide gauge 8557380 (D). Significant wave height (A), Peak wave period (B), Wave direction relative to North (C), Water elevation (solid) and storm surge (broken) (D).

While the Saffir-Simpson scale is appropriate to classify hurricanes due to large wind speeds and duration on the scale of hours, it is not an appropriate classification scale for nor'easters where wind speed magnitudes are rarely that of a hurricane and the duration is on the scale of days. In response, various storm impact scales for nor'easters (Table 1.1) have been proposed that use a combination of offshore wave conditions, duration, storm surge, and storm tide (Dolan \& Davis, 1992; Kriebel \& Dalrymple, 1995; Zhang et al., 2001).

Dolan \& Davis (1992) proposed a nor'easter intensity scale based on storm power $(S P)$ calculated as: 


$$
S P=H_{\max }{ }^{2} * T_{D},
$$

where $H_{\max }$ is the maximum significant wave height and $T_{D}$ is the storm duration. Here, a storm was defined as having offshore significant wave heights greater than or equal to $1.5 \mathrm{~m}$. To include the effects of storm surge, Kriebel \& Dalrymple (1995) proposed a nor'easter risk index $(I)$ as:

$$
I=S_{\text {max }} * H_{\text {max }} * T_{D}^{0.3},
$$

where $S_{\max }$ is the maximum storm surge during the nor'easter. It should be noted in Equation 1.2 that the storm duration is raised to the 0.3 power to reflect a weak dependence on storm duration. An important parameter that Equations 1.1 and 1.2 fail to include is storm tide, the sum of the astronomical tide and storm surge. Multiple studies (Balsillie, 1986, 1999; FitzGerald et al., 1994; Hughes, 1983; Hughes \& Chiu, 1981; Steetzel, 1993; Wood, 1982) have shown that a rise in water elevation during a storm event can have a large impact on beach and dune erosion. Zhang et al. (2001) proposed a storm erosion potential index (SEPI) that includes the effects of storm tide as:

$$
S E P I=\sum_{t=0}^{T_{D}} S_{2 S D}(t) * \eta_{M H H W}(t) * \Delta t,
$$

where $S_{2 S D}$ is storm surge values greater than two standard deviations, $\eta_{M H H W}$ is the water elevation greater than the MHHW (mean higher high water) and $\Delta t$ is the time interval between measurement values. 
Table 1.1: Storm intensity quantification.

\begin{tabular}{|c|c|c|c|}
\hline & $\begin{array}{l}\text { Storm } \\
\text { Power }(S P)\end{array}$ & $\begin{array}{l}\text { Nor'easter Risk } \\
\text { Index }(I)\end{array}$ & $\begin{array}{l}\text { Storm Erosion } \\
\text { Potential Index } \\
\text { (SEPI) }\end{array}$ \\
\hline $\begin{array}{l}\text { Nor'easter } \\
\text { Riley }\end{array}$ & $1,488 \mathrm{~m}^{2} \cdot \mathrm{hrs}$ & $14.6 \mathrm{~m}^{2} \cdot \mathrm{hrs}^{0.3}$ & $20.5 \mathrm{~m}^{2} \cdot \mathrm{hrs}$ \\
\hline $\begin{array}{l}\text { Nor'easter } \\
\text { Toby }\end{array}$ & $1,225 \mathrm{~m}^{2} \bullet \mathrm{hrs}$ & $13.3 \mathrm{~m}^{2} \cdot \mathrm{hrs}^{0.3}$ & $10.9 \mathrm{~m}^{2} \cdot \mathrm{hrs}$ \\
\hline $\begin{array}{l}\text { Easter Eve } \\
\text { Storm }\end{array}$ & $254 \mathrm{~m}^{2} \cdot \mathrm{hrs}$ & $1.72 \mathrm{~m}^{2} \cdot \mathrm{hrs}^{0.3}$ & $0 \mathrm{~m}^{2} \cdot \mathrm{hrs}$ \\
\hline
\end{tabular}

\subsection{Study Site}

The field studies were conducted at Bethany Beach, Delaware (Figure 1.3). Bethany Beach is east facing and undergoes periodic berm-dune renourishment projects led by state and federal agencies. The tidal pattern is semidiurnal and the mean oceanic tidal range is $1.24 \mathrm{~m}$, classified as microtidal (Whitfield \& Elliott, 2011). The pre-storm intertidal beach slope (defined from MHHW to MLLW) for Nor'easter Riley, Nor'easter Toby, and the Easter Eve Storm were 0.07 (1:14), 0.14 (1:7), and 0.04 (1:24) respectively, suggesting an intermediate beach state (Wright \& Short, 1984). The mean sediment grain size at this location is classified as medium sand $(\sim 0.3 \mathrm{~mm})$ and well-sorted (Ramsey, 1999). Figures $1.4-1.6$ show the pre-storm bathymetry, subaerial beach profile, tidal datums, and deployment station locations for the field studies. Bathymetry data, below MHHW, was provided by Delaware Department of Natural Resources and Environmental Control (DNREC). 


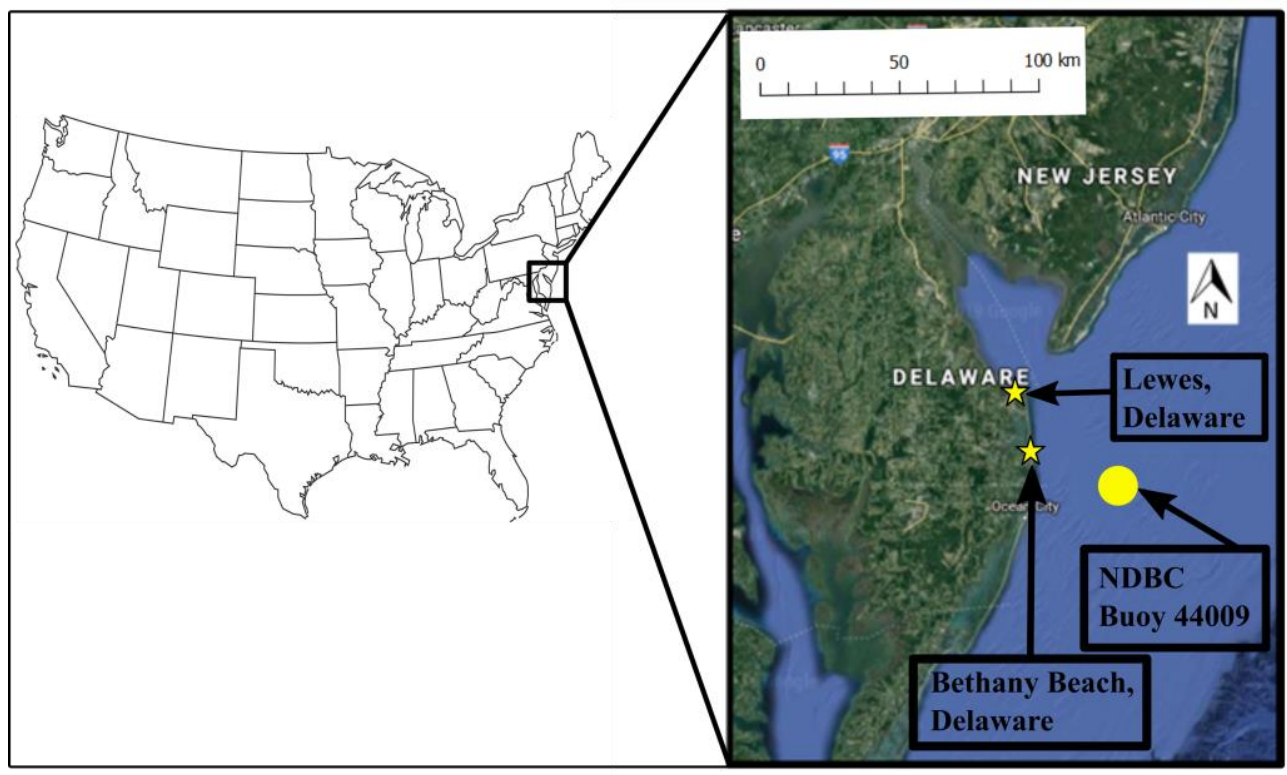

Figure 1.3: Geographical locations of field study site (Bethany Beach, DE), NOAA tide gauge 8557380 (Lewes, DE), and NDBC wave buoy 44009.

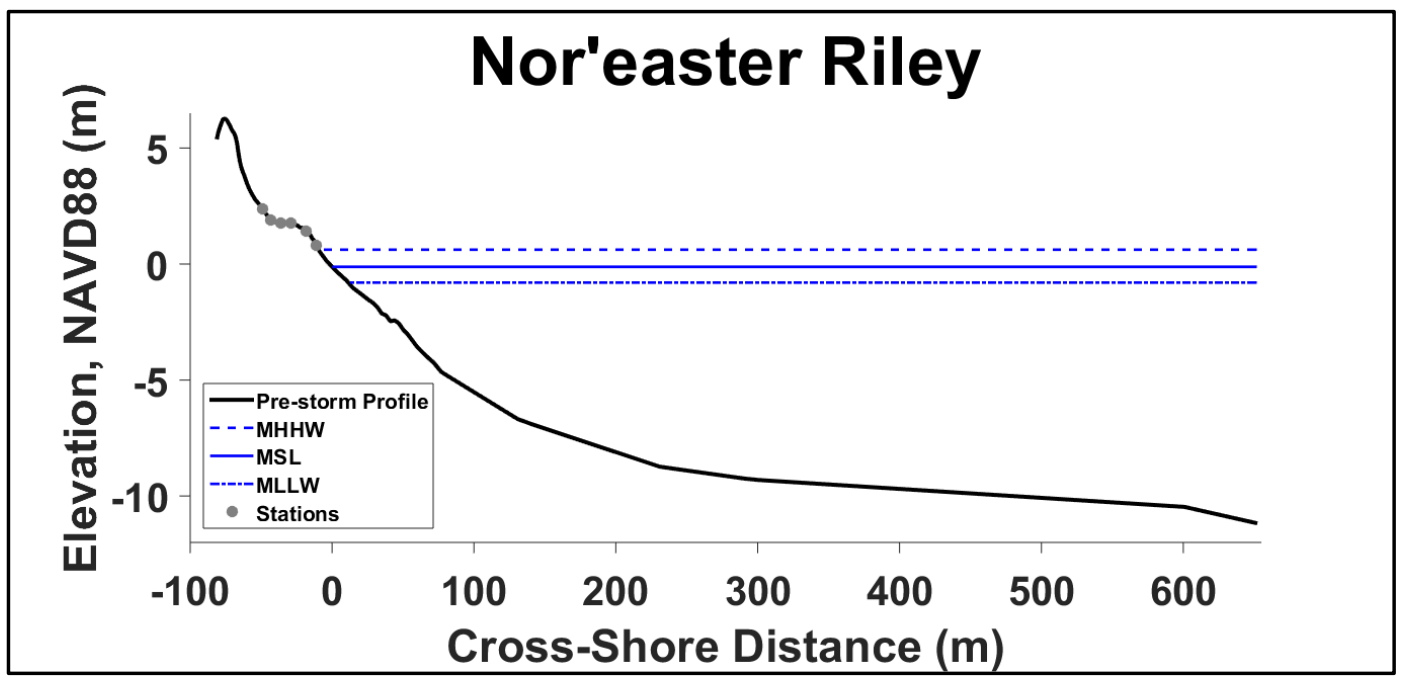

Figure 1.4: Cross-shore bathymetry measured in February 2018, subaerial beach profile, tidal datums, and deployment station locations at the field study site before Nor'easter Riley. 


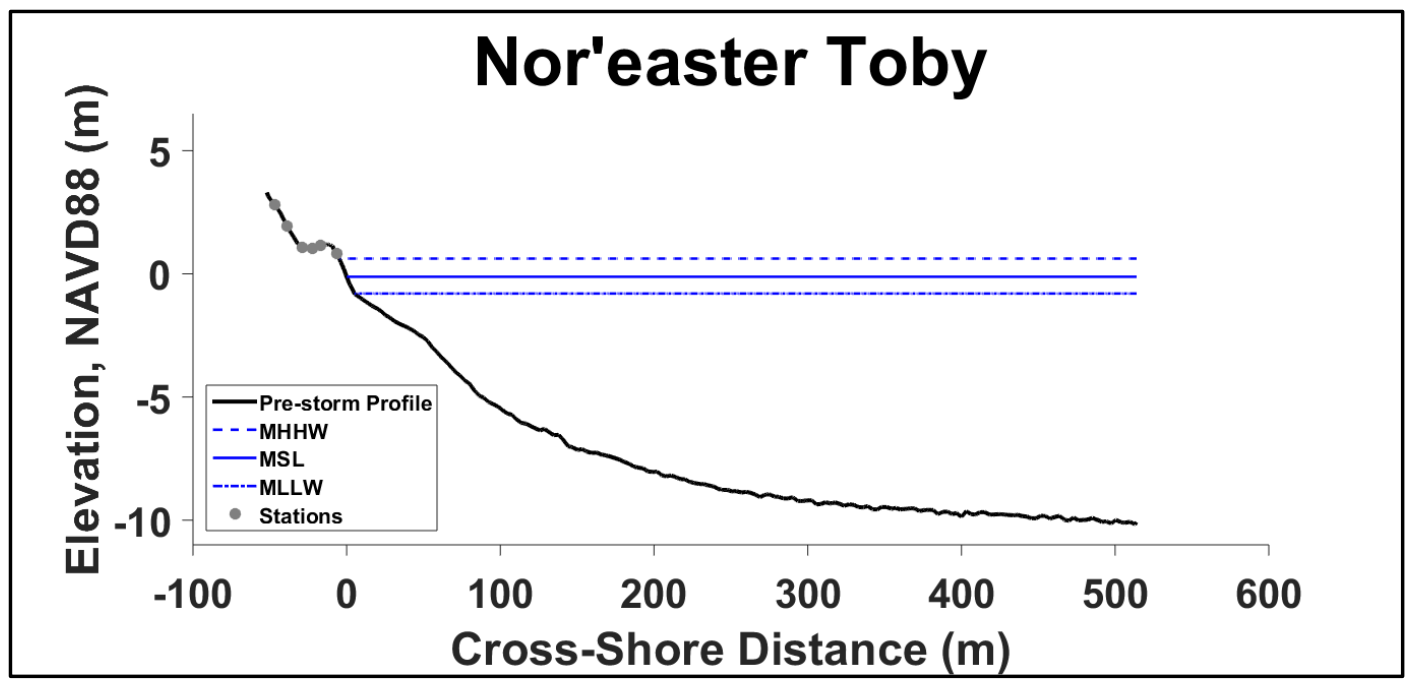

Figure 1.5: Cross-shore bathymetry measured in March 2018, subaerial beach profile, tidal datums, and station locations at the field study site before Nor'easter Toby.

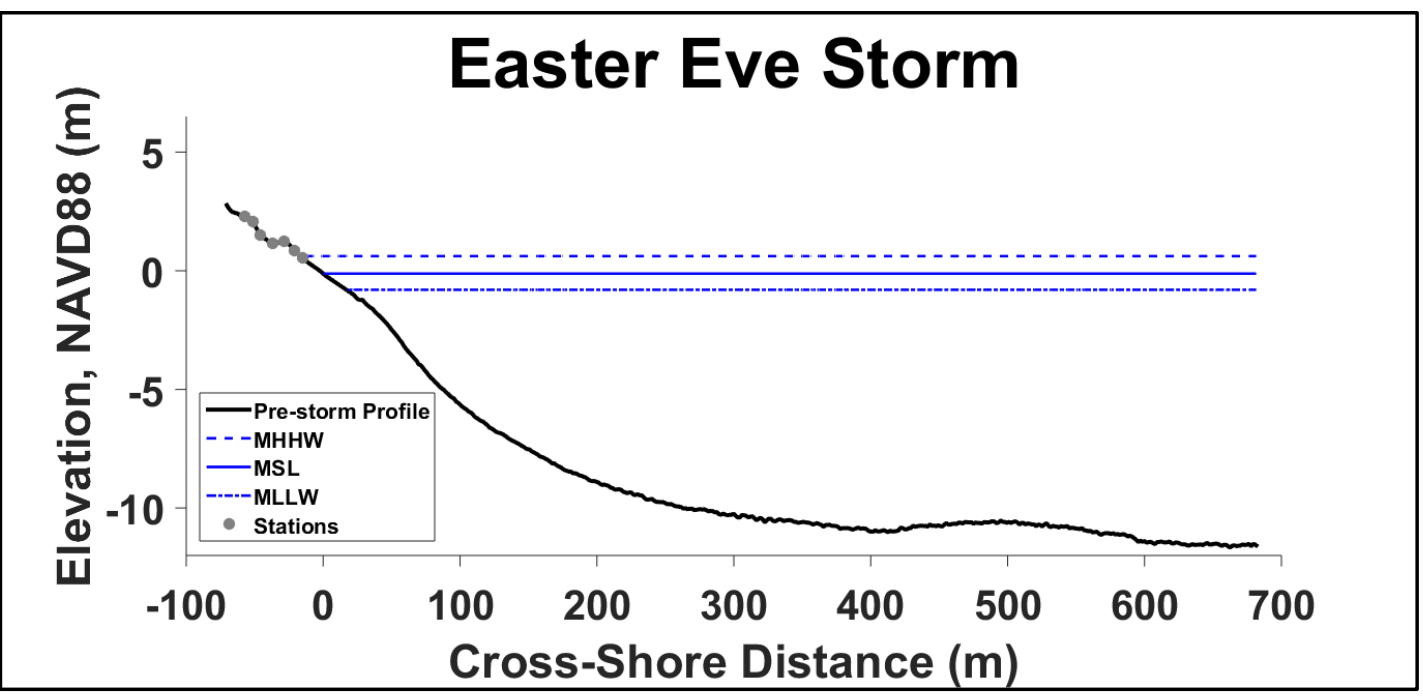

Figure 1.6: Cross-shore bathymetry measured in March 2019, subaerial beach profile, tidal datums, and deployment station locations at the field study site before the Easter Eve Storm. 


\section{Chapter 2}

\section{DEPLOYMENT TECHNIQUE}

\subsection{Sensors Used}

The complex dynamics and processes that occur across the beach face during a storm require the measurement of various physical quantities including: water elevation, bed elevation, water depth, and water velocity. Various sensors were deployed at multiple deployment stations in a single cross-shore transect to measure the aforementioned quantities. It was necessary to use self-logging and self-powered sensors to eliminate the need of cabling back to an external data logger or power source. This approach was taken to facilitate a rapid-response deployment. A schematic diagram of used sensors at a cross-shore deployment station is shown in Figure 2.1. 


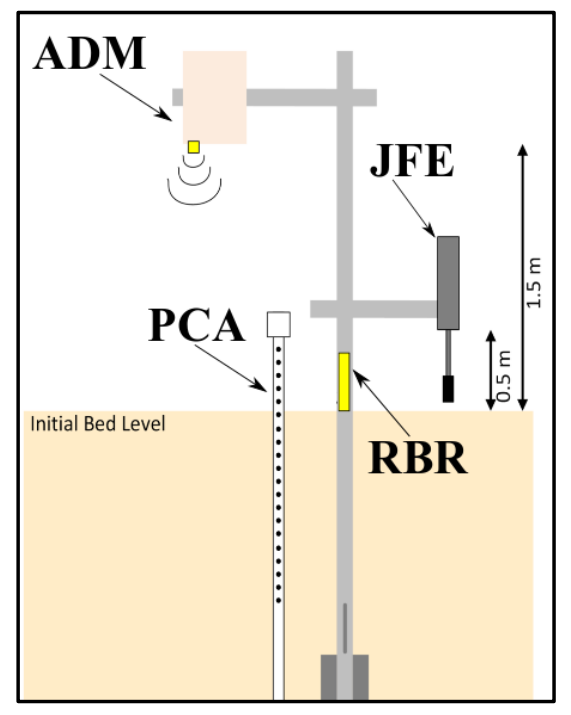

Figure 2.1: Schematic of deployed sensors and deployment station during field studies.

\subsubsection{Acoustic Distance Meter (ADM)}

A Banner U-Gage T30UX Series ultrasonic sensor, also referred to as an acoustic distance meter (ADM, Figure 2.1), was used to measure water (when the area below the sensor is submerged) and bed (when the area below the sensor is exposed) elevation. The ADM emits acoustic energy (i.e. sound waves) and measures the amount of time for that energy to reflect off a target and return to the sensor. Using this measured amount of time and the known speed of sound in air, the sensor-to-target distance $(D)$ can be calculated as:

$$
D=\left(C * t_{A D M}\right) / 2,
$$

where $C$ is the speed of sound in air, and $t_{A D M}$ is the measured transit time of the emitted acoustic energy. The ADM compensates for ambient temperature, as the speed of sound in air is temperature dependent (Equation 2.2). 


$$
C=20 * \sqrt{273+T_{C}}
$$

where $T_{C}$ is the measured temperature in Celsius. It should be noted that the use of Equation 2.2 results in the speed of sound in air to have units of meters per second.

Maximum and minimum distance limits are required to be manually set before using the ADM. The ADM outputs an analog electrical current signal (4 $\mathrm{mA}-20 \mathrm{~mA}$ ) that is either proportional or inversely proportional to the measured distance, depending on how the limits are set by the user. In this application, the maximum and minimum distance limits were $2.75 \mathrm{~m}$ and $0.40 \mathrm{~m}$ respectively, the electrical current was proportional to the measured distance, and the sampling rate was $4 \mathrm{~Hz}$.

The ADM itself is not self-logging nor self-powered. It was necessary to house the sensor, a power source, and a data logger inside of a self-contained waterproof box (Figure 2.2). The power source used was a 22.2 V (6S) $12 \mathrm{Ah}$ Turnigy LIPO battery and the data logger used was a MadgeTech Volt101A. The Volt101A data logger measures voltage signals from positive and negative wire leads connected to the logger's terminal port. Due to the ADM outputting an electrical current signal, it was necessary to install a resistor across the terminal port. An 820 -ohm resistor was used to ensure that the voltage values resulting from the ADM output current signals were within the measurable range of the data logger $(-8 \mathrm{~V}-24 \mathrm{~V})$. 


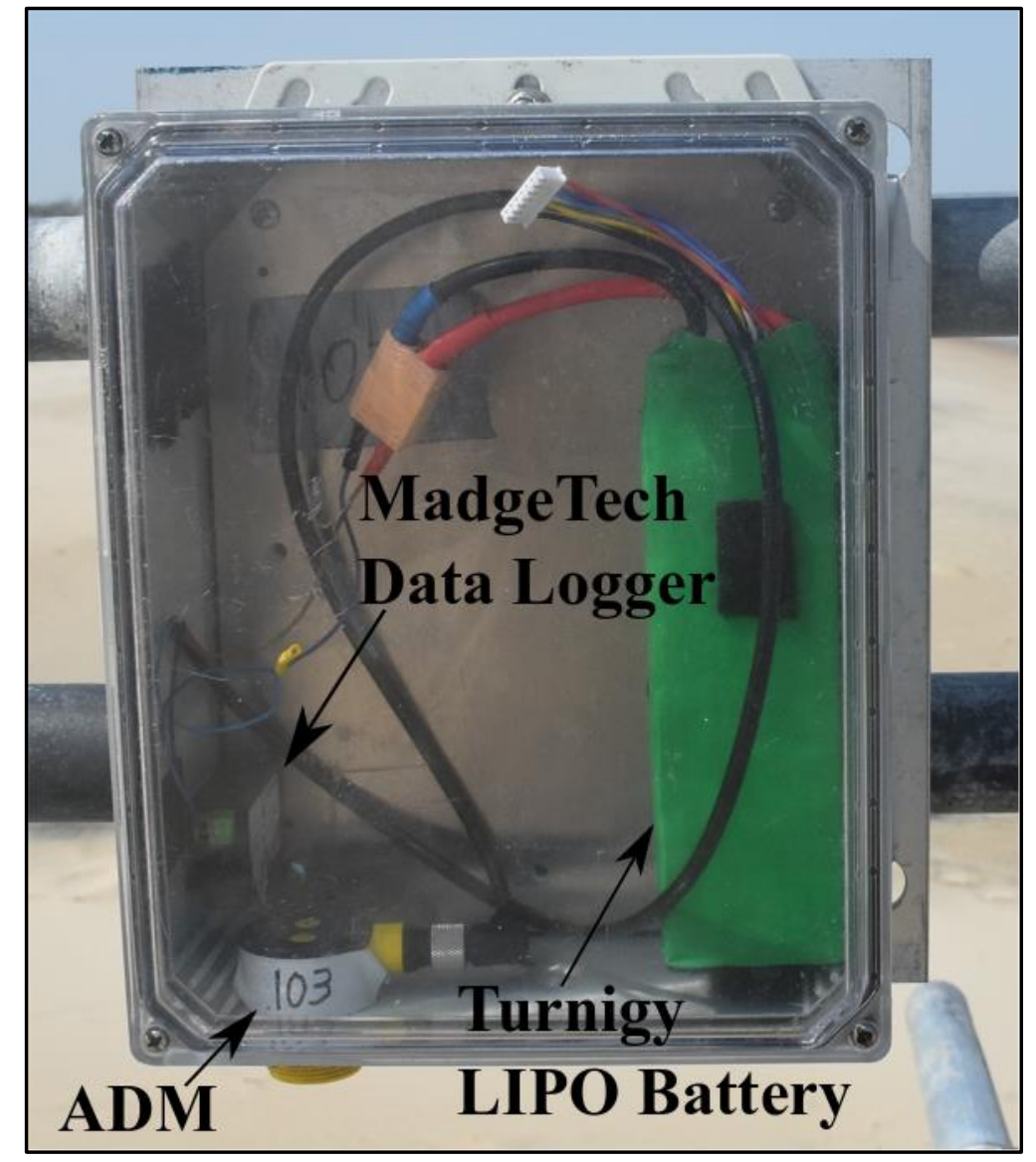

Figure 2.2: Self-contained waterproof box housing the ADM, Turnigy LIPO battery, and MadgeTech data logger.

\subsubsection{Electro-magnetic Current Meter (JFE)}

JFE Advantech Infinity-EM current meters (JFE, Figure 2.1) were used to measure the horizontal velocity components. The JFE uses the principle of Faraday's Law, stating that the voltage induced across a conductor (e.g. water) as it moves through a magnetic field is proportional to the velocity of that conductor. Due to the generated magnetic field, it is important to keep the sensing unit (Figure 2.3) of the JFE at least $0.15 \mathrm{~m}$ away from any steel. 
The JFE sensors are self-logging, using a mini-SD card, and self-powered, using lithium CR-V3 batteries. The horizontal velocity components are oriented with respect to the temperature probe (Figure 2.3) on the sensor. The JFE sensors were deployed so that the

temperature probe faced seaward, the sensing unit elevation was $0.10 \mathrm{~m}$ above the initial bed, and at a sample rate of $5 \mathrm{~Hz}$. Due to a dynamically changing bed elevation, it was necessary to adjust the JFE sensors to $0.10 \mathrm{~m}$ above the bed at every day-time low tide throughout the field studies to optimize data collection.

\subsubsection{RBR Pressure Sensor (RBR)}

RBR Solo D and Solo D Wave pressure sensors (RBR, Figure 2.1) were deployed to measure water depth and atmospheric pressure. The RBR sensors are compact as well as self-logging, using an internal data logger, and self-powered, using 3.6 $\mathrm{V} \mathrm{LiSOCl}_{2} \mathrm{AA}$ batteries. The RBR sensors measure hydrostatic pressure and use Equation 2.3 to calculate water depth $(h)$ as:

$$
h=\frac{P-P_{a t m}}{\rho * g},
$$

where $P$ is measured hydrostatic pressure, $P_{a t m}$ is atmospheric pressure, $\rho$ is density of sea water, and $g$ is acceleration due to gravity. Atmospheric pressure can change drastically during storm events, especially nor'easters. An RBR pressure sensor was deployed on top of the most landward deployment station (Figure 2.3) to measure atmospheric pressure to accurately calculate water depth.

The RBR Solo D Wave sensors were deployed at the most seaward deployment stations due to a higher sampling frequency of $16 \mathrm{~Hz}$, while the Solo D sensors were deployed at the more landward deployment stations due to a lower 
sampling rate of $2 \mathrm{~Hz}$. Like the JFE sensors, the RBR sensors had to be adjusted to the bed at every day-time low tide due to dynamically changing bed elevation.

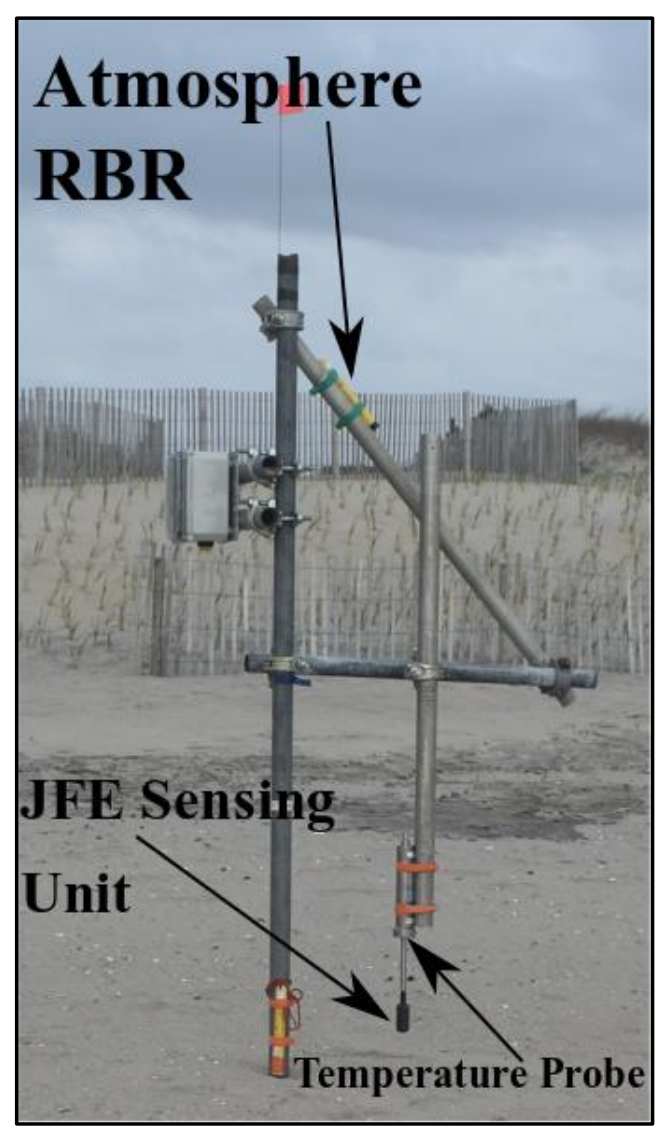

Figure 2.3: Photo of deployment station showing the Atmosphere RBR, JFE sensing unit, and JFE temperature probe.

\subsubsection{Real-Time Kinematic Global Positioning System (RTK GPS)}

A Leica RTK GPS was used to measure cross-shore elevation profiles of the beach face at every day-time low tide during the field studies and to record the spatial coordinates of the deployment stations as well as the vertical elevation of 
the individual sensors. All spatial coordinates and vertical elevations were captured in UTM zone 18 and relative to the vertical datum NAVD88, respectively.

Cross-shore elevation profiles were measured by mounting the Leica RTK GPS unit to a push-cart and program the unit to continuously record spatial and elevation data. At least four cross-shore profile lines were completed on each side of the transect and then averaged to obtain the cross-shore elevation profile. The measured profiles provided spatially continuous elevation data of the beach face evolution and confirmed measured bed elevation values from the ADM.

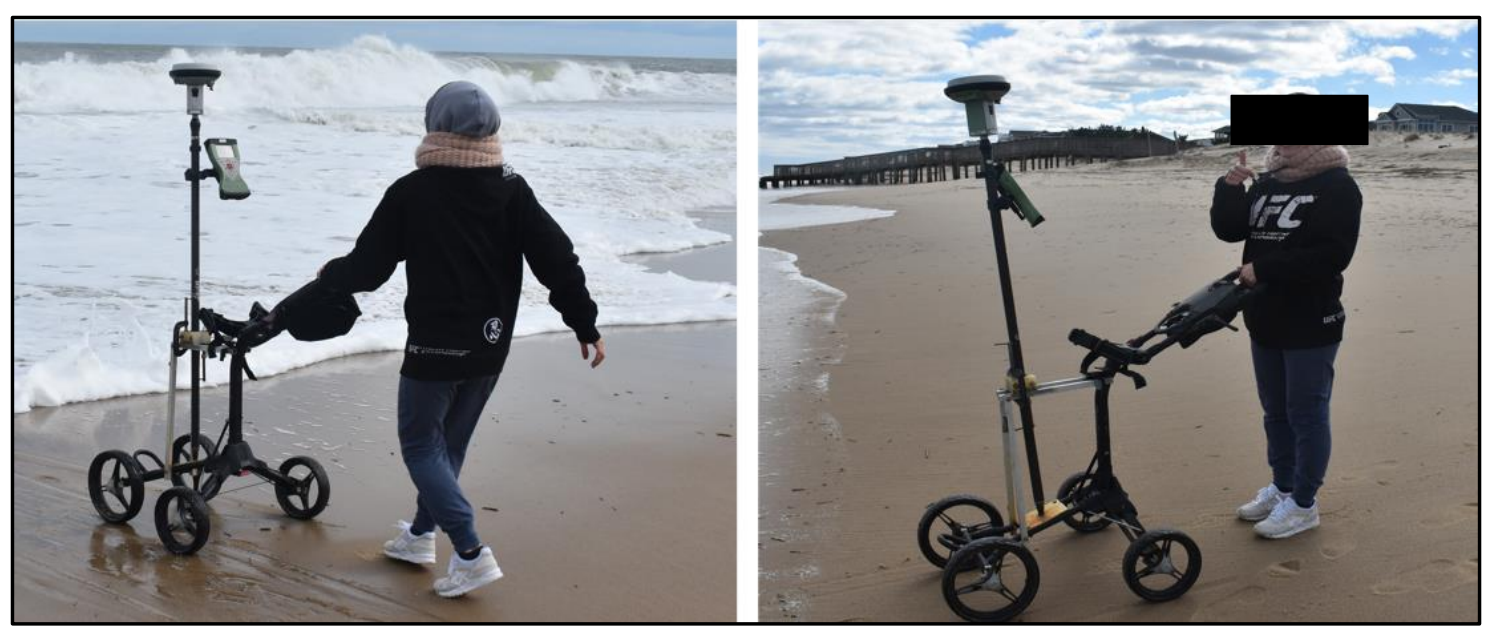

Figure 2.4: Photos of Leica RTK GPS and push-cart to obtain cross-shore elevation profiles. 


\subsubsection{Photocell Array (PCA)}

Efforts were made to develop a low-cost sensor to continuously measure bed elevation change even when the bed would become submerged. This sensor was referred to as a Photocell Array (PCA, Figure 2.1) as it used a vertical array of 30 photocells, spaced $0.04 \mathrm{~m}$ apart, to quantify bed elevation change. When a photocell is exposed (i.e. not buried) ambient light excites the cell, generates an electrical current which flows across a resistor, and the resultant electrical voltage can be recorded by a data logger. However, a major drawback of this sensor is that it would only be viable to use during daylight hours when enough ambient light is present to excite the exposed photocells.

Originally, the PCA used programmed Arduino boards to record data from the photocells as Arduino boards were low-cost and compact. However, this required a custom written program to successfully operate the Arduino boards. Also, extreme care had to be taken when transporting the PCA as the wired connections from the photocells to the Arduino boards were delicate and could easily be damaged. The drawbacks of the original PCA prototype inspired the use of a traditional data logger in place of the Arduino boards. This approached seemed to be more successful than the original. However, the design is still undergoing modifications and PCA data are not used in this study. 


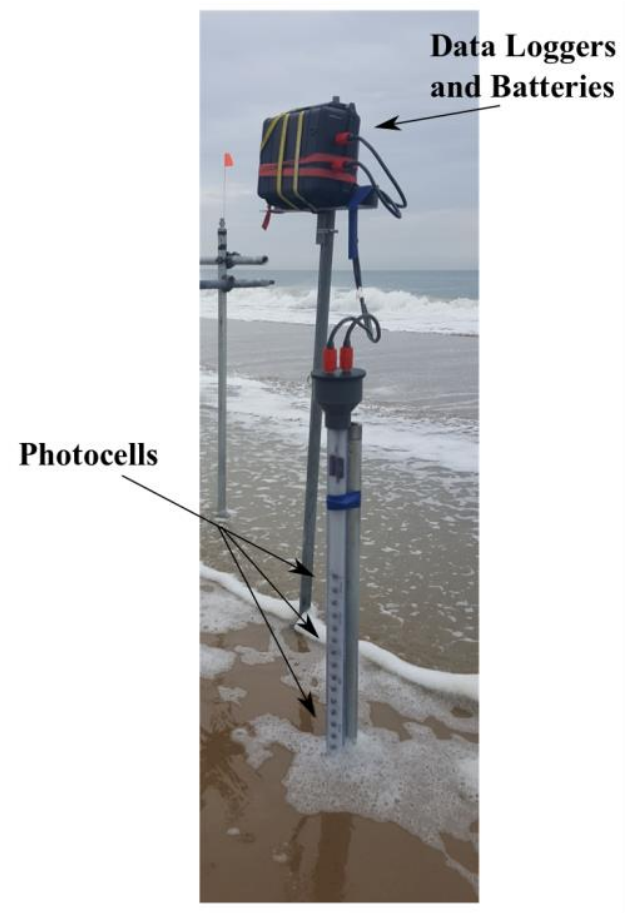

Figure 2.5: Photo of PCA during Easter Eve Storm deployment.

\subsection{Cross-shore Transect}

The deployment stations were installed in a cross-shore transect extending from the dune toe to seaward of the berm, spaced 5 - $10 \mathrm{~m}$ apart. The deployment stations were constructed

from scaffold pipes and were water-jet driven $2 \mathrm{~m}$ below the pre-storm bed level. Highly pressurized water from a fire hydrant located near the study site was used to water-jet the scaffold pipes into the bed and prevented personnel from having to enter cold sea water as would be needed with a traditional centrifugal pump approach for pipe jetting. 
Two different installment techniques of the deployment stations were used during the field studies. The primary support structure of the deployment stations during Nor'easter Riley and Nor'easter Toby were 3 - 3.65 m monopoles (Figure 2.6). The use of monopoles was in the interest to minimize infrastructure and time expended in the deployment process. Fins were welded to the bottom of the monopoles to prevent rotation from hydrodynamic forces during the storm.

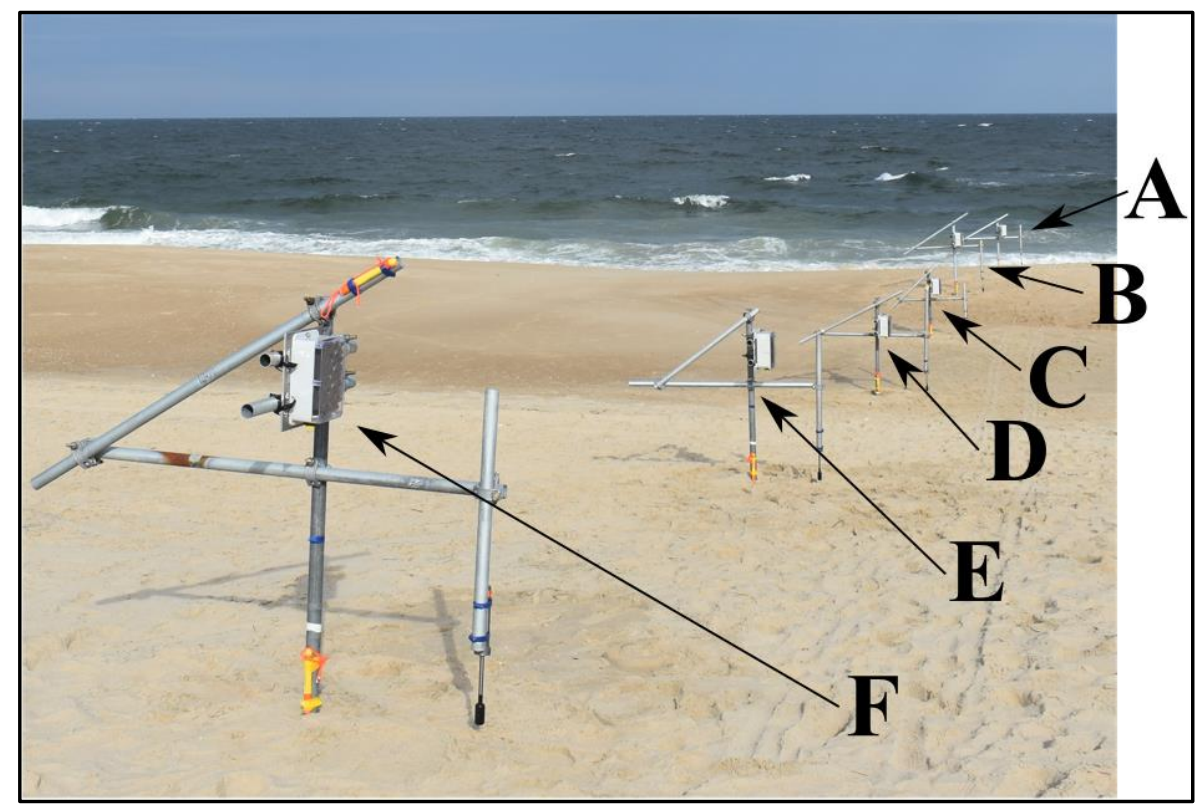

Figure 2.6: Cross-shore transect of monopole deployment stations (with identification labels) installed during Nor'easter Toby. Same installation technique was used during Nor'easter Riley.

Despite increasing installation efficiency, the use of monopoles as the primary support 
structure for the most seaward deployment stations was found to be inadequate during the storm events. Deployment Stations A - C during Nor'easter Riley and Nor'easter Toby experienced severe structural failure (Figure 2.7) due to the extreme hydrodynamic forcing conditions. The structural failure experienced during both nor'easters forced sensors (and thus collected data) to be retrieved prematurely or completely discarded. In response, frames of scaffold pipes were constructed for the most seaward deployment stations (Figure 2.8) during the Easter Eve Storm. The frames did not experience any structural failure; however, this installation technique was used during a much less extreme storm event compared to the nor'easter storm events.

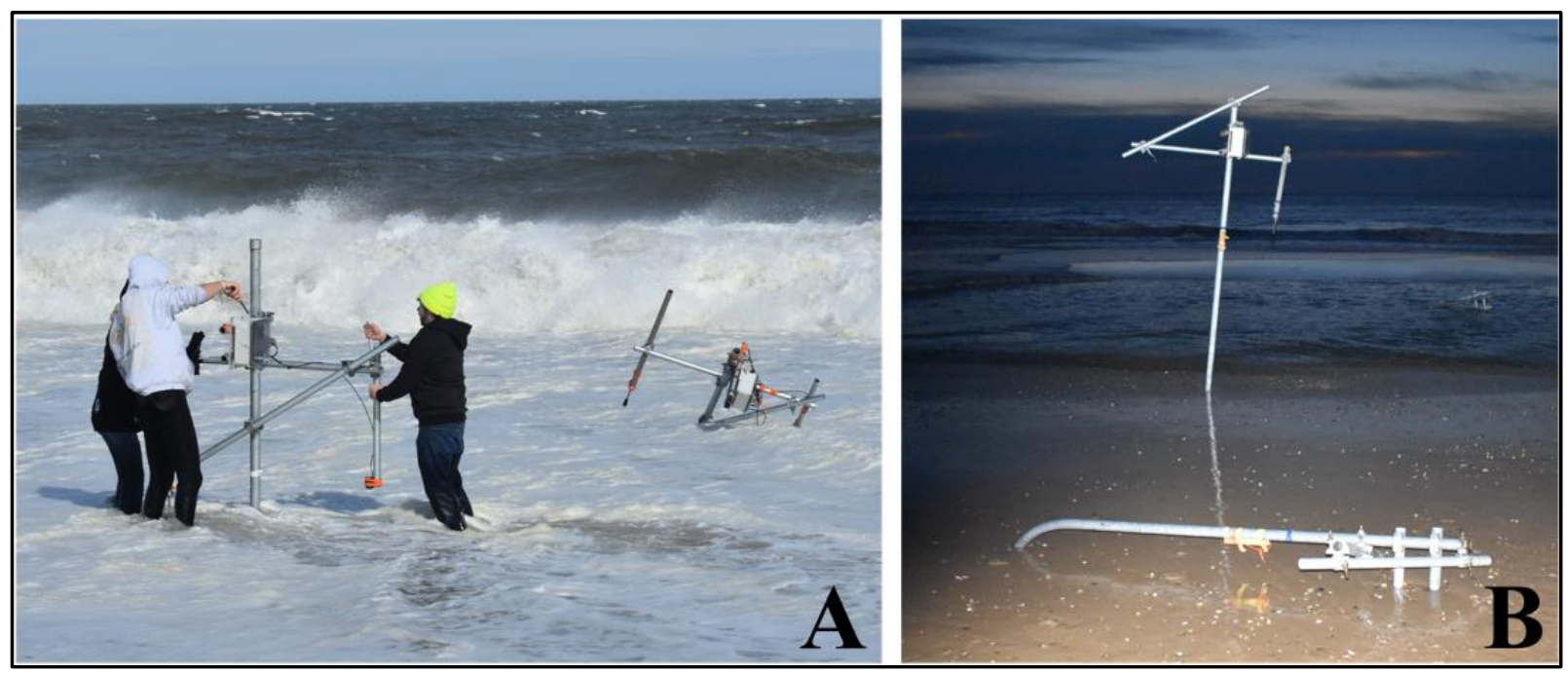

Figure 2.7: Photos of monopole deployment station structural failure during Nor'easter Riley (A) and Nor'easter Toby (B). 


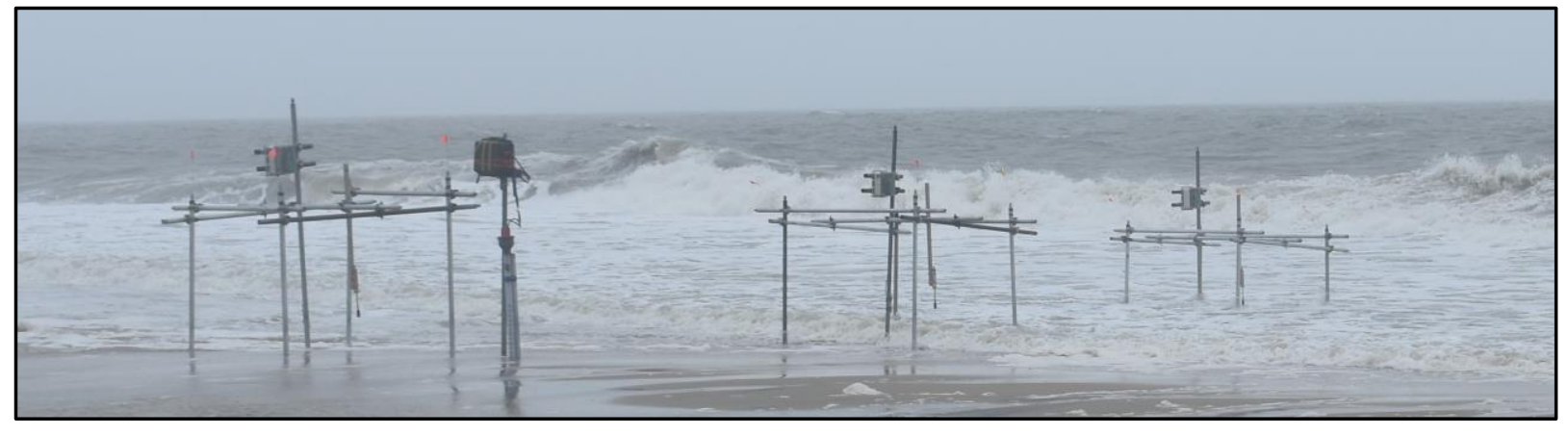

Figure 2.8: Photo of framed deployment stations during the Easter Eve Storm.

\subsection{Deployment Logistics}

The deployment stations were not permanently installed at the field study site but were installed (removed) before (after) the storm events. This rapidresponse deployment strategy required constant tracking of wave height forecasts, thorough equipment preparation, and detailed logistical planning. Multiple wave height forecast websites (e.g. swellinfo.com, magicseaweed.com, windy.com) were consulted to determine the likelihood a storm event would occur and cause significant morphological change to the field study site. Similar to a standard weather forecast, wave height forecast accuracy decreases as the prediction time relative to the present time increases. Oftentimes the final decision to execute a rapid-response field deployment would be made two to three days prior to the storm event.

Visiting the field study site daily at low tide was necessary to adjust or retrieve sensors, obtain cross-shore beach elevation profiles, and perform any other work that was needed. This required accommodation near the field study 
site to be considered and secured during the logistical planning of the deployments. That said, accommodation near the field study site during Nor'easter Toby was not able to be secured and resulted in less than ideal results. A JFE sensor was lost, no cross-shore elevation profiles throughout the storm were obtained, and sensors were not able to be adjusted to optimize data collection. 


\section{Chapter 3}

\section{COLLECTED DATA}

\subsection{Bed \& Water Elevations}

\subsubsection{Converting ADM Voltage to Elevation}

As mentioned in section 2.1.1, the ADM output an electrical current signal that flowed across a resistor and the resultant voltage was recorded by a data logger. Recorded voltage values had to be converted to units of distance (i.e. meters) through ADM calibration. Recorded voltage values at the prescribed maximum and minimum distance limits were used to find linear calibration equations for each ADM sensor. An intermediate distance point was recorded during calibration to confirm the accuracy of the linear calibration curve (Figure $3.1)$. 


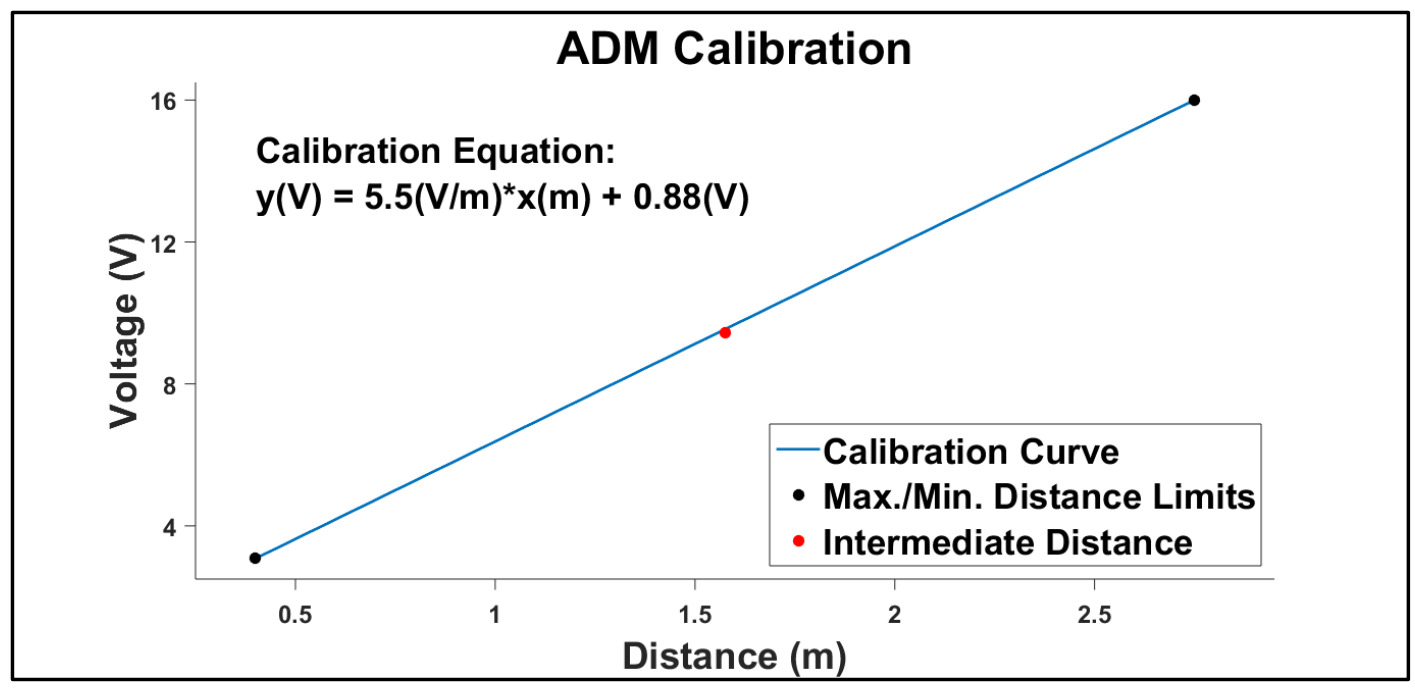

Figure 3.1: Example of an ADM calibration plot. Calibration equation was used to convert ADM output voltage to units of distance.

The distance values calculated by the ADM calibration equations had to then be converted to an elevation value. The pre-storm elevation values surveyed by the GPS at the deployment station locations were used for this conversion and were relative to the fixed vertical datum, NAVD88. Figure 3.2 shows ADM distance values converted to elevation values during Nor'easter Riley at deployment Station C. 


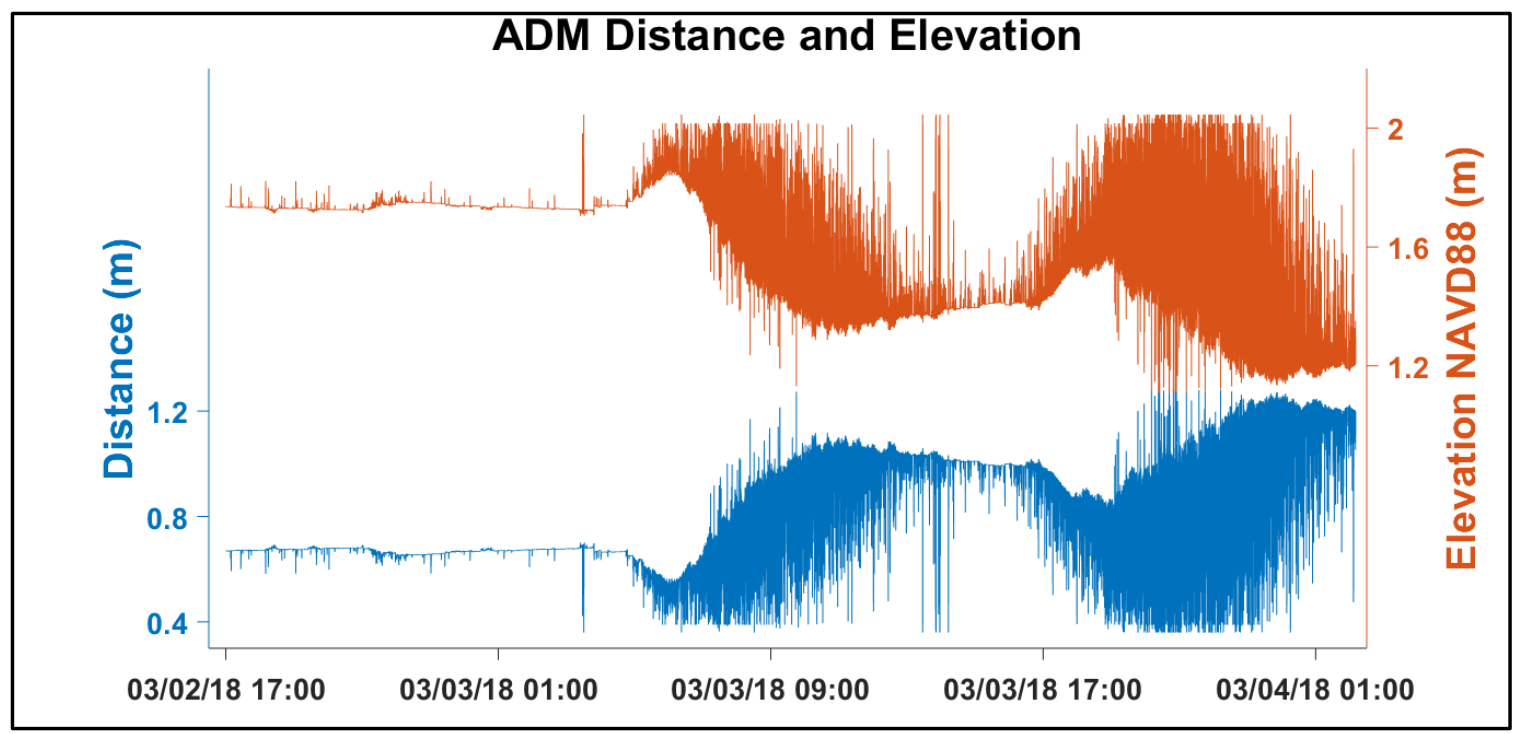

Figure 3.2: Example of ADM distance (blue) and elevation (orange) values at deployment Station C during Nor'easter Riley.

\subsubsection{Measuring Bed Elevations}

Efforts were made during the Nor'easter Riley field study to use various in situ sonar sensors to measure bed elevation when the sensor was submerged.

However, the data obtained from the sonar sensors were deemed unusable as no realistic measurements were recovered. Submerged acoustic sensors in the swash zone struggle to make reliable measurements due to intermittent inundation, suspended sediment, and the influence of bubbles (Puleo \& Torres-Freyermuth, 2016).

An algorithm was previously proposed using an ultrasonic sensor similar to the ADM to

measure bed elevation change on a wave-by-wave time scale in the swash zone (Turner et al., 2008). The algorithm identifies bed elevation from water 
elevation measurements through the application of the following criteria equations:

$$
\begin{gathered}
|z(t+d t)-z(t)| * f_{s}<\left(\frac{d z}{d t}\right)_{c} \\
t_{\text {int }}>t_{c}
\end{gathered}
$$

where $z(t+d t)$ and $z(t)$ are two successive elevation measurements as functions of time $(t), d t$ is the sampling rate, $f_{s}(=1 / d t)$ is the sampling frequency $(4 \mathrm{~Hz})$,

$\left(\frac{d z}{d t}\right)_{c}$ is the critical rate of elevation change, $t_{\text {int }}$ is a selected time interval (multiple of $1 / f_{s}$ ), and $t_{c}$ is the minimal time that Equation 3.1 persisted over. In this application the critical rate of elevation change was $2 \mathrm{~mm} / \mathrm{s}$ and the minimal time, $t_{c}$, was $1 \mathrm{~s}$. Both Equations 3.1 and 3.2 must have been true for a segment of bed elevation to be identified, suggesting a relatively constant distance measurement within the sensor accuracy. Bed elevations were identified during Nor'easter Riley and the Easter Eve Storm, but were not identified during Nor'easter Toby due to unusable ADM data.

\subsubsection{Data Cleaning}

The recorded water and identified bed elevation data directly from the ADM was found to be noisy, especially during the violent storms such as Nor'easter Riley, and required systematic data cleaning. Some of the raw identified bed elevation values were not realistic due to voltage saturation appearing in the data (Figure 3.3). Voltage saturation can be attributed to the minimum distance limit being exceeded, measurement error due to water contact on the sensing transducer, and delayed sensor response. Despite the numerous 
invalid bed elevations, realistic bed elevations were successfully identified by the algorithm and could be used to quantify bed elevation change during the storm events.

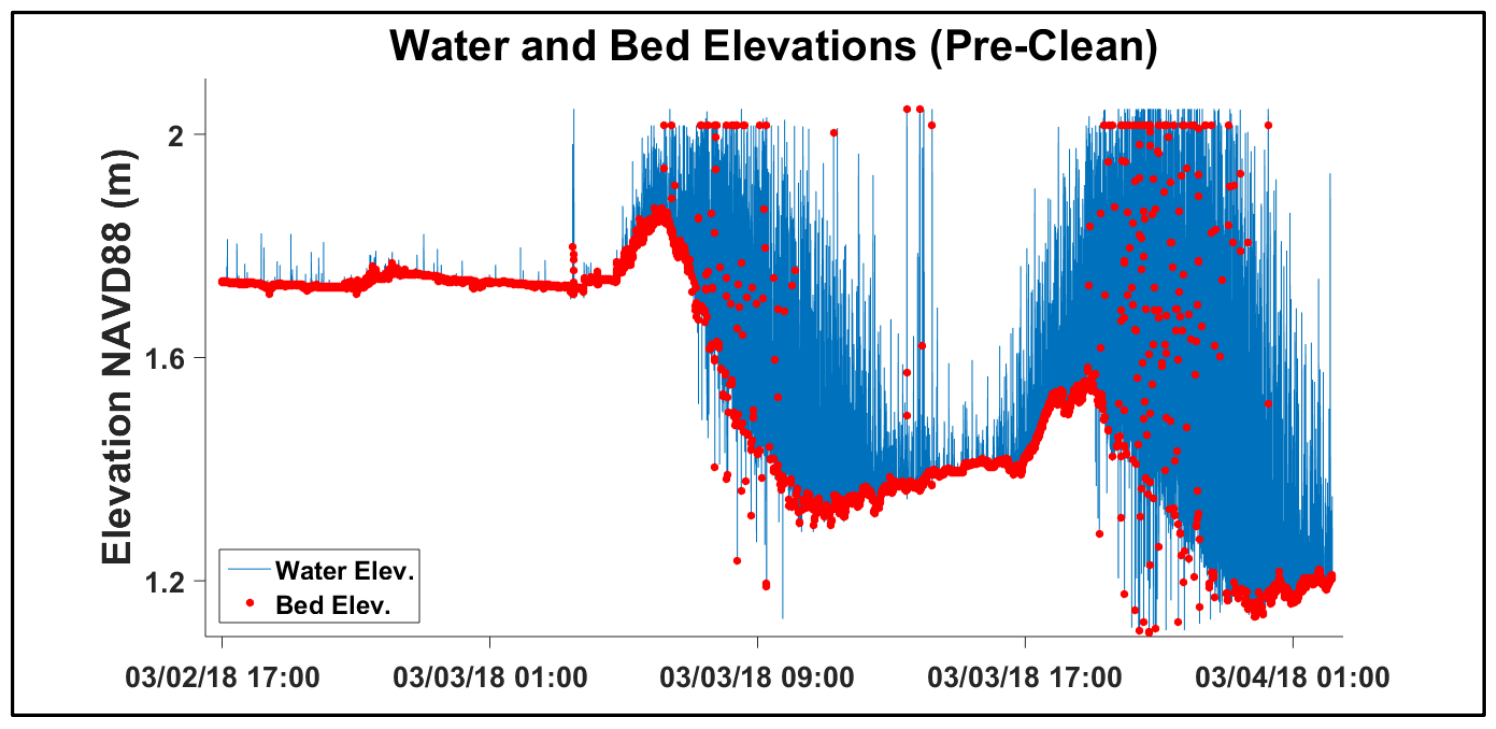

Figure 3.3: Water elevation (blue) and raw identified bed elevation (red) data at deployment Station C during Nor'easter Riley.

The first data cleaning technique applied, herein referred to as "RBR Filter", used a first pass threshold value and the standard deviation of water surface data measured by the RBR sensor. The first pass threshold value eliminated any unrealistic bed elevation values greater than the determined critical elevation. In the case of Figure 3.3, the used first pass threshold value was $1.9 \mathrm{~m}$. A time segment of identified bed elevations was eliminated if the standard deviation of water surface data measured by the RBR sensor exceeded a 
prescribed tolerance value during that same time segment (Figure 3.4). A larger water surface standard deviation value over a time segment implies uprush or backwash and thus, bed submergence. For both Nor'easter Riley and the Easter Eve Storm the prescribed standard deviation tolerance value was $0.01 \mathrm{~m}$.

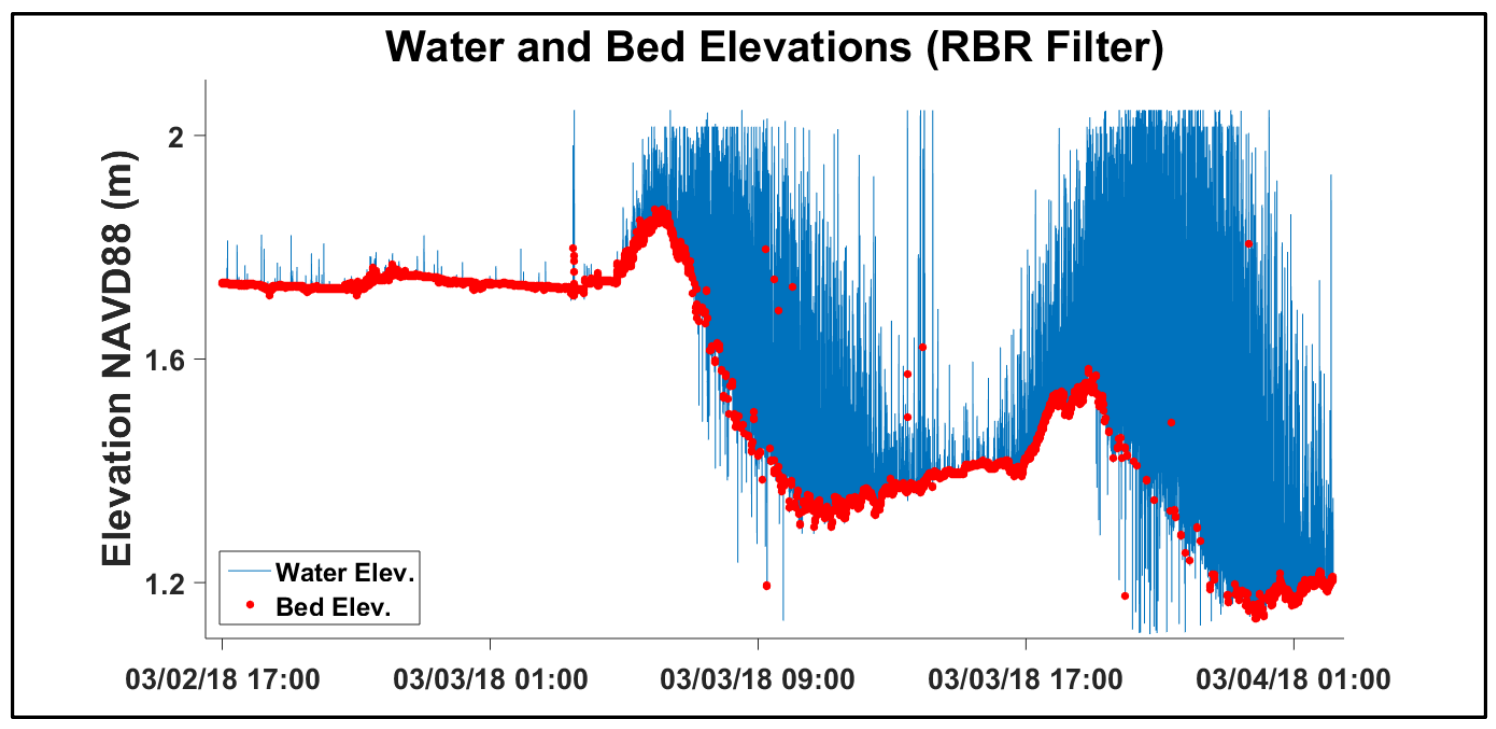

Figure 3.4: Water elevation (blue) and identified bed elevation (red) data at deployment Station C during Nor'easter Riley. Bed elevation data was cleaned using the RBR Filter.

The second data cleaning technique that was applied, herein referred to as "Sigma Filter", using Equation 3.3:

$$
\bar{Z}+W * Z_{\sigma}<Z^{\prime}<\bar{Z}-W * Z_{\sigma},
$$

where $Z^{\prime}$ is a segment of bed elevations over a prescribed time interval, $\bar{Z}$ is the mean of $Z^{\prime}, Z_{\sigma}$ is the standard deviation of $Z^{\prime}$, and $W$ is a prescribed filter weight. Bed elevation values within segment $Z^{\prime}$ are eliminated if true by Equation 3.3. 
The Sigma Filter was applied to eliminate any identified bed elevation values that are not close in magnitude to other bed elevation values within a given time interval (Figure 3.5). Various filter weights and time intervals were used for each deployment station and storm event (Table 3.1 and Table 3.2).

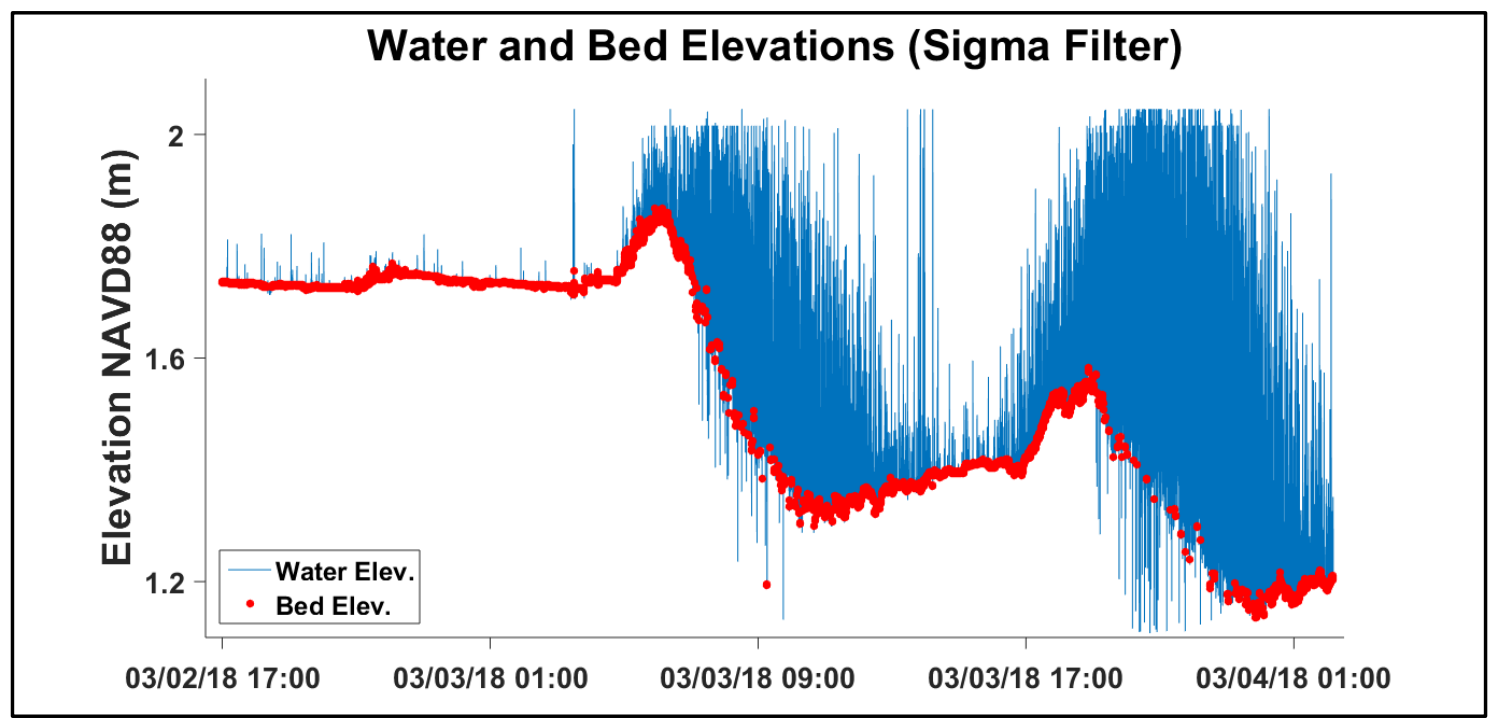

Figure 3.5: Water elevation (blue) and identified bed elevation (red) data at deployment Station C during Nor'easter Riley. Bed elevation data was cleaned using the Sigma Filter.

Table 3.1: Sigma Filter Values - Nor'easter Riley.

\begin{tabular}{|l|l|l|}
\hline & Filter Weight $(\boldsymbol{W})$ & Time Interval (mins) \\
\hline Station B & 3 & 10 \\
\hline Station C & 3 & 120 \\
\hline Station D & 3 & 10 \\
\hline Station E & 3 & 10 \\
\hline Station F & 3 & 10 \\
\hline
\end{tabular}


Table 3.2: $\quad$ Sigma Filter Values - Easter Eve Storm.

\begin{tabular}{|l|l|l|}
\hline & Filter Weight $(\boldsymbol{W})$ & Time Interval (mins) \\
\hline Station A & 1 & 20 \\
\hline Station B & INF & - \\
\hline Station C & 1 & 10 \\
\hline Station D & 1 & 10 \\
\hline Station E & 1 & 20 \\
\hline Station F & 1 & 10 \\
\hline
\end{tabular}

The third data cleaning technique involved low pass filtering bed elevation values to obtain a continuous low frequency $(<0.01 \mathrm{~Hz})$ fit $(\mathrm{CLFF})$ and calculating upper and lower tolerance values around the CLFF (Figure 3.6), herein referred to as "CLFF Filter". Bed and water elevations were eliminated using Equation 3.4 and Equation 3.5, respectively:

$$
\begin{gathered}
Z_{C L F F}^{\prime}+W_{B U} * \eta_{\sigma^{2}}^{\prime}<Z^{\prime}<Z_{C L F F}^{\prime}-W_{B L} * \eta_{\sigma^{2}}^{\prime} \\
\eta^{\prime}<Z_{C L F F}^{\prime}-W_{W} * \eta_{\sigma^{2}}^{\prime},
\end{gathered}
$$

where $Z_{C L F F}^{\prime}$ is a CLFF segment over a prescribed time interval, $\eta^{\prime}$ is a segment of water elevation over a prescribed time interval, $\eta_{\sigma^{2}}^{\prime}$ is the variance of $\eta^{\prime}, W_{B U}$ $\left(W_{B L}\right)$ is a prescribed upper (lower) filter weight for bed elevations, and $W_{W}$ is a prescribed filter weight for water elevations. The CLFF Filter was used as a final method to eliminate unrealistic bed and water elevation values (Figure 3.7). The filter used the water elevation variance during 20-minute time intervals and multiplication weights to determine upper and lower limits for bed elevations and lower limits for water elevations. Various filter weights were used for each deployment station and storm event (Table 3.3 and Table 3.4). 


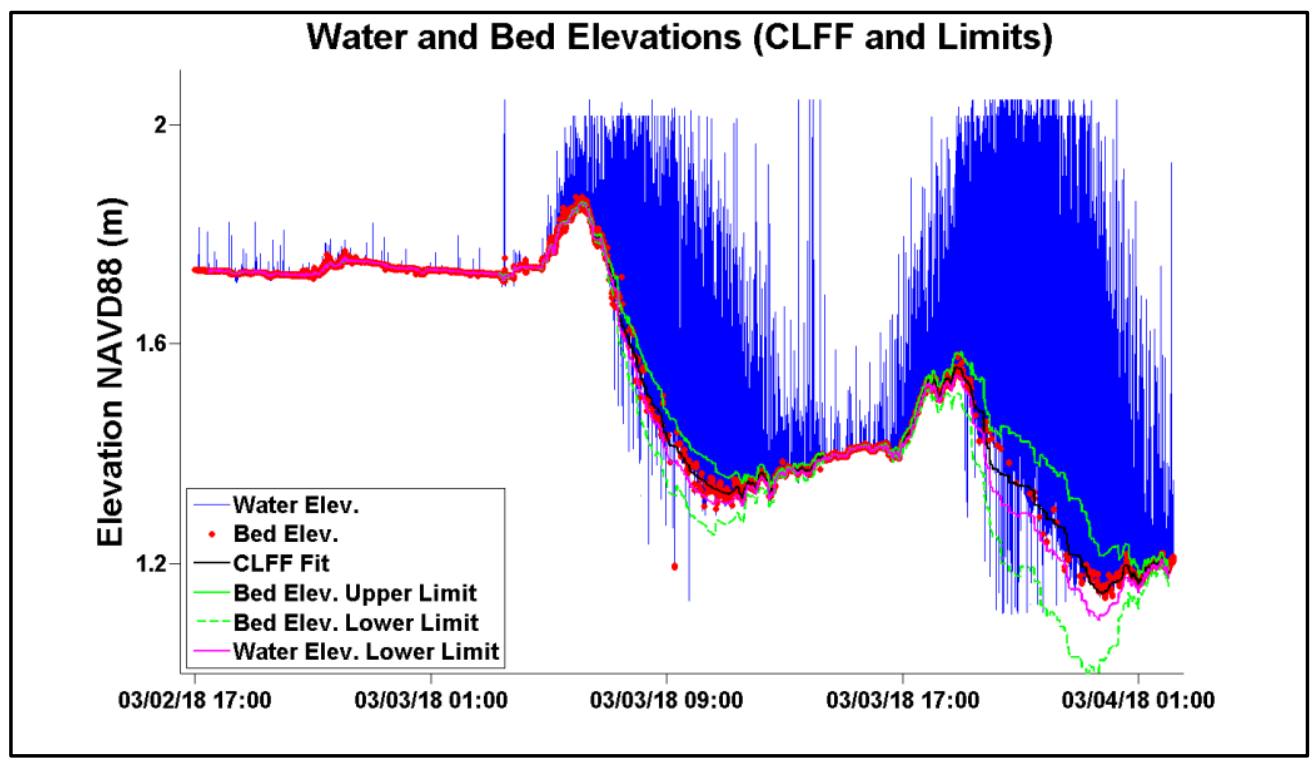

Figure 3.6: Water elevation (blue), identified bed elevation (red), and CLFF Filter tolerance values (green and magenta) at deployment Station C during Nor' easter Riley.

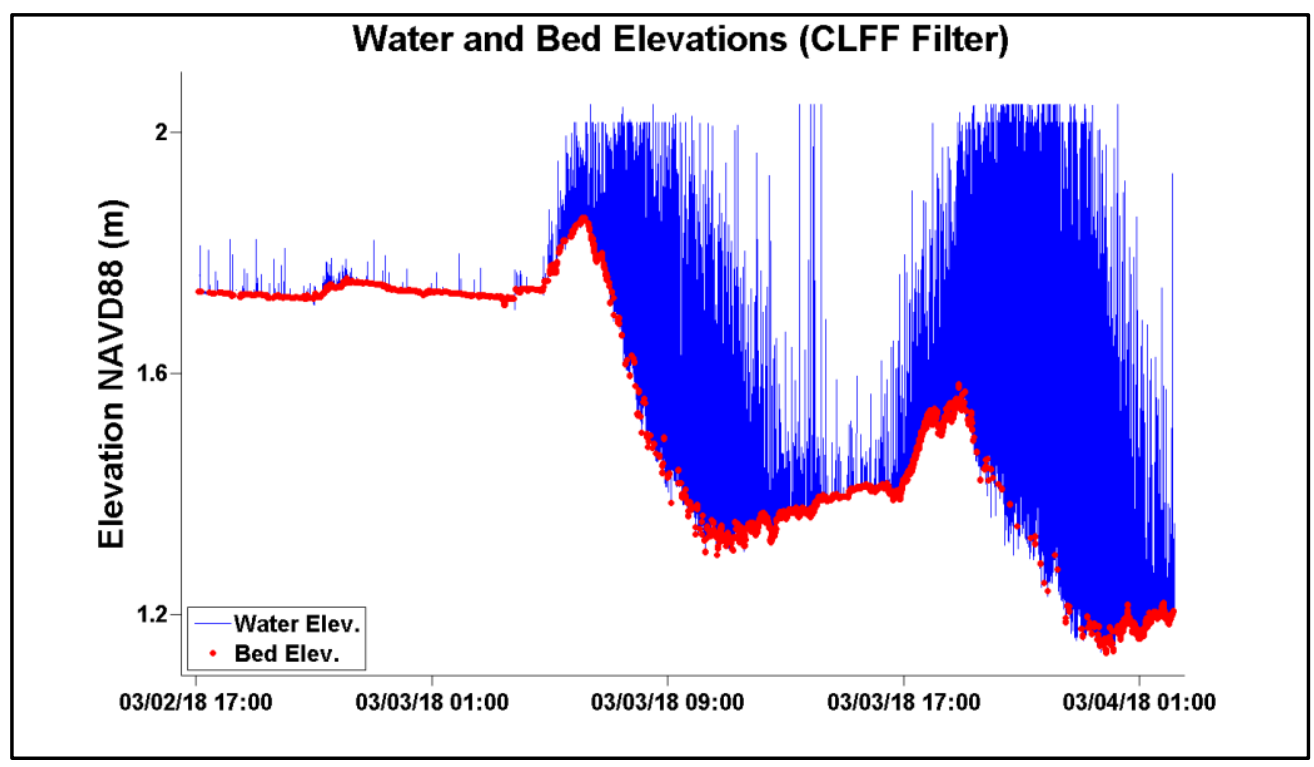

Figure 3.7: Water elevation (blue) and identified bed elevation (red) data at deployment Station C during Nor'easter Riley. Bed elevation data was cleaned using the CLFF Filter. 
Table 3.3: CLFF Filter Values - Nor'easter Riley.

\begin{tabular}{|l|l|l|l|}
\hline & $\begin{array}{l}\text { Bed Elev. Upper } \\
\left(\boldsymbol{W}_{\boldsymbol{B} U}\right)\end{array}$ & $\begin{array}{l}\text { Bed Elev. Lower } \\
\left(\boldsymbol{W}_{\boldsymbol{B} \boldsymbol{L}}\right)\end{array}$ & $\begin{array}{l}\text { Water Elev. } \\
\left(\boldsymbol{W}_{\boldsymbol{W}}\right)\end{array}$ \\
\hline Station B & 10 & 10 & 4 \\
\hline Station C & 2.5 & 4.5 & 1.5 \\
\hline Station D & 0.85 & 3 & 3 \\
\hline Station E & 2 & 4 & 4 \\
\hline Station F & 2 & 4 & 4 \\
\hline
\end{tabular}

Table 3.4: CLFF Filter Values - Easter Eve Storm.

\begin{tabular}{|l|l|l|l|}
\hline & $\begin{array}{l}\text { Bed Elev. Upper } \\
\left(\boldsymbol{W}_{\boldsymbol{B} U}\right)\end{array}$ & $\begin{array}{l}\text { Bed Elev. Lower } \\
\left(\boldsymbol{W}_{\boldsymbol{B} \boldsymbol{L}}\right)\end{array}$ & $\begin{array}{l}\text { Water Elev. } \\
\left(\boldsymbol{W}_{\boldsymbol{W}}\right)\end{array}$ \\
\hline Station A & 0.25 & 10 & 10 \\
\hline Station B & 3 & 3 & 3 \\
\hline Station C & 3 & 3 & 3 \\
\hline Station D & 3 & 3 & 3 \\
\hline Station E & 3 & 3 & 3 \\
\hline Station F & 3 & 3 & 3 \\
\hline
\end{tabular}

The remaining bed elevation data from the aforementioned data cleaning techniques were again low pass filtered at a higher frequency $(0.25 \mathrm{~Hz})$ to obtain a second CLFF. The second CLFF allowed for the calculation of water depth which accounted for bed morphodynamics (Section 3.3.3). However, when bed elevations are not able to be identified due to continuously submerged bed, the CLFF does not accurately represent instantaneous bed elevation and cannot be used. Figure 3.8 and Figure 3.9 show water and bed elevations, as well as the CLFF, for each deployment station during Nor'easter Riley and the Easter Eve Storm, respectively. 


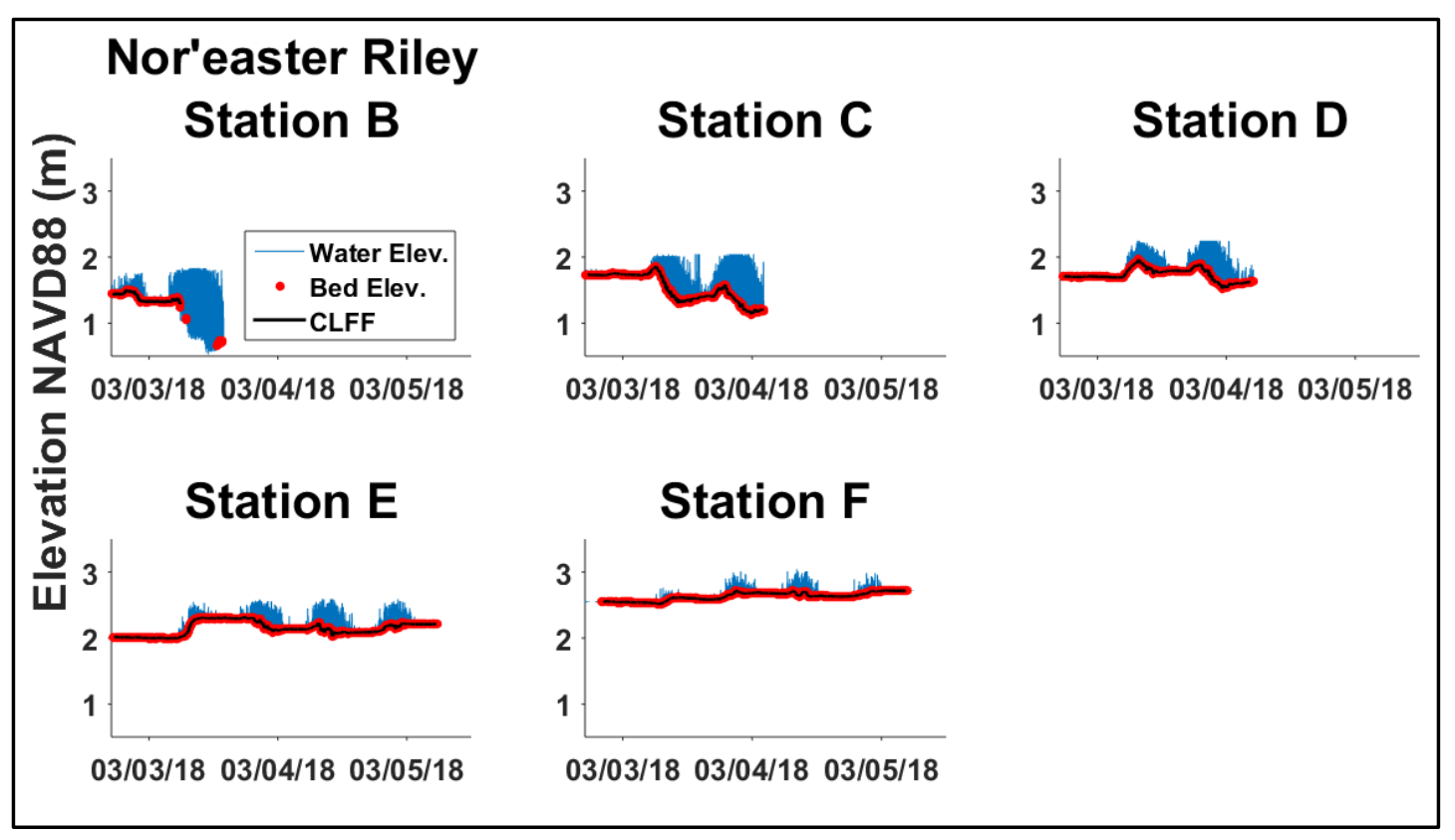

Figure 3.8: Water elevation (blue), bed elevation (red), and continuous low frequency fit (CLFF, black) at all deployment stations during Nor' easter Riley. 


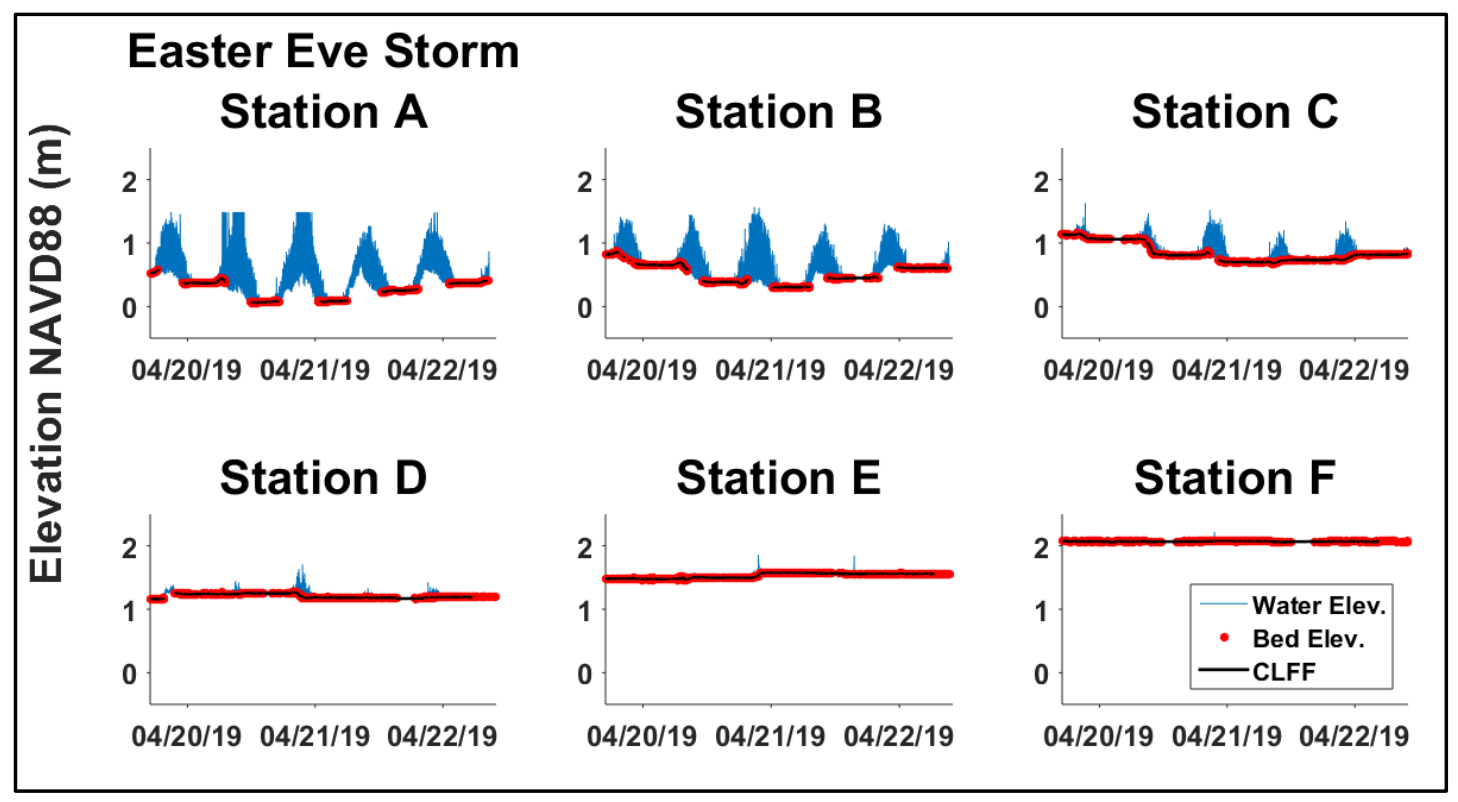

Figure 3.9: Water elevation (blue), bed elevation (red), and continuous low frequency fit (CLFF, black) at all deployment stations during the Easter Eve Storm.

\subsubsection{Data During Storm Events}

The wave forcing (i.e. wave height, storm tide, storm surge and wave period), relative bed elevation change, and beach face slope measured at each cross-shore station during the storm events are shown in Figure 3.10 (Nor'easter Riley) and Figure 3.11 (Easter Eve Storm). The mean and maximum significant wave height, mean peak period, mean storm surge, and maximum storm tide elevation during each tidal cycle of the storm events are listed in Table 3.5 (Nor'easter Riley) and Table 3.6 (Easter Eve Storm).

The accuracy of measured elevation data by the ADM was evaluated by calculating the root-mean-square error $(R M S E)$ during every day-time low tide. 
The RMSE was calculated using the measured ADM elevation and GPS surveyed elevation at the cross-shore deployment stations. The $R M S E$ is calculated through use of Equation 3.6:

$$
R M S E=\sqrt{\frac{\sum\left(<Z_{D T L T}>-Z_{G P S}\right)^{2}}{N}},
$$

where $Z_{D T L T}$ is the bed elevation measured by the ADM during day-time low tide, $Z_{G P S}$ is the GPS surveyed elevation during day-time low tide, and $N$ is the number of elevations being evaluated at a particular deployment station. Figure 3.12 (Nor'easter Riley) and Figure 3.13 (Easter Eve Storm) are 1:1 plots comparing measured ADM bed elevation to GPS surveyed bed elevation. The final reported $R M S E$ value for each storm event is the averaged $R M S E$ value calculated at each deployment station. The calculated RMSE values were within a small enough range to suggest that the measured $\mathrm{ADM}$ bed elevation was realistic and usable for further analysis.

\subsubsection{Nor'easter Riley}

The largest measured morphodynamic change occurred during tidal cycles 2 and 3 (Figure 3.10, C) where the greatest mean (maximum) significant wave heights were recorded at $3.87 \mathrm{~m}(4.16 \mathrm{~m})$ and $3.74 \mathrm{~m}(3.94 \mathrm{~m})$, respectively. Nor'easter Riley began to impact the beach during tidal cycle 2 when the mean storm surge and maximum storm tide elevation difference relative to the previous tidal cycle was the greatest (Table 3.5). The amount of erosion measured at the stations located on the pre-storm berm (Stations B and C) was $0.4 \mathrm{~m}-0.8 \mathrm{~m}$ while $0.05 \mathrm{~m}-0.3 \mathrm{~m}$ of accretion was 
measured at more landward stations (Stations D-F). Erosion was measured at more landward stations (Stations D and E) during tidal cycle 3 compared to tidal cycle 2, despite a decrease in mean and maximum significant wave height. However, there was an increase in mean peak period, mean storm surge, and maximum storm tide elevation (Table 3.5). Erosion was measured for the first time at Station F during tidal cycle 4, while accretion was measured on the backbeach at Stations E and F during tidal cycle 5. The maximum mean peak period occurred during tidal cycles 4 and 5 (Table 3.5).

Table 3.5: Wave forcing conditions during Nor'easter Riley for each tidal cycle. Brackets $(<>)$ denote time averaged values. Parentheses denote the difference relative to previous tidal cycle. $H_{1 / 3}, H_{\max }$, and $T_{p}$ are from NBDC 44009 , storm surge and maximum storm tide data are from NOAA tide gauge 8557380 .

\begin{tabular}{|l|l|l|l|l|l|}
\hline $\begin{array}{l}\text { Nor'easter } \\
\text { Riley }\end{array}$ & $\begin{array}{c}\left\langle\boldsymbol{H}_{\mathbf{1 / 3}}\right\rangle \\
(\mathbf{m})\end{array}$ & $\begin{array}{c}\boldsymbol{H}_{\max } \\
(\mathbf{m})\end{array}$ & $\begin{array}{c}\left\langle\mathbf{T}_{\boldsymbol{p}}\right\rangle \\
(\mathbf{s})\end{array}$ & $\begin{array}{c}\langle\mathbf{S}> \\
(\mathbf{m})\end{array}$ & $\begin{array}{c}\text { Max Storm } \\
\text { Tide } \\
(\mathbf{N A V D 8 8}, \mathbf{m})\end{array}$ \\
\hline $\begin{array}{l}\text { Tidal } \\
\text { Cycle 1 }\end{array}$ & 3.24 & 3.68 & 7.08 & 0.28 & 0.82 \\
\hline $\begin{array}{l}\text { Tidal } \\
\text { Cycle 2 }\end{array}$ & $3.87(0.63)$ & $4.16(0.48)$ & $9.40(2.32)$ & $0.59(0.31)$ & $1.21(0.39)$ \\
\hline $\begin{array}{l}\text { Tidal } \\
\text { Cycle 3 }\end{array}$ & $3.74(-0.13)$ & $3.94(-0.22)$ & $13.6(4.2)$ & $0.75(0.16)$ & $1.32(0.11)$ \\
\hline $\begin{array}{l}\text { Tidal } \\
\text { Cycle 4 }\end{array}$ & $3.61(-0.13)$ & $3.88(-0.06)$ & $14.1(0.50)$ & $0.73(-0.02)$ & $1.35(0.03)$ \\
\hline $\begin{array}{l}\text { Tidal } \\
\text { Cycle 5 }\end{array}$ & $3.04(-0.57)$ & $3.50(-0.38)$ & $14.1(0)$ & $0.68(-0.05)$ & $1.28(-0.07)$ \\
\hline
\end{tabular}




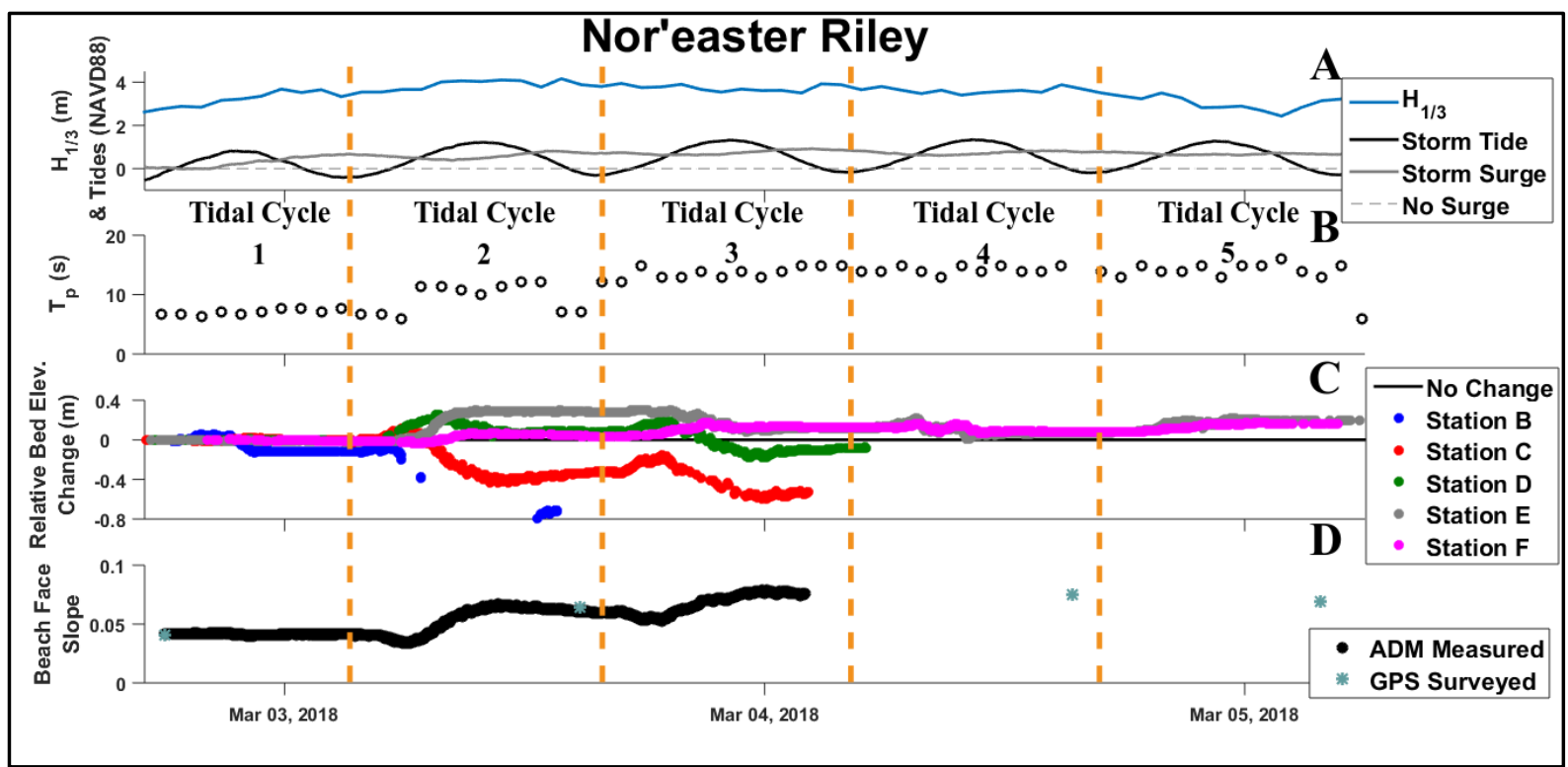

Figure 3.10: Wave forcing (A and B), relative bed elevation change (C), and beach face slope measured from Station $C$ and Station F (D) during Nor' easter Riley. The significant wave height (A, blue) and peak wave period (B) are from NDBC Buoy 44009. The tidal and storm surge data (A, black and grey) are from NOAA tide gauge 8557380 .

The beach face slope steepened throughout tidal cycles 2 - 4 during Nor'easter Riley. The beach face slope for tidal cycles 1 - 3 was calculated using the CLFF of measured bed elevations collected at Stations C and F (Figure 3.10 $\mathrm{D}$, blue) but were not used to calculate the beach face slope for tidal cycles 4 and 5 due to lack of ADM measurements. The beach face slope was also calculated using GPS surveyed elevations obtained during day-time low tides (Figure 3.10 $\mathrm{D}$, black). The initial beach face slope was 0.041 (1:24) and the steepest measured beach face slope was 0.079 (1:13), during tidal cycle 3 . The beach face slope 
flattened to $0.075(1: 13)$ and $0.07(1: 14)$ during tidal cycles 4 and 5 respectively, suggesting the beginning of beach recovery.

\subsubsection{Easter Eve Storm}

Less morphodynamic change occurred during the Easter Eve Storm compared to that of Nor' easter Riley, yet similarities between the two storms were observed. The impact of the storm

began during tidal cycle 1 and continued through tidal cycle 3 (Figure 3.11 C). The maximum significant wave height increased, despite a decreased mean value, during tidal cycle 3 compared to tidal cycle 2. Erosion was measured during tidal cycles 1 and 2 at stations located on and seaward of the pre-storm berm (Stations A - C) and ranged from $0.35 \mathrm{~m}-0.47 \mathrm{~m}$. Accretion was measured at Stations D and E ranging from $0.03 \mathrm{~m}-0.1 \mathrm{~m}$, while no morphodynamic change was measured at Station F. The maximum mean significant wave height during tidal cycle 2 was measured at $2.19 \mathrm{~m}$ (Table 3.6). Small to no amounts of erosion $(0 \mathrm{~m}-0.11 \mathrm{~m})$ continued through tidal cycle 3 at Stations A - C. Erosion was measured at Station D for the first time during this storm and there was 0.08 $\mathrm{m}$ of accretion measured at Station E during tidal cycle 3. Tidal cycle 3 was also when the greatest mean peak period and maximum significant wave height was measured at $9.97 \mathrm{~s}$ and $2.46 \mathrm{~m}$, respectively. The beginning of berm recovery was measured at Stations A - C during tidal cycles 4 and 5 where the mean significant wave height and peak period decreased (Table 3.6). The accretion associated with this recovery ranged from $0.12 \mathrm{~m}-0.31 \mathrm{~m}$. The measurement campaign ceased following tidal cycle 5 but it is assumed the beach continued to recover. 
The beach face during the Easter Eve Storm did not steepen as much as Nor'easter Riley due to the less extreme wave conditions. The beach face slope for all tidal cycles was calculated using the CLFF of measured bed elevations collected at Stations A and F. The initial beach face slope was 0.042 (1:24) and became the steepest following tidal cycle 3 with a slope of 0.055 (1:18). The final beach face slope after tidal cycle 5 was 0.034 (1:29).

Table 3.6: Wave forcing conditions during the Easter Eve Storm for each tidal cycle. Brackets $(<>)$ denote time averaged values. Parentheses denote the difference relative to previous tidal cycle. $H_{1 / 3}, H_{\max }$, and $T_{p}$ are from NBDC 44009 , storm surge and maximum storm tide data are from NOAA tide gauge 8557380 .

\begin{tabular}{|l|l|l|l|l|l|}
\hline \multicolumn{1}{|c|}{$\begin{array}{l}\text { Easter } \\
\text { Eve } \\
\text { Storm }\end{array}$} & \multicolumn{1}{|c|}{$\begin{array}{c}\left\langle\boldsymbol{H}_{\mathbf{1 / 3}}\right\rangle \\
(\mathbf{m})\end{array}$} & \multicolumn{1}{|c|}{$\begin{array}{c}\boldsymbol{H}_{\max } \\
(\mathbf{m})\end{array}$} & $\begin{array}{c}\left\langle\boldsymbol{T}_{\boldsymbol{p}}\right\rangle \\
(\mathbf{s})\end{array}$ & $\begin{array}{c}<\mathrm{S}\rangle \\
(\mathbf{m})\end{array}$ & $\begin{array}{c}\text { Max Storm } \\
\text { Tide } \\
(\mathbf{N A V D 8 8 , ~} \mathbf{m})\end{array}$ \\
\hline $\begin{array}{l}\text { Tidal Cycle } \\
\mathbf{1}\end{array}$ & 1.73 & 2.11 & 7.81 & 0.13 & 0.95 \\
\hline $\begin{array}{l}\text { Tidal Cycle } \\
\mathbf{2}\end{array}$ & $2.19(0.46)$ & $2.38(0.27)$ & $9.17(1.36)$ & $0.14(0.01)$ & $0.79(-0.16)$ \\
\hline $\begin{array}{l}\text { Tidal Cycle } \\
\mathbf{3}\end{array}$ & $2.11(-0.08)$ & $2.46(0.08)$ & $9.97(0.80)$ & $0.12(-0.02)$ & $0.94(0.15)$ \\
\hline $\begin{array}{l}\text { Tidal Cycle } \\
\mathbf{4}\end{array}$ & $1.63(-0.48)$ & $1.82(-0.64)$ & $9.32(-0.65)$ & $0.14(0.02)$ & $0.69(-0.25)$ \\
\hline $\begin{array}{l}\text { Tidal Cycle } \\
\mathbf{5}\end{array}$ & $1.34(-0.29)$ & $1.42(-0.40)$ & $9.24(-0.08)$ & $0.13(-0.01)$ & $0.89(0.20)$ \\
\hline
\end{tabular}




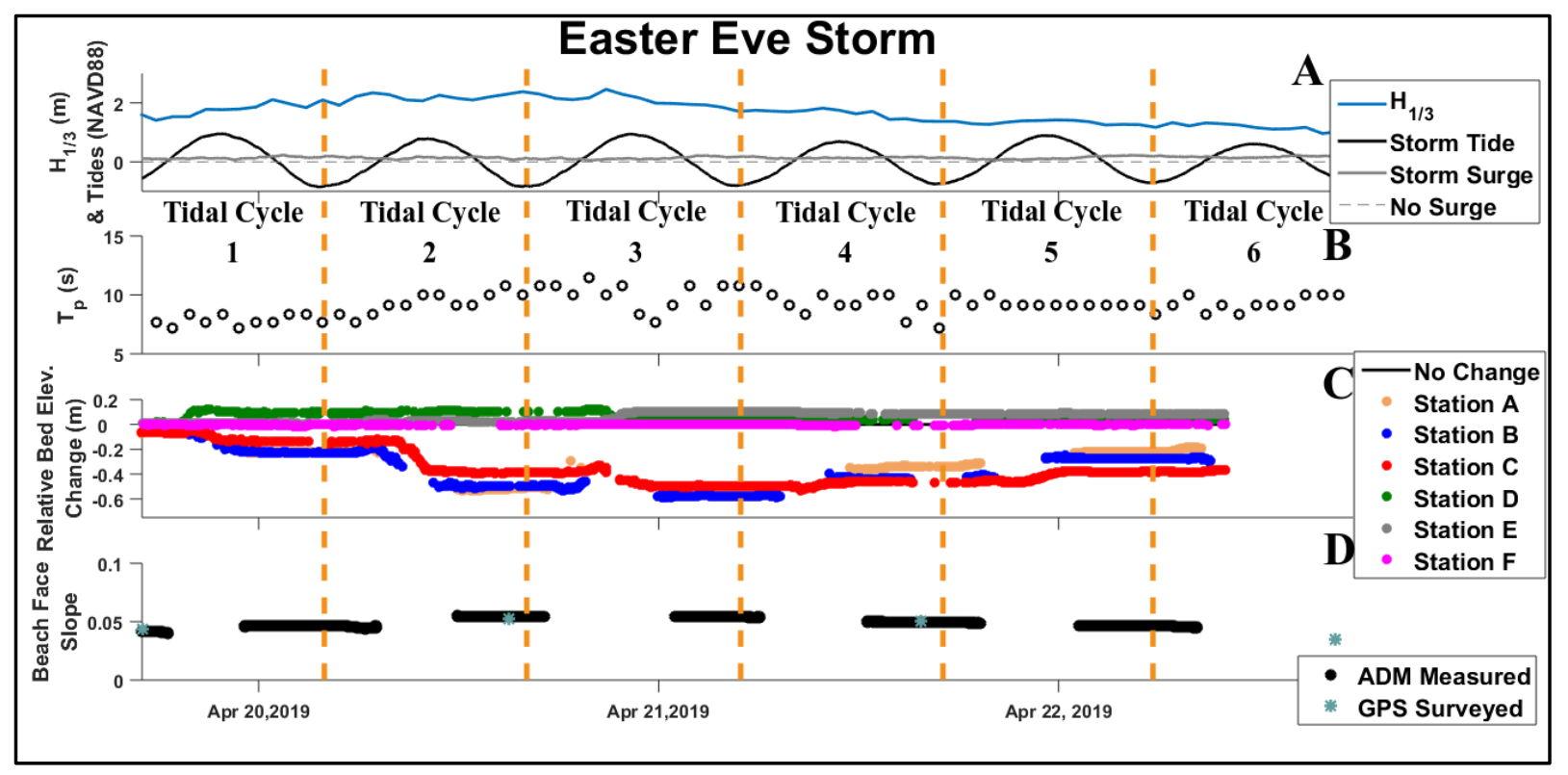

Figure 3.11: Wave forcing (A and B), relative bed elevation change (C), and beach face slope measured from Station A and Station F (D) during the Easter Eve Storm. The significant wave height (A, blue) and peak wave period (B) are from NDBC Buoy 44009. The tidal and storm surge data (A, black and grey) are from NOAA tide gauge 8557380 . 


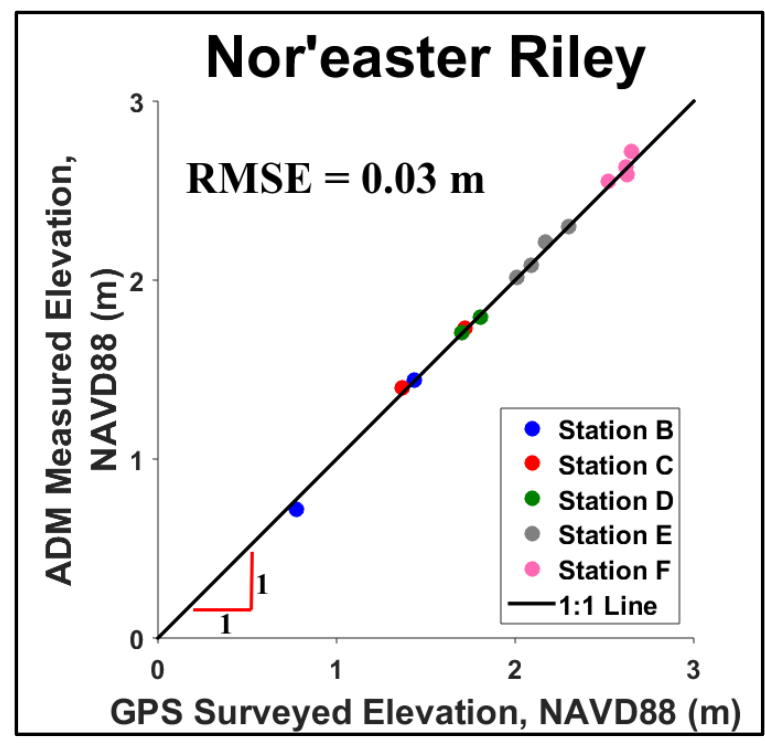

Figure 3.12: 1:1 comparison plot of elevation data measured by the ADM vs. elevation data surveyed by the GPS at each day-time low tide during Nor'easter Riley. The root-mean-square error ( $R M S E)$ was calculated at each station and averaged to obtain a final $R M S E$ value. 


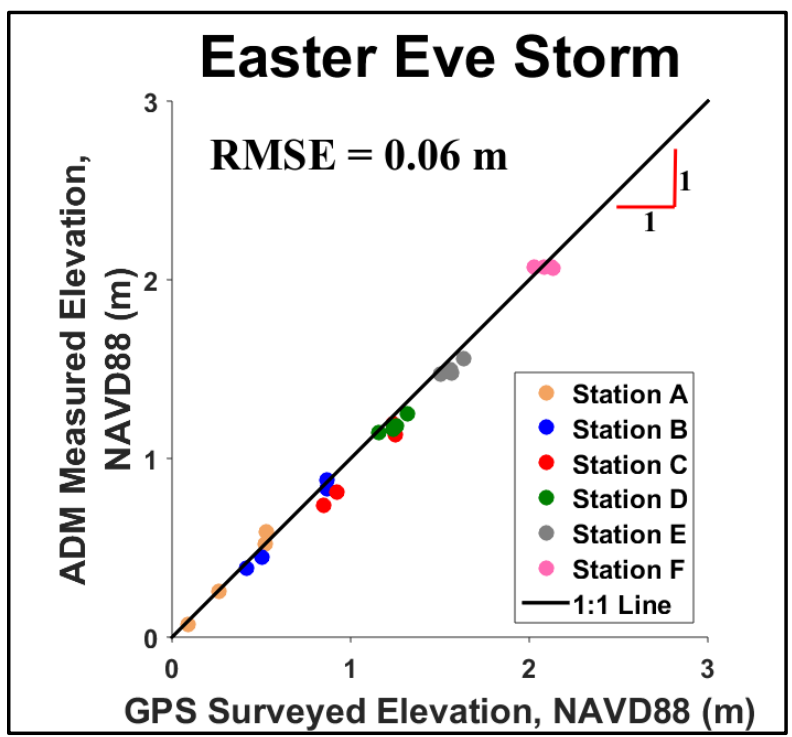

Figure 3.13: 1:1 comparison plot of elevation data measured by the ADM vs. elevation data surveyed by the GPS at each day-time low tide during the Easter Eve Storm. The root-mean-square error (RMSE) was calculated at each station and averaged to obtain a final $R M S E$ value.

\subsection{Water Velocity}

\subsubsection{Data Cleaning}

As described in section 2.1.2, the JFE sensing unit was initially deployed $0.10 \mathrm{~m}$ above the pre-storm bed elevation and was adjusted to $0.10 \mathrm{~m}$ above the day-time low tide bed elevation in response to a naturally dynamic bed. Due to the rapid morphodynamic beach response during a storm event, it was imperative to eliminate recorded velocity data at the time when the JFE sensing unit was buried due to accretion or at an elevation too high to be submerged by the uprush or backwash (Figure 3.14). A CLFF of bed elevations, measured water elevations, and GPS surveyed bed elevation assisted in determining invalid JFE velocity data. 
Equation 3.7 provides the condition to eliminate invalid JFE velocity data between times of day-time low tide. The condition is updated every day-time low tide due to JFE adjustment of $0.10 \mathrm{~m}$ above the present bed elevation at that time.

$$
z_{C L F F}>z_{J F E}-d_{J F E}^{b} \mid \eta<Z_{G P S}+d_{J F E}^{\eta},
$$

where $z_{C L F F}$ is the CLFF of bed elevations, $z_{J F E}$ is the JFE sensing unit elevation $\left(Z_{G P S}+0.10 \mathrm{~m}\right), d_{J F E}^{b}$ is a tolerance distance for bed elevations applied to the $\mathrm{JFE}$, and $d_{J F E}^{\eta}$ is a tolerance distance for water elevations applied to the JFE. Tolerance values of $0.04 \mathrm{~m}$ and $0.125 \mathrm{~m}$ were prescribed to $d_{J F E}^{b}$ and $d_{J F E}^{\eta}$, respectively.

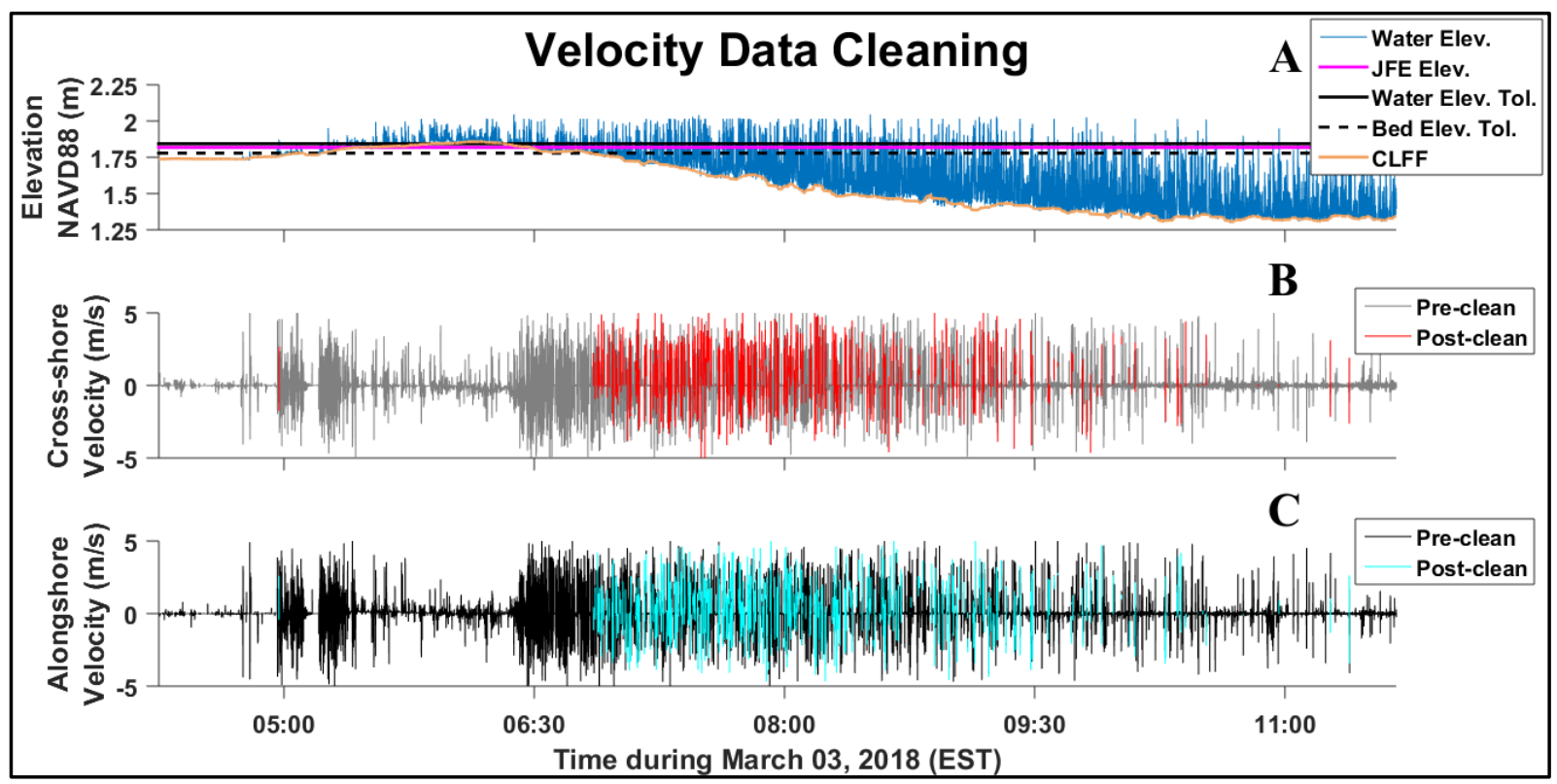

Figure 3.14: Elevation data recorded by the ADM (A, blue and tan), adjusted JFE elevation (A, magenta), water and bed elevation tolerance values (A, black), and velocity data recorded by the JFE (B and C) during Nor'easter Riley at deployment Station C. Velocity data was cleaned using Equation 3.7. 


\subsubsection{Data During Storm Events}

Cross-shore velocity data collected during Nor'easter Riley and the Easter Eve Storm are shown in Figure 3.15 (Nor'easter Riley) and Figure 3.16 (Easter Eve Storm). Unfortunately, the in situ velocity collected was determined to be unreliable due to unrealistic measurements. Pre-storm and mid-storm velocity magnitudes were both measured at $4-5 \mathrm{~m} / \mathrm{s}$. The unrealistic pre-storm measurements could be due to poor sensor response to immediate inundation and/or sensor response in sediment- and bubble-laden flows.

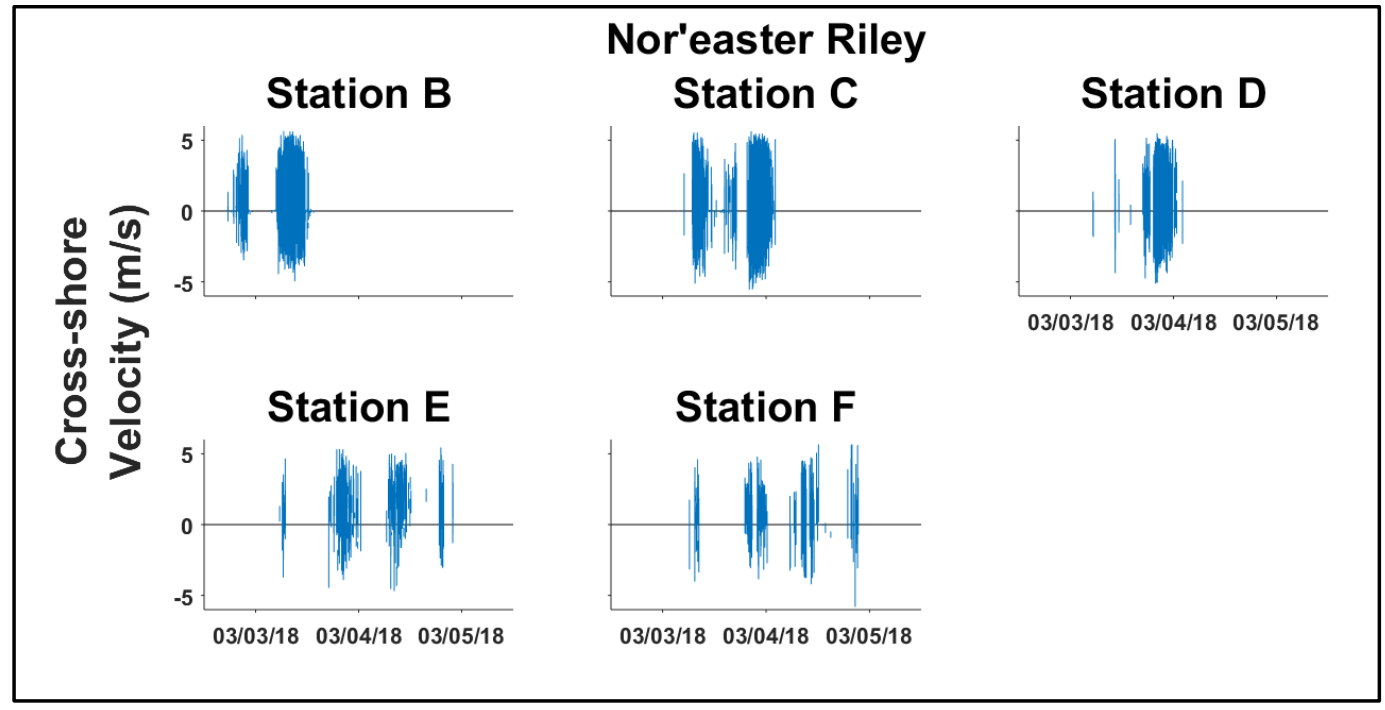

Figure 3.15: Cross-shore velocity measurements during Nor'easter Riley. 


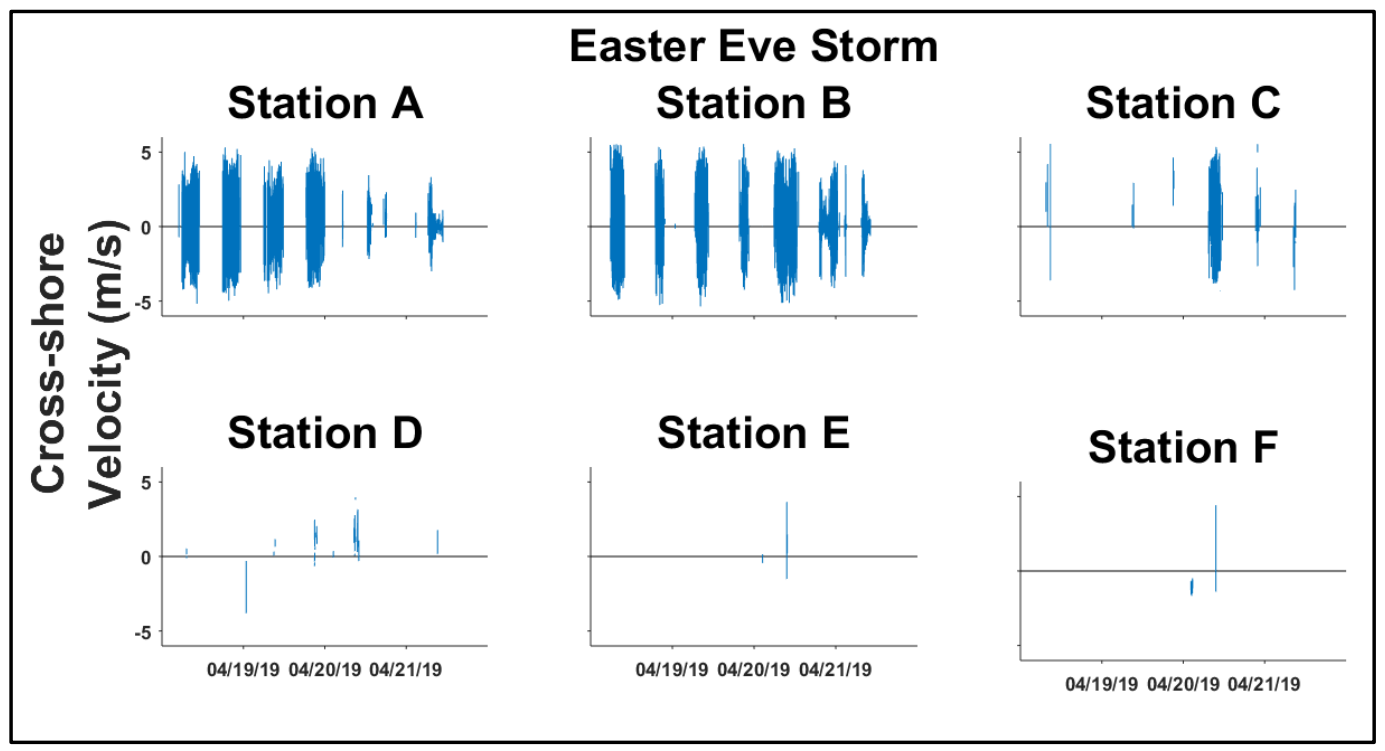

Figure 3.16: Cross-shore velocity measurements during Nor'easter Riley.

\subsection{Water Depth}

\subsubsection{Depth Data Adjustments}

As detailed in section 2.3.1, a measured atmospheric pressure time series was used in

Equation 2.3 to accurately calculate water depth measured by the RBR sensor. A vertical offset adjustment had to be applied so that no depth was measured during times of continuous emergence (i.e. low tide) and values below zero were removed (Figure 3.17). Atmospheric pressure data measured at Bethany Beach, DE was provided by Delaware Environmental Observing System (DEOS) during Nor'easter Riley. During the Easter Eve Storm, a RBR sensor was deployed to measure the atmospheric pressure in situ (Figure 2.3). 


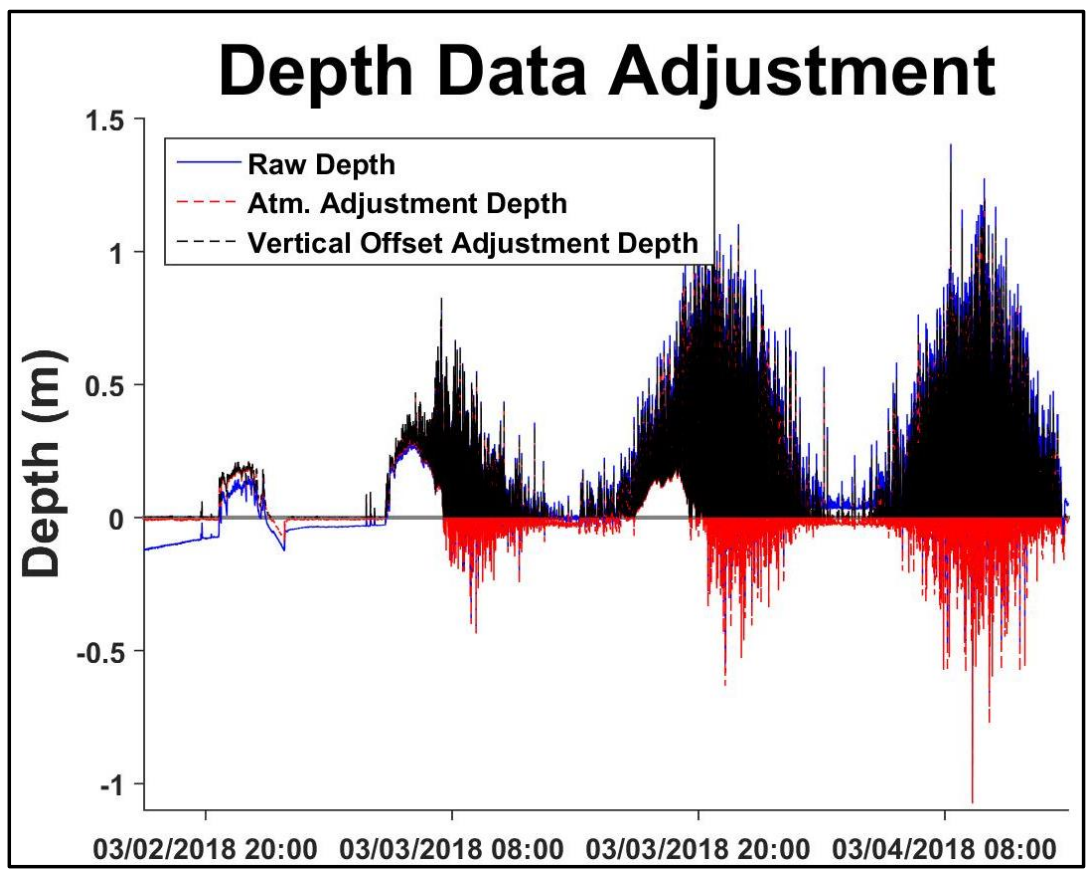

Figure 3.17: Depth data (raw and adjusted) measured by the RBR pressure sensor from deployment Station C during Nor'easter Riley. Raw depth (blue) data is directly off the RBR before adjustments were applied (red and black).

\subsubsection{Data Cleaning}

The use of fixed in situ pressure sensors in the swash or inner surf zone to measure water depth has drawbacks due to bed morphodynamics during storm events. The effects of bed morphodynamics can result in the mismeasurement of water depth when the bed below the fixed RBR sensor elevation rises or falls. Similarly to the JFE sensor, the RBR sensor became buried due to accretion and the time of burial had to be determined to properly clean the measured depth data (Figure 3.18). The data cleaning technique applied to determine the RBR time of burial is similar to Equation 3.7 that was applied to determine JFE time of burial. 
Equation 3.8 is the condition to eliminate invalid RBR depth data between times of day-time low tide. The condition is updated every day-time low tide due to RBR adjustment to the present bed elevation at that time.

$$
z_{C L F F}>z_{R B R}-d_{R B R}^{b},
$$

where $z_{R B R}$ is the RBR elevation, and $d_{R B R}^{b}$ is a tolerance elevation for bed elevations applied to the RBR. A tolerance value of $0.05 \mathrm{~m}$ was used for both storm events.

\subsubsection{Calculated Water Depth from CLFF}

To account for bed morphodynamics, water depth was calculated by subtracting bed elevation obtained from a CLFF from water elevation data measured by the ADM (Figure 3.19). The use of the bed elevation CLFF was necessary to obtain a more accurate time series of water depth during the storm event, as opposed to using a fixed in situ pressure sensor. A major drawback of using the bed elevation CLFF is when the bed would become continuously submerged and no bed elevation CLFF was able to be obtained. 


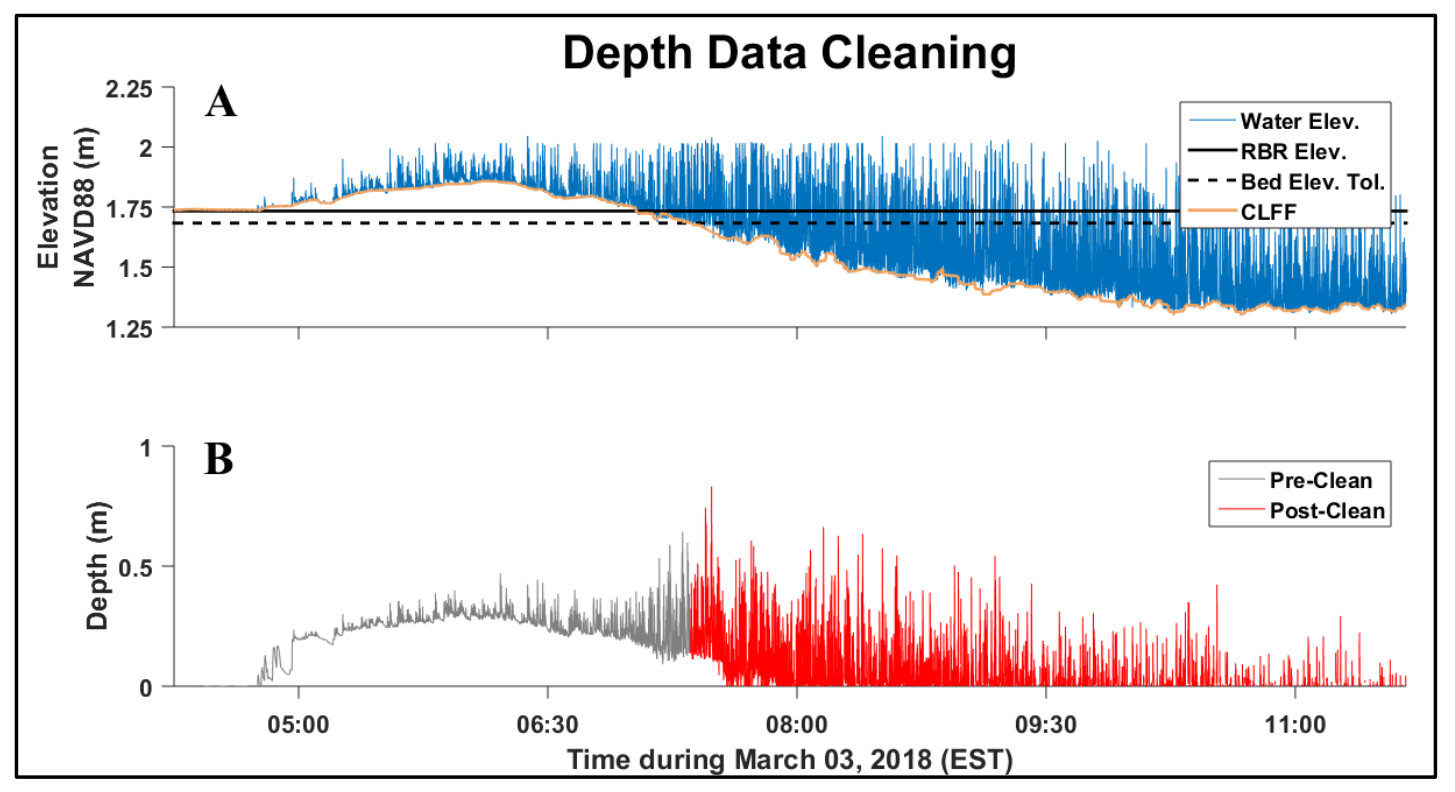

Figure 3.18: Elevation data recorded by the $\mathrm{ADM}$ (A, blue and tan), adjusted RBR elevation (A, solid black), bed elevation tolerance values (A, broken black), and depth data recorded by the RBR (B) during Nor'easter Riley at deployment Station C. Depth data was cleaned using Equation 3.8. 


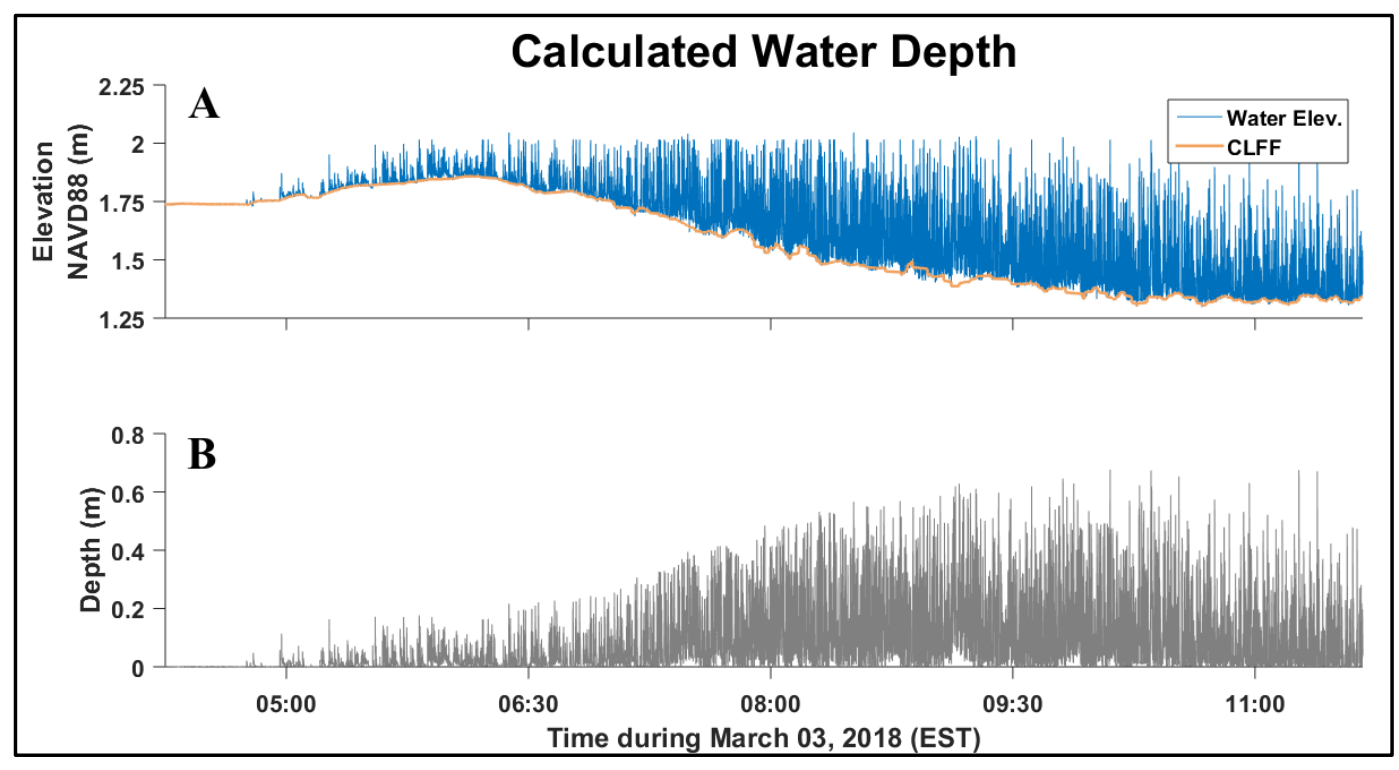

Figure 3.19: Measured water elevation (A, blue) and bed elevation CLFF (A, tan) used to calculate water depth (B) during Nor'easter Riley at deployment Station C.

\subsubsection{Data During Storm Events}

The wave forcing (i.e. wave height, storm tide, storm surge and wave period), measured water depth, and calculated water depth at each cross-shore station during the storm events are shown in Figure 3.20 (Nor'easter Riley) and Figure 3.22 (Easter Eve Storm). The mean measured and calculated water depth per tidal cycle during Nor'easter Riley are shown in Figure 3.21A and Figure 3.21B, while the maximum measured and calculated water depth per tidal cycle are shown in Figure 3.21C and Figure 3.21D. The mean measured and calculated water depth per tidal cycle during the Easter Eve Storm are shown in Figure 3.23A and Figure 3.23B, while the mean measured and calculated water depth per tidal cycle are shown in Figure 3.23C and Figure 3.23D. Measured and calculated 
water depth data are presented to show the different magnitudes resulting from both methods.

\subsubsection{Nor'easter Riley}

Measured and calculated water depths increased throughout Nor'easter Riley until tidal cycle 5 when the storm significantly weakened. The lack of measured water depth data (Figure 3.20C, Figure 3.21A, and Figure 3.21C) from deployment stations is due to the data cleaning technique applied (Equation 3.8) while the lack of calculated water depth data (Figure 3.20D, Figure 3.21B, and Figure 3.21D) is due to either continuous bed submergence, deployment station structural failure, or ADM retrieval during the field study.

The calculated pre-storm maximum water depths show that Station B was the only deployment station to experience water depth greater than $0.10 \mathrm{~m}$ and mean water depth of $0.06 \mathrm{~m}$. However, the mean (maximum) calculated water depth increased to $0.13 \mathrm{~m}(0.68 \mathrm{~m})$ at Station $\mathrm{C}$ and $0.05 \mathrm{~m}(0.23 \mathrm{~m})$ at Station $\mathrm{F}$ during the first tidal cycle of the storm event (tidal cycle 2). The lesser mean and maximum calculated water depth at Station B during tidal cycle 2 was due to deployment station structural failure and ADM retrieval. The greatest mean (maximum) water depth was calculated at Station C during tidal cycle 3 at $0.22 \mathrm{~m}$ $(0.87 \mathrm{~m})$. Similarly to Station B during tidal cycle 2 , Station D during tidal cycle 4 experienced structural failure and resulted in a lesser mean and maximum calculated water depth compared to the previous tidal cycle. The mean (maximum) water depth at Station $\mathrm{E}$ and Station $\mathrm{F}$ increased to $0.11 \mathrm{~m}(0.55 \mathrm{~m})$ 
during tidal cycle 4 before decreasing to $0.09 \mathrm{~m}(0.41 \mathrm{~m})$ and $0.07 \mathrm{~m}(0.31) \mathrm{m}$ during tidal cycle 5, respectively.

Discrepancies between measured and calculated water depths were consistent and can be attributed to the effects of bed morphodynamics, periodic emergence and submergence, or sensor malfunction. An observed issue with the measured data by the RBR sensor was that the water depth would not always fall to zero during times when the bed was being measured by the ADM. The RMSE calculated between the measured and calculated water depths at Stations B-E were $0.14 \mathrm{~m}, 0.17 \mathrm{~m}, 0.11 \mathrm{~m}$, and $0.15 \mathrm{~m}$, respectively. Measured water depth data was not usable from Station F due to burial.

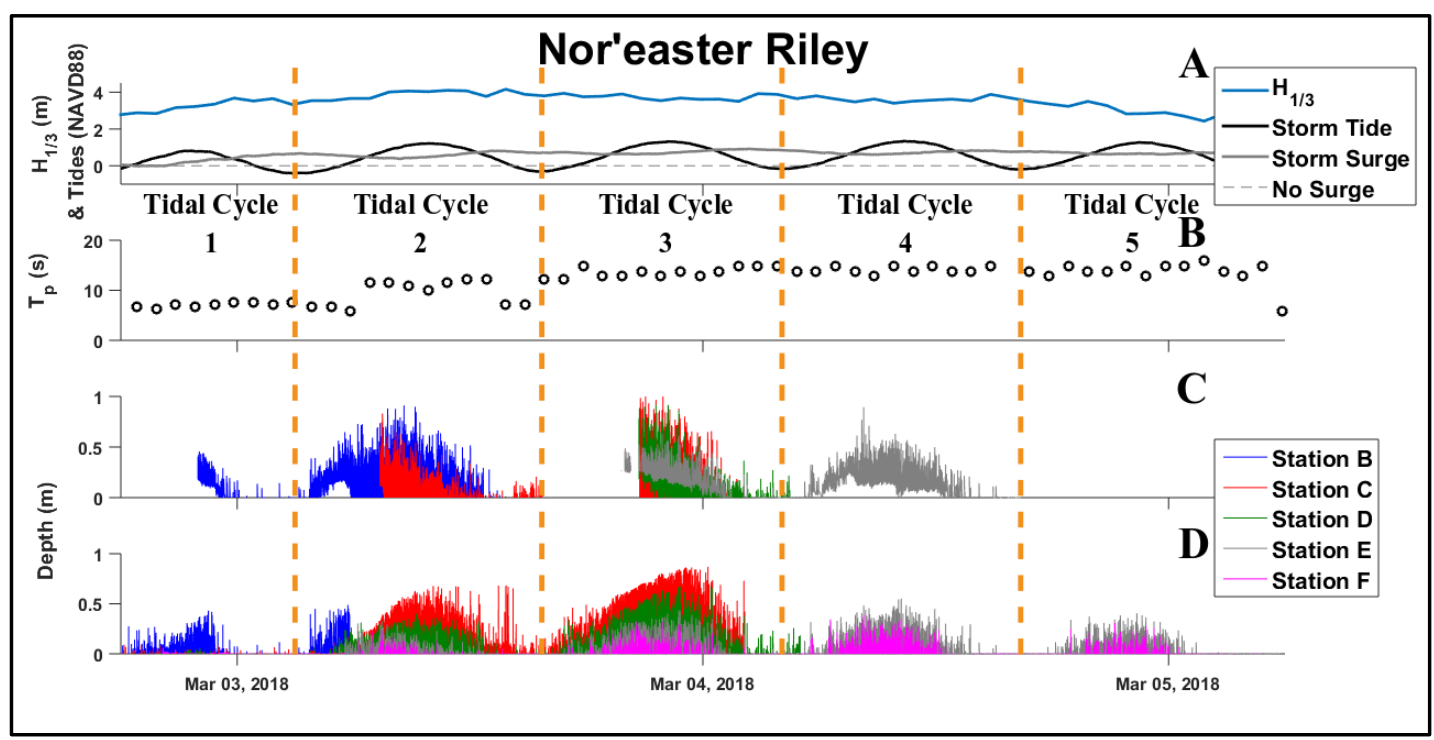

Figure 3.20: Wave forcing (A and B), measured water depth (C), and calculated water depth (D) during Nor' easter Riley. The significant wave height (A, blue) and peak wave period (B) are from NDBC Buoy 44009. The tidal and storm surge data (A, black and grey) are from NOAA tide gauge 8557380 . 


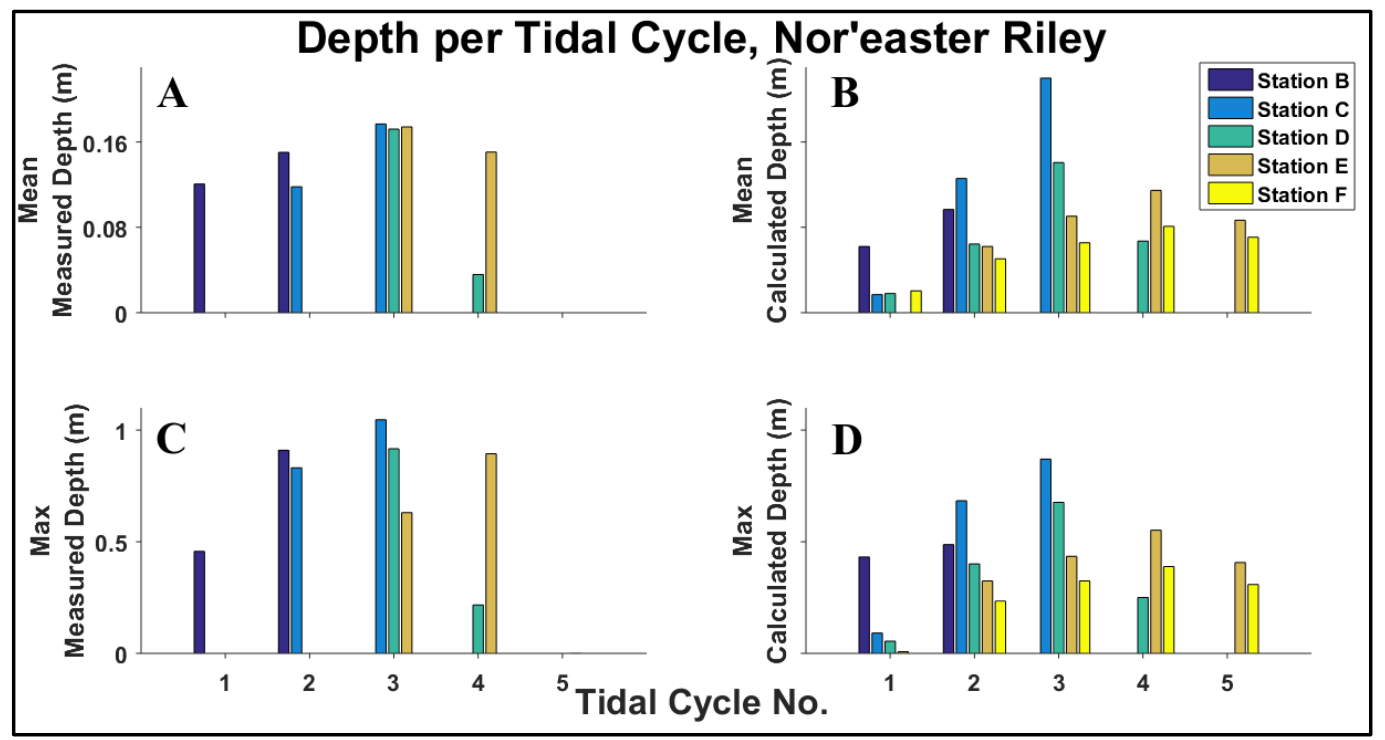

Figure 3.21: Mean measured (A), mean calculated (B), maximum measured (C), maximum calculated (D) water depths per tidal cycle at each deployment station during Nor'easter Riley.

\subsubsection{Easter Eve Storm}

Measured and calculated water depths increased during tidal cycles 2 and 3 of the Easter Eve Storm. As was the case during Nor'easter Riley, the lack of measured water depth data (Figure 3.22C, Figure 3.23A, and Figure 3.23C) was due to the applied data cleaning technique (Equation 3.8) and the lack of calculated water depth data (Figure 3.22D, Figure 3.23B, and Figure 3.23D) is due to continuous bed submergence. Unlike Nor'easter Riley, no structural failure and ADM retrieval took place during the Easter Eve Storm resulting in calculated water depths during each tidal cycle at each deployment station.

The calculated pre-storm maximum water depths show that Stations A-C were the only deployment stations to experience water depth greater than $0.13 \mathrm{~m}$ 
and a mean water depth of $0.03 \mathrm{~m}$. However, the mean (maximum) calculated water depth increased to $0.05 \mathrm{~m}(0.50 \mathrm{~m})$ at Station D and $0.08 \mathrm{~m}(0.14 \mathrm{~m})$ at Station F during tidal cycle 3. The greater mean calculated water depth at Station F compared to Station D and Station E was due to fewer swashes being measured. The greatest mean water depth was calculated at Station A during tidal cycle 3 at $0.15 \mathrm{~m}$, whereas the greatest maximum water depth was calculated at Station B during tidal cycle 3 at $0.86 \mathrm{~m}$.

The reported mean and maximum calculated water depth values at Station A and Station B are underestimated due to continuous bed submergence at times of rising or peak high tide. The greatest maximum water depth was measured at Station A during tidal cycle 3 at $1.32 \mathrm{~m}$, however the greatest mean water depth was measured at Station A during tidal cycle 5 at $0.54 \mathrm{~m}$. 


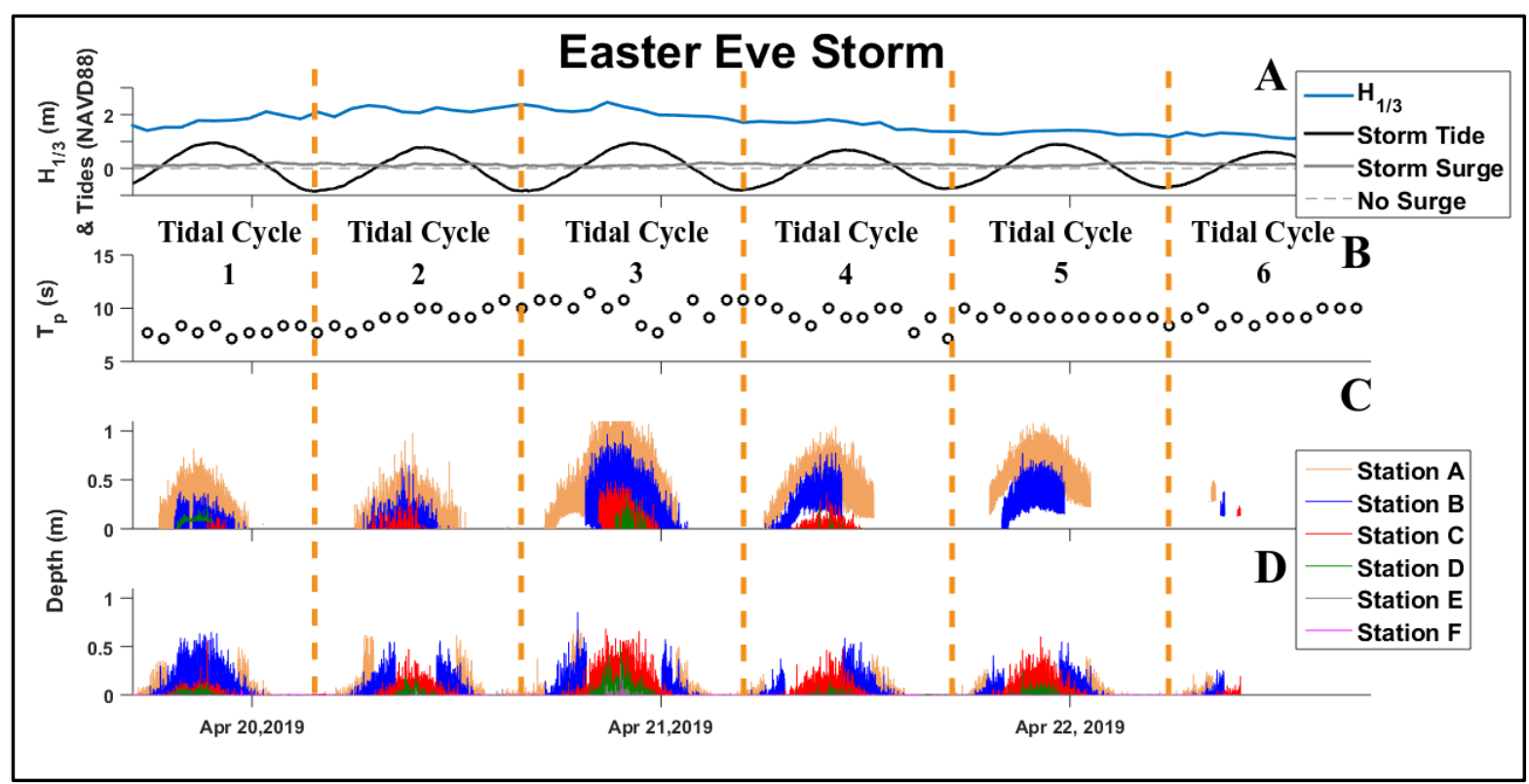

Figure 3.22: Wave forcing (A and B), measured water depth (C), and calculated water depth (D) during the Easter Eve Storm. The significant wave height (A, blue) and peak wave period (B) are from NDBC Buoy 44009. The tidal and storm surge data (A, black and grey) are from NOAA tide gauge 8557380 . 


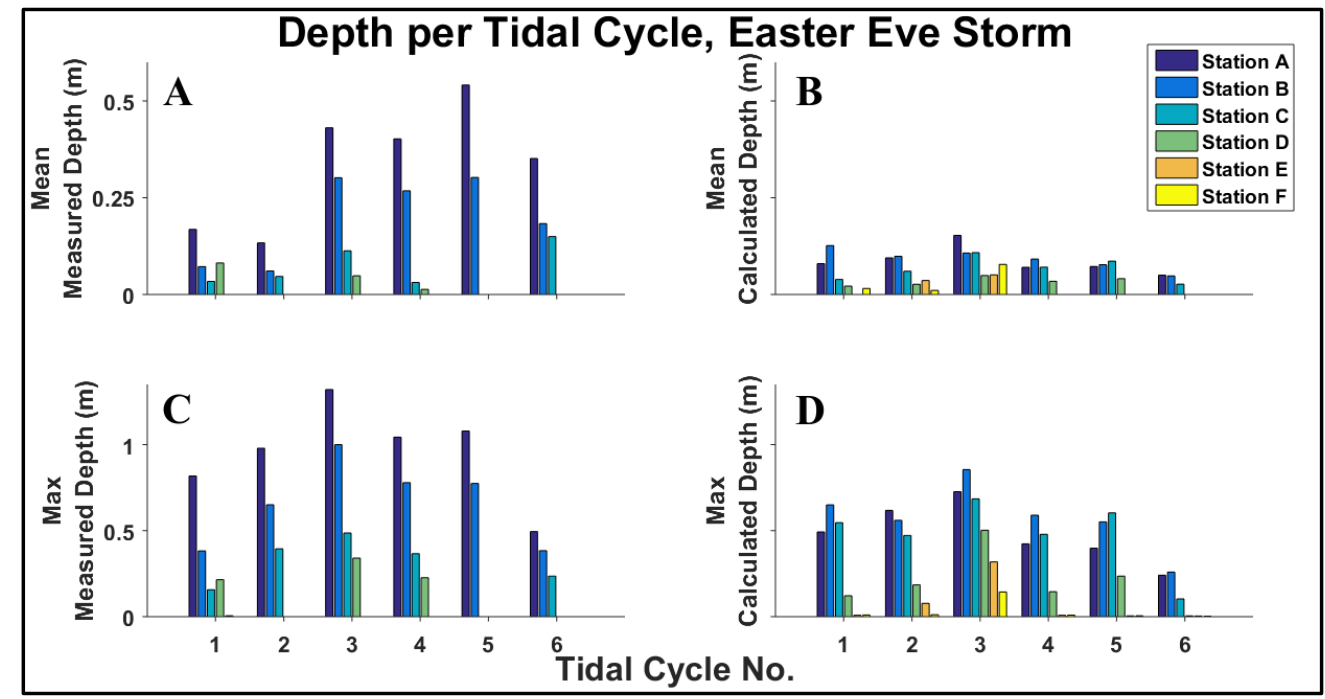

Figure 3.23: Mean measured (A), mean calculated (B), maximum measured (C), maximum calculated (D) water depths per tidal cycle at each deployment station during the Easter Eve Storm.

\subsection{GPS Surveyed Profiles}

Figure 3.24 (Nor'easter Riley), Figure 3.25 (Nor'easter Toby), and Figure 3.26 (Easter Eve Storm) are of cross-shore beach face profiles collected using a RTK GPS mounted to a push-cart (Figure 2.4). The cross-shore profiles show a spatially continuous evolution of beach face elevation, whereas the bed elevation data measured by the ADM show temporally continuous evolution. The profile lines shown in Figure 3.24 and Figure 3.26 were collected at every day-time low tide during the field studies. The profile lines shown in Figure 3.25 were collected at times of sensor deployment and sensor collection, as logistical problems inhibited the ability to collect profiles throughout the storm event. The dune was able to be surveyed in the cross-shore profile shown in Figure 3.24 but not in the cross-shore profiles shown in Figure 3.25 and Figure 3.26. 
The spatially continuous cross-shore profiles allowed for the calculation of cross-shore sediment volume loss per unit alongshore. The greatest calculated cross-shore sediment volume loss values during the storm events were $17.8 \mathrm{~m}^{3} \mathrm{~m}^{-1}$ (Nor'easter Riley), $36.3 \mathrm{~m}^{3} \mathrm{~m}^{-1}$ (Nor'easter

Toby), and $15.6 \mathrm{~m}^{3} \mathrm{~m}^{-1}$ (Easter Eve Storm). The day where the greatest cross-shore sediment volume loss occurred during Nor'easter Riley was March 04, 2018 and during the Easter Eve Storm was April 21, 2019.

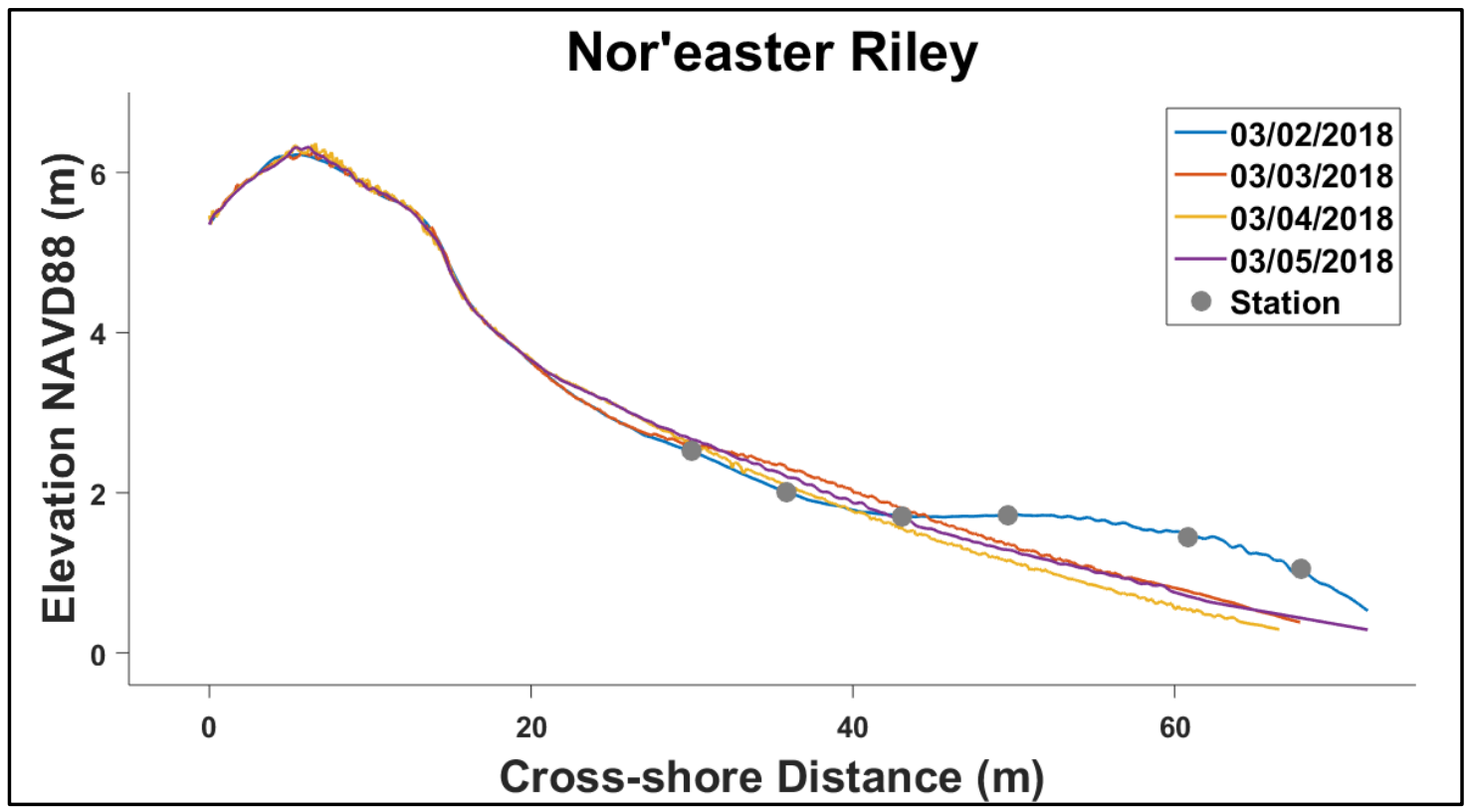

Figure 3.24: GPS surveyed profiles of the beach face during Nor'easter Riley. 


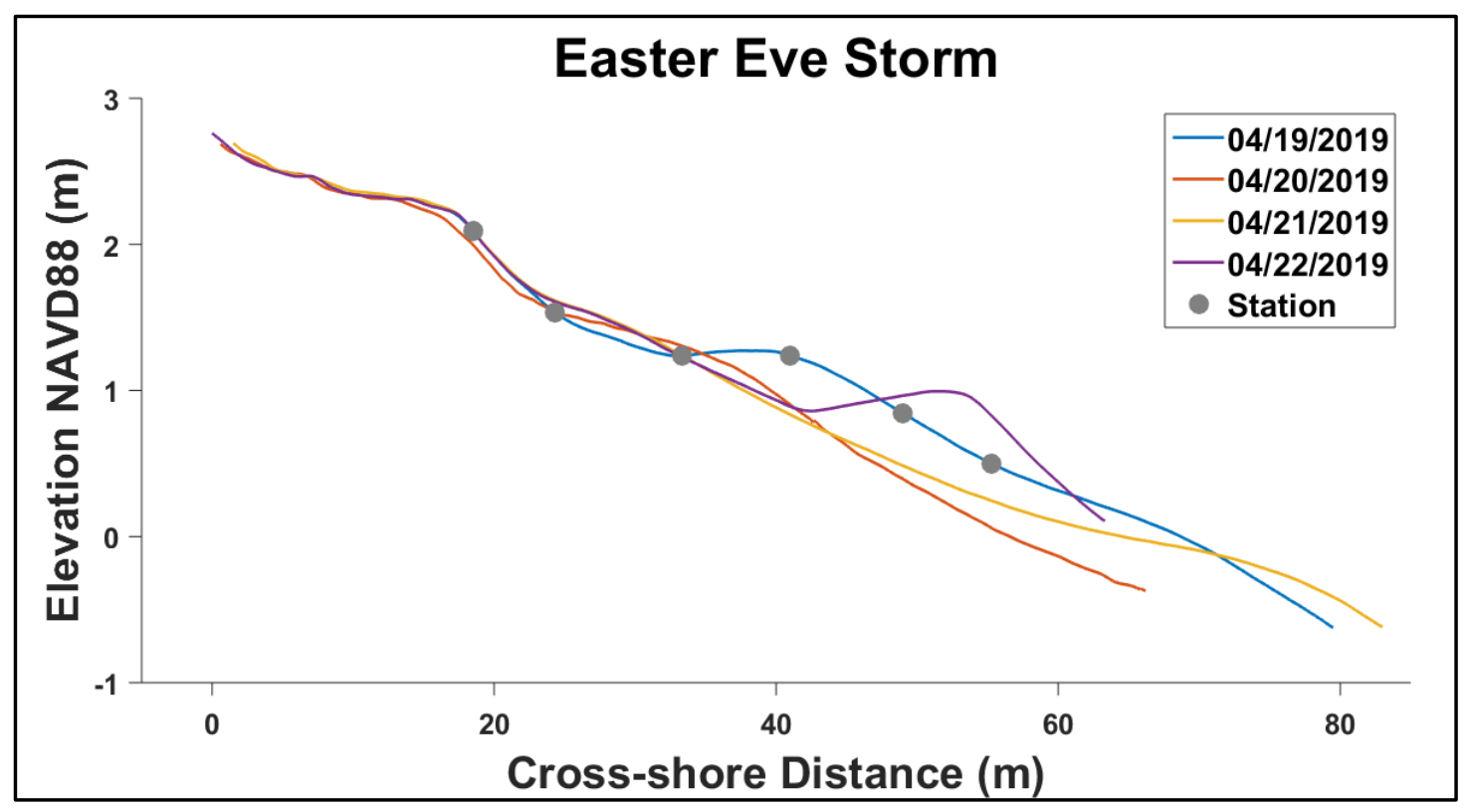

Figure 3.25: GPS surveyed profiles of the beach face during the Easter Eve Storm.

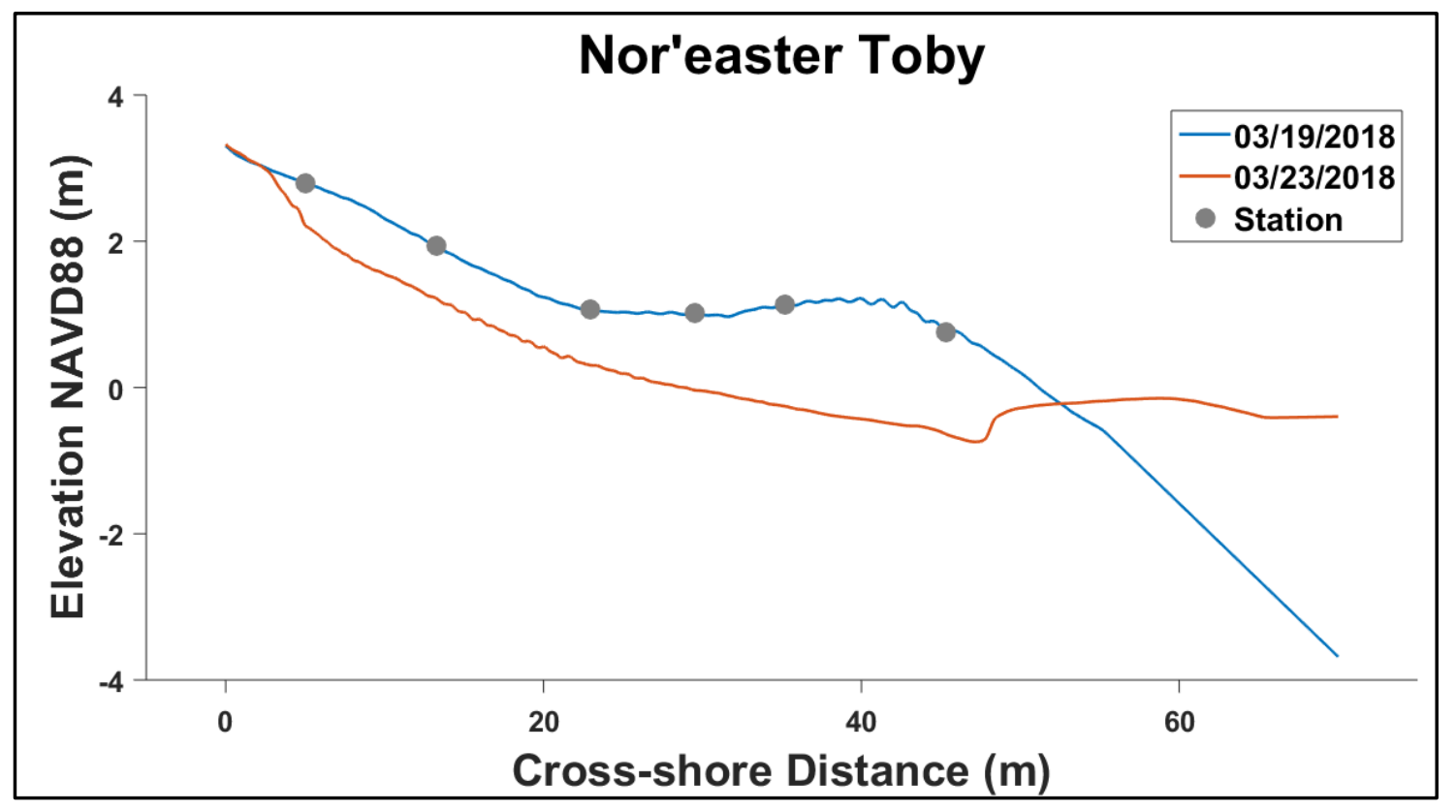

Figure 3.26: GPS surveyed profiles of the beach face during Nor'easter Toby. 


\subsection{Sediment Samples}

Sediment samples were collected during the Easter Eve Storm and grain size analysis was performed. The samples were collected during every day-time low tide at each deployment station. The purpose of performing grain size analysis was to quantify sediment characteristic changes in response to storm forcing conditions. The commonly accepted understanding of grain size response to storm conditions is that coarser sediment grains will remain while finer sediment grains are transported offshore, resulting in a steeper beach slope (Dean \& Dalrymple, 2004; Komar, 1998).

\subsubsection{Sieving Technique}

A popular technique to obtain a statistical size description of a sediment sample is by using sieves. Sieves are pans with a wired mesh screen of a certain diameter size (Figure 3.27A). The method of sieving sediment involves stacking sieves of various diameter sizes with the coarser mesh sizes at the top and the finer mesh sizes at the bottom (Figure 3.27B). The stack of sieves is then shaken causing the individual sediment grains to fall through and become trapped by the appropriately sized sieves. After the shaking process is complete, the sediment trapped by each sieve is weighed and a cumulative grain diameter distribution plot is produced. While time consuming, sieving sediment is a robust and reliable method to obtain the cumulative grain diameter distribution for a sediment sample. 


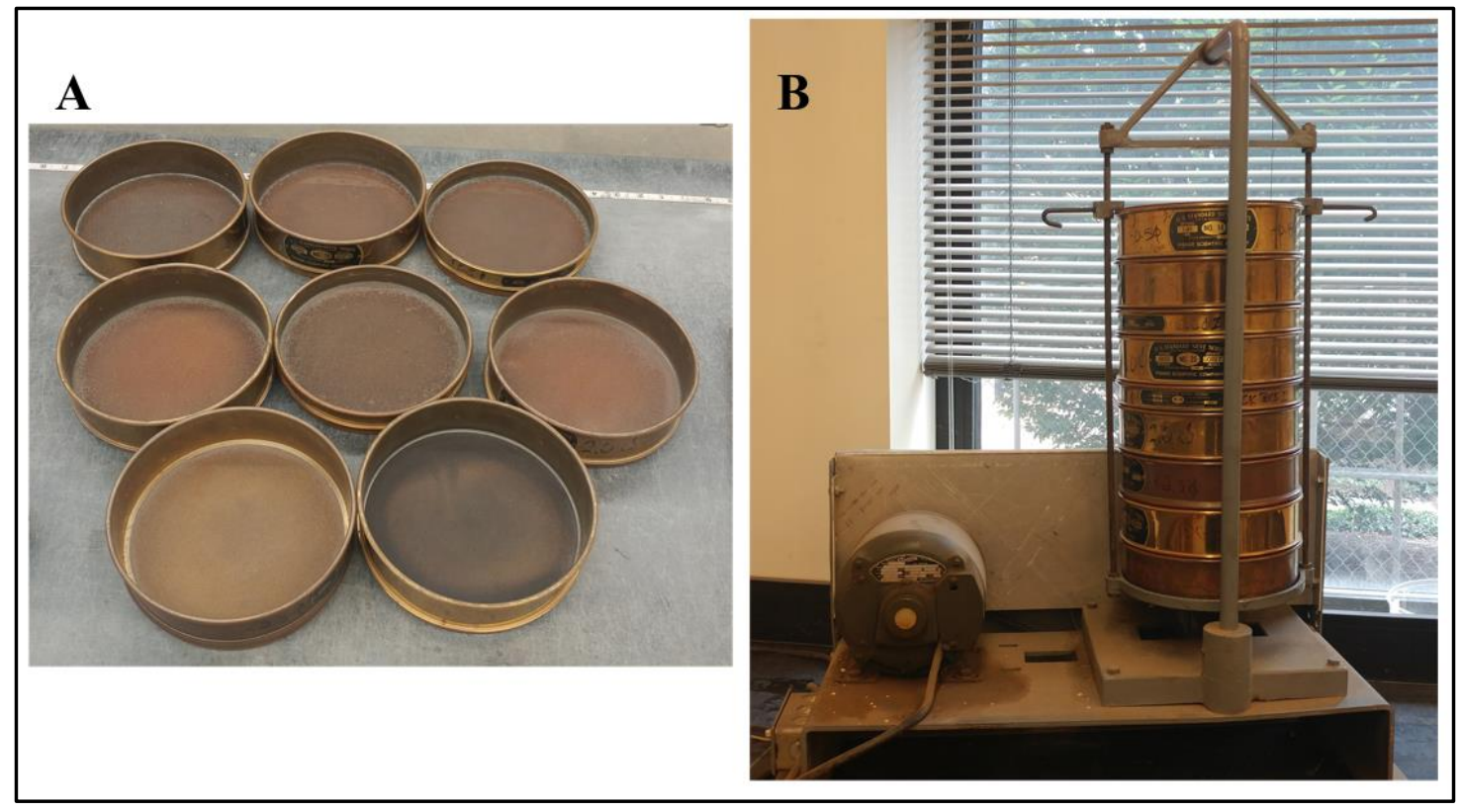

Figure 3.27: Various sized sieves (A) and stack of sieves in descending size on a machine used for shaking sediment samples (B).

The Wentworth scale (Table 3.7) is a popular classification of sediment grain diameter. Sediment is classified by the Wentworth scale in units of millimeters, however the phi scale (Krumbein, 1936) was introduced due to the Wentworth scale being based on powers of two. The conversion between millimeters and phi units $(\varphi)$ are given by Equation 3.9:

$$
\varphi=-\log _{2} d
$$

where $d$ is the sediment grain diameter in millimeters. The sieve sizes used to perform grain size analysis on the Easter Eve sediment samples ranged from $3 \varphi$ $(0.125 \mathrm{~mm})$ to $-0.5 \varphi(1.41 \mathrm{~mm})$ in $0.5 \varphi$ increments. 
Table 3.7: Wentworth Scale (adopted from (Dean \& Dalrymple, 2004)) for sand.

\begin{tabular}{|l|l|l|}
\hline $\begin{array}{l}\text { Scale Size } \\
\text { Description }\end{array}$ & Phi Units $(\boldsymbol{\varphi})$ & Grain Diameter (mm) \\
\hline Very Coarse & 0 & 1.0 \\
\hline Coarse & 1 & 0.50 \\
\hline Medium & 1.25 & 0.42 \\
\hline Fine & 2.32 & 0.20 \\
\hline Very Fine & 3.76 & 0.07 \\
\hline
\end{tabular}

\subsubsection{Grain Diameter Statistics}

The cumulative grain diameter distributions at each deployment station during the Easter Eve Storm are shown in Figure 3.28. There is a clear shift towards coarser grain diameters in the cumulative distributions for Stations A - C after the storm event while Stations D - F do not show as clear of a shift, if any shift at all. The shift towards a coarser grain diameter distribution at the most seaward deployment stations is consistent with the understanding of sediment size response to erosive storm events.

Informative sediment sample characteristics can be obtained from the cumulative grain size distribution curves. These characteristics include the median grain diameter $\left(d_{50}\right)$, mean grain diameter (Equation 3.10), sorting (Equation 3.11), skewness (Equation 3.12), and kurtosis (Equation 3.13). It should be noted that Equations 3.10-3.13 use phi units and the subscripts are in terms of percent coarser.

$$
M_{d \varphi}=\frac{\varphi_{84}+\varphi_{50}+\varphi_{16}}{3}
$$




$$
\begin{gathered}
\sigma_{\varphi}=\frac{\varphi_{84}-\varphi_{16}}{2}, \\
\alpha_{\varphi}=\frac{M_{d \varphi}-\varphi_{50}}{\sigma_{\varphi}} \\
\beta_{\varphi}=\frac{\left(\varphi_{16}-\varphi_{5}\right)+\left(\varphi_{95}-\varphi_{84}\right)}{2 \sigma_{\varphi}}
\end{gathered}
$$

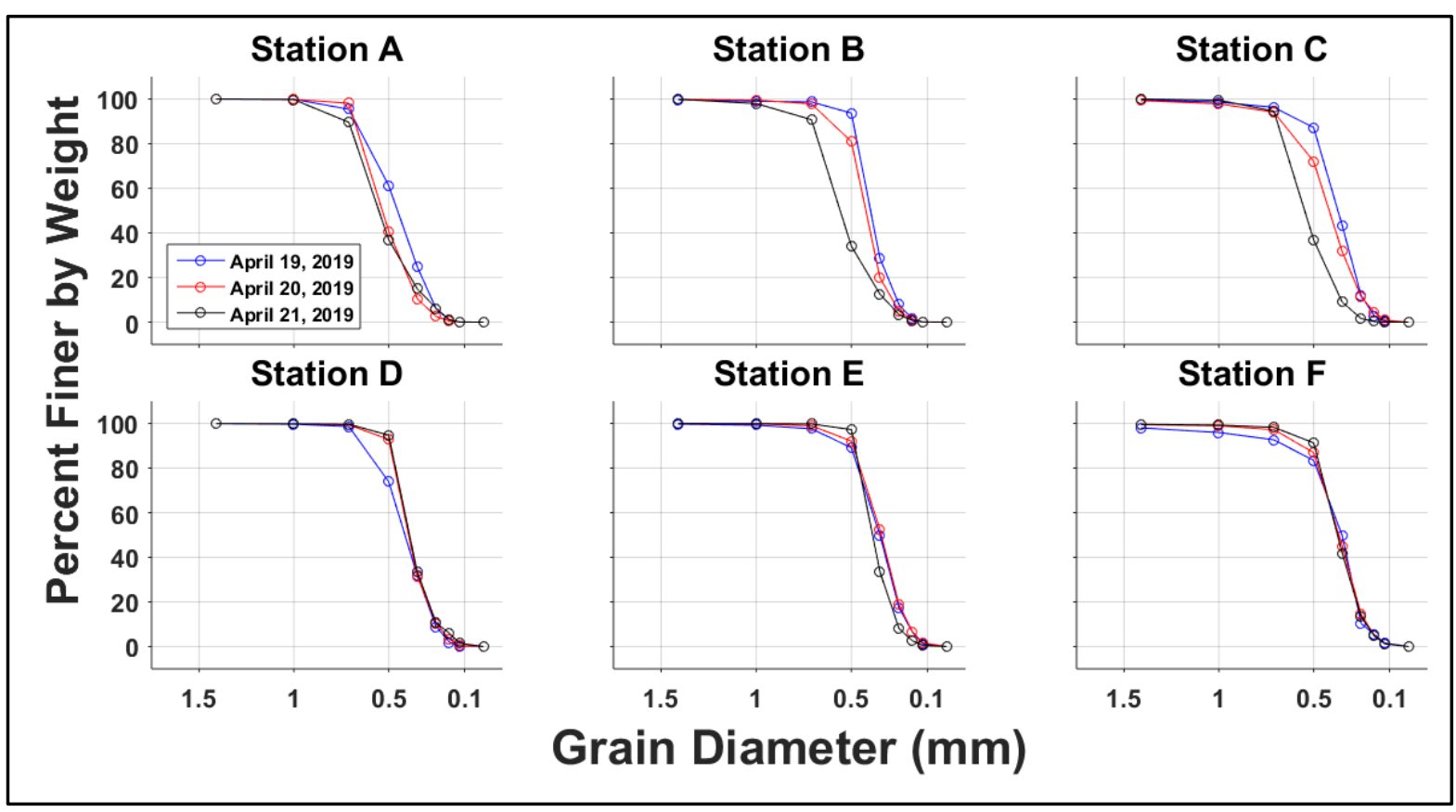

Figure 3.28: Cumulative grain size distribution at each deployment station during the Easter Eve Storm.

The $d_{50}$ is a commonly reported statistic to describe a sediment sample and is the grain diameter where half of the sample is coarser and half of the sample is finer, by weight. The $\sigma_{\varphi}$ determines the range of diameters present in a sediment sample, where a small range of grain diameters $\left(\sigma_{\varphi} \leq 0.5\right)$ is referred to as well-sorted or poorly graded and a large range $\left(\sigma_{\varphi} \geq 1\right)$ is referred to as 
well graded or poorly sorted. The $\alpha_{\varphi}$ determines the symmetry of a sediment sample and can possibly indicate erosive $\left(\alpha_{\varphi}<0\right)$ or accretive $\left(\alpha_{\varphi}>0\right)$ conditions (Duane, 1964). The $\beta_{\varphi}$ determines the peakedness of the grain size distribution (Inman, 1952) where $\beta_{\varphi}=0.65$ indicates a normal distribution, $\beta_{\varphi}<$ 0.65 indicates a wider distribution (i.e. larger range), and $\beta_{\varphi}>0.65$ indicates a narrower distribution (i.e. smaller range).

The pre-storm (April 19, 2019), mid-storm (April 20, 2019) and poststorm (April 21, 2019) sediment sample statistics described in Equations 3.10 3.13 are listed in Table 3.8, Table 3.9 and Table 3.10, respectively. The mid-storm and post-storm median grain diameter became coarser compared to pre-storm values for at Stations A-C and Station F. The median grain diameter consistently became finer at Station D while Station E mid-storm sample was finer and the post-storm sample was coarser compared to pre-storm values. All post-storm samples were considered well-sorted while there was some variability with the pre-storm and mid-storm samples, however no samples were considered poorly sorted. The only sample with a negative skewness was pre-storm Station F, inconsistent with assessments made by Duane (1964). The kurtosis values consistently increased at Station A, Station B, and Station D while consistently decreasing at Station $\mathrm{C}$ and Station E. The only samples with $\beta_{\varphi}<0.65$ are prestorm Station A, mid-storm Station A, and pre-storm Station D. 
Table 3.8: Pre-storm sediment sample statistics during the Easter Eve Storm.

\begin{tabular}{|l|l|l|l|l|l|}
\hline $\begin{array}{l}\text { Pre- } \\
\text { Storm }\end{array}$ & $\begin{array}{l}\text { Median } \\
\text { grain } \\
\text { diameter } \\
\left(\boldsymbol{d}_{\mathbf{5 0}}\right)\end{array}$ & $\begin{array}{l}\text { Mean grain } \\
\text { diameter } \\
\left(\boldsymbol{M}_{\boldsymbol{d}}\right)\end{array}$ & $\begin{array}{l}\text { Sorting } \\
(\boldsymbol{\sigma})\end{array}$ & $\begin{array}{l}\text { Skewness } \\
(\boldsymbol{\alpha})\end{array}$ & $\begin{array}{l}\text { Kurtosis } \\
(\boldsymbol{\beta})\end{array}$ \\
\hline $\begin{array}{l}\text { Station } \\
\text { A }\end{array}$ & $0.45 \mathrm{~mm}$ & $0.44 \mathrm{~mm}$ & $0.69 \mathrm{~mm}$ & $\begin{array}{l}0.96 \mathrm{~mm} \\
(0.05 \varphi)\end{array}$ & $\begin{array}{l}0.73 \mathrm{~mm} \\
(0.46 \varphi)\end{array}$ \\
\hline Station B & $0.40 \mathrm{~mm}$ & $0.38 \mathrm{~mm}$ & $0.78 \mathrm{~mm}$ & $0.88 \mathrm{~mm}$ & $0.55 \mathrm{~mm}$ \\
& $(1.32 \varphi)$ & $(1.39 \varphi)$ & $(0.36 \varphi)$ & $(0.19 \varphi)$ & $(0.85 \varphi)$ \\
\hline Station & $0.37 \mathrm{~mm}$ & $0.36 \mathrm{~mm}$ & $0.73 \mathrm{~mm}$ & $0.95 \mathrm{~mm}$ & $0.50 \mathrm{~mm}$ \\
$\mathbf{C}$ & $(1.42 \varphi)$ & $(1.46 \varphi)$ & $(0.45 \varphi)$ & $(0.08 \varphi)$ & $(0.99 \varphi)$ \\
\hline Station & $0.41 \mathrm{~mm}$ & $0.41 \mathrm{~mm}$ & $0.69 \mathrm{~mm}$ & $0.97 \mathrm{~mm}$ & $0.67 \mathrm{~mm}$ \\
$\mathbf{D}$ & $(1.27 \varphi)$ & $(1.29 \varphi)$ & $(0.53 \varphi)$ & $(0.04 \varphi)$ & $(0.59 \varphi)$ \\
\hline Station E & $0.35 \mathrm{~mm}$ & $0.34 \mathrm{~mm}$ & $0.71 \mathrm{~mm}$ & $0.96 \mathrm{~mm}$ & $0.51 \mathrm{~mm}$ \\
& $(1.51 \varphi)$ & $(1.54 \varphi)$ & $(0.50 \varphi)$ & $(0.06 \varphi)$ & $(0.98 \varphi)$ \\
\hline Station F & $0.35 \mathrm{~mm}$ & $0.36 \mathrm{~mm}$ & $0.72 \mathrm{~mm}$ & $1.07 \mathrm{~mm}$ & $0.35 \mathrm{~mm}$ \\
& $(1.51 \varphi)$ & $(1.46 \varphi)$ & $(0.48 \varphi)$ & $(-0.10 \varphi)$ & $(1.50 \varphi)$ \\
\hline
\end{tabular}

Table 3.9: Mid-storm sediment sample statistics during the Easter Eve Storm.

\begin{tabular}{|l|l|l|l|l|l|}
\hline $\begin{array}{l}\text { Mid- } \\
\text { Storm }\end{array}$ & $\begin{array}{l}\text { Median } \\
\text { grain } \\
\text { diameter } \\
\left(\boldsymbol{d}_{\mathbf{5 0}}\right)\end{array}$ & $\begin{array}{l}\text { Mean grain } \\
\text { diameter } \\
\left(\boldsymbol{M}_{\boldsymbol{d}}\right)\end{array}$ & $\begin{array}{l}\text { Sorting } \\
(\boldsymbol{\sigma})\end{array}$ & $\begin{array}{l}\text { Skewness } \\
(\boldsymbol{\alpha})\end{array}$ & $\begin{array}{l}\text { Kurtosis } \\
(\boldsymbol{\beta})\end{array}$ \\
\hline $\begin{array}{l}\text { Station } \\
\text { A }\end{array}$ & $\begin{array}{l}0.53 \mathrm{~mm} \\
(0.91 \varphi)\end{array}$ & $\begin{array}{l}0.51 \mathrm{~mm} \\
(0.97 \varphi)\end{array}$ & $\begin{array}{l}0.76 \mathrm{~mm} \\
(0.40 \varphi)\end{array}$ & $\begin{array}{l}0.89 \mathrm{~mm} \\
(0.16 \varphi)\end{array}$ & $\begin{array}{l}0.64 \mathrm{~mm} \\
(0.63 \varphi)\end{array}$ \\
\hline Station B & $0.42 \mathrm{~mm}$ & $0.42 \mathrm{~mm}$ & $0.78 \mathrm{~mm}$ & $0.97 \mathrm{~mm}$ & $0.52 \mathrm{~mm}$ \\
& $(1.24 \varphi)$ & $(1.25 \varphi)$ & $(0.37 \varphi)$ & $(0.04 \varphi)$ & $(0.95 \varphi)$ \\
\hline Station & $0.42 \mathrm{~mm}$ & $0.41 \mathrm{~mm}$ & $0.67 \mathrm{~mm}$ & $0.98 \mathrm{~mm}$ & $0.59 \mathrm{~mm}$ \\
C & $(1.26 \varphi)$ & $(1.28 \varphi)$ & $(0.59 \varphi)$ & $(0.04 \varphi)$ & $(0.76 \varphi)$ \\
\hline Station & $0.40 \mathrm{~mm}$ & $0.37 \mathrm{~mm}$ & $0.76 \mathrm{~mm}$ & $0.87 \mathrm{~mm}$ & $0.52 \mathrm{~mm}$ \\
$\mathbf{D}$ & $(1.34 \varphi)$ & $(1.42 \varphi)$ & $(0.39 \varphi)$ & $(0.20 \varphi)$ & $(0.93 \varphi)$ \\
\hline Station E & $0.34 \mathrm{~mm}$ & $0.34 \mathrm{~mm}$ & $0.71 \mathrm{~mm}$ & $0.96 \mathrm{~mm}$ & $0.55 \mathrm{~mm}$ \\
& $(1.54 \varphi)$ & $(1.58 \varphi)$ & $(0.50 \varphi)$ & $(0.07 \varphi)$ & $(0.86 \varphi)$ \\
\hline Station F & $0.37 \mathrm{~mm}$ & $0.36 \mathrm{~mm}$ & $0.72 \mathrm{~mm}$ & $0.95 \mathrm{~mm}$ & $0.50 \mathrm{~mm}$ \\
& $(1.44 \varphi)$ & $(1.48 \varphi)$ & $(0.47 \varphi)$ & $(0.08 \varphi)$ & $(1.00 \varphi)$ \\
\hline
\end{tabular}


Table 3.10: Post-storm sediment sample statistics during the Easter Eve Storm.

\begin{tabular}{|l|l|l|l|l|l|}
\hline $\begin{array}{l}\text { Post- } \\
\text { Storm }\end{array}$ & $\begin{array}{l}\text { Median } \\
\text { grain } \\
\text { diameter } \\
\left(\boldsymbol{d}_{\mathbf{5 0}}\right)\end{array}$ & $\begin{array}{l}\text { Mean grain } \\
\text { diameter } \\
\left(\boldsymbol{M}_{\boldsymbol{d}}\right)\end{array}$ & $\begin{array}{l}\text { Sorting } \\
(\boldsymbol{\sigma})\end{array}$ & $\begin{array}{l}\text { Skewness } \\
(\boldsymbol{\alpha})\end{array}$ & $\begin{array}{l}\text { Kurtosis } \\
(\boldsymbol{\beta})\end{array}$ \\
\hline $\begin{array}{l}\text { Station } \\
\text { A }\end{array}$ & $\begin{array}{l}0.55 \mathrm{~mm} \\
(0.86 \varphi)\end{array}$ & $\begin{array}{l}0.51 \mathrm{~mm} \\
(0.96 \varphi)\end{array}$ & $\begin{array}{l}0.72 \mathrm{~mm} \\
(0.47 \varphi)\end{array}$ & $\begin{array}{l}0.86 \mathrm{~mm} \\
(0.22 \varphi)\end{array}$ & $\begin{array}{l}0.50 \mathrm{~mm} \\
(1.00 \varphi)\end{array}$ \\
\hline Station B & $0.56 \mathrm{~mm}$ & $0.52 \mathrm{~mm}$ & $0.74 \mathrm{~mm}$ & $0.86 \mathrm{~mm}$ & $0.51 \mathrm{~mm}$ \\
& $(0.84 \varphi)$ & $(0.93 \varphi)$ & $(0.44 \varphi)$ & $(0.22 \varphi)$ & $(0.97 \varphi)$ \\
\hline Station & $0.55 \mathrm{~mm}$ & $0.52 \mathrm{~mm}$ & $0.76 \mathrm{~mm}$ & $0.89 \mathrm{~mm}$ & $0.63 \mathrm{~mm}$ \\
$\mathbf{C}$ & $(0.87 \varphi)$ & $(0.94 \varphi)$ & $(0.40 \varphi)$ & $(0.17 \varphi)$ & $(0.66 \varphi)$ \\
\hline Station & $0.39 \mathrm{~mm}$ & $0.37 \mathrm{~mm}$ & $0.76 \mathrm{~mm}$ & $0.87 \mathrm{~mm}$ & $0.49 \mathrm{~mm}$ \\
$\mathbf{D}$ & $(1.36 \varphi)$ & $(1.44 \varphi)$ & $(0.40 \varphi)$ & $(0.20 \varphi)$ & $(1.02 \varphi)$ \\
\hline Station E & $0.39 \mathrm{~mm}$ & $0.37 \mathrm{~mm}$ & $0.77 \mathrm{~mm}$ & $0.88 \mathrm{~mm}$ & $0.63 \mathrm{~mm}$ \\
& $(1.36 \varphi)$ & $(1.43 \varphi)$ & $(0.37 \varphi)$ & $(0.18 \varphi)$ & $(0.67 \varphi)$ \\
\hline Station F & $0.37 \mathrm{~mm}$ & $0.36 \mathrm{~mm}$ & $0.74 \mathrm{~mm}$ & $0.91 \mathrm{~mm}$ & $0.51 \mathrm{~mm}$ \\
& $(1.42 \varphi)$ & $(1.48 \varphi)$ & $(0.44 \varphi)$ & $(0.14 \varphi)$ & $(0.98 \varphi)$ \\
\hline
\end{tabular}

\subsection{Discussion of Results}

Morphodynamic change, greater calculated water depth, and more landward calculated water depth during Nor'easter Riley and the Easter Eve Storm occurred in response to increased wave forcing conditions from previously calm conditions (Figure 3.10, Figure 3.11, Figure 3.20, and Figure 3.22). The time during the tidal cycle also played a major role, as the greatest water depth and most morphodynamic change occurred during the rising tide or at peak high tide. Erosion at the most seaward stations and accretion at the most landward stations were simultaneously measured during the storm events (Figure 3.10C, tidal cycle 2 and Figure 3.11C, tidal cycle 1), suggesting that both divergent and convergent cross-shore sediment transport occurred. The calculated water depth at the crossshore locations (Figure 3.20D, tidal cycle 2 and Figure 3.22D, tidal cycle 1), 
suggesting that other physical quantities (e.g. water velocity or sediment grain size) may be more indicative of erosive or accretive conditions.

The effect of storm tides was of interest as both storm events occurred during spring tides. Storm tide elevation has shown to be an important factor in beach erosion during storms due to the combination of storm surge and astronomical high tides (Zhang et al., 2001). The maximum storm tide elevation was higher during Nor'easter Riley than the Easter Eve Storm due to the larger associated storm surge (Table 3.5 and Table 3.6). However, storm tide alone had a limited impact on backbeach morphodynamic change. A slight $(<12 \%)$ increase in maximum storm tide elevation during Nor'easter Riley occurred during times of backbeach morphodynamic change (Figure 3.10C, tidal cycles 3 and 4), while the effects of storm tide for the Easter Eve Storm were minimal due to the small $(<0.20 \mathrm{~m})$ storm surge.

Whether erosion or accretion was measured at a cross-shore location was dependent on the storm wave forcing and the severity of berm erosion. When the berm eroded, the beach became steeper (Figure 3.10D and Figure 3.11D), allowed for greater vertical run-up (Stockdon et al., 2006) to occur, and induced morphodynamic change on the backbeach. The effect of berm erosion precluding backbeach morphodynamic change was observed during both storm events (Figure 3.10C, tidal cycle 3 and Figure 3.11C, tidal cycle 3), despite a decrease in mean significant wave height but an increase in mean wave period. Greater calculated water depth at more landward cross-shore locations was also in response to berm erosion, as water depth was previously not calculated precluding berm erosion. This hydrodynamic and morphodynamic feedback is particularly 
important during nor'easters that typically impact the beach over multiple tidal cycles.

The ADM was successful in continuously measuring beach elevation but with limitations. The method to distinguish measured bed elevations failed when the bed became continuously submerged. A lack of identified bed elevation data during times of complete bed submergence resulted in the inability to obtain a CLFF of bed elevation, resulting in failure to calculate water depth. It is important to reemphasize that the use of a fixed in situ pressure sensor to accurately measure water depth in the swash zone or inner surf zone is impractical during storm events due to the highly variable morphodynamic conditions. Despite the limitations using the ADM, bed elevation measurements were able to be obtained during times when GPS surveying would be impractical or impossible. The ability to temporally identify the beginning and end of complete bed submergence at a cross-shore location allows for the identification of the swash-to-inner surf zone (and vice versa) transition.

Valuable lessons were learned during the field studies to better improve data collection such as the installment of a structurally robust frame of scaffold pipes for seaward stations and the importance of visiting the study site throughout the field study. The installation of a frame, as opposed to monopoles, could have allowed for data to be recovered at Station A and a longer data collection period at Stations B-D during Nor'easter Riley. Having the ability to visit the study site during Nor'easter Toby would have allowed for sensor adjustment or retrieval, resulting in reliable data collection. The lack of GPS surveyed beach face profiles 
during Nor'easter Toby prevented the ability to confirm ADM elevation measurements throughout the storm. 


\section{Chapter 4}

\section{DATA ANALYSIS}

\subsection{Dimensionless Numbers}

Dimensionless numbers and parameters are often used in coastal engineering to provide insight of various physical phenomena (e.g. turbulence or wave breaking). The advantage of using dimensionless numbers or parameters is that their application is valid over a wide range of physical magnitudes as the dynamics of interest maintain scale. Dimensionless numbers or parameters calculated during Nor'easter Riley and the Easter Eve Storm are examined in the following sections and include: the Iribarren number (Iribarren \& Nogales, 1949), the surf-scaling parameter (Robert T. Guza \& Inman, 1975), and the dimensionless sediment fall velocity (Dean, 1973).

\subsubsection{Iribarren Number}

\subsubsection{Iribarren Number Background}

The Iribarren number was originally proposed by Iribarren and Nogales (1949) as a parameter to determine if wave breaking would occur as waves approached a plane slope near the still water line and is given by Equation 4.1:

$$
\xi=\frac{\tan \theta}{\sqrt{H_{O} / L_{o}}},
$$


where $\tan \theta$ is the beach or coastal structure slope, $H_{o}$ is the deep water wave height, and $L_{o}$ is the deep water wave length (Equation 4.2). It can be seen in Equation 4.1 that $\xi$ is simply the ratio between the beach or coastal structure slope and the square root of the deep water wave steepness $\left(\frac{H_{O}}{L_{O}}\right)$.

The derivation of $\xi$ involved the use of shallow water trochoidal theory for uniform progressive waves, which states that progressive waves reach a limit of stability (i.e. wave breaking) when their amplitude is equal to the mean water depth. Iribarren and Nogales (1949) analytically found, and empirically confirmed, a value of $\xi \approx 2.3$ that corresponds to a regime halfway between complete wave reflection and complete wave breaking even when various numerical schemes are used in the formulation (Battjes, 1974). The fact that $\xi$ has been empirically confirmed and derived using various numerical schemes has justified the parameters importance. Numerous empirical formulas used in coastal engineering to quantify processes such as run-up, run-down, and reflection are dependent on the parameter $\xi$ (Battjes, 1974; Battjes \& Roos, 1975; van Gent, 2001; Hunt, 1959; Mase, 1989).

A major development made by Battjes (1974) was to use $\xi$ values to quantitatively indicate the wave breaker type (Table 4.1) and not just as a binary wave breaking criteria. The wave breaker types that were assessed included spilling breakers, plunging breakers, and collapsing/surging breakers (Galvin, 1972). Spilling breakers occur during a highly dissipative beach state, while collapsing/surging breakers occur during a highly reflective beach state (Wright $\&$ Short, 1984). 
Table 4.1: Wave breaking types and morphodynamic beach states for ranges of $\xi$.

\begin{tabular}{|l|l|l|c|}
\hline $\begin{array}{l}\text { Wave Breaker } \\
\text { Type }\end{array}$ & $\begin{array}{l}\text { Spilling } \\
\text { Breaker }\end{array}$ & $\begin{array}{l}\text { Plunging } \\
\text { Breaker }\end{array}$ & $\begin{array}{l}\text { Collapsing/Surging } \\
\text { Breaker }\end{array}$ \\
\hline $\begin{array}{l}\text { Range of } \xi \\
\text { Values }\end{array}$ & $0.1 \leq \xi<1.0$ & $1.0 \leq \xi<3.0$ & $3.0 \leq \xi<5.0$ \\
\hline $\begin{array}{l}\text { Morphodynamic } \\
\text { Beach State }\end{array}$ & $\begin{array}{l}\text { Highly } \\
\text { dissipative }\end{array}$ & Highly reflective \\
\hline
\end{tabular}

\subsubsection{Measured Wave Data}

Wave height and period data used to calculate $\xi$ were obtained from NDBC Station 44009 wave buoy. Calculation of the deep water wave length and equivalent deep water wave height (Goda, 2010) were necessary to obtain $\xi$ values during Nor'easter Riley and the Easter Eve Storm. Wave height transformation effects (e.g. shoaling and refraction) had to be considered to accurately calculate the equivalent deep water wave height $\left(H_{o}^{\prime}\right)$ and were used in place of $H_{o}$ in Equation 4.1.

The deep water wave length was calculated using Equation 4.2:

$$
L_{o}=\frac{g * T_{p}^{2}}{2 \pi},
$$

where $T_{p}$ is the measured peak period obtained from the wave buoy.

The measured wave height from the wave buoy had to be reverse shoaled, if necessary, to accurately estimate the deep water wave height. Reverse shoaling 
was applied to the measured wave height if the deep water condition (Equation 4.3) was not true. The water depth where wave measurements were obtained was $30 \mathrm{~m}$.

$$
\frac{h}{L_{o}} \geq 0.5
$$

Reverse shoaling involved calculation of the shoaling coefficient (Equation 4.4) and the application of the shoaling coefficient to the measured wave data (Equation 4.5).

$$
\begin{gathered}
K_{s}=\left[\tanh k h+k h\left(1-\tanh ^{2} k h\right)\right]^{-1 / 2}, \\
H_{o}=\frac{H_{1 / 3}}{K_{S}},
\end{gathered}
$$

where $k$ is the wave number $\left(k=\frac{2 \pi}{L_{o}}\right)$.

The effects of wave refraction involved the calculation of the refraction coefficient (Equation 4.6) and the application of the refraction coefficient (Equation 4.7) to the deep water wave height found in Equation 4.5.

$$
\begin{aligned}
& K_{r}=\sqrt{\frac{\cos \theta_{o}}{\cos \theta}}, \\
& H_{o}^{\prime}=K_{r} * H_{o},
\end{aligned}
$$

where $\theta_{o}$ is the measured wave direction relative to shore-normal and $\theta$ is the post-refraction wave direction relative to shore-normal. Here, $\theta=0$ (therefore $\cos \theta=1$ ) and Equation 4.6 was only applied if $\theta_{N} \leq 180^{\circ}$. If $\theta_{N}>180^{\circ}, K_{r}$ was set equal to unity.

The measured, deep water, and equivalent deep water wave heights during Nor'easter Riley (Figure 4.1A) and the Easter Eve Storm (Figure 4.1B) are 
shown. It should be noted that buoy data were only used during times when the significant wave height exceeded $1.5 \mathrm{~m}$ for 3 consecutive hours.

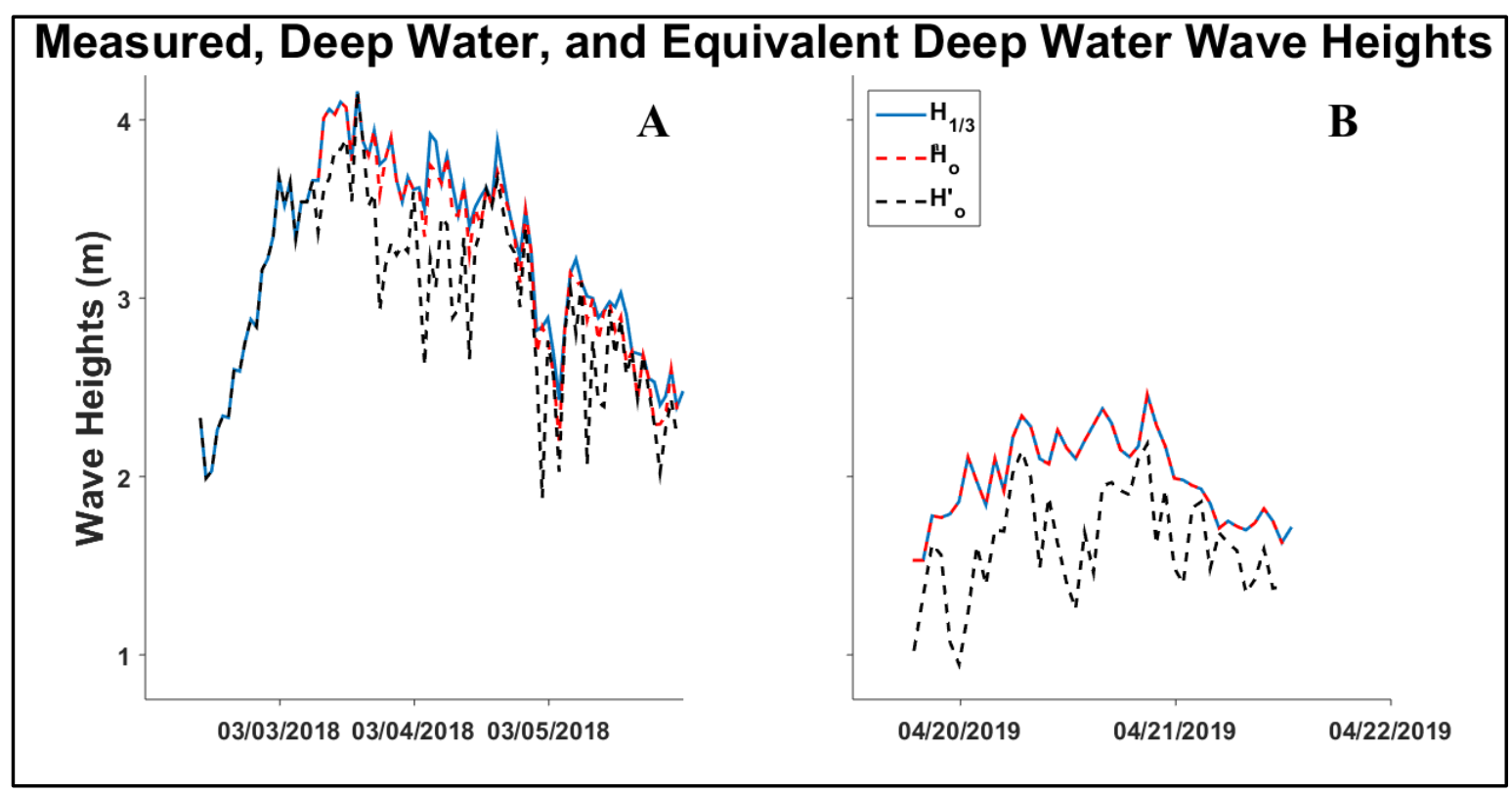

Figure 4.1: Measured significant wave height (blue), deep water wave height (red) and equivalent deep water wave height (black) during Nor'easter Riley (A) and the Easter Eve Storm (B).

\subsubsection{Iribarren Number During Storm Events}

Wave forcing, beach face slope, and calculated $\xi$ values during Nor'easter Riley (Figure 4.2) and the Easter Eve Storm (Figure 4.3) are shown. Beach face slope values were calculated using CLFF bed elevations and GPS surveyed crossshore station positions. For Nor'easter

Riley, the beach face slope was calculated from elevation and cross-shore position data between Station C and Station F, while between Station A and 
Station F for the Easter Eve Storm. The equivalent deep water wave height

(Figure 4.1, black) was used to account for wave shoaling and refraction.

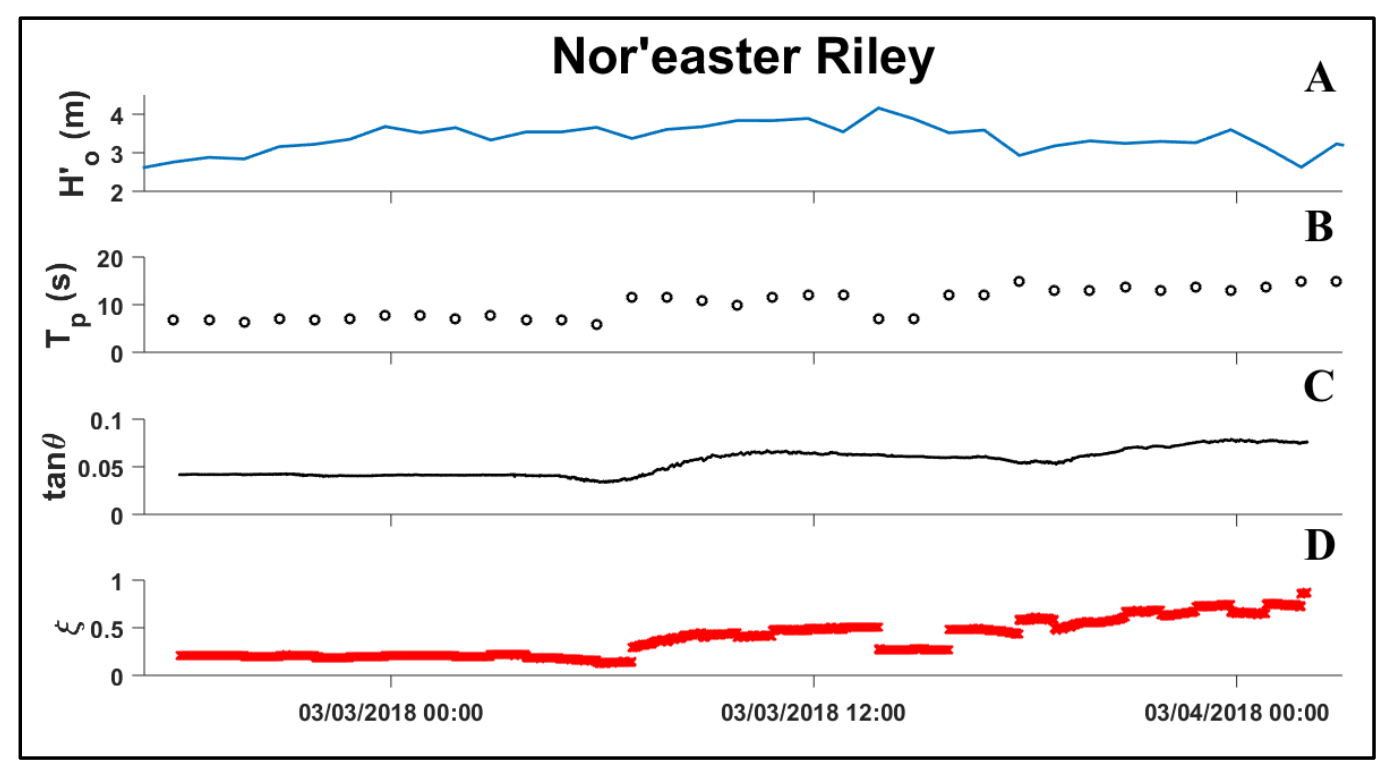

Figure 4.2: Equivalent deep water wave height (A), peak wave period (B), beach face slope (C), and Iribarren number values (D) during Nor' easter Riley. 


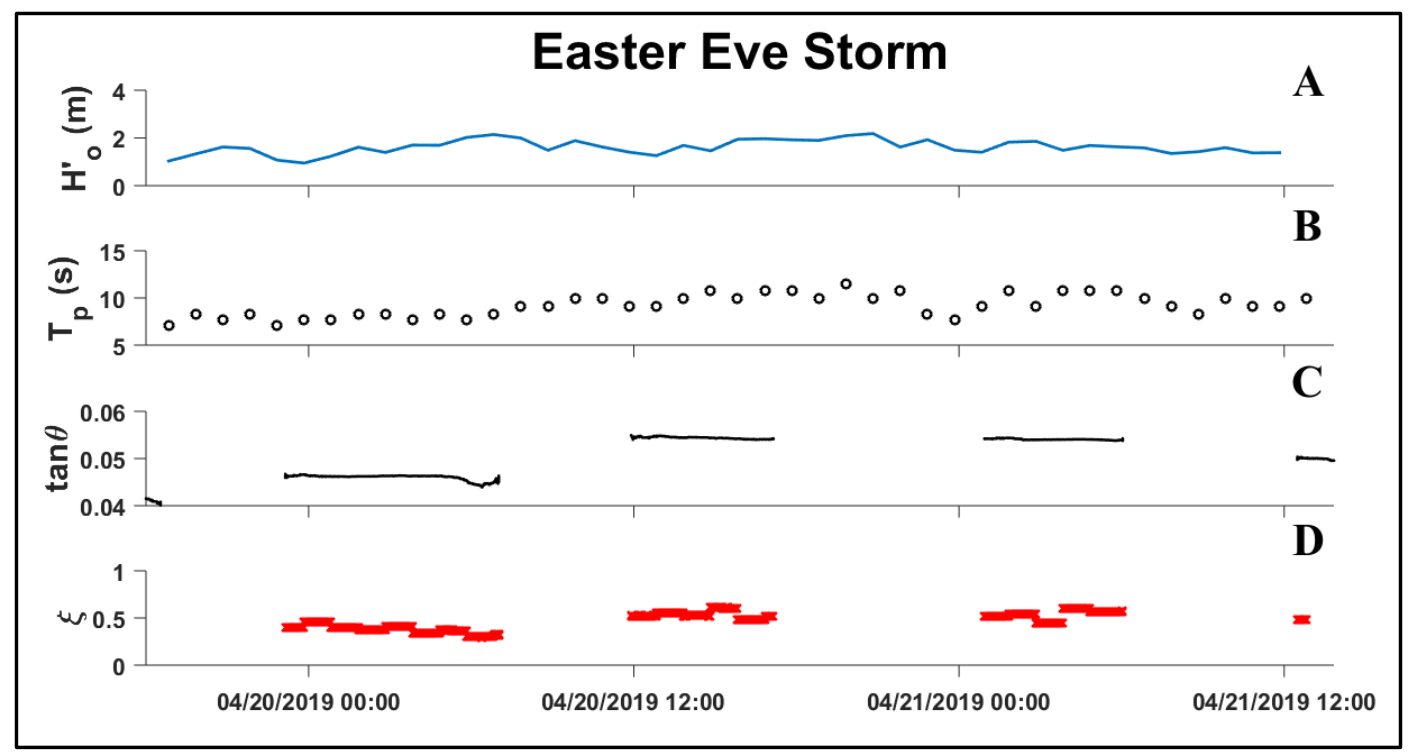

Figure 4.3: Equivalent deep water wave height (A), peak wave period (B), beach face slope (C), and Iribarren number values (D) during the Easter Eve Storm.

Values of $\xi$ increased during the storm events due to erosion and the resulting steepening of the beach face. Values of $\xi$ ranged from $0.13-0.87$ (569\% increase) during Nor'easter Riley and $0.30-0.61$ (103\% increase) during the Easter Eve Storm. Table 4.1 suggests that the wave breaking type was consistently spilling breakers during both storm events if the assumption that the measured beach face slope remained constant throughout the inner surf zone is made. The smaller $\xi$ values calculated during Nor'easter Riley, prior to beach face steepening, was due to larger wave heights and steeper waves as compared to the Easter Eve Storm. It is possible that even larger $\xi$ values during Nor'easter Riley would have been calculated if structural failure did not result in premature sensor retrieval. 


\subsubsection{Surf Scaling Parameter}

\subsubsection{Surf Scaling Parameter Background}

The surf scaling parameter was used by Guza and Inman (1975) during their work on beach cusps and sub-harmonic wave excitation and is given by Equation 4.8:

$$
\epsilon=\frac{H_{b} * \omega^{2}}{2 * g * \tan ^{2} \theta}
$$

where $H_{b}$ is the wave breaking height and $\omega$ is the wave radian frequency

$\left(\omega=\frac{2 \pi}{T_{p}}\right)$. Similar to $\xi$, calculated $\epsilon$ values can be used determine wave breaking type and morphodynamic beach state (Table 4.2).

Table 4.2: Wave breaking types and morphodynamic beach states for ranges of $\epsilon$.

\begin{tabular}{|l|l|l|l|}
\hline $\begin{array}{l}\text { Wave Breaker } \\
\text { Type }\end{array}$ & $\begin{array}{l}\text { Spilling } \\
\text { Breaker }\end{array}$ & $\begin{array}{l}\text { Plunging } \\
\text { Breaker }\end{array}$ & $\begin{array}{l}\text { Collapsing/Surging } \\
\text { Breaker }\end{array}$ \\
\hline $\begin{array}{l}\text { Range of } \epsilon \\
\text { Values }\end{array}$ & $\epsilon>20$ & $20 \geq \epsilon>2.5$ & $\epsilon \leq 2.5$ \\
\hline $\begin{array}{l}\text { Morphodynamic } \\
\text { Beach State }\end{array}$ & $\begin{array}{l}\text { Highly } \\
\text { dissipative }\end{array}$ & & Highly reflective \\
\hline
\end{tabular}

\subsubsection{Estimation of Wave Breaking Height}

Values of $H_{b}$ were estimated using Equation 4.9:

$$
H_{b}=k_{b} * g^{1 / 5} *\left(T_{p} * H_{o}^{\prime 2}\right)^{2 / 5},
$$

where $k_{b}$ is an empirical coefficient found to equal 0.39 when Equation 4.9 was fitted against three sets of laboratory data and one set of field data (Komar \& 
Gaughan, 1972). Equation 4.9 was derived using Airy wave theory, the conservation of energy flux, and the breaker index (Equation 4.10):

$$
\gamma_{b}=\frac{H_{b}}{h_{b}}
$$

where $\gamma_{b}$ is the breaker index and $h_{b}$ is the breaker depth. Commonly used is $\gamma_{b}=0.78$, the spilling breaker assumption, which has been theoretically determined using solitary wave theory (McCowan, 1894) and confirmed in the field on beaches with low gradients (Scripps Institution of Oceanography, 1944; Sverdrup \& Munk, 1946). However, the empirically found value of 0.39 for $k_{b}$ implies $\gamma_{b}=1.42$ which is almost twice as large as the commonly used value of 0.78 . The laboratory and field data sets that were used to find $k_{b}=0.39$ were on beach slopes that ranged from $0.03-0.1$ and may be the reason for the larger $\gamma_{b}$ value.

\subsubsection{Surf Scaling Parameter During Storm Events}

Wave forcing, beach face slope, and calculated $\epsilon$ values during Nor' easter Riley (Figure 4.4) and the Easter Eve Storm (Figure 4.5) are shown. The same values for beach face slope were used as in section 4.1.1.3. The $\epsilon$ values to classify the wave breaking type and morphodynamic state $(\epsilon=2.5$ and $\epsilon=20)$ are shown in Figure 4.4D and Figure 4.5D as the broken blue lines. 


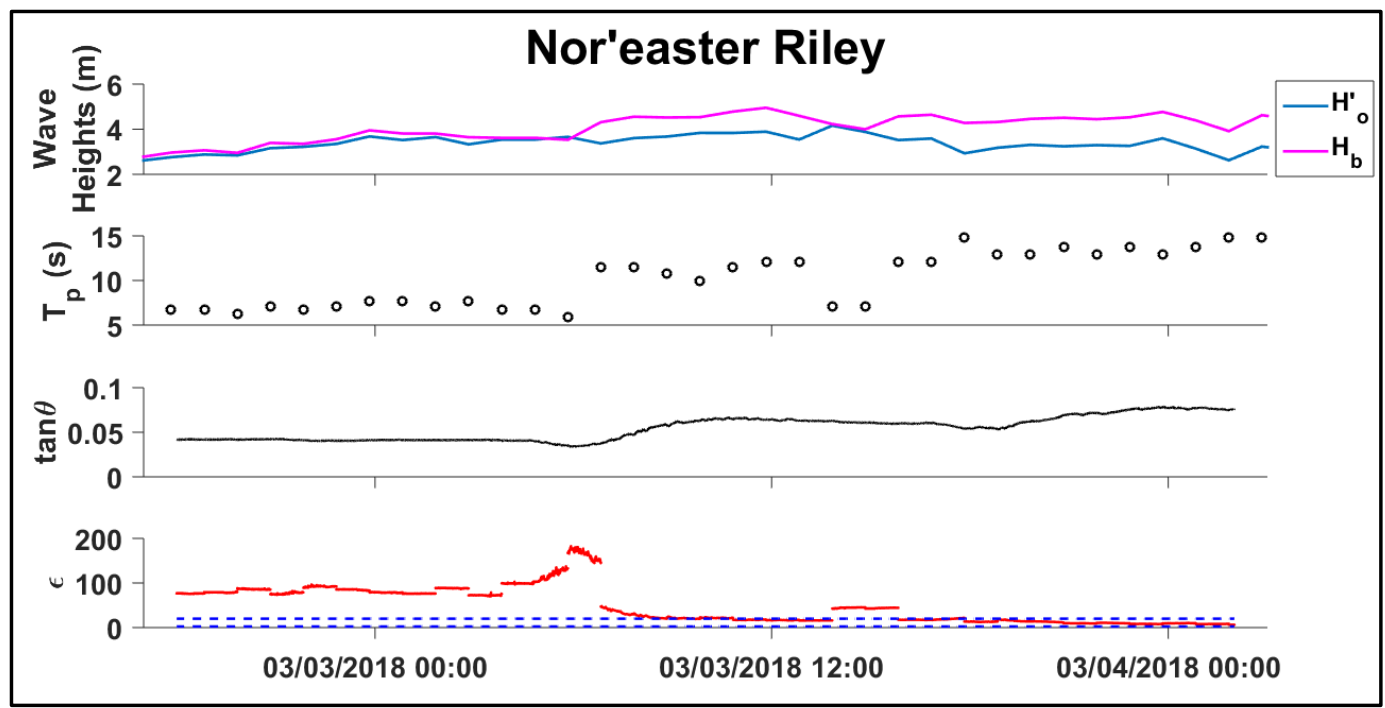

Figure 4.4: Equivalent deep water and breaking wave height (A), wave peak period (B), beach face slope (C), and surf scaling parameter (D) during Nor'easter Riley.

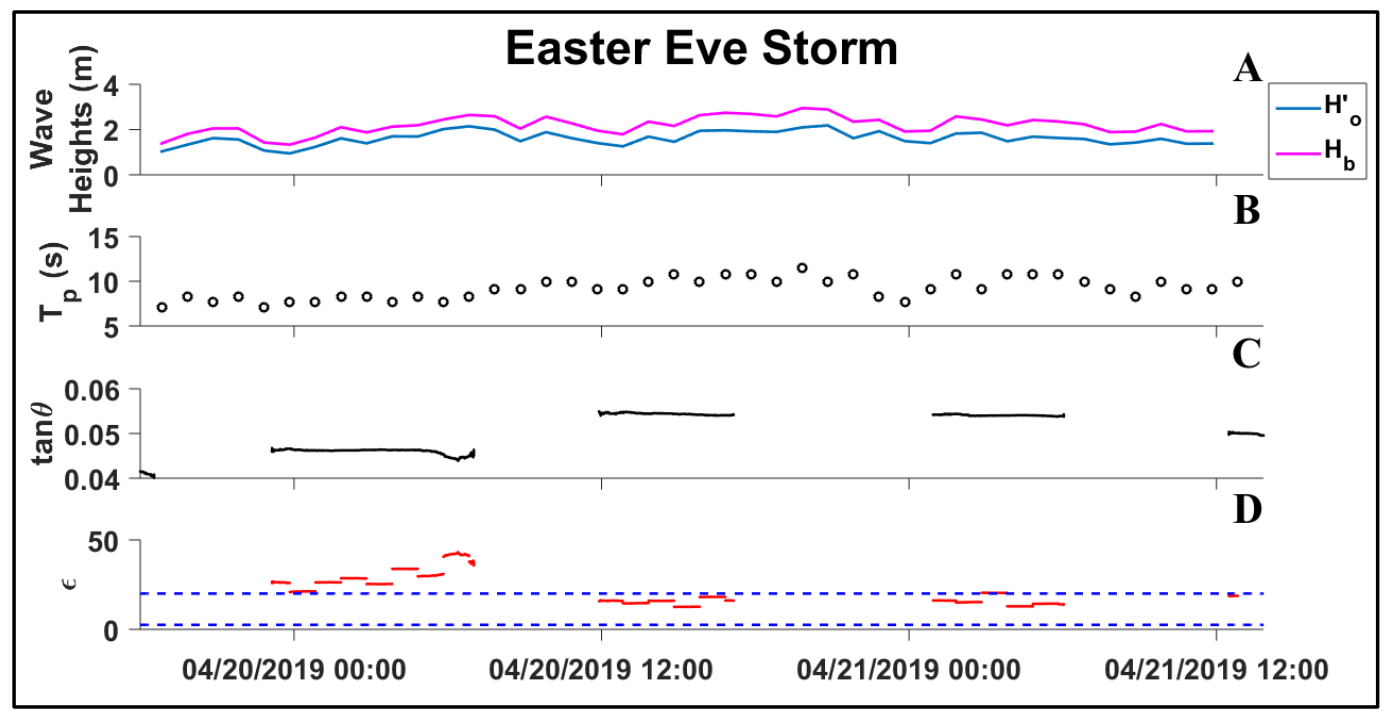

Figure 4.5: Equivalent deep water and breaking wave height (A), wave peak period (B), beach face slope (C), and surf scaling parameter (D) during the Easter Eve Storm. 
Values of $\epsilon$ decreased during the storm events due to erosion and the resulting steepening of the beach face. Values of $\epsilon$ ranged from $6.17-182$ (97\% decrease) during Nor'easter Riley and 12.6 - 43.1 (71\% decrease) during the Easter Eve Storm. Table 4.2 suggests that the wave breaking type was initially spilling breakers but transitioned to plunging breakers as the beach face eroded during both storm events. Similar to the evaluation of $\xi$ values, the assumption that the measured beach face slope remained constant throughout the inner surf zone was made.

The influence of $T_{p}$ and $\tan \theta$ was greater for $\epsilon$ values than $\xi$ values due to the inverse square dependence of both variables. The $\epsilon$ values calculated during Nor'easter Riley reflect this dependence from the sharp decrease when the beach slope and peak wave period increased.

\subsubsection{Dimensionless Sediment Fall Velocity}

\subsubsection{Dimensionless Sediment Fall Velocity Background}

The dimensionless sediment fall velocity (Equation 4.11) was originally proposed by Dean (1973) to parameterize onshore or offshore transport by using offshore wave conditions

and the sediment fall velocity as:

$$
\Omega_{o}=\frac{H_{o}}{w_{s} * T_{p}}
$$


where $w_{s}$ is the sediment fall velocity. Laboratory studies have shown that there is an inverse relationship between $\tan \theta$ and $\Omega_{o}$, since $w_{s}$ is dependent on sediment grain size (Dalrymple \& Thompson, 1977).

Similar to the previously examined dimensionless parameters, Wright and Short (1984) used a variation of $\Omega_{o}$ (Equation 4.12) to identify morphodynamic beach states:

$$
\Omega_{b}=\frac{H_{b}}{w_{s} * T_{p}}
$$

where Table 4.3 shows the ranges of $\Omega_{b}$ values that correspond to different morphodynamic beach states.

Table 4.3: Morphodynamic beach states for ranges of $\Omega_{b}$.

\begin{tabular}{|l|c|c|c|}
\hline $\begin{array}{l}\text { Morphodynamic } \\
\text { Beach State }\end{array}$ & Reflective & Intermediate & Dissipative \\
\hline $\begin{array}{l}\text { Range of } \Omega_{b} \\
\text { Values }\end{array}$ & $\Omega_{b} \leq 1$ & $1<\Omega_{b}<6$ & $\Omega_{b} \geq 6$ \\
\hline
\end{tabular}

\subsubsection{Estimation of Sediment Fall Velocity}

Values for $w_{s}$ were calculated based on the relationship between particle Reynolds number and the Archimedes buoyancy index (Hallermeier, 1981). The particle Reynolds number is given as:

$$
R e=\frac{w_{s} * d}{v},
$$

where $v$ is the kinematic fluid viscosity $\left(\mathcal{O} \sim 10^{-6} \frac{\mathrm{m}^{2}}{\mathrm{~s}}\right)$. The Archimedes buoyancy index is given as:

$$
A=\frac{(s-1) * g * d^{3}}{v^{2}}
$$


where $s$ is the sediment-to-fluid density ratio $(s \approx 2.65)$. The relationship proposed by Hallermeier (1981) is given as:

$$
R e=\frac{A^{0.7}}{6},
$$

for $39<A<10^{4}(0.13 \mathrm{~mm}<d<0.85 \mathrm{~mm})$.

In this application, $d=d_{50}$ and it can be seen in Tables $3.8-3.10$ that the study site $d_{50}$ is within the range where Equation 4.15 is valid. A uniform $d_{50}=$ $0.40 \mathrm{~mm}$ was used to calculate $w_{s}$ during Nor'easter Riley due to the lack of collected sediment samples. However, time varying $d_{50}$ values were used to calculate $w_{s}$ during the Easter Eve Storm due to collected sediment samples. The time varying $d_{50}$ values were used between collection times and were the average value from the cross-shore locations. The estimated sediment fall velocity was $0.05 \mathrm{~m} / \mathrm{s}$ during Nor'easter Riley and ranged from $0.05-0.06 \mathrm{~m} / \mathrm{s}$ during the Easter Eve Storm, increased throughout the storm due to the increase in the crossshore averaged $d_{50}$.

\subsubsection{Dimensionless Sediment Fall Velocity During Storm Events}

Wave forcing and calculated $\Omega_{b}$ values during Nor'easter Riley (Figure 4.6) and the Easter Eve Storm (Figure 4.7) are shown. The $\Omega_{b}$ values to classify the morphodynamic beach state $\left(\Omega_{b}=1\right.$ and $\left.\Omega_{b}=6\right)$ are shown in Figure 4.6C and Figure 4.7C as the broken blue lines. 


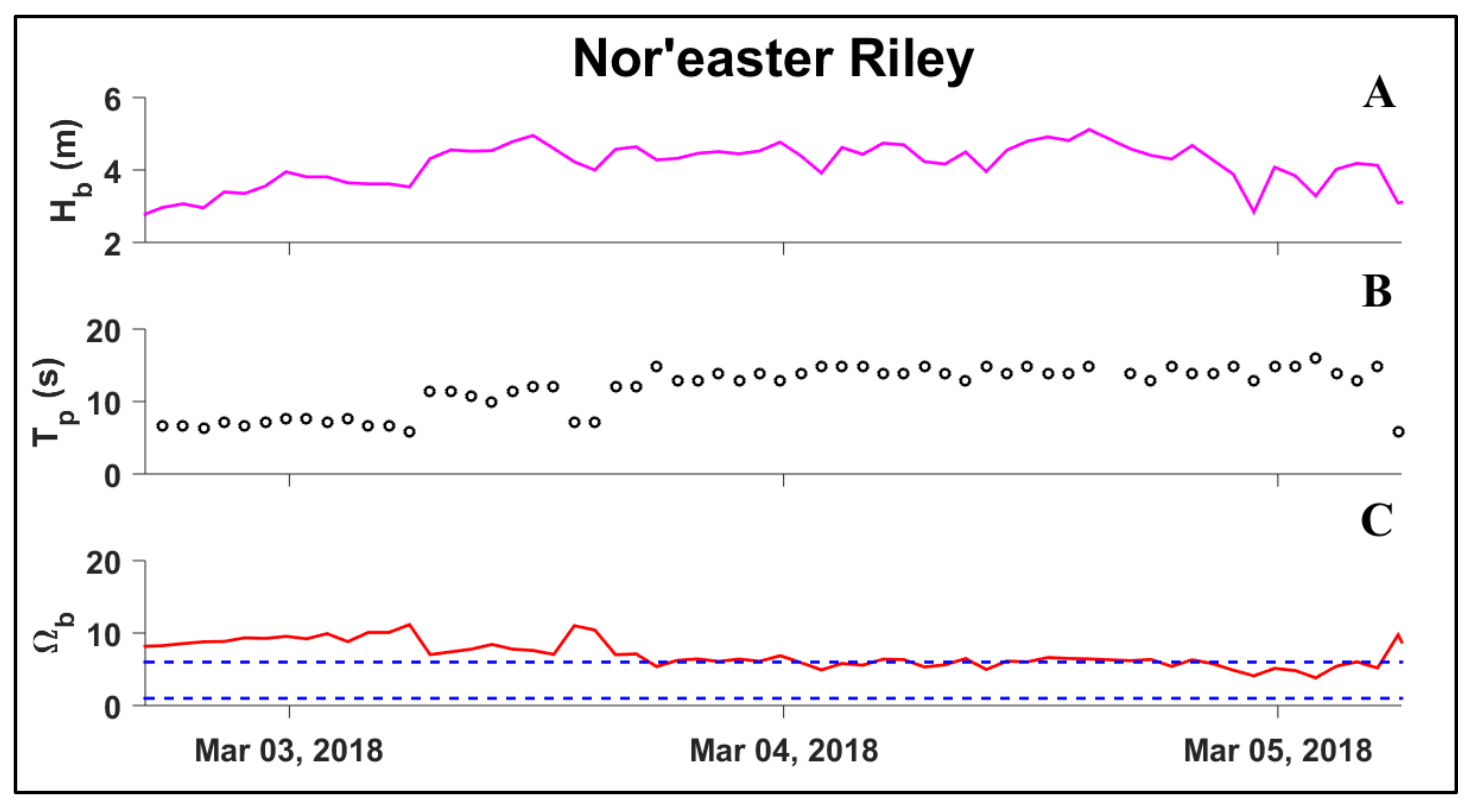

Figure 4.6: Breaking wave height (A), wave peak period (B), and dimensionless sediment fall velocity (C) during Nor' easter Riley.

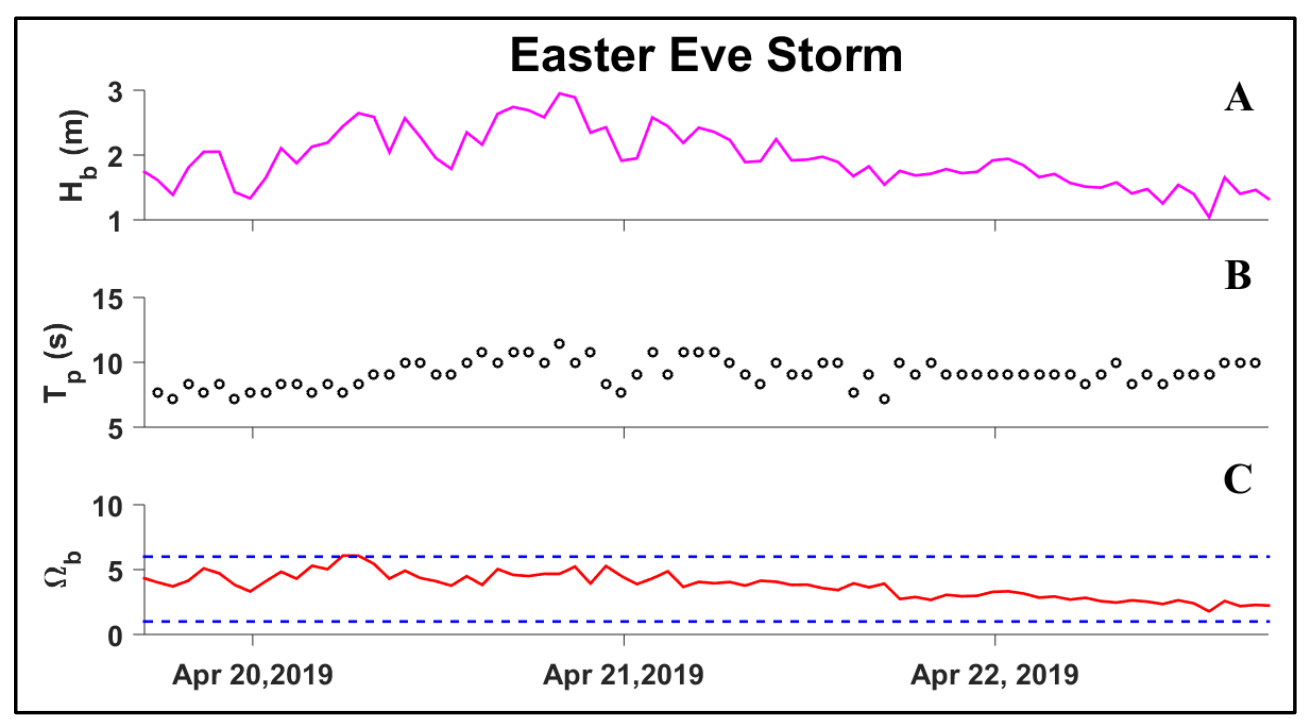

Figure 4.7: Breaking wave height (A), wave peak period (B), and dimensionless sediment fall velocity (C) during the Easter Eve Storm. 
Values of $\Omega_{b}$ generally decreased during the storm events, suggesting a steepening of the beach face which was confirmed through measurements of the beach face slope shown in previous figures. Values of $\Omega_{b}$ ranged from $3.82-11.2$ (66\% decrease) during Nor'easter Riley and $1.78-6.08$ (71\% decrease) during the Easter Eve Storm. Table 4.3 suggests that the morphodynamic beach state began as dissipative and transitioned to intermediate during Nor'easter Riley while almost constantly as intermediate state during the Easter Eve Storm.

It is likely that the $\Omega_{b}$ values calculated during Nor'easter Riley (Figure 4.6C) are overestimates due to a uniform $d_{50}$ value used in the calculation. Tables 3.8 - 3.10 suggest that the $d_{50}$ values will increase throughout a storm event that would result in a lesser $\Omega_{b}$ value. Therefore, it is highly encouraged that future efforts collect sediment samples during storm events and perform grain size analysis to more accurately calculate $\Omega_{b}$ to quantitatively describe the morphodynamic beach state.

\subsection{Spectral Analysis}

A popular and powerful data analysis technique used in coastal engineering is spectral analysis. Spectral analysis involves transforming time series data (e.g. wave height or run-up) to the frequency domain using the Fourier Transform. Examining data in the frequency domain is advantageous and allows the generation of physical processes to be identified. It is common practice in coastal engineering to calculate the total energy of a wave field by integrating the energy density spectrum which is obtained through spectral analysis (Dean \& Dalrymple, 1991). 
Spectral analysis has been performed on a time series of hydrodynamic data (e.g. water elevation or water velocity) during storm events to study the propagation of low frequency energy (i.e. infragravity waves). Infragravity waves have periods ranging from $20 \mathrm{~s}-300 \mathrm{~s}$ and have been shown to play a role in offshore bar formation and migration, coastline erosion, and beach cusp formation from specific types of infragravity waves known as edge waves (Aagaard, 1990; Holman, et al., 1978; Russell, 1993; Senechal et al., 2011). Studies conducted to measure vertical run up elevation have also examined the role of spectral energy within the infragravity frequency band $(f<0.05 \mathrm{~Hz})$, as vertical run up within the incident frequency band $(f>0.05 \mathrm{~Hz})$ has been shown to saturate even as offshore wave heights increase due to wave breaking (Baldock \& Holmes, 1999; R.T. Guza et al., 1984; Senechal et al., 2011; Stockdon et al., 2006).

\subsubsection{Spectral Energy During Storm Events}

Spectral analysis was performed on 20-minute time intervals of demeaned water elevation data collected during Nor'easter Riley and the Easter Eve Storm. A popular spectral estimator, Welch's method (Welch, 1967), results in a spectral estimation with severe reduction in low frequency resolution (Barbour \& Parker, 2014). Therefore, the use of multiple orthogonal tapers (Thomson, 1982) was chosen to perform spectral analysis to enhance low frequency resolution and lower variance. 


\subsubsection{Spectral Energy During Nor'easter Riley}

Spectral energy time stack plots from deployment stations are shown during Nor'easter Riley. The time stack plots from Station B (Figure 4.8) and Station C (Figure 4.9) are included to show the spectral energy density estimated at the most seaward stations while Station E (Figure 4.10) is included to show the spectral energy density estimated for the entire duration of the storm event. The estimated spectral energy values during the 20-minute segments are shown between the solid red lines.

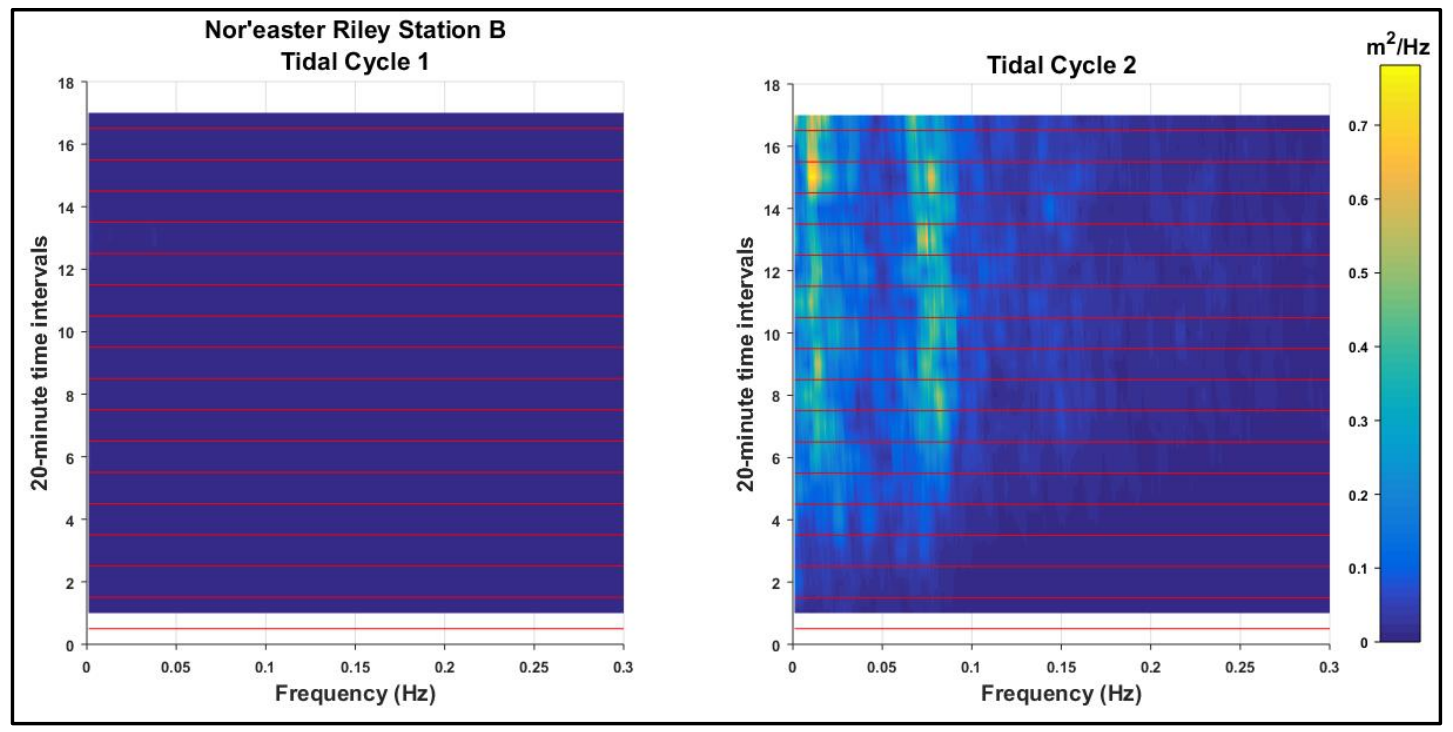

Figure 4.8: Spectral energy time stack during Nor'easter Riley at deployment Station B. 


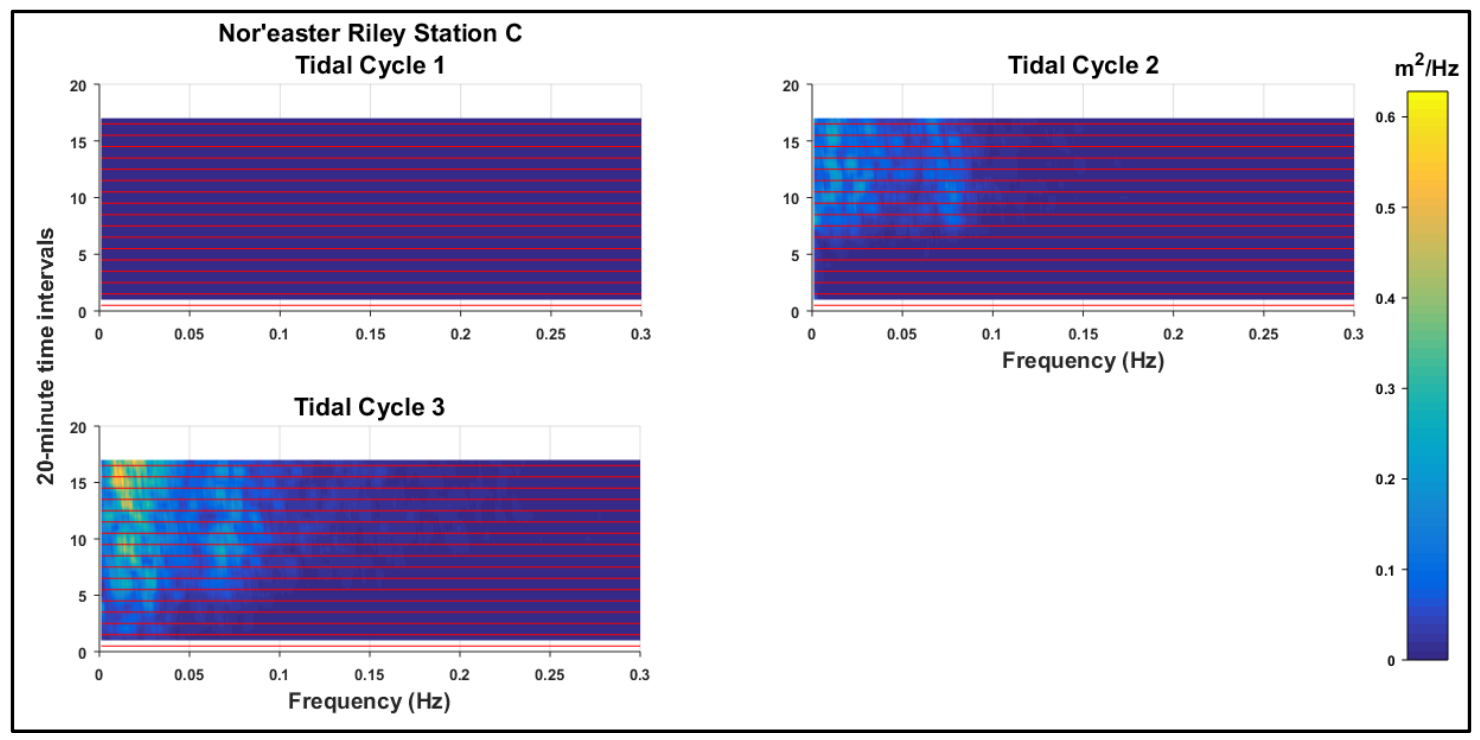

Figure 4.9: Spectral energy time stack during Nor'easter Riley at deployment Station C.

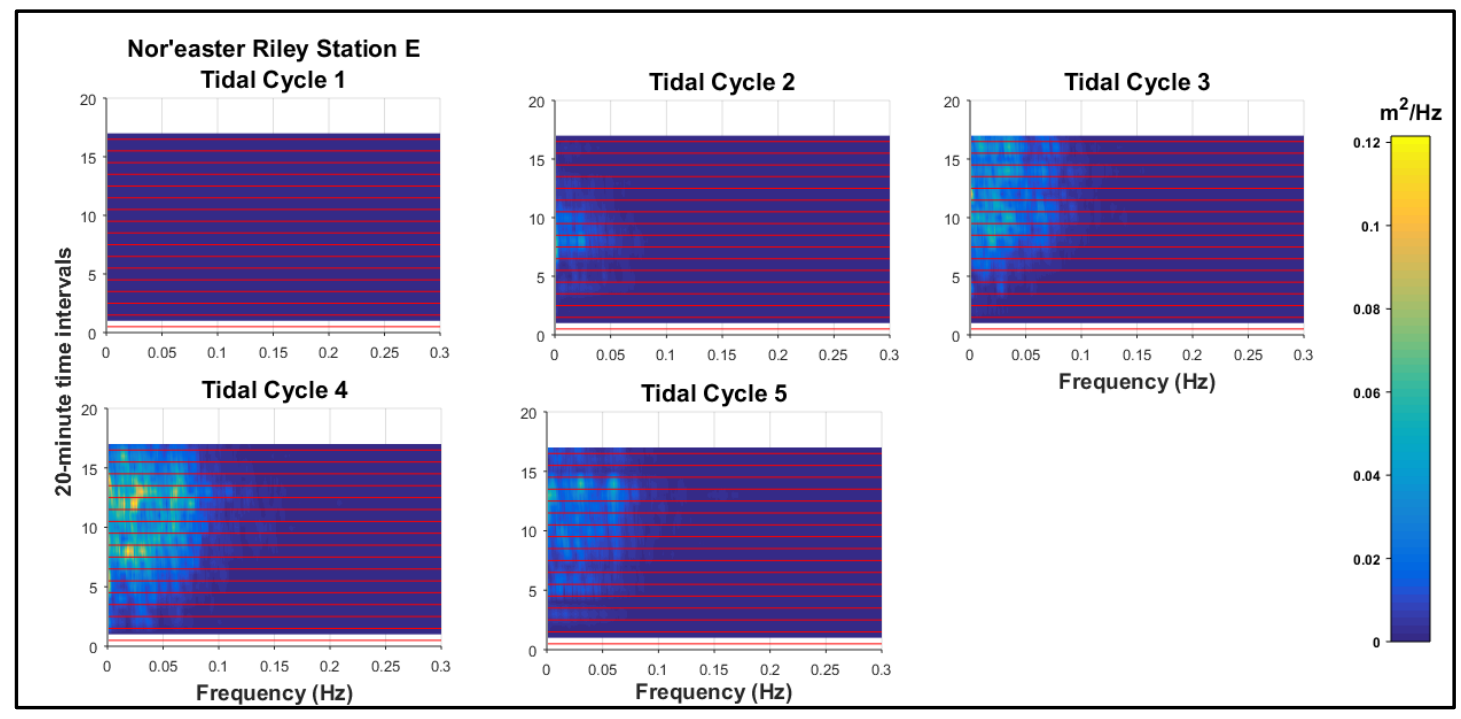

Figure 4.10: Spectral energy time stack during Nor'easter Riley at deployment Station E. 
Figures $4.8-4.10$ show an increase in low frequency energy within the infragravity band was measured during Nor'easter Riley compared to pre-storm (tidal cycle 1) conditions throughout the cross-shore. Figures showing the time during Nor'easter Riley, the demeaned water elevation segment, and the energy spectra of the 20-minute water elevation segment when large amounts of low frequency energy was present are shown (Figure 4.11 and Figure 4.12).

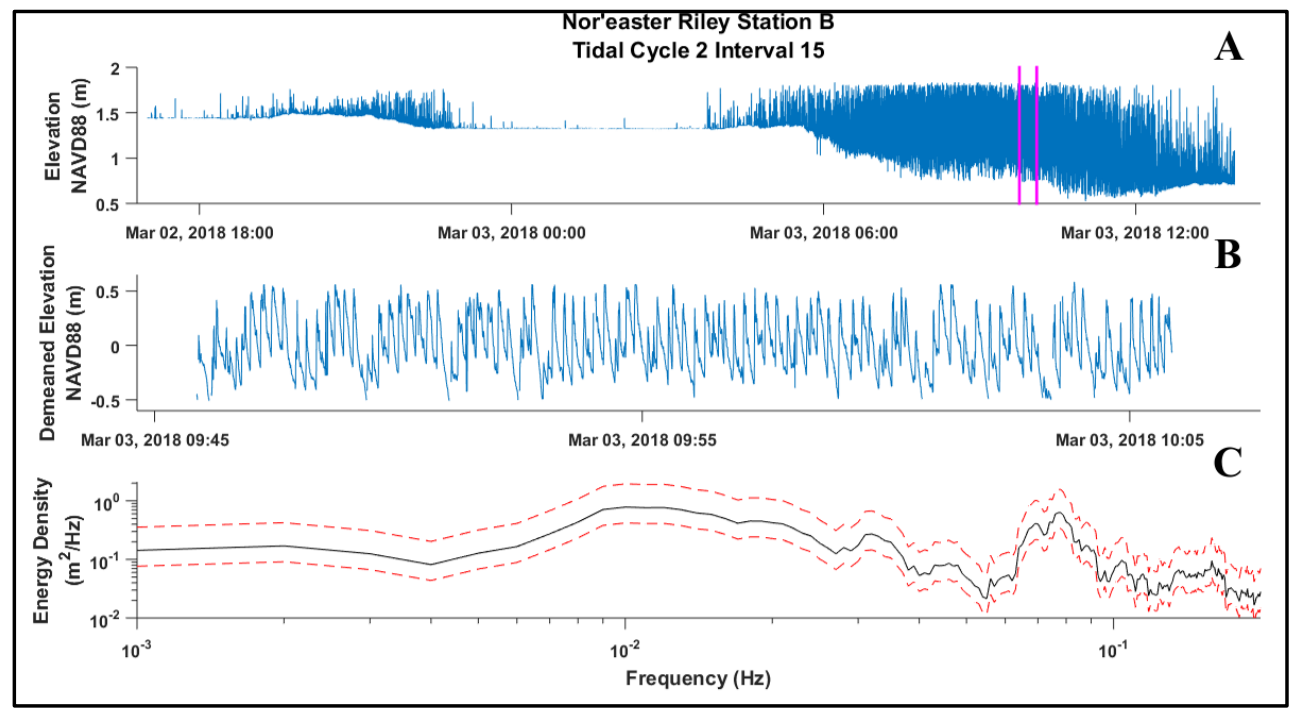

Figure 4.11: Time series of water elevation (A) with denoted 20-minute time segment (solid magenta), demeaned water elevation during 20minute time segment (B), and power spectral density (C) during tidal cycle 2 of Nor'easter Riley at Station B. 


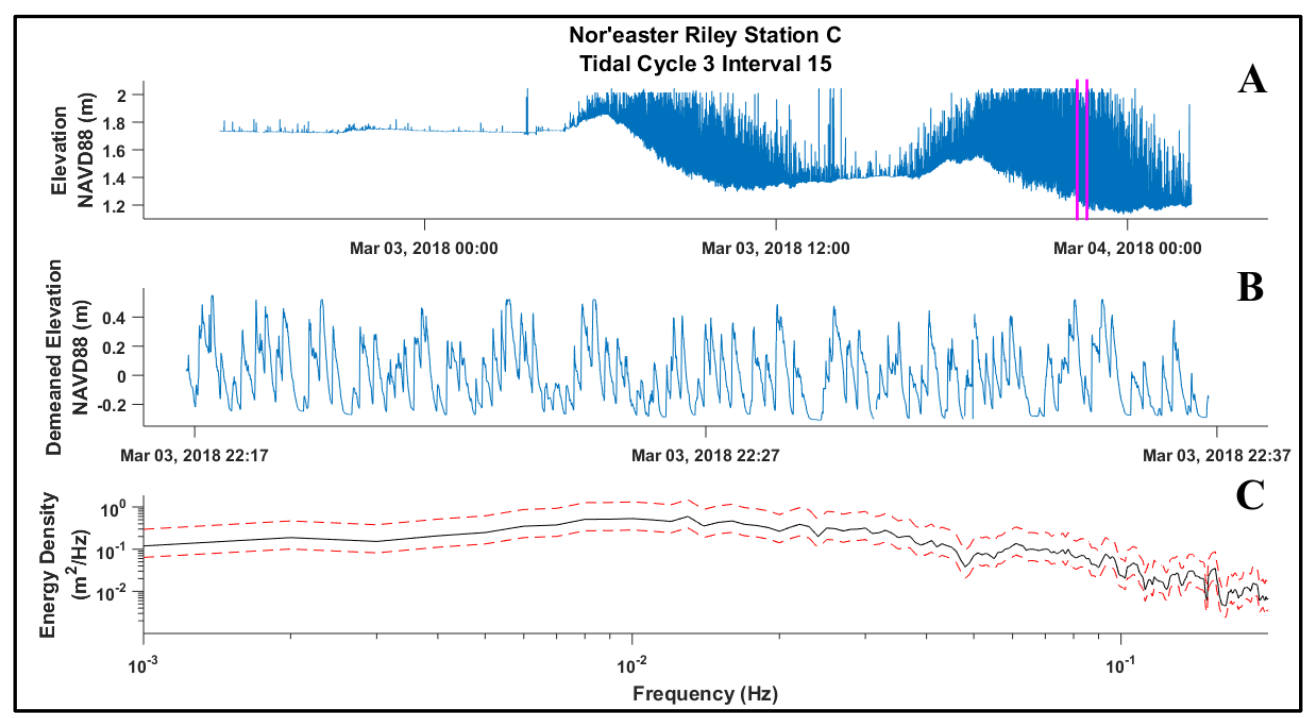

Figure 4.12: Time series of water elevation (A) with denoted 20-minute time segment (solid magenta), demeaned water elevation during 20minute time segment (B), and power spectral density (C) during tidal cycle 3 of Nor'easter Riley at Station C.

Incident and infragravity energy were calculated during Nor'easter Riley by summing the spectral energy within the respective frequency bands. The incident energy band was taken as $0.05 \mathrm{~Hz}<f \leq 0.24 \mathrm{~Hz}$ and the infragravity band was taken as $0.004 \mathrm{~Hz} \leq f \leq 0.05 \mathrm{~Hz}$, consistent with Senechal (2011). The total energy was also calculated by summing the spectral energy within the $0.004 \mathrm{~Hz} \leq f \leq 0.24 \mathrm{~Hz}$ frequency range. Time series of the total, incident, and infragravity energies at each cross-shore deployment station are shown (Figure 4.13). At times where the total spectral energy was greater than $0.0025 \mathrm{~m}^{2}$, over $50 \%$ of that energy was within the infragravity band at deployment Stations A E. Station B was the only cross-shore deployment station where over $50 \%$ of the 
total energy was within the incident band when the total spectral energy was greater than $0.0025 \mathrm{~m}^{2}$ (Figure 4.14).

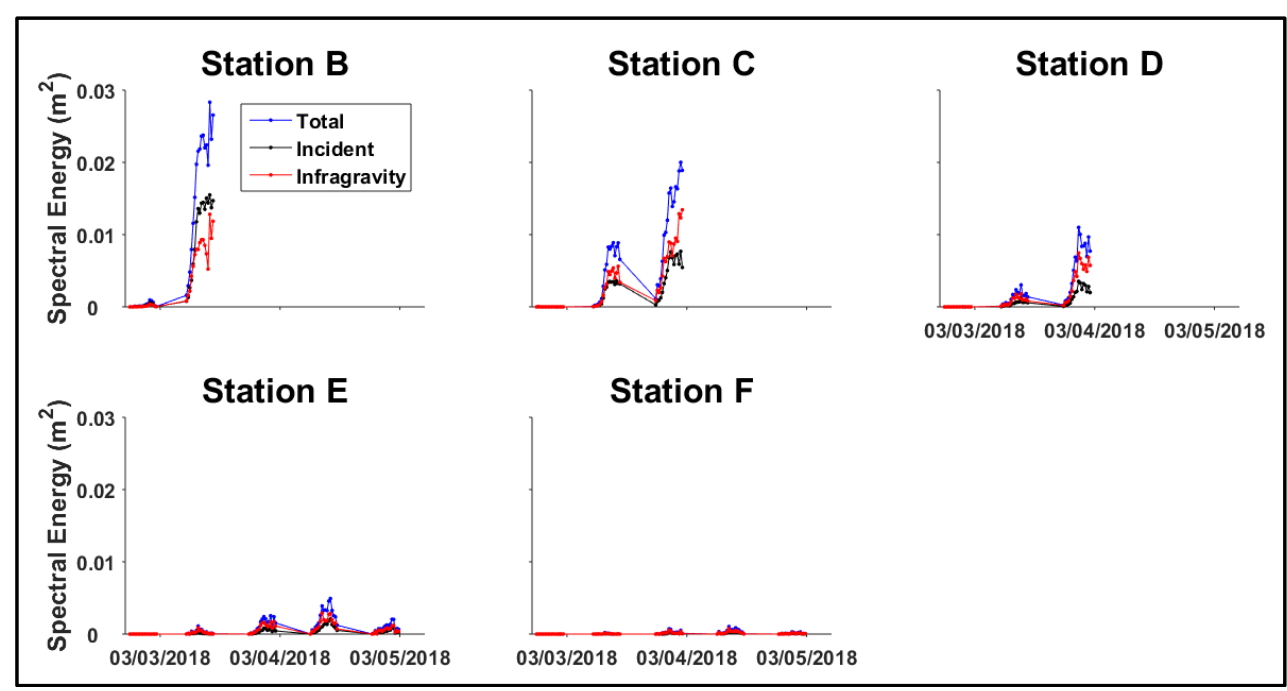

Figure 4.13: Time series of the total (blue), incident (black), and infragravity (red) band energy during Nor'easter Riley. 


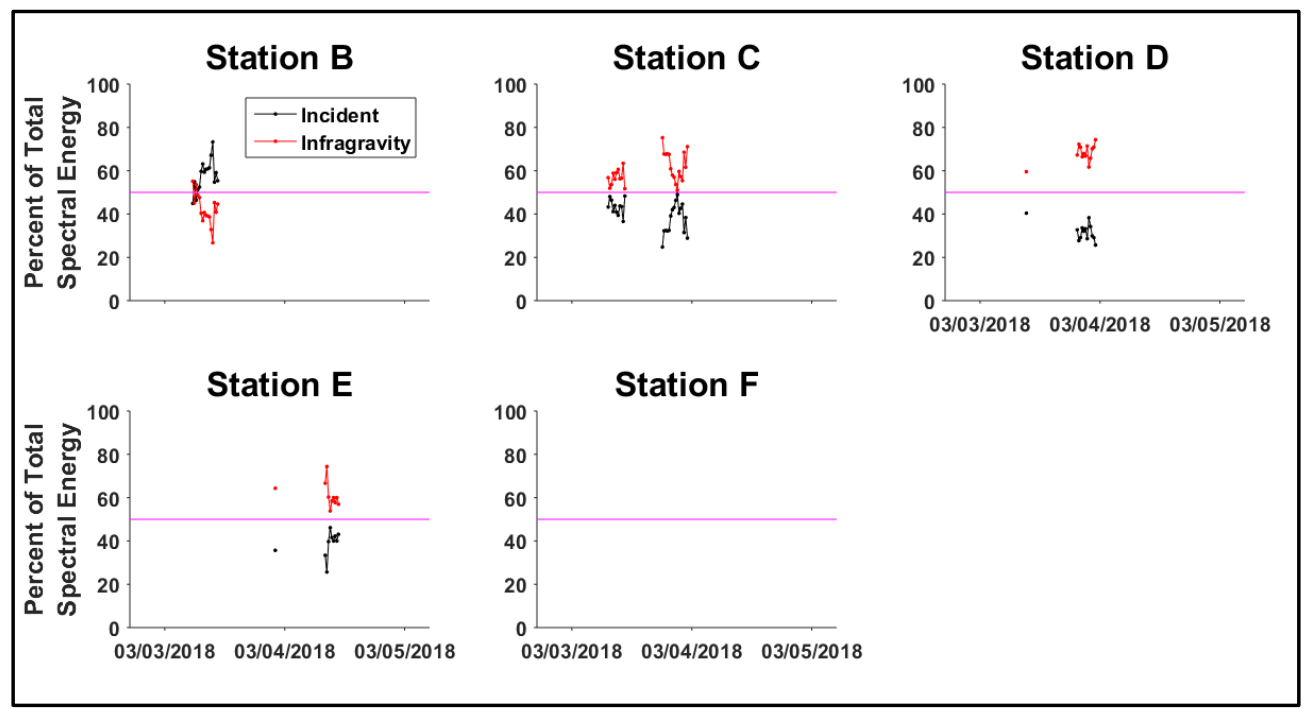

Figure 4.14: Percent of total spectral energy time series of the incident (black) and infragravity (red) band during Nor'easter Riley. The 50\% threshold (magenta) is shown.

\subsubsection{Spectral Energy During Easter Eve Storm}

Spectral energy time stack plots from deployment stations are shown during the Easter Eve Storm. The time stack plots from Station A (Figure 4.15), Station B (Figure 4.16), and Station C (Figure 4.17) show the spectral energy density estimated at the most seaward stations. Here, all the time stack plots are over the duration of the deployment. The estimated spectral energy values during the 20-minute segments are shown between the solid red lines. 


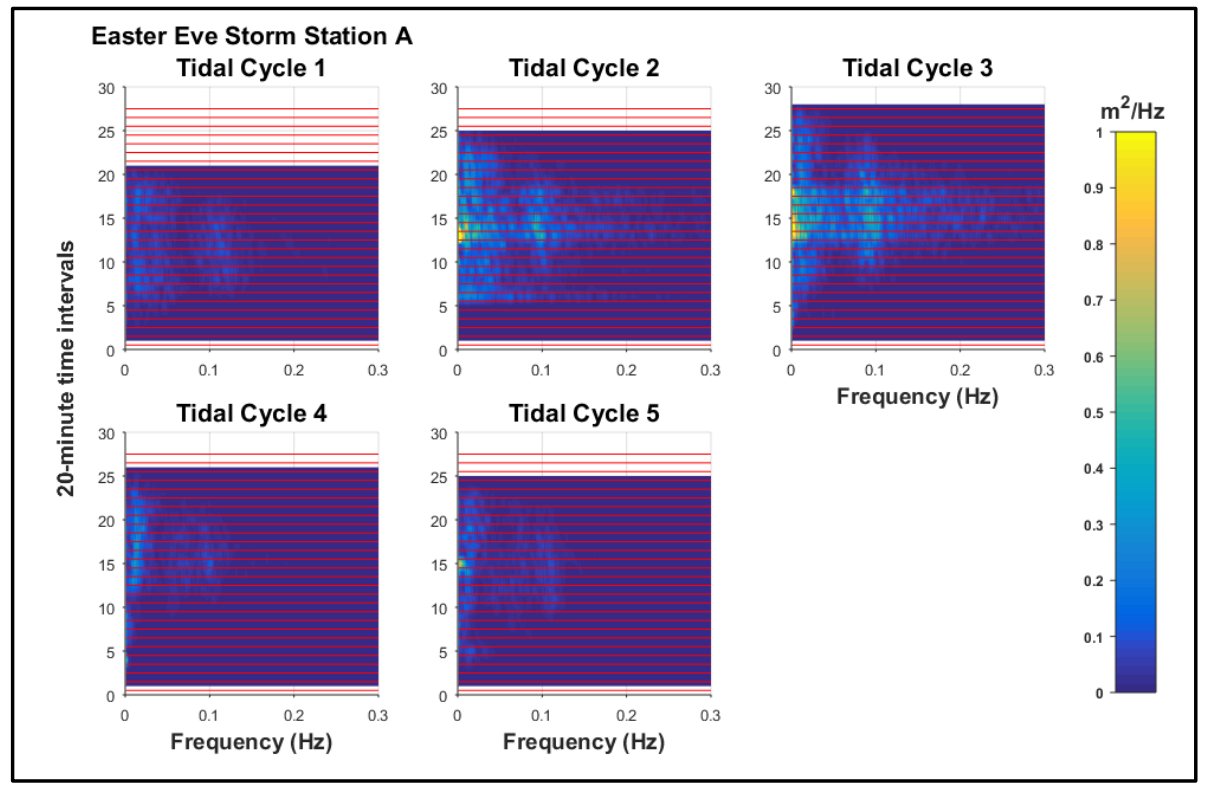

Figure 4.15: Spectral energy time stack during the Easter Eve Storm at deployment Station A.

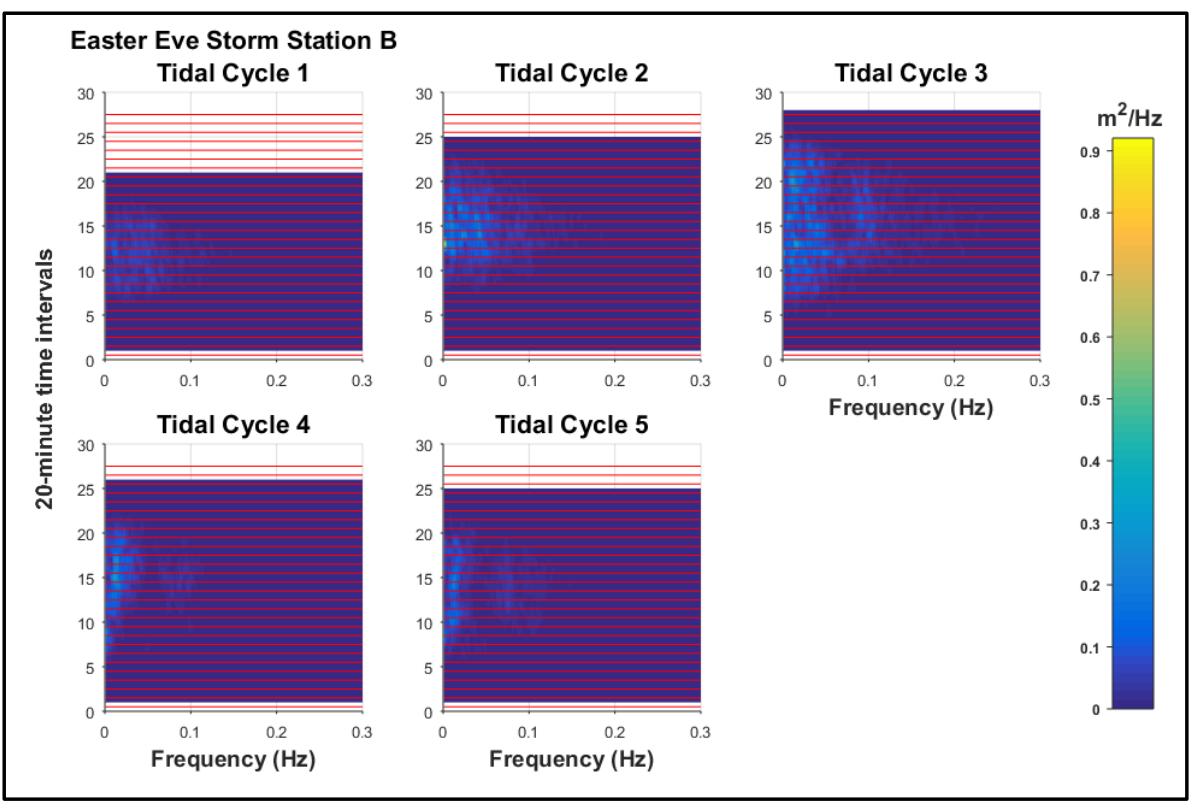

Figure 4.16: Spectral energy time stack during the Easter Eve Storm at deployment Station B. 


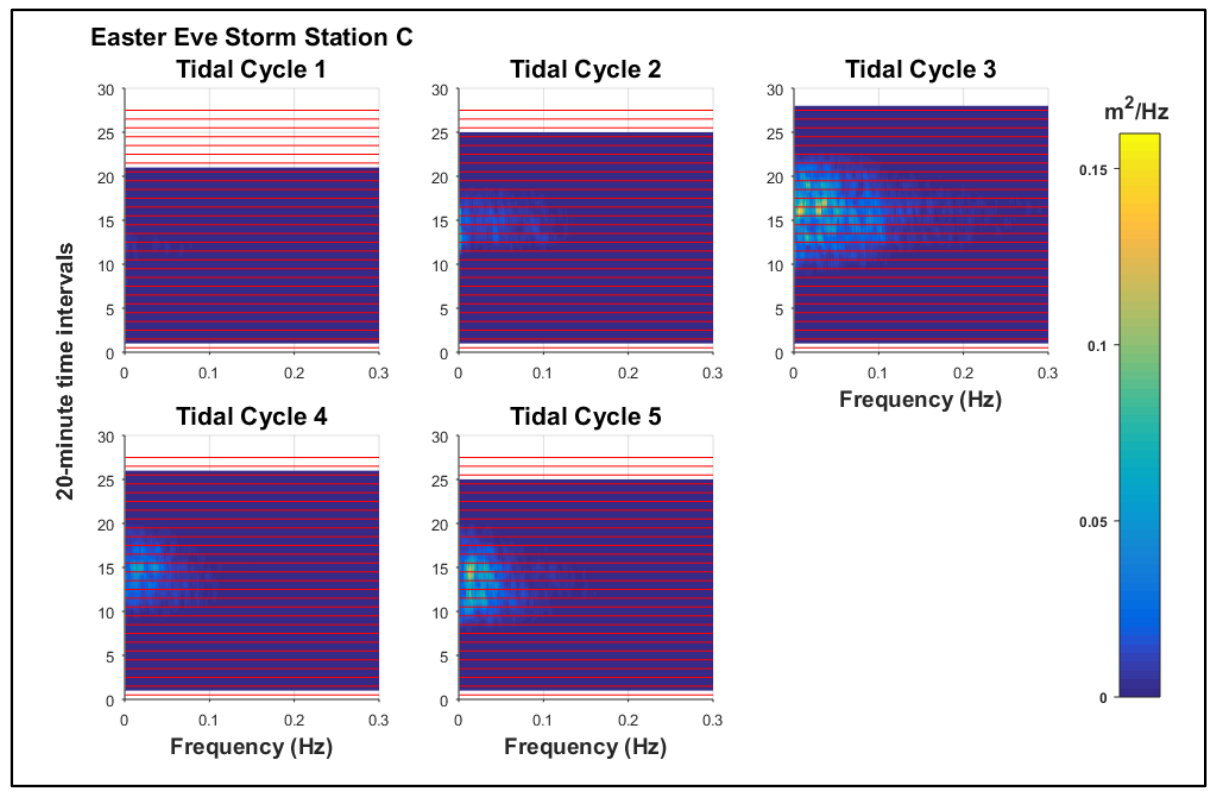

Figure 4.17: Spectral energy time stack during the Easter Eve Storm at deployment Station C.

Figures $4.15-4.17$ show an increase in low frequency energy within the infragravity band was measured during the Easter Eve Storm compared to prestorm (tidal cycle 1) conditions throughout the cross-shore. Figures showing the time during the Easter Eve Storm, the demeaned water elevation segment, and the energy spectra of the 20-minute water elevation segment when large amounts of low frequency energy was present are shown (Figure $4.18-4.20$ ). 


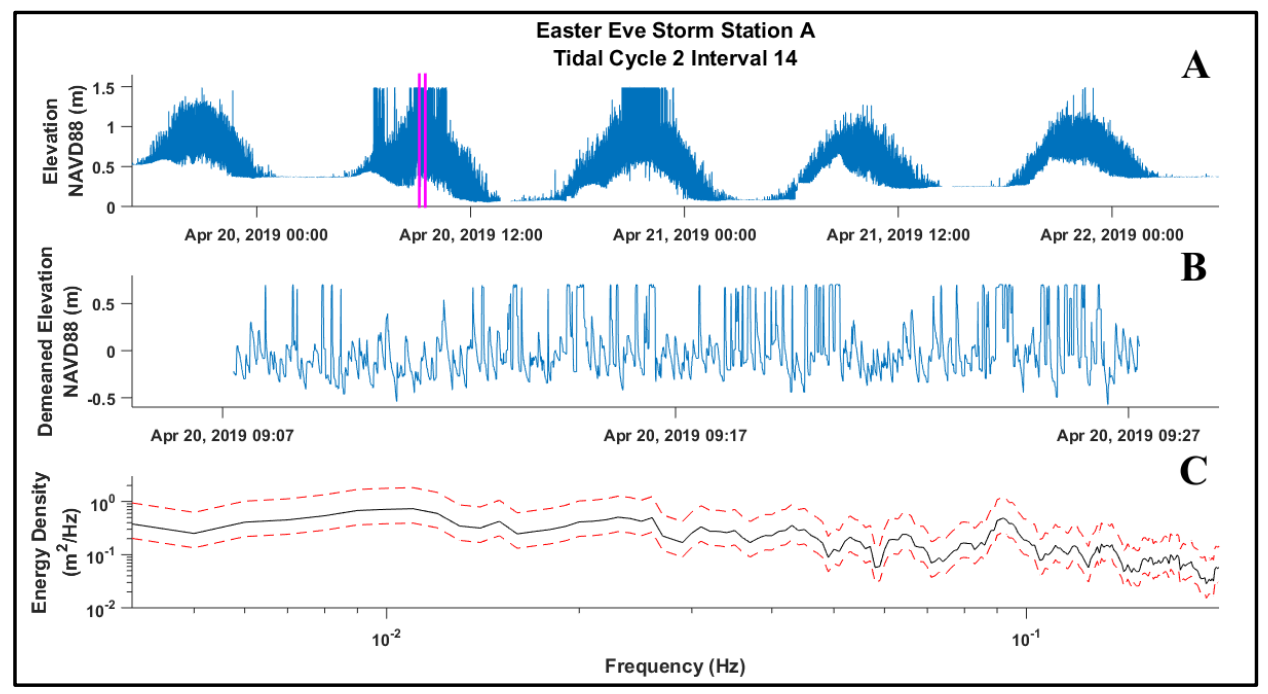

Figure 4.18: Time series of water elevation (A) with denoted 20-minute time segment (solid magenta), demeaned water elevation during 20minute time segment (B), and power spectral density (C) during tidal cycle 2 of Easer Eve Storm at Station A.

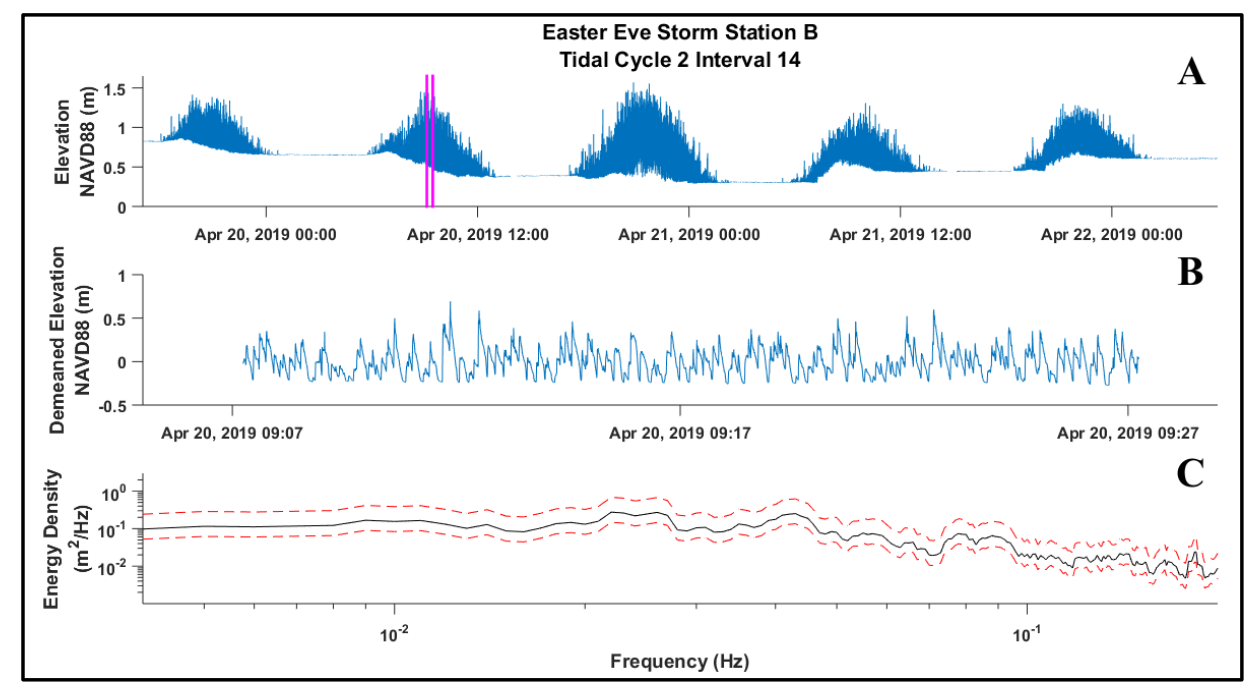

Figure 4.19: Time series of water elevation (A) with denoted 20-minute time segment (solid magenta), demeaned water elevation during 20minute time segment (B), and power spectral density (C) during tidal cycle 2 of Easer Eve Storm at Station B. 


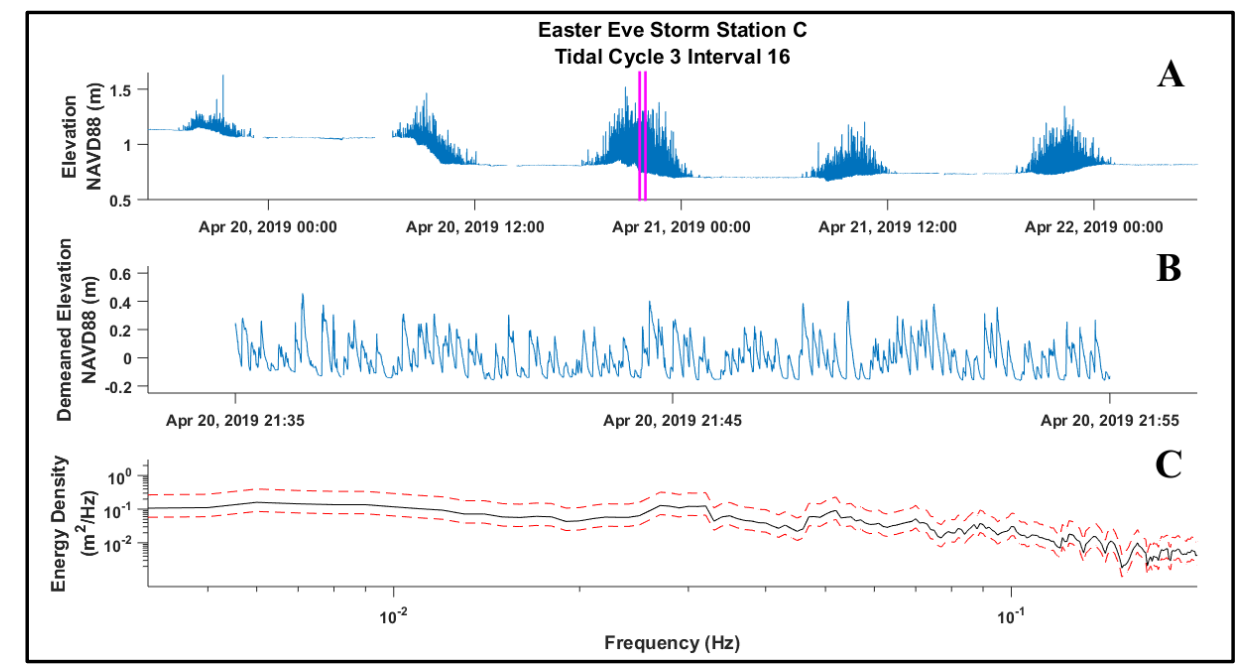

Figure 4.20: Time series of water elevation (A) with denoted 20-minute time segment (solid magenta), demeaned water elevation during 20minute time segment (B), and power spectral density (C) during tidal cycle 3 of Easer Eve Storm at Station C.

Total, incident, and infragravity energy was calculated as described in Section 4.2.1.1. Time series of the total, incident, and infragravity energies at each cross-shore deployment station during the Easter Eve Storm are shown (Figure 4.21). Spectral energy within the infragravity band exceeded $50 \%$ at all crossshore deployment stations. However, the infragravity energy would exceed $50 \%$ near the beginning and end of the pre-storm tidal cycles. There was a significant increase in spectral energy when the storm event began (Figure 4.22). 


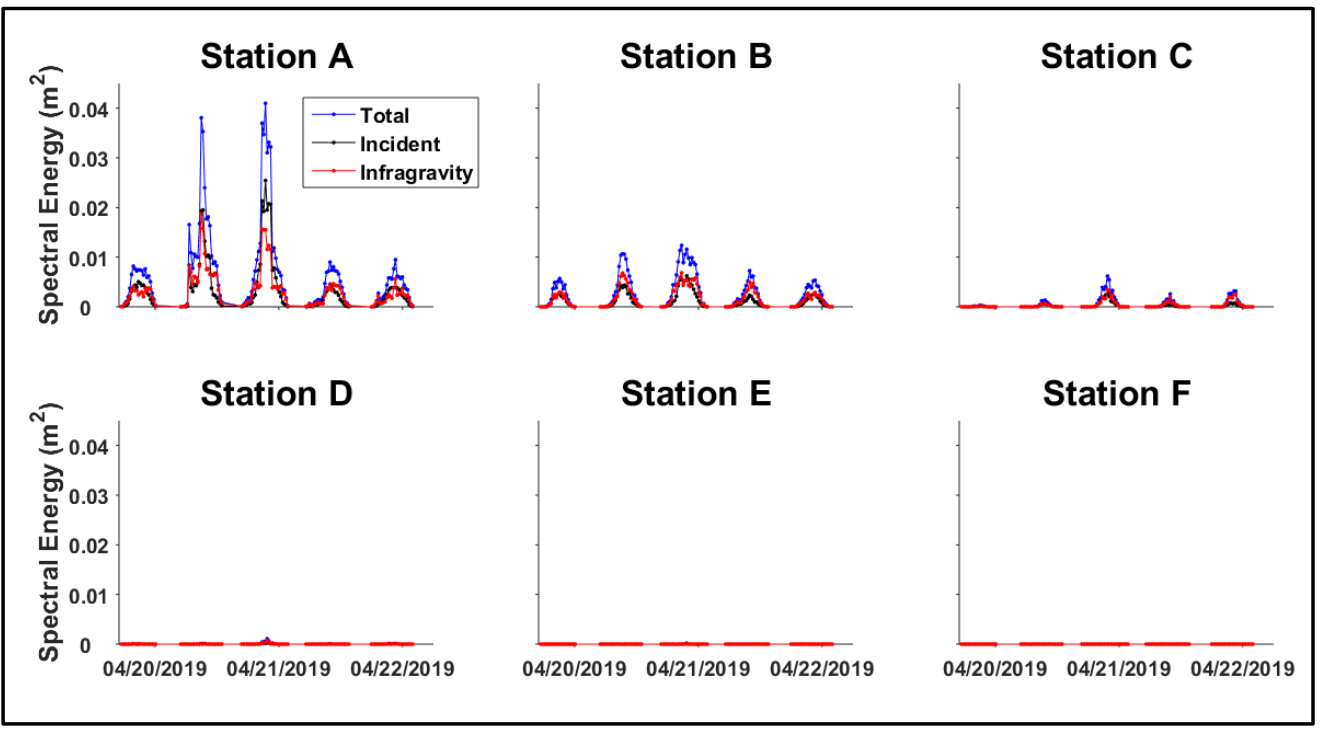

Figure 4.21: Time series of the total (blue), incident (black), and infragravity (red) band energy during the Easter Eve Storm.

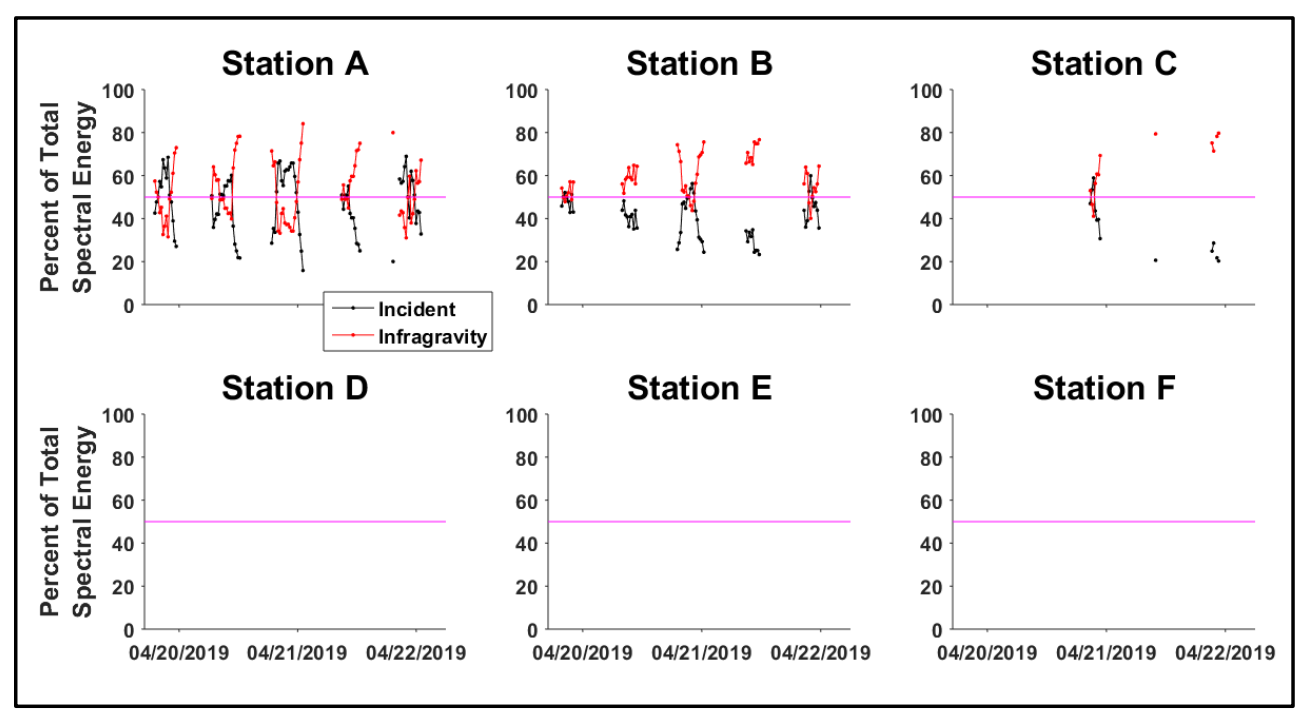

Figure 4.22: Percent of total spectral energy time series of the incident (black) and infragravity (red) band during the Easter Eve Storm. The 50\% threshold (magenta) is shown. 


\subsubsection{Spectral Energy and Offshore Wave Conditions}

Studies by Senechal (2011) and Stockdon (2006) examined runup on various beaches using video techniques. Spectral analysis was performed to relate significant vertical runup height to offshore wave conditions to study incident and infragravity band saturation. In this application, significant demeaned water elevation was used in place of runup due to data being measured in an Eulerian reference frame as opposed to Lagrangian reference frame.

Significant water elevations were calculated similar to how significant runup was calculated in Senechal (2011) and Stockdon (2006) by using Equation 4.16:

$$
\eta_{S}=4 * \sqrt{\sum P S D(f) * d f},
$$

where $P S D$ is the energy spectra and $d f$ is the frequency resolution. In this application, $d f$ was taken as $0.001 \mathrm{~Hz}$. As in Section 4.2.1, the total significant water elevation was calculated using $0.004 \mathrm{~Hz} \leq f \leq 0.24 \mathrm{~Hz}$, the infragravity band significant water elevation $\left(\eta_{S, I G}\right)$ was calculated using $0.004 \mathrm{~Hz} \leq f \leq$ $0.05 \mathrm{~Hz}$, and the incident band significant water elevation $\left(\eta_{S, I N C}\right)$ was calculated using $0.05 \mathrm{~Hz}<f \leq 0.24 \mathrm{~Hz}$ at each cross-shore deployment station during Nor'easter Riley (Figure 4.23) and the Easter Eve Storm (Figure 4.24). 


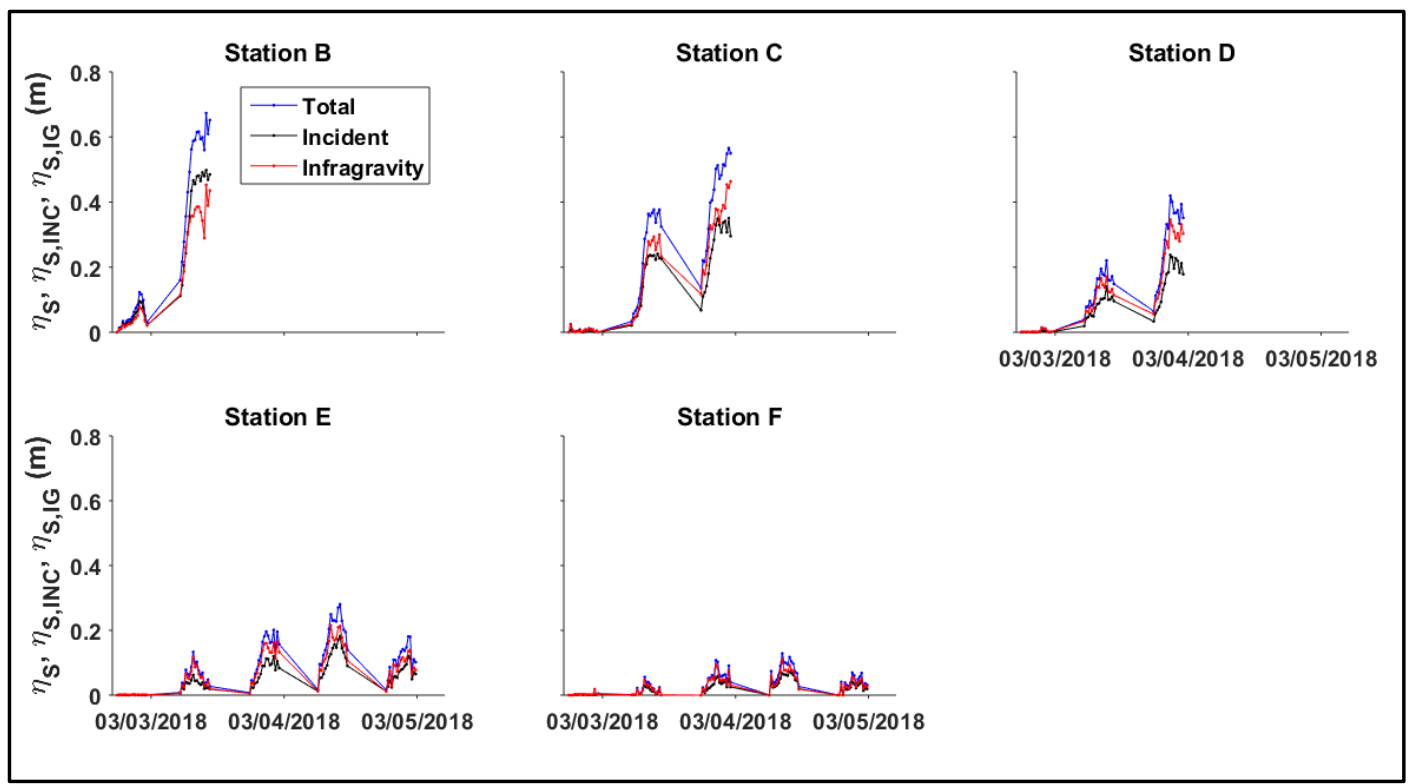

Figure 4.23: Timeseries of demeaned significant water elevation at each crossshore deployment station during Nor' easter Riley. The total (blue), incident band (black) and infragravity band (red) significant water elevations are shown. 


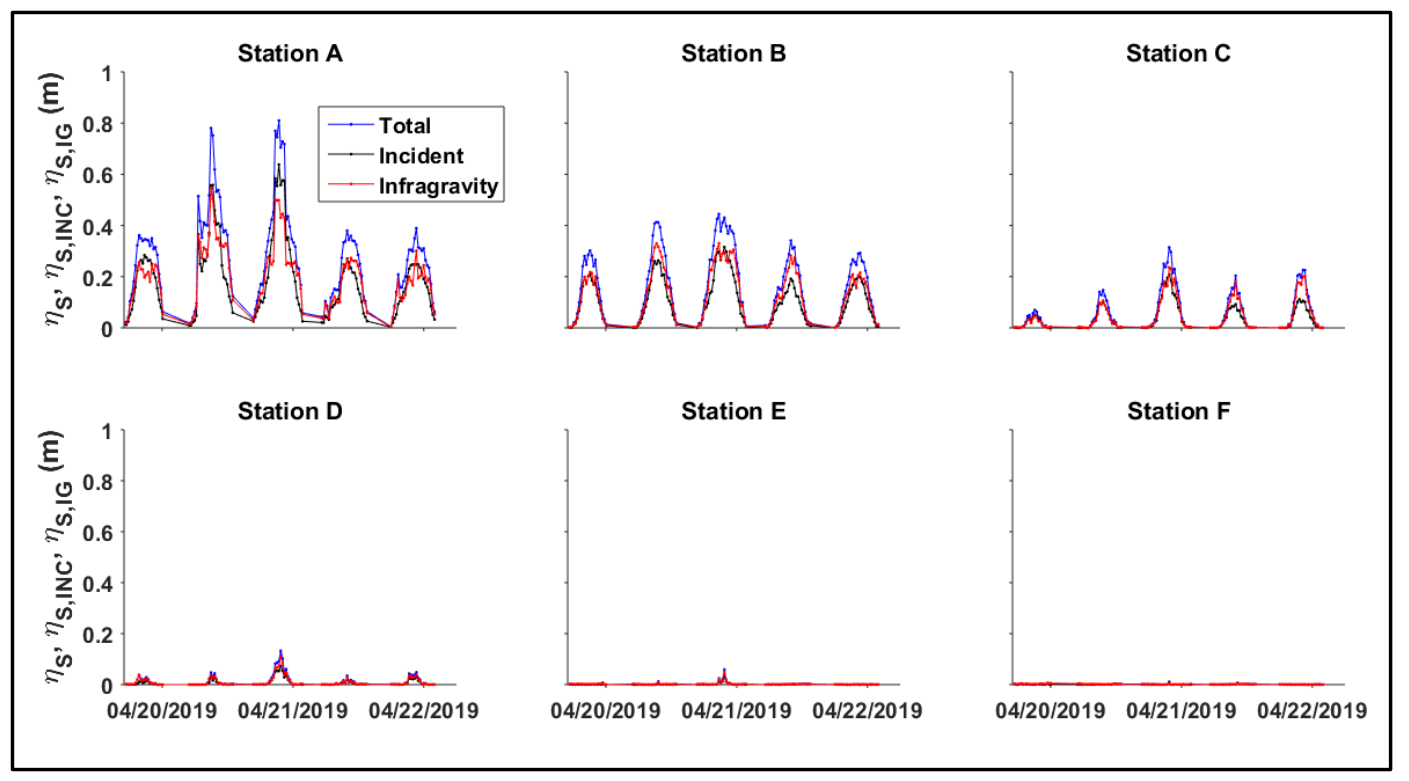

Figure 4.24: Timeseries of demeaned significant water elevation at each crossshore deployment station during the Easter Eve Storm. The total (blue), incident band (black) and infragravity band (red) significant water elevations are shown.

Demeaned significant water elevation was related to offshore wave conditions through correlation with $\xi$ and two dimensional parameters (Equation 4.17 and Equation 4.18) proposed by Stockdon (2006).

$$
\begin{gathered}
\gamma_{1}=\sqrt{H_{o} * L_{o}}, \\
\gamma_{2}=\tan \theta * \sqrt{H_{o} * L_{o}}
\end{gathered}
$$

In this application, $H_{o}^{\prime}$ was used in place of $H_{o}$ to remain consistent with previous analysis.

The dimensional parameters, $\gamma_{1}$ and $\gamma_{2}$, were correlated using linear regression with $\eta_{S}, \eta_{S, I G}$ and $\eta_{S, I N C}$ (Nor'easter Riley: Figure 4.25 and Figure 4.26, Easter Eve Storm: Figure 4.27 and Figure 4.28) while $\xi$ was correlated with 
$\eta_{S} / H_{o}^{\prime}, \eta_{S, I G} / H_{o}^{\prime}$, and $\eta_{S, I N C} / H_{o}^{\prime}$ to keep non-dimensionality consistent (Nor'easter Riley, Figure 4.29 and Easter Eve Storm, Figure 4.30). The yintercepts of all linear regressions were forced through zero to preserve the physical interpretation of positive significant water elevation. The slope $(m)$ and coefficient of determination $\left(r^{2}\right)$ are given in Table 4.4 - Table 4.9.

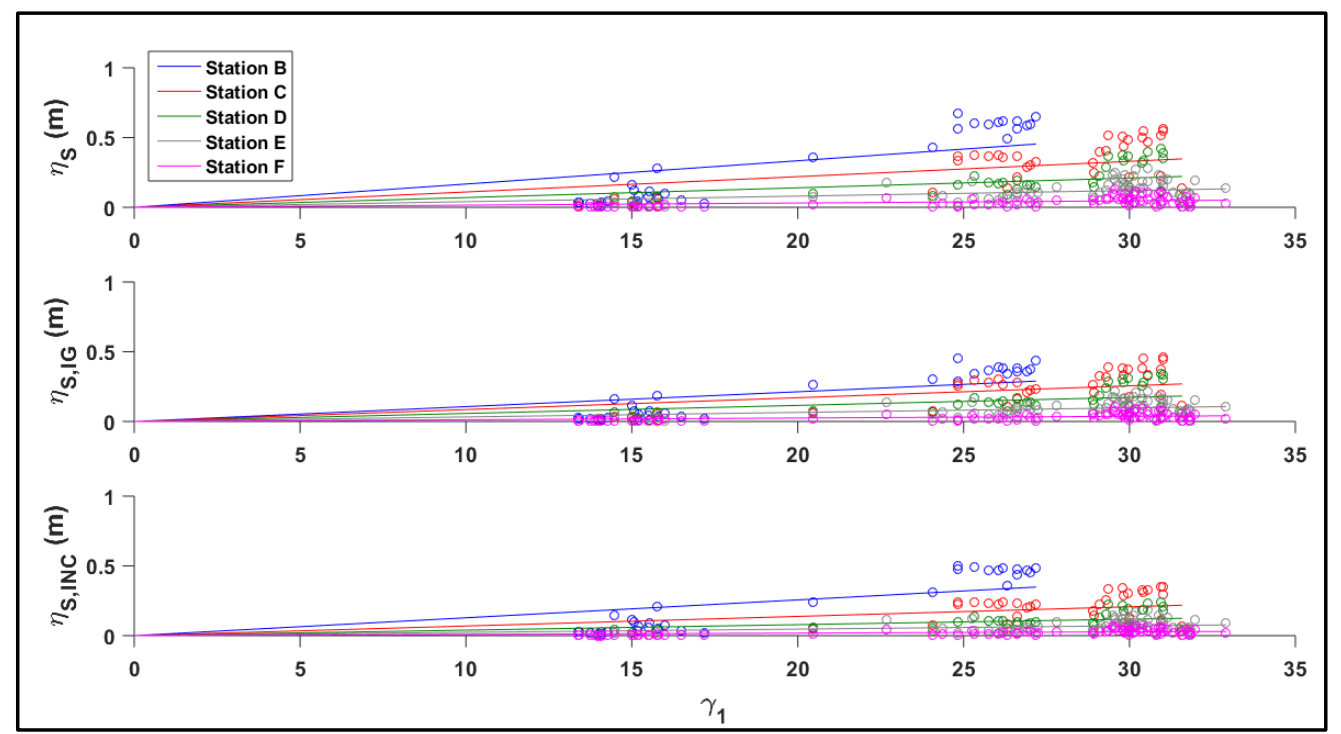

Figure 4.25: Total (top), infragravity band (middle), and incident band (bottom) significant water elevation (circles) correlated using linear regression (solid lines) with $\gamma_{1}$ parameter proposed by Stockdon (2006) at each cross-shore deployment station during Nor'easter Riley. 
Table 4.4: Linear regression coefficients of significant water elevation $\left(\eta_{S}\right.$, $\left.\eta_{S, I G}, \eta_{S, I N C}\right)$ vs. $\gamma_{1}$ during Nor'easter Riley

\begin{tabular}{|l|c|c|c|}
\hline & $\eta_{S}$ & $\eta_{S, I G}$ & $\eta_{S, I N C}$ \\
& $m\left(r^{2}\right)$ & $m\left(r^{2}\right)$ & $m\left(r^{2}\right)$ \\
\hline Station B & $0.02(0.25)$ & $0.01(0.25)$ & $0.01(0.25)$ \\
\hline Station C & $0.01(0.25)$ & $0.01(0.25)$ & $0.01(0.24)$ \\
\hline Station D & $0.01(0.21)$ & $0.01(0.21)$ & $<0.01(0.21)$ \\
\hline Station E & $<0.01(0.15)$ & $<0.01(0.16)$ & $<0.01(0.13)$ \\
\hline Station F & $<0.01(0.11)$ & $<0.01(0.11)$ & $<0.01(0.11)$ \\
\hline
\end{tabular}

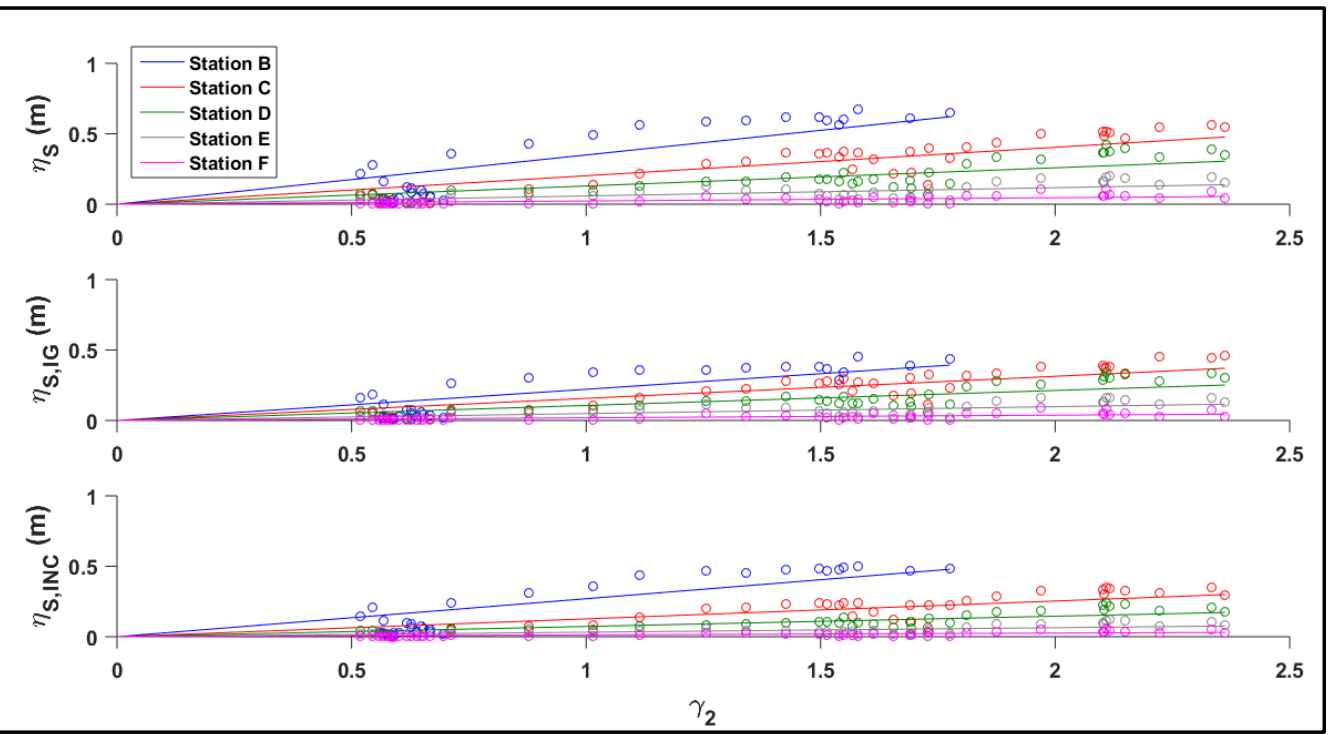

Figure 4.26: Total (top), infragravity band (middle), and incident band (bottom) significant water elevation (circles) correlated using linear regression (solid lines) with $\gamma_{2}$ parameter proposed by Stockdon (2006) at each cross-shore deployment station during Nor'easter Riley. 
Table 4.5: Linear regression coefficients of significant water elevation $\left(\eta_{S}\right.$, $\left.\eta_{S, I G}, \eta_{S, I N C}\right)$ vs. $\gamma_{2}$ during Nor'easter Riley

\begin{tabular}{|l|c|c|c|}
\hline & $\eta_{S}$ & $\eta_{S, I G}$ & $\eta_{S, I N C}$ \\
& $m\left(r^{2}\right)$ & $m\left(r^{2}\right)$ & $m\left(r^{2}\right)$ \\
\hline Station B & $0.35(0.55)$ & $0.22(0.52)$ & $0.27(0.55)$ \\
\hline Station C & $0.20(0.66)$ & $0.16(0.66)$ & $0.13(0.62)$ \\
\hline Station D & $0.13(0.57)$ & $0.11(0.57)$ & $0.07(0.56)$ \\
\hline Station E & $0.06(0.44)$ & $0.05(0.44)$ & $0.03(0.43)$ \\
\hline Station F & $0.02(0.34)$ & $0.02(0.33)$ & $0.01(0.36)$ \\
\hline
\end{tabular}

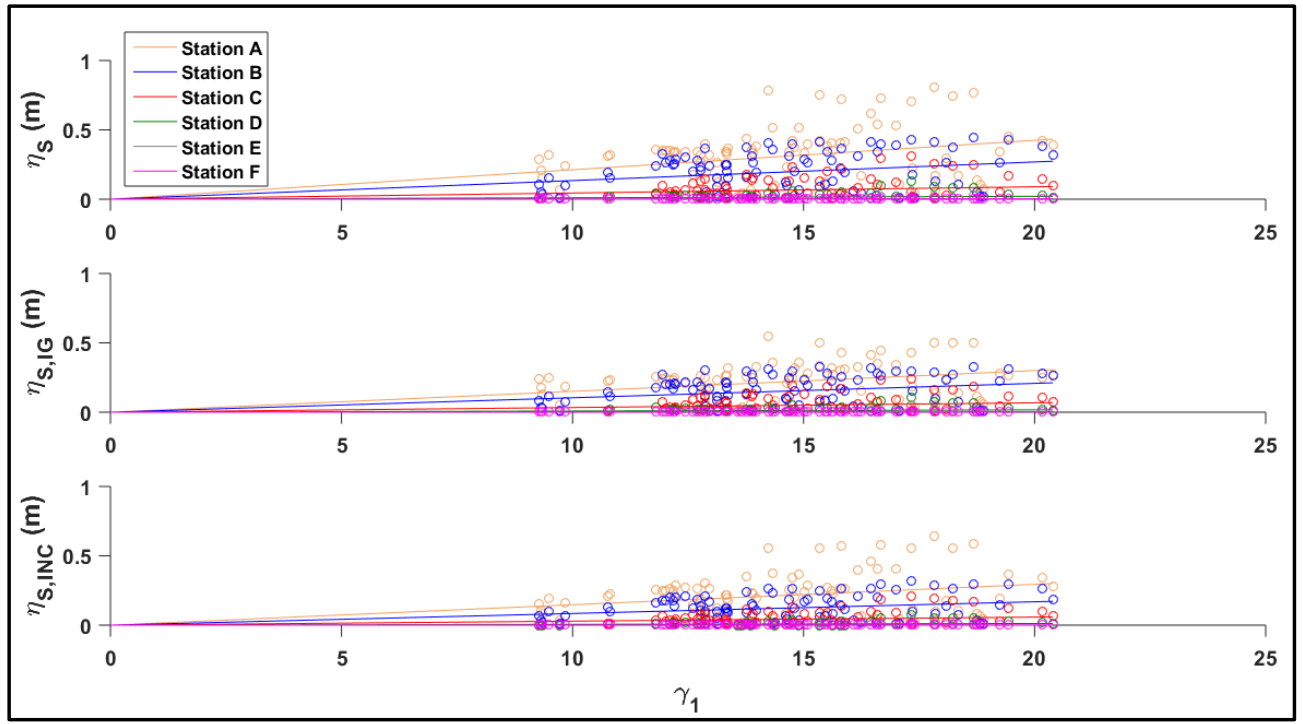

Figure 4.27: Total (top), infragravity band (middle), and incident band (bottom) significant water elevation (circles) correlated using linear regression (solid lines) with $\gamma_{1}$ parameter proposed by Stockdon (2006) at each cross-shore deployment station during the Easter Eve Storm. 
Table 4.6: Linear regression coefficients of significant water elevation $\left(\eta_{S}\right.$, $\left.\eta_{S, I G}, \eta_{S, I N C}\right)$ vs. $\gamma_{1}$ during the Easter Eve Storm

\begin{tabular}{|l|c|c|c|}
\hline & $\eta_{S}$ & $\eta_{S, I G}$ & $\eta_{S, I N C}$ \\
& $m\left(r^{2}\right)$ & $m\left(r^{2}\right)$ & $m\left(r^{2}\right)$ \\
\hline Station A & $0.02(0.08)$ & $0.02(0.09)$ & $0.01(0.06)$ \\
\hline Station B & $0.01(0.07)$ & $0.01(0.07)$ & $0.01(0.06)$ \\
\hline Station C & $<0.01(0.02)$ & $<0.01(0.02)$ & $<0.01(0.02)$ \\
\hline Station D & $<0.01(0.01)$ & $<0.01(0.01)$ & $<0.01(0.01)$ \\
\hline Station E & $<0.01(0.01)$ & $<0.01(0.01)$ & $<0.01(0.01)$ \\
\hline Station F & $<0.01(0.04)$ & $<0.01(0.04)$ & $<0.01(0.02)$ \\
\hline
\end{tabular}

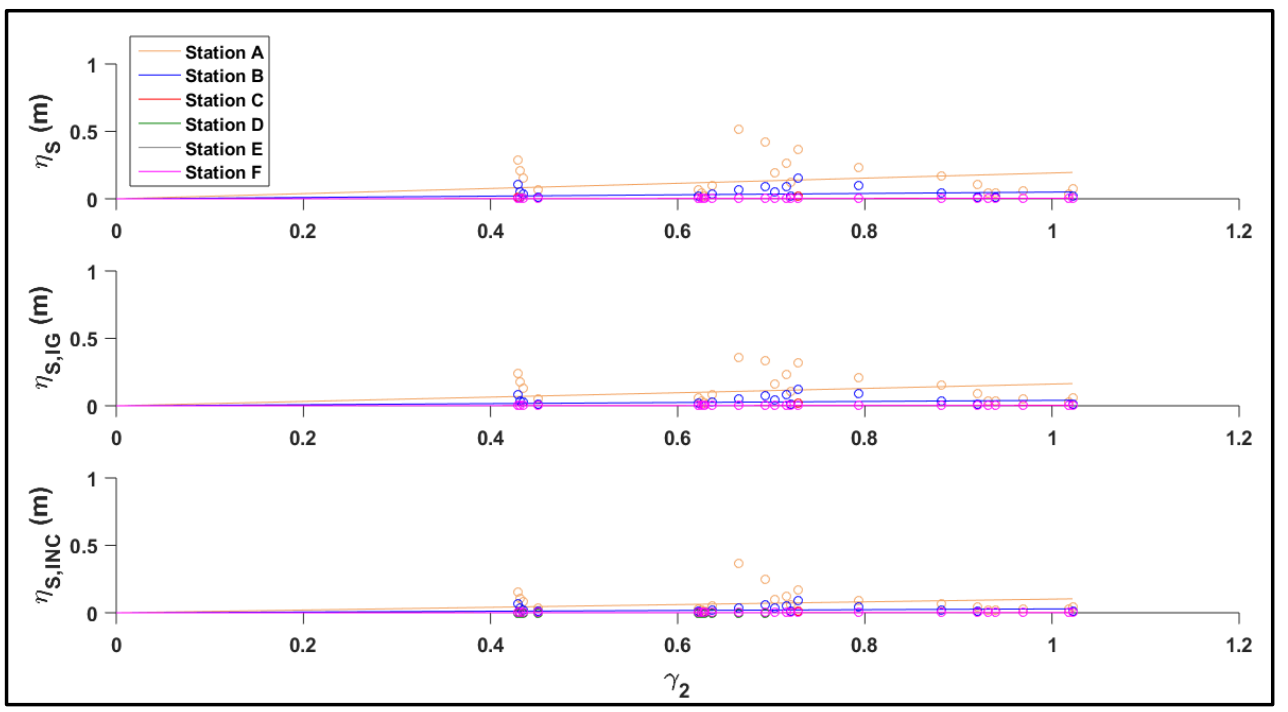

Figure 4.28: Total (top), infragravity band (middle), and incident band (bottom) significant water elevation (circles) correlated using linear regression (solid lines) with $\gamma_{2}$ parameter proposed by Stockdon (2006) at each cross-shore deployment station during the Easter Eve Storm. 
Table 4.7: Linear regression coefficients of significant water elevation $\left(\eta_{S}\right.$, $\left.\eta_{S, I G}, \eta_{S, I N C}\right)$ vs. $\gamma_{2}$ during the Easter Eve Storm

\begin{tabular}{|l|c|c|c|}
\hline & $\eta_{S}$ & $\eta_{S, I G}$ & $\eta_{S, I N C}$ \\
& $m\left(r^{2}\right)$ & $m\left(r^{2}\right)$ & $m\left(r^{2}\right)$ \\
\hline Station A & $0.19(0.07)$ & $0.16(0.07)$ & $0.10(0.05)$ \\
\hline Station B & $0.05(0.05)$ & $0.04(0.05)$ & $0.03(0.05)$ \\
\hline Station C & $<0.01(0.03)$ & $<0.01(0.04)$ & $<0.01(0.02)$ \\
\hline Station D & $<0.01(0.07)$ & $<0.01(0.06)$ & $<0.01(0.10)$ \\
\hline Station E & $<0.01(0.06)$ & $<0.01(0.05)$ & $<0.01(0.07)$ \\
\hline Station F & $<0.01(0.10)$ & $<0.01(0.09)$ & $<0.01(0.07)$ \\
\hline
\end{tabular}

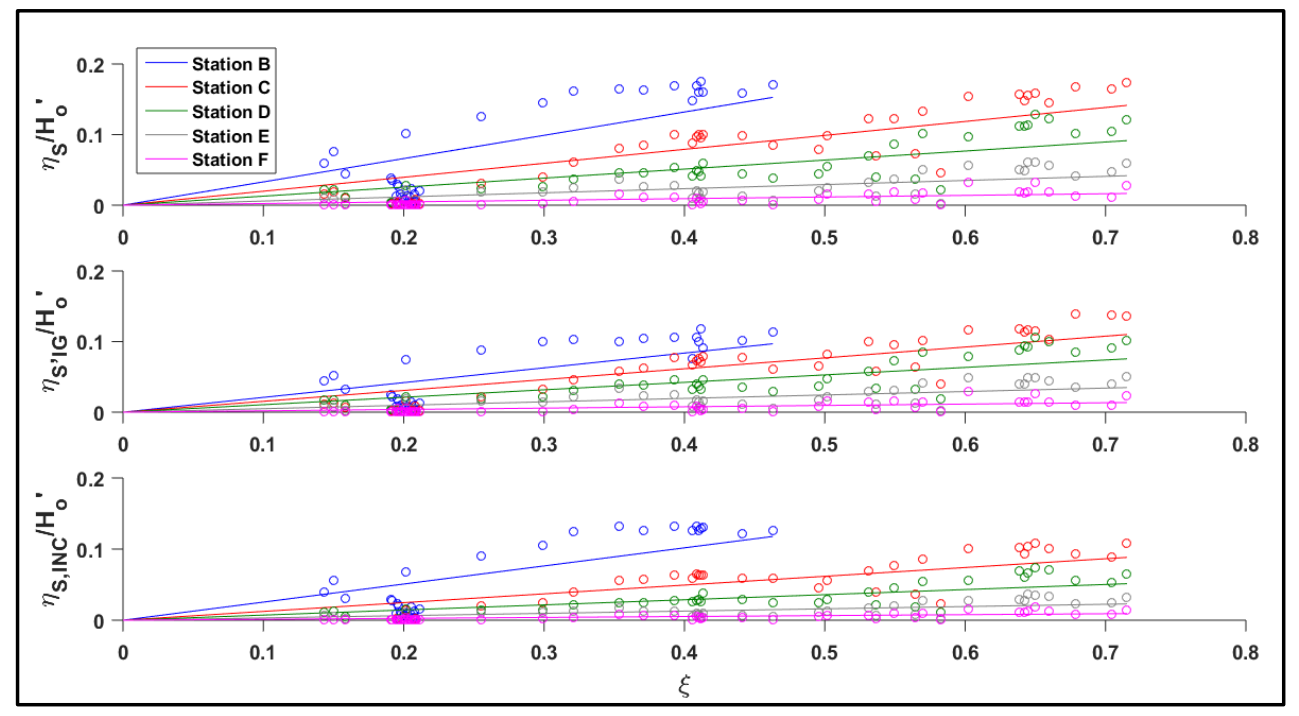

Figure 4.29: Total (top), infragravity band (middle), and incident band (bottom) significant water elevation (circles) correlated using linear regression (solid lines) with $\xi$ at each cross-shore deployment station during Nor'easter Riley. 
Table 4.8: Linear regression coefficients of normalized significant water elevation $\left(\eta_{S} / H_{o}^{\prime}, \eta_{S, I G} / H_{o}^{\prime}, \eta_{S, I N C} / H_{o}^{\prime}\right)$ vs. $\xi$ during Nor'easter Riley

\begin{tabular}{|l|c|c|c|}
\hline & $\begin{array}{c}\eta_{S} / H_{o}^{\prime} \\
m\left(r^{2}\right)\end{array}$ & $\begin{array}{c}\eta_{S, I G} / H_{o}^{\prime} \\
m\left(r^{2}\right)\end{array}$ & $\begin{array}{c}\eta_{S, I N C} / H_{o}^{\prime} \\
m\left(r^{2}\right)\end{array}$ \\
\hline Station B & $0.33(0.38)$ & $0.21(0.36)$ & $0.25(0.38)$ \\
\hline Station C & $0.20(0.62)$ & $0.15(0.63)$ & $0.12(0.58)$ \\
\hline Station D & $0.13(0.54)$ & $0.11(0.54)$ & $0.07(0.53)$ \\
\hline Station E & $0.06(0.43)$ & $0.05(0.43)$ & $0.03(0.42)$ \\
\hline Station F & $0.02(0.34)$ & $0.02(0.33)$ & $0.01(0.36)$ \\
\hline
\end{tabular}

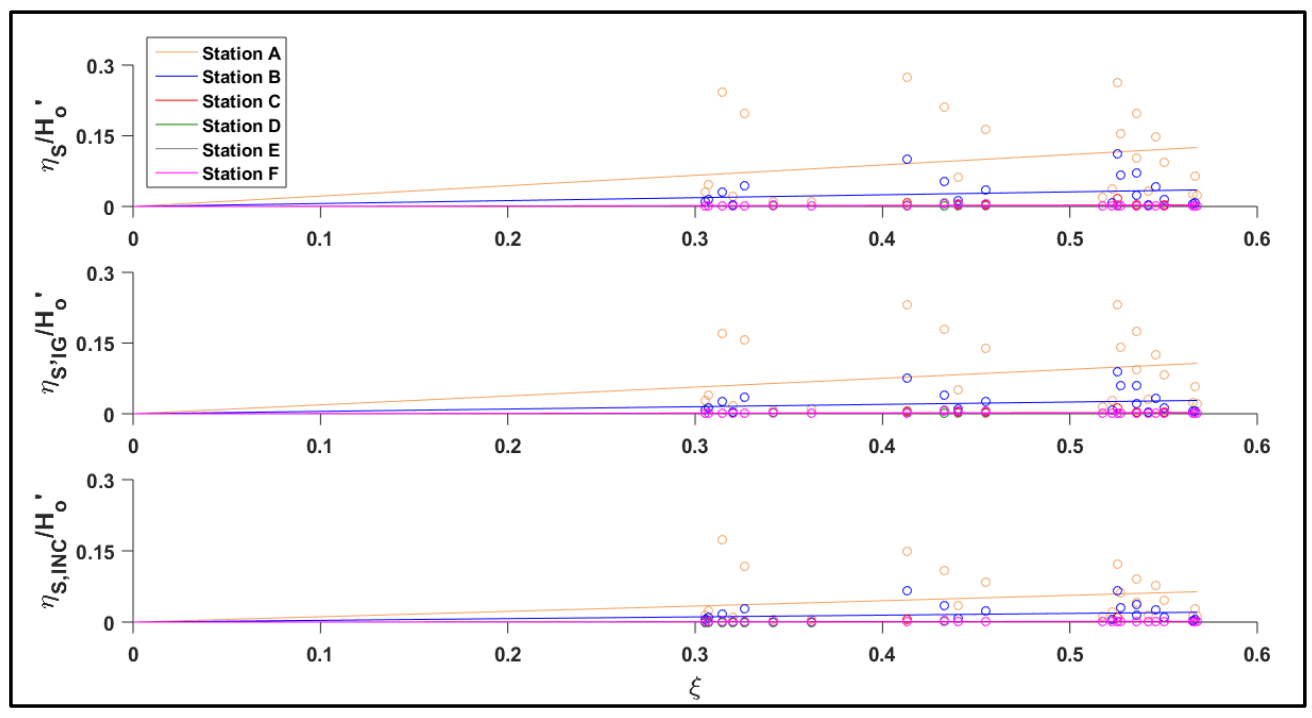

Figure 4.30: Total (top), infragravity band (middle), and incident band (bottom) significant water elevation (circles) correlated using linear regression (solid lines) with $\xi$ at each cross-shore deployment station during the Easter Eve Storm. 
Table 4.9: Linear regression coefficients of normalized significant water elevation $\left(\eta_{S} / H_{o}^{\prime}, \eta_{S, I G} / H_{o}^{\prime}, \eta_{S, I N C} / H_{o}^{\prime}\right)$ vs. $\xi$ during the Easter Eve Storm

\begin{tabular}{|l|c|c|c|}
\hline & $\begin{array}{c}\eta_{S} / H_{o}^{\prime} \\
m\left(r^{2}\right)\end{array}$ & $\begin{array}{c}\eta_{S, I G} / H_{o}^{\prime} \\
m\left(r^{2}\right)\end{array}$ & $\begin{array}{c}\eta_{S, I N C} / H_{o}^{\prime} \\
m\left(r^{2}\right)\end{array}$ \\
\hline Station A & $0.22(0.06)$ & $0.19(0.06)$ & $0.11(0.05)$ \\
\hline Station B & $0.06(0.04)$ & $0.05(0.04)$ & $0.04(0.03)$ \\
\hline Station C & $<0.01(0.02)$ & $<0.01(0.03)$ & $<0.01(0.01)$ \\
\hline Station D & $<0.01(0.06)$ & $<0.01(0.05)$ & $<0.01(0.07)$ \\
\hline Station E & $<0.01(0.02)$ & $<0.01(0.02)$ & $<0.01(0.04)$ \\
\hline Station F & $<0.01(0.05)$ & $<0.01(0.04)$ & $<0.01(0.04)$ \\
\hline
\end{tabular}

The linear correlation between the (normalized) significant water elevation and (dimensionless) dimensional parameters was more evident during Nor'easter Riley than the Easter Eve Storm. In general, the linear correlations during Nor'easter Riley had $r^{2}$ values greater than those during the Easter Eve Storm. A possible explanation for the poor calculated $r^{2}$ values during the Easter Eve Storm was the decreased $\gamma_{1}, \gamma_{2}$, and $\xi$ value dues to less extreme wave forcing compared to Nor'easter Riley.

Focusing on Nor'easter Riley, $r^{2}$ values increased when $\tan \theta$ was incorporated (i.e. $\gamma_{2}$ and $\xi$ ) where values increased over $100 \%$ when $\tan \theta$ was incorporated. The values for $m$ showed to decrease as cross-shore location moved landward (Table 4.4, Table 4.5, and Table 4.8).

The increase in low frequency energy during the storm events coincides with past studies and has shown to be important during storm events. The correlation of significant water elevation with various parameters showed to have 
a linear relationship and the magnitude of this correlation $(m)$ was dependent on cross-shore location. 


\section{Chapter 5}

\section{NUMERICAL MODELING}

Numerical models are widely used in coastal engineering to predict and analyze nearshore coastal processes (e.g. sediment transport) at various spatial and temporal scales. XBeach is an open-source numerical model to predict coastal hydrodynamics and morphodynamics during extreme events. Numerous studies (Berard et al., 2017; Daly et al., 2017; Kolokythas et al., 2016; van Rijn et al., 2003; Smallegan et al., 2016; Vousdoukas \& Almeida, 2011) have used collected field or laboratory data to qualitatively evaluate model performance and calibrate

input parameters. XBeach was originally funded by the United States Army Corps of Engineers (USACE) to assess hurricane impacts on sandy beaches, but has since been extended to apply to coral fringing, atoll reefs, vegetative damping, and ship wake studies (XBeach Manual, 2018).

XBeach solves for wave propagation, flow (depth-averaged), sediment transport, and bottom change through coupled 2D horizontal equations. The model allows for varying spectral waves, varying flow boundary conditions, and long-wave motions known as 'surf beat'. Wave forcing is obtained by the time dependent wave-action balance equation where the directional action density distribution is accounted for. The dissipation from the wave-action balance is a source term for the roller energy balance used to represent a shoreward shift in wave forcing due to momentum stored in surface rollers. Sediment transport is 
modeled using a depth-averaged advection-diffusion equation and avalanching is included to account for slumping sand from dune erosion (Roelvink et al., 2009).

XBeach has two simulation modes, hydrostatic and non-hydrostatic, that solves wave hydrodynamics on the scale of wave groups and individual waves, respectively. The hydrostatic mode was used in this study due to the reduced computational time and that the non-hydrostatic mode has been validated under fewer scenarios (e.g. gravel beaches; McCall et al., 2015).

\subsection{Model Set-up}

One-dimensional model simulations using the environmental conditions, bathymetry, and collected beach face profiles during Nor'easter Riley were performed to evaluate the performance of XBeach and calibrate various input parameters. Nor' easter Riley was the only storm modeled for this study due to available wave data from USACE DE003 buoy, the severity of the storm, and that in situ intra-storm data were collected to allow for model evaluation on a finer temporal scale than previously studies. All model simulations used wind, wave, and tidal forcing data from March 02, 2018 09:00 - March 05, 2018 06:00 and outputted results every minute of simulation time.

\subsubsection{Bathymetry and Grid}

Bathymetry data used for all model simulations were provided by DNREC while the pre-simulation beach face profiles were collected by RTK GPS. The cross-shore grid spacing $(d x)$ varied where offshore grid spacing was $10 \mathrm{~m}$ and onshore grid spacing was $1 \mathrm{~m}$ (Figure 5.1). The coarser offshore grid spacing was 
used to reduce computational time and the finer onshore grid spacing was used to increase spatial resolution in the highly dynamic nearshore region of the model domain.

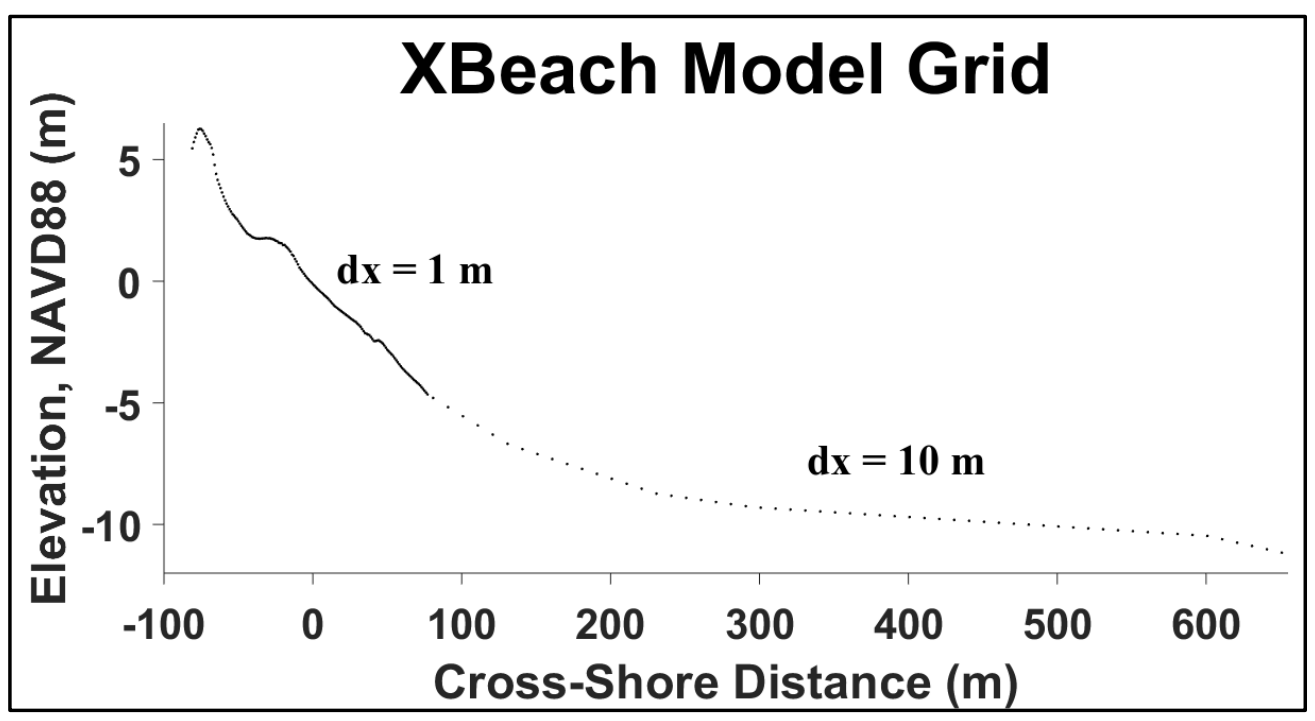

Figure 5.1: Pre-simulation cross-shore bathymetry and beach face profile with variable grid spacing.

\subsubsection{Environmental Conditions}

Wave and tidal forcing data were obtained from USACE DE003 buoy that is located offshore near Bethany Beach, Delaware $(38.5370 \mathrm{~N}, 75.0460 \mathrm{~W})$ in a nominal water depth of $11 \mathrm{~m}$, a similar offshore depth the provided bathymetry data reached. The wave forcing time series was input as a JONSWAP spectrum (Hasselmann et al., 1973) with a spreading parameter equal to 10 for wind waves (Goda, 2010). Wind forcing data were obtained from the Bethany Beach Boardwalk Station of the Delaware Environmental Observing System (DEOS). 
Figure 5.2 shows the timeseries of the wave, tidal, and wind forcing used in all model simulations.

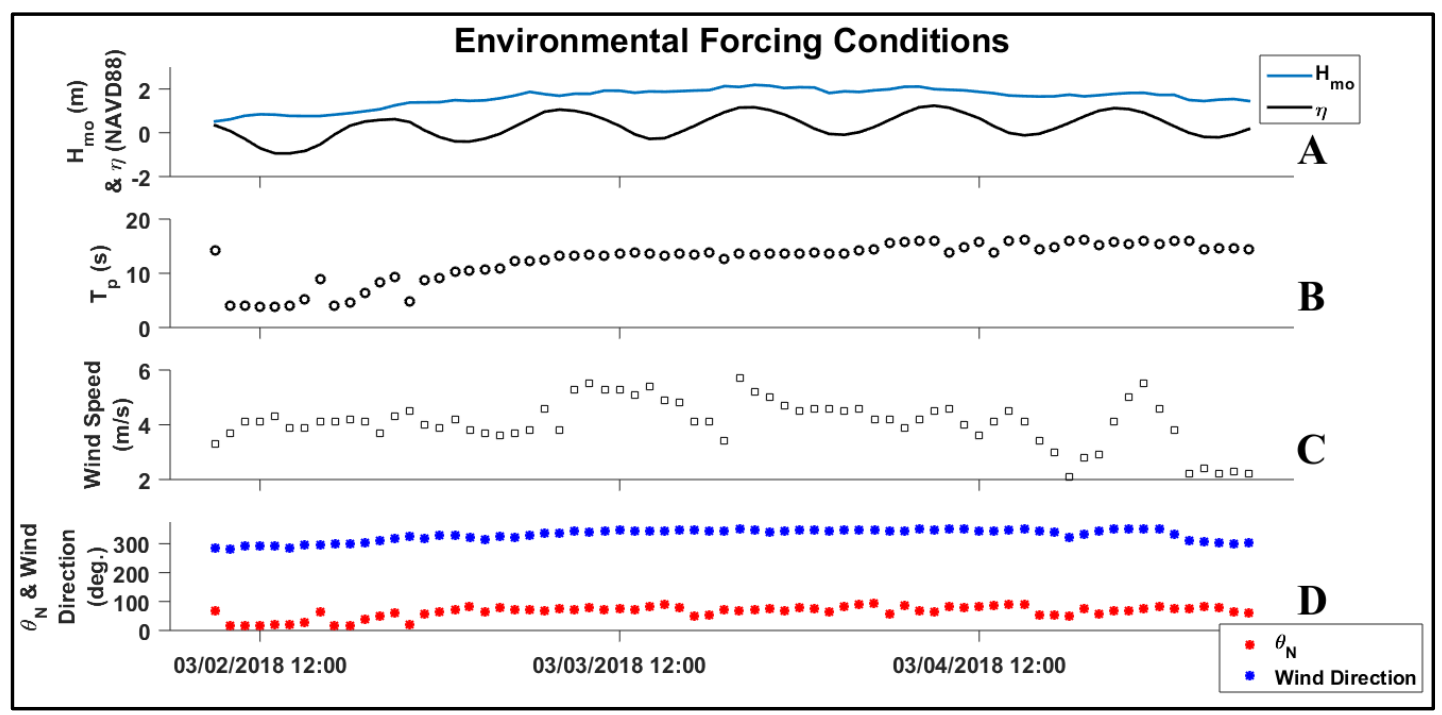

Figure 5.2: Environmental (wave, tidal, and wind) forcing conditions used in XBeach model simulations. Wave height (A, blue), water elevation (A, black), wave period (B), and wave direction (D, red) were obtained from USACE DE003 buoy. Wind speed (C) and wind direction $(\mathrm{D}$, blue) were obtained from the Bethany Beach Boardwalk Station of DEOS.

The sediment grain sizes used in all model simulations were taken to be consistent with previous analysis performed on the Delaware coast (Ramsey, 1999; Roberts et al., 2013) due to a lack of collected sediment samples during the Nor'easter Riley deployment. The $d_{50}$ and the $d_{90}$ (90\% finer by weight) used in the model simulations were $0.3 \mathrm{~mm}$ and $0.4 \mathrm{~mm}$, respectively. 


\subsubsection{Input Parameters}

XBeach allows for approximately 250 variable input parameters for various physical processes and model development. Sensitivity or calibration analysis is often performed using XBeach and other numerical models to determine the importance of tuning certain parameters and evaluating what parameter values result in the most accurate model simulation compared to collected laboratory or field data.

In this study, various input parameters were varied (Table 5.1) to calibrate XBeach during Nor'easter Riley and were chosen based on a review of the literature. The only non-default input parameter, not specified in Table 5.1, applied to all model simulations was to include bed slope effects in the direction of bed load sediment transport (bdslpeffdir $=$ talmon).

Table 5.1: Varied model input parameters

\begin{tabular}{|l|l|l|}
\hline Parameter & Description & Values \\
\hline facAs & $\begin{array}{l}\text { Calibration factor time } \\
\text { averaged flows due to wave } \\
\text { asymmetry }\end{array}$ & $0,0.05,0.1$ \\
\hline facSk & $\begin{array}{l}\text { Calibration factor time } \\
\text { averaged flows due to wave } \\
\text { skewness }\end{array}$ & $0.4,0.5,0.6,0.7,0.8$ \\
\hline wetslp & $\begin{array}{l}\text { Critical avalanching slope } \\
\text { under water }\end{array}$ & $0.05,0.1,0.3,0.5$ \\
\hline bedfriction & Bed friction formulation & manning, white-colebrook \\
\hline bedfriccoef & Bed friction coefficient & $\begin{array}{l}\mathrm{n}=0.017,0.02(\text { manning) } \\
\text { ks }=2.5 * d_{50}, 9.2 * d_{50} \text { (white- } \\
\text { colebrook })\end{array}$ \\
\hline
\end{tabular}




\subsection{Model Results}

\subsubsection{Input Parameter Sensitivity}

Morphodynamic results from XBeach model simulations have shown to be especially sensitive to the facAs and facSk parameters (Verheyen et al., 2014; Vousdoukas \& Almeida, 2011), as they directly affect the magnitude of onshore sediment transport through Equation 5.1:

$$
u_{a}=\left(f_{S k} * S_{k}-f_{A s} * A_{s}\right) * u_{r m s},
$$

where $u_{a}$ is the sediment advection velocity, $f_{S k}$ is the fac $S k$ parameter value, $S_{k}$ is the wave skewness, $f_{A s}$ is the facAs parameter value, $A_{s}$ is the wave asymmetry, and $u_{r m s}$ is the root-mean square velocity. The morphodynamic sensitivity resulting from variations in facAs and facSk values are shown in Figure 5.3 . 


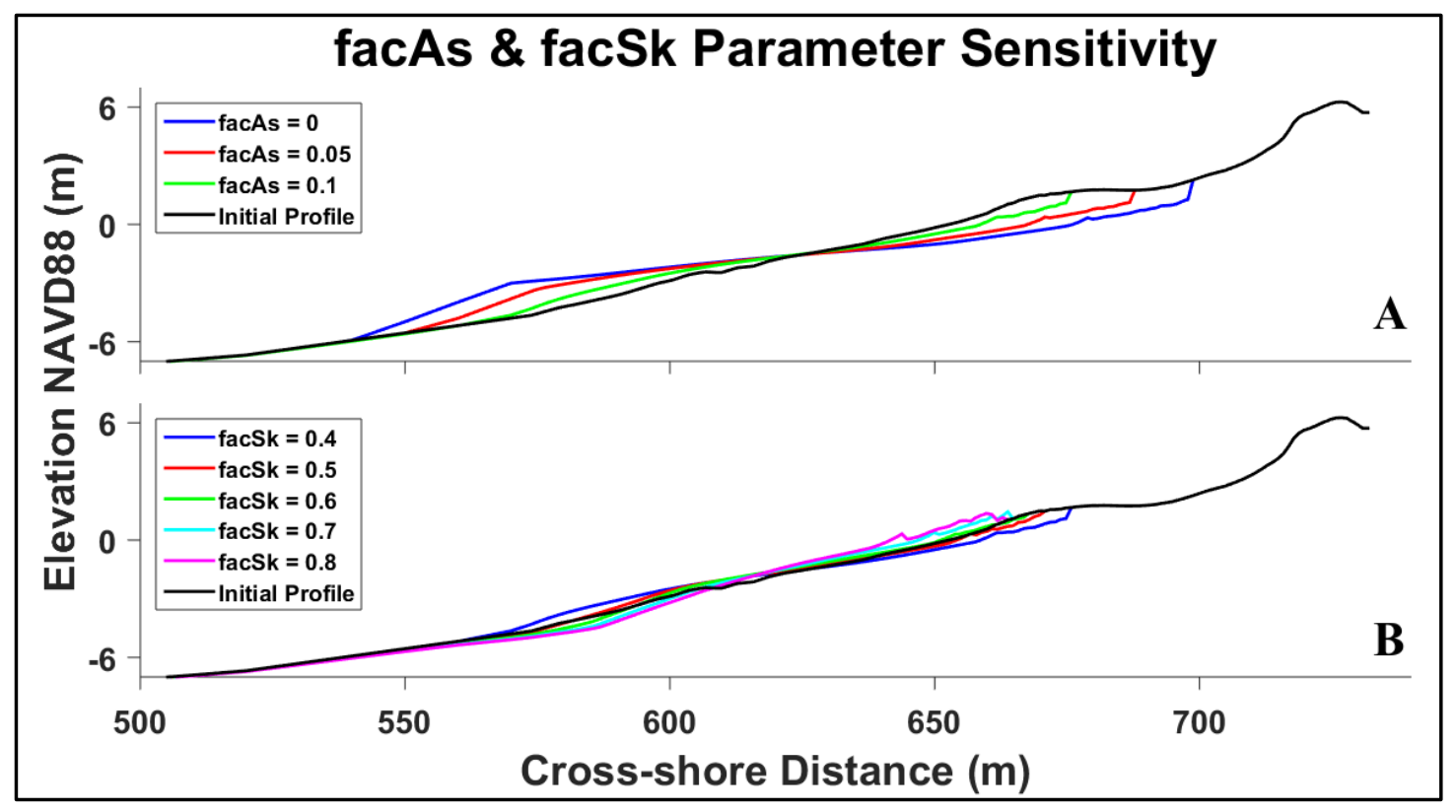

Figure 5.3: XBeach model simulations evaluating the sensitivity of the facAs (A) and facSk (B) parameters. The parameters wetslp, bedfriction, and bedfriccoef had values of 0.1 , manning, and 0.02, respectively, for all model simulations.

The wetslp parameter (default $=0.3$ ) defines the critical underwater bed slope to initiate the morphodynamic process of avalanching. Avalanching was included to account for sediment transport induced from slumping during storminduced beach erosion. When avalanching occurs, sediment is exchanged to adjacent grid cells until the critical bed slope is reestablished. The mathematical condition used in XBeach to induce avalanching is given by:

$$
\left|\frac{\partial z_{b}}{\partial x}\right|>\text { wetslp }
$$

where $\frac{\partial z_{b}}{\partial x}$ is the underwater bed slope. The sensitivity of the wetslp parameter values used for this study are given in Figure 5.4. 


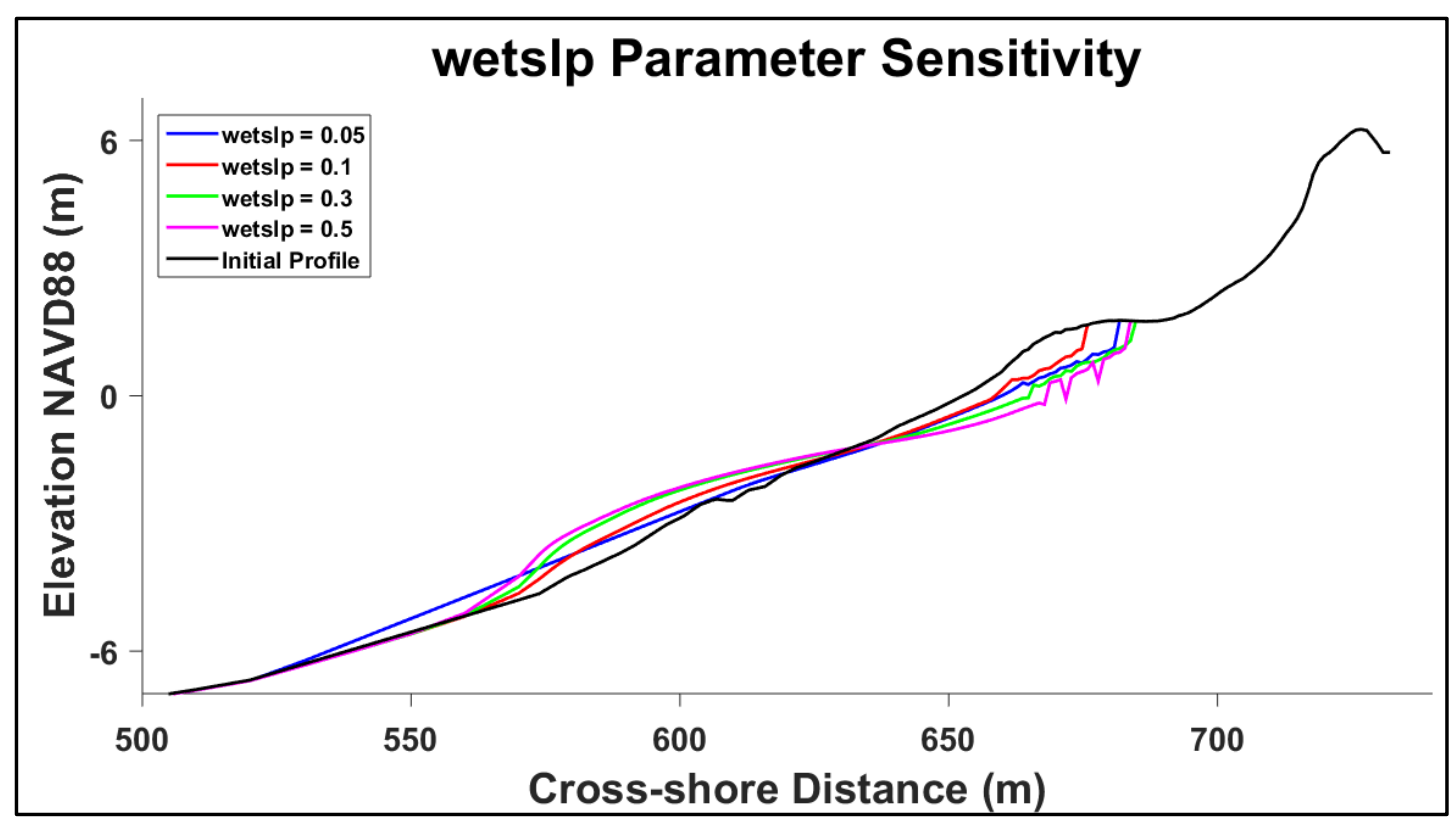

Figure 5.4: XBeach model simulations evaluating the sensitivity of the wetslp parameter. The parameters facAs, facSk, bedfriction, and bedfriccoef had values of 0.1, 0.4, manning, and 0.02 , respectively, for all model simulations.

The evaluation of bed friction is important in calculating bed shear stress which in turn affects the sediment transport rate. Bed shear stress is calculated in XBeach by:

$$
\begin{gathered}
\tau_{b x}^{E}=c_{f} * \rho * u_{E} * \sqrt{\left(1.16 * u_{r m s}\right)^{2}+\left(u_{E}+v_{E}\right)^{2}}, \\
\tau_{b y}^{E}=c_{f} * \rho * v_{E} * \sqrt{\left(1.16 * u_{r m s}\right)^{2}+\left(u_{E}+v_{E}\right)^{2}},
\end{gathered}
$$

where $u_{E}$ and $v_{E}$ are spatial components of the Eurlerian flow velocity and $c_{f}$ is the dimensionless bed friction coefficient. XBeach allows for $c_{f}$ to be calculated using multiple formulations. In this study, model simulations using the Manning (bedfriction $=$ manning $)$ and White-Colebrook (bedfriction $=$ white-colebrook $)$ 
formulations to calculate $c_{f}$ were evaluated. The sensitivity of the used values for $c_{f}$ (bedfriccoef) using the Manning formulation and White-Colebrook formulation are shown in Figure 5.5.

The Manning formulation calculates $c_{f}$ by:

$$
c_{f}=\sqrt{\frac{g * n^{2}}{h^{1 / 3}}}
$$

where $n$ is the Manning coefficient and is typically on the order of $0.02 \mathrm{~s} / \mathrm{m}^{1 / 3}$, as described in the XBeach manual and used in model simulations. A second value of $n\left(0.017 \mathrm{~s} / \mathrm{m}^{1 / 3}\right)$ used in model simulations was calculated from the following empirical formula (Bray, 1982):

$$
n=\frac{d_{50}^{1 / 6}}{4.9 * \sqrt{g}}
$$

The White-Colebrook formulation calculates $c_{f}$ by:

$$
c_{f}=\sqrt{\frac{g}{\left(18 * \log \left(\frac{12 * h}{k_{S}}\right)\right)^{2}}},
$$

where $k_{s}$ is the Nikurdase grain roughness and is typically on the order of $0.01-$ $0.15 \mathrm{~m}$, as given by the XBeach manual. A constant, nominal value of $k_{s}=2.5 *$ $d_{50}$ has been used in past studies (Barnes et al., 2009) and was used in model simulations. However, it may be more appropriate to use $k_{s}>2.5 * d_{50}$ during highly energetic events (i.e. storms) due to an increase in roughness from the occurrence of sheet flow (Mieras et al., 2017). To account for the probable presence of sheet flow during Nor'easter Riley, $k_{s}$ was estimated as a time 
averaged value of grain roughness as a function of the Shields parameter (Ribberink, 1998):

$$
k_{s}=\left\{\begin{array}{c}
d_{50}, \Theta \leq 1 \\
d_{50} *(1+6 *(\Theta-1)), \Theta>1
\end{array},\right.
$$

where $\Theta$ is the Shields parameter defined as:

$$
\Theta=\frac{\tau_{b}}{\rho * g *(s-1) * d_{50}},
$$

where $\tau_{b}$ is the bed shear stress estimated using the quadratic drag law:

$$
\tau_{b}=\frac{1}{2} * \rho * c_{f} * u *|u|,
$$

where $u$ is the cross-shore velocity measured in situ. Here, the maximum uprush velocity per swash event was used in Equation 5.9. By substituting Equation 5.9 and Equation 5.8 into Equation 5.7, a time dependent value for $k_{s}$ can be calculated. After time averaging, the value $k_{s}=9.2 * d_{50}$ was found and used in model simulations. 


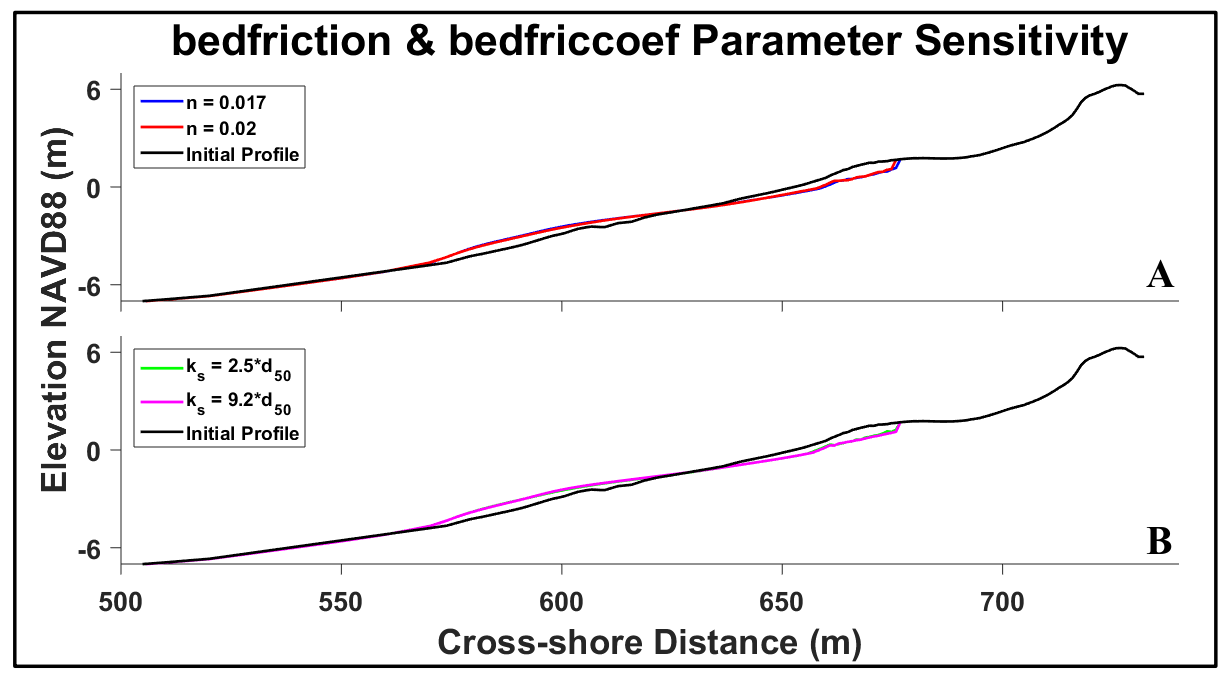

Figure 5.5: XBeach model simulations evaluating the sensitivity of the bedfriction (manning, A and white-colebrook, B) and bedfriccoef parameters. The parameters facAs, facSk, and wetslp had values of $0.1,0.4$, and 0.1 , respectively, for all model simulations.

\subsubsection{Model Calibration}

Calibration of the five varied input parameters required 240 model simulations to be executed. The Brier Skill Score (BSS) was used to quantitively evaluate model performance with respect to morphology:

$$
B S S=1-\frac{\left[\left(\left|z_{c}-z\right|\right)^{2}\right]}{\left[\left(z_{o}-z\right)^{2}\right]}
$$

where $z_{c}$ is the computed bed elevation from the XBeach model simulations, $z_{o}$ is the initial bed elevation and [...] denotes spatial averaging. The BSS will yield a score of 1 in the case of perfect computed-measured agreement, a score of 0 if model performance is as good as if no change was predicted, and a negative value if model performance is worse than predicting no change. Table 5.2 is a 
qualification of model performance based on ranges of BSS values (van Rijn et al., 2003; Smallegan et al., 2016).

Table 5.2: Qualification of model performance

\begin{tabular}{|l|l|}
\hline Qualification & BSS value range \\
\hline Excellent & $0.8-1.0$ \\
\hline Good & $0.6-0.8$ \\
\hline Fair & $0.3-0.6$ \\
\hline Poor & $0-0.3$ \\
\hline Bad & $<0$ \\
\hline
\end{tabular}

The input parameters used in the model simulations that resulted in the highest BSS value (0.83) are listed in Table 5.3 and the bed elevation results, along with collected GPS surveys, are shown in Figure 5.6. The time series of bed and water elevation at each cross-shore deployment station is shown in Figure 5.7 and Figure 5.8, respectively.

Table 5.3: Model simulation input parameters yielding the highest BSS value $(0.83)$

\begin{tabular}{|l|l|}
\hline Input Parameter & Value \\
\hline facAs & 0.05 \\
\hline facSk & 0.5 \\
\hline wetslp & 0.05 \\
\hline bedfriction & white-colebrook \\
\hline bedfriccoef & $2.5 * d_{50}$ \\
\hline
\end{tabular}




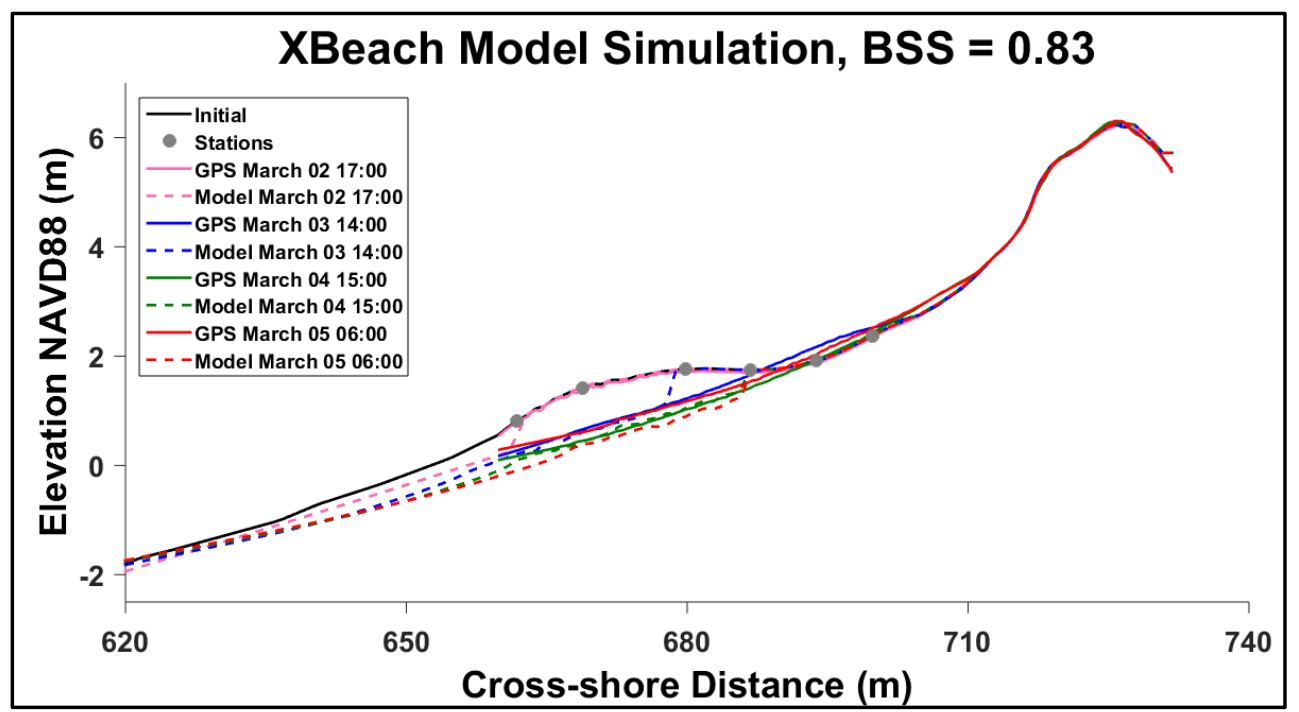

Figure 5.6: XBeach model results (broken lines) yielding the highest BSS (0.83) compared to collected GPS surveys (solid lines). Deployment stations (grey circles) are shown for reference.

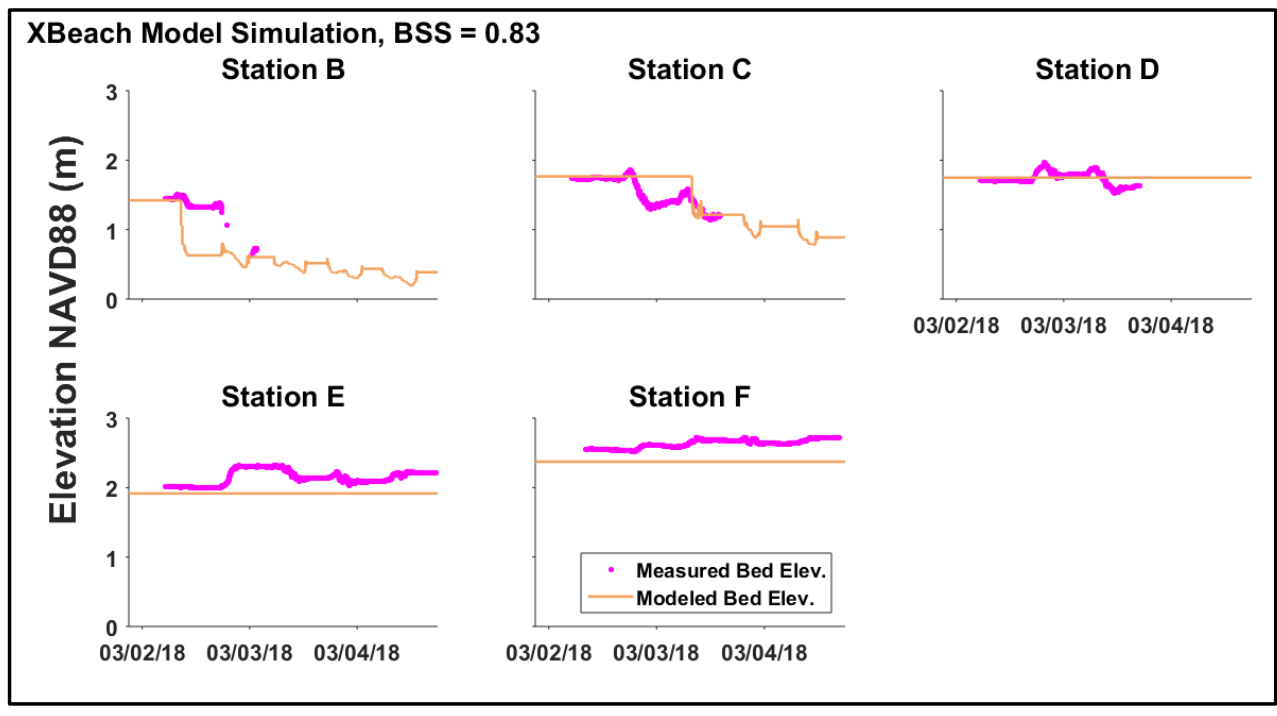

Figure 5.7: XBeach model results (tan) and collected in situ field data (magenta) time series of bed elevation at each cross-shore deployment station. 


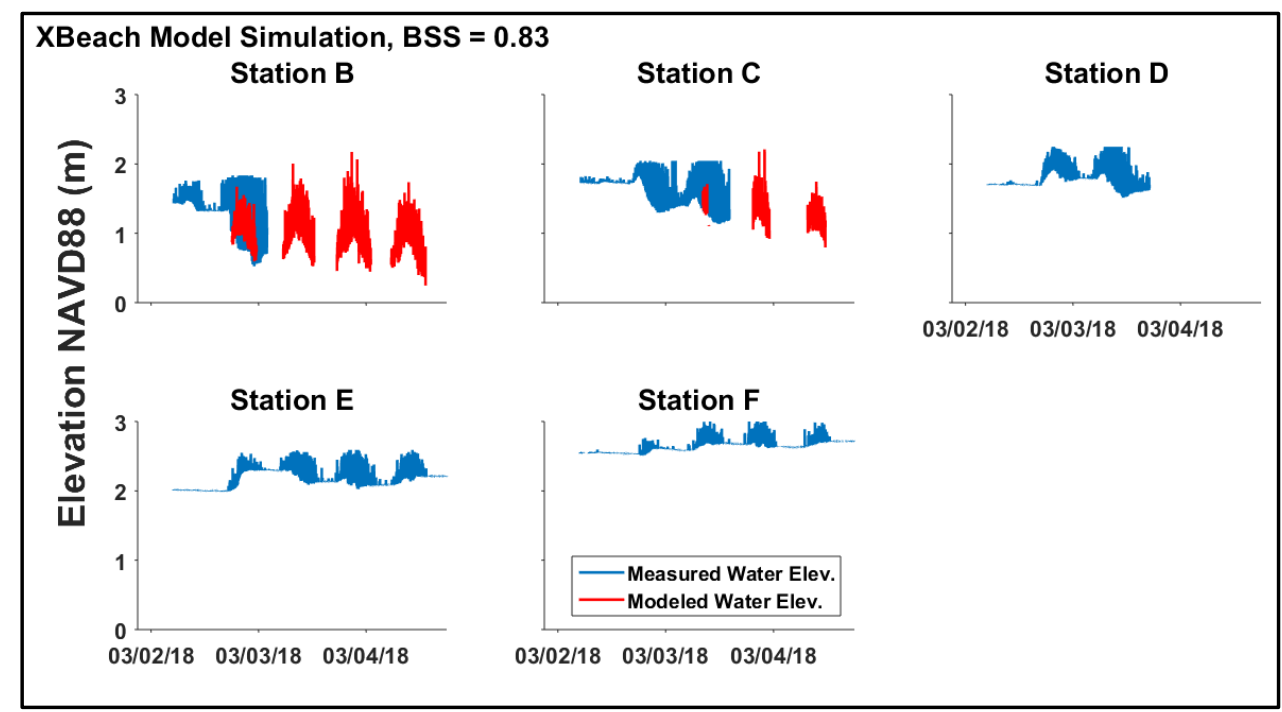

Figure 5.8: XBeach model results (red) and collected in situ field data (blue) time series of water elevation at each cross-shore deployment station.

\subsubsection{Discussion of Model Results}

Despite the excellent model performance, deficiencies in the model with respect to morphodynamics and hydrodynamics are present. The model results showed severe berm scarping to occur, but this did not match field measurements and observations (Figure 5.6). A possible explanation for the exaggerated scarping is that XBeach was originally developed to evaluate dune erosion where scarping is prevalent during storm events.

XBeach failed to resolve the onshore sediment transport and accretion that was present during Nor'easter Riley. The model resulted in no morphodynamic change or hydrodynamic forcing at Station D - F which clearly did not match field measurements and observations (Figure 5.7 and Figure 5.8). The lack of hydrodynamic forcing and morphodynamic change at Station D - F could be a 
result of berm scarping and the resulting inhibition of important morphodynamic feedback processes. From the above results, it can be concluded that a calibrated XBeach simulation can accurately predict morphodynamic change on the time scale of hours but fails to simulate morphodynamic change and hydrodynamic forcing on a shorter time scale.

The calibrated parameters shown in Table 5.3 should be used to model other storm events on the Delaware coast to evaluate their validity. Interestingly, the calibrated value for the wetslp parameter (0.05) resulted in no offshore bar formation (Figure 5.4), unlike the other tested parameter values, consistent with surf zone morphodynamics observed on the Delaware coast (Roberts et al., 2013). In a more model-intensive study, other input parameters and values should be tested for further calibration. 


\section{Chapter 6}

\section{CONCLUSION}

In situ field data were collected during an extreme storm event (Nor'easter Riley) and an energetic storm event (Easter Eve Storm) at Bethany Beach, Delaware to further understanding of the hydrodynamics and morphodynamics that occur across the beach face during storms. In situ data collection was attempted during a second extreme storm event (Nor'easter Toby) but was unsuccessful due to structural failure, emphasizing the necessity to deploy sensors with extreme structural integrity and to frequently visit the study site for sensor adjustment and retrieval. Despite the drawbacks experienced during Nor'easter Toby, the field studies during Nor'easter Riley and the Easter Eve Storm demonstrated the ability to successfully collect in situ field data during storm events and to identify possible research areas for future studies.

The ADM proved to be useful in the Nor'easter Riley and Easter Eve Storm deployments with the ability to measure water and bed elevation. Water depth was able to be calculated using a CLFF of measured bed elevations, when bed elevations were able to be identified, and showed to be more accurate than measuring water depth in situ due to a dynamic bed. Water velocity proved to be 
difficult to accurately measure, as the continuous submergence and emergence of the JFE EM resulted in unrealistic velocities during calm conditions.

Bed elevation measurements from the ADM allowed for nearly instantaneous measurements to study morphodynamics during storm events. The primary morphodynamic processes measured during Nor'easter Riley and the Easter Eve Storm was berm erosion and the resulting beach face steepening. While the effects of storm wave forcing on beach erosion is well known, berm erosion proved to also be an important factor to backbeach vulnerability. The largest amount of measured berm erosion was $0.8 \mathrm{~m}$ (Nor'easter Riley) and 0.47 m (Easter Eve Storm).

Morphodynamic change was measured at the more landward deployment stations following berm erosion coupled with increased wave heights and wave periods compared to pre-storm conditions. The morphodynamic feedback associated with intensified wave forcing and berm erosion was shown to increase backbeach vulnerability but could also increase dune vulnerability during more intense storms. Through spectral analysis an increase in low frequency (infragravity) energy was measured during the storm events, suggesting an importance to berm erosion and backbeach morphodynamic change.

The in situ field data collected during Nor'easter Riley were used to calibrate the numerical model, XBeach. The calibration of five input parameters were performed and evaluated based on the highest resulting BSS value. The 
calibrated input parameter values are shown in Table 5.3 and should be applied to other storm events on the Delaware coast to evaluate their validity.

The types of collected in situ field data during Nor'easter Riley and the Easter Eve Storm are fundamental in understanding the complexity of beach response to extreme forcing, which in turn can be used to improve predictive numerical models (e.g. XBeach, CShore) and coastal management decisions. Despite successful data collection, areas of improvement have been identified and should be implemented in future studies. These areas include a more accurate way to measure water velocity in the swash zone during storm events, the inclusion of more cross-shore transects to measure alongshore coastal processes, and the development (and inclusion) of a sensor, similar to the PCA, to continuously measure bed elevation even when the bed is submerged. 


\section{REFERENCES}

Aagaard, T. (1990). Infragravity waves and nearshore bars in protected, stormdominated coastal environments. Marine Geology, 94(3), 181-203. https://doi.org/10.1016/0025-3227(90)90069-V

Aagaard, T., Kroon, A., Andersen, S., Møller Sørensen, R., Quartel, S., \& Vinther, N. (2005). Intertidal beach change during storm conditions; Egmond, The Netherlands. Marine Geology, 218(1-4), 65-80. https://doi.org/10.1016/j.margeo.2005.04.001

Almeida, L. P., Masselink, G., Russell, P., Davidson, M., Poate, T., McCall, R., et al. (2013). Observations of the swash zone on a gravel beach during a storm using a laser-scanner (Lidar). Journal of Coastal Research, 65, 636641. https://doi.org/10.2112/SI65-108.1

Baldock, T. E., \& Holmes, P. (1999). Simulation and prediction of swash oscillations on a steep beach. Coastal Engineering, 36(3), 219-242. https://doi.org/10.1016/S0378-3839(99)00011-3

Balsillie, J. H. (1986). Beach and Coast Erosion Due to Extreme Event Impact. Shore and Beach, (54), 22-37.

Balsillie, J. H. (1999). Volumetric Beach and Coast Erosion Due to Storm and Hurricane Impact (Open File Report No. 78) (p. 37). Tallahassee, Florida: Florida Geological Survey.

Barbour, A. J., \& Parker, R. L. (2014). PSD: Adaptive, sine multitaper power spectral density estimation for R. Computers \& Geosciences, 63, 1-8.

Barnes, M. P., O’Donoghue, T., Alsina, J. M., \& Baldock, T. E. (2009). Direct bed shear stress measurements in bore-driven swash. Coastal Engineering, 56(8), 853-867. https://doi.org/10.1016/j.coastaleng.2009.04.004

Bascom, W. N. (1953). Characteristics of Natural Beaches. Coastal Engineering Proceedings, 1(4), 10. https://doi.org/10.9753/icce.v4.10

Bason, C., Borleske, S., Carter, D., Cole, P., Kasper, J., Leathers, D., et al. (2009). Recommended Sea Level Rise Scenarios for Delaware (Delaware Department of Natural Resources and Environmental Control (DNREC) Sea Level Rise Policy). Delaware Coastal Program Section of DNREC.

Battjes, J. A. (1974). Computation of set-up, longshore currents, run-up and overtopping due to wind-generated waves (Doctoral Thesis). Delft University of Technology, Delft, Netherlands.

Battjes, J. A., \& Roos, A. (1975). Characteristics of flow in run-up of periodic waves (No. 75-3). Delft, Netherlands: Delft University of Technology. 
Bender, M. A., Knutson, T. R., Tuleya, R. E., Sirutis, J. J., Vecchi, G. A., Garner, S. T., \& Held, I. M. (2010). Modeled Impact of Anthropogenic Warming on the Frequency of Intense Atlantic Hurricanes. Science, 327(5964), 454458. https://doi.org/10.1126/science. 1180568

Berard, N. A., Mulligan, R. P., da Silva, A. M. F., \& Dibajnia, M. (2017). Evaluation of XBeach performance for the erosion of a laboratory sand dune. Coastal Engineering, 125, 70-80. https://doi.org/10.1016/j.coastaleng.2017.04.002

Bray, D. I. (1982). Flow resistance in gravel-bed rivers. In Gravel-bed Rivers (pp. 109-137). New York: Wiley.

Breslin, S., \& Carr, A. (2018). Winter Storm Toby Strikes the Northeast: 3 Killed, 100,000 Lose Power as Millions Dig Out [Weather News]. Retrieved from https://weather.com/news/news/2018-03-20-winter-storm-toby-impactsmid-atlantic-northeast

Dalrymple, R. A., \& Thompson, W. W. (1977). Study of Equilibrium Beach Profiles (pp. 1277-1296). Presented at the 15th International Conference on Coastal Engineering, Honolulu, Hawaii: Coastal Engineering.

Daly, C., Floc'h, F., Almeida, L. P., \& Almar, R. (2017). Modelling accretion at Nha Trang Beach, Vietnam. Coastal Dynamics, (170), 1886-1896.

Davis, R. E., \& Dolan, R. (1993). Nor'easters. American Scientist, 81(5), 428439.

Dean, R. G. (1973). Heuristic models of sand transport in the surf zone (pp. 215221). Presented at the First Australian Conference on Coastal Engineering, Sydney, N.S.W.: Engineering Dynamics of the Coastal Zone.

Dean, R. G., \& Dalrymple, R. A. (1991). Water Wave Mechanics for Engineers and Scientists (Vol. 2). Hackensack, New Jersey: World Scientific Publishing Co. Pte. Ltd.

Dean, R. G., \& Dalrymple, R. A. (2004). Coastal Processes with Engineering Applications. Cambridge, UK: Cambridge University Press.

Dolan, R., \& Davis, R. E. (1992). An Intensity Scale for Atlantic Coast Northeast Storms. Journal of Coastal Research, 8(4), 840-853.

Duane, D. B. (1964). Significance Of Skewness In Recent Sediments, Western Pamlico Sound, North Carolina. Journal of Sedimentary Petrology, 34(4), 864-874. https://doi.org/10.1306/74D711B8-2B21-11D78648000102C1865D

Elko, N., Feddersen, F., Foster, D., Hapke, C., McNinch, J., Mulligan, R., et al. (2014). The Future of Nearshore Processes Research. The Nearshore Processes Community.

FitzGerald, D. M., van Heteren, S., \& Montello, T. M. (1994). Shoreline Processes and Damage Resulting from the Halloween Eve Storm of 1991 
Along the North and South Shores of Massachusetts Bay, U.S.A. Journal of Coastal Research, 10(1), 113-132.

Galvin, C. J. (1972). Wave Breaking in Shallow Water. In R. E. Meyer (Ed.), Waves on Beaches and Resuling Sediment Transport (pp. 413-456). New York: Academic Press.

van Gent, M. R. A. (2001). Wave Runup on Dikes with Shallow Foreshores. Journal of Waterway, Port, Coastal, and Ocean Engineering, 127(5), 254-262.

Goda, Y. (2010). Random Seas and Design of Maritime Structures (3rd ed., Vol. 33). Hackensack, New Jersey: World Scientific Publishing Co. Pte. Ltd.

Guza, Robert T., \& Inman, D. L. (1975). Edge waves and beach cusps. Journal of Geophysical Research, 80(21), 2997-3012. https://doi.org/10.1029/JC080i021p02997

Guza, R.T., Thornton, E. B., \& Holman, R. A. (1984). Swash on steep and shallow beaches (pp. 708-723). Presented at the 19th International Conference on Coastal Engineering, Houston, Texas: American Society of Civil Engineers.

Hallermeier, R. J. (1981). Terminal settling velocity of commonly occuring sand grains. Sedimentology, 28, 859-865.

Harley, M. D., Turner, I. L., Kinsela, M. A., Middleton, J. H., Mumford, P. J., Splinter, K. D., et al. (2017). Extreme coastal erosion enhanced by anomalous extratropical storm wave direction. Scientific Reports, 7(1). https://doi.org/10.1038/s41598-017-05792-1

Hasselmann, K., Barnett, T. P., Bouws, E., Carlson, H., Cartwright, D. E., Enke, K., et al. (1973). Measurements of wind-wave growth and swell decay during the Joint North Sea Wave Project (Hydraulic Engineering Reports No. 12). Hamburg, Germany: Deutsches Hydrographisches Institut.

Holman, R. A., Huntley, D. A., \& Bowen, A. J. (1978). Infragravity waves in storm conditions (pp. 268-284). Presented at the 16th International Conference on Coastal Engineering, Hamburg, Germany: American Society of Civil Engineers.

Hughes, S. A. (1983). Movable-Bed Modeling Law for Coastal Dune Erosion. Journal of Waterway, Port, Coastal, and Ocean Engineering, 109(2), 164-179. https://doi.org/10.1061/(ASCE)0733-950X(1983)109:2(164)

Hughes, S. A., \& Chiu, T. Y. (1981). Beach and Dune Erosion During Severe Storms (TR No. 43) (p. 290). Gainesville, Florida: Coastal and Oceanographic Engineering Department, University of Florida.

Hunt, I. A. (1959). Design of sea-walls and breakwaters. Journal of Waterways and Harbours Division, ASCE, 85(WW3), 123-152. 
Inman, D. L. (1952). Measures for Describing the Size Distribution of Sediments. Journal of Sedimentary Petrology, 22(3), 125-145.

Iribarren, C. R., \& Nogales, C. (1949). Protection des Ports (pp. 31-80). Presented at the XVII Congress of PIANC, Lisbon.

Kolokythas, G. A., Raquel, S., \& Blanco, M. R. D. (2016). Morphological evolution of a bed profile induced by a storm event at the Belgian coast predicted by XBeach model (pp. 1239-1246). Presented at the 26th International Ocean and Polar Engineering Conference, Rhodes, Greece: International Society of Offshore and Polar Engineers (ISOPE).

Komar, P. D. (1998). Beach Processes and Sedimentation (2nd ed.). Upper Saddle River, New Jersey: Prentice Hall.

Komar, P. D., \& Gaughan, M. K. (1972). Airy Wave Theory and Breaker Height Prediction. In Coastal Engineering (pp. 405-418). Vancouver, British Columbia, Canada: American Society of Civil Engineers.

Kriebel, D. L., \& Dalrymple, R. A. (1995). A Northeaster Risk Index. $R \& D$ Coastal Engineering.

Krumbein, W. C. (1936). Applications of Logarithmic Moments to Size Frequency Distribution of Sediments. Journal of Sedimentary Petrology, 6(1), 35-47.

Latham, W., \& Lewis, K. (2012). The Contribution of the Coastal Economy to the State of Delaware, 24.

LeComte, D. (2019). U.S. Weather Highlights 2018: Another Historic Hurricane and Wildfire Season. Weatherwise, 72(3), 12-23. https://doi.org/10.1080/00431672.2019.1586492

Mase, H. (1989). Random Wave Runup Height on Gentle Slope. Journal of Waterway, Port, Coastal, and Ocean Engineering, 115(5), 649-661. https://doi.org/10.1061/(ASCE)0733-950X(1989)115:5(649)

Masters, J. (2018). Winter Storm Riley Kills 7, Knocks out Power to 2 Million [Weather News].

McCall, R. T., Masselink, G., Poate, T. G., Roelvink, J. A., \& Almeida, L. P. (2015). Modelling the morphodynamics of gravel beaches during storms with XBeach-G. Coastal Engineering, 103, 52-66. https://doi.org/10.1016/j.coastaleng.2015.06.002

McCowan, J. (1894). On the highest wave of permanent type. The London, Edinburgh, and Dublin Philosophical Magazine and Journal of Science, 38(233), 351-358.

Mieras, R. S., Puleo, J. A., Anderson, D., Cox, D. T., \& Hsu, T.-J. (2017). Largescale experimental observations of sheet flow on a sandbar under skewed- 
asymmetric waves: WAVE-INDUCED SHEET FLOW ON SANDBAR. Journal of Geophysical Research: Oceans, 122(6), 5022-5045.

https://doi.org/10.1002/2016JC012438

New Jersey Office of Emergency Management. (2014). New Jersey State Hazard Mitigation Plan 2014 (pp. 5.9-5). State of New Jersey.

Puleo, J. A., \& Torres-Freyermuth, A. (2016). The second international workshop on swash-zone processes. Coastal Engineering, 115, 1-7. https://doi.org/10.1016/j.coastaleng.2015.09.007

Ramsey, K. (1999). Beach Sand Textures from the Atlantic Coast of Delaware (No. 41). State of Delaware: Delaware Geological Survey.

Ribberink, J. (1998). Bed-load transport for steady flows and unsteady oscillatory flows. Coastal Engineering, 34(1-2), 59-82.

van Rijn, L. C., Walstra, D. J. R., Grasmeijer, B., Sutherland, J., Pan, S., \& Sierra, J. P. (2003). The predictability of cross-shore bed evolution of sandy beaches at the time scale of storms and seasons using process-based Profile models. Coastal Engineering, 47, 295-327. https://doi.org/10.1016/S0378-3839(02)00120-5

Roberts, T. M., Wang, P., \& Puleo, J. A. (2013). Storm-driven cyclic beach morphodynamics of a mixed sand and gravel beach along the Mid-Atlantic Coast, USA. Marine Geology, 346, 403-421. https://doi.org/10.1016/j.margeo.2013.08.001

Roelvink, D., Reniers, A., van Dongeren, A., van Thiel de Vries, J., McCall, R., \& Lescinski, J. (2009). Modelling storm impacts on beaches, dunes and barrier islands. Coastal Engineering, 56, 1133-1152. https://doi.org/10.1016/j.coastaleng.2009.08.006

Runkle, J., Kunkel, K. E., Easterling, D., Frankson, R., Champion, S., Stewart, B. C., et al. (2017). Delaware State Climate Summary (State Summaries No. 149- DE). NOAA National Centers for Environmental Information.

Russell, P. E. (1993). Mechanisms for beach erosion during storms. Continental Shelf Research, 13(11), 1243-1265. https://doi.org/10.1016/02784343(93)90051-X

Saffir, H. S. (1977). Design and Construction Requirements for Hurricane Resistant Construction (No. 2830) (p. 20). American Society of Civil Engineers.

Savadove, L., \& Buchholz, M. T. (1997). Great Storms of the Jersey Shore (1st ed.). New Jersey: Down the Shore Publishing.

Scripps Institution of Oceanography. (1944). Effect of bottom slope on breaker characteristics as observed along the Scripps Institution pier (Wave Report No. 24). La Jolla, California. 
Senechal, N., Coco, G., Bryan, K. R., \& Holman, R. A. (2011). Wave runup during extreme storm conditions. Journal of Geophysical Research, 116(C7). https://doi.org/10.1029/2010JC006819

Shepard, F. P. (1950). Beach cycles in Southern California (Beach Erosion Board Technical Memo No. 20). US Army Corps of Engineers.

Simpson, R. H. (1971). A Proposed Scale for Ranking Hurricanes by Intensity. Miami, Florida: Minutes of the Eighth NOAA, NWS Hurricane Conference.

Smallegan, S. M., Irish, J. L., Van Dongeren, A. R., \& Den Bieman, J. P. (2016). Morphological response of a sandy barrier island with a buried seawall during Hurricane Sandy. Coastal Engineering, 110, 102-110. https://doi.org/10.1016/j.coastaleng.2016.01.005

Smith, A., Lott, N., Houston, T., Shein, K., Crouch, J., \& Enloe, J. (2019). U.S. Billion-Dollar Weather \& Climate Disasters 1980-2019. NOAA National Centers for Environmental Information.

Steetzel, H. J. (1993). Cross-shore Transport During Storm Surges (Ph. D. Dissertation). Delft University of Technology, Delft, Netherlands.

Stockdon, H. F., Holman, R. A., Howd, P. A., \& Sallenger, A. H. (2006). Empirical parameterization of setup, swash, and runup. Coastal Engineering, 53(7), 573-588. https://doi.org/10.1016/j.coastaleng.2005.12.005

Sverdrup, H. U., \& Munk, W. H. (1946). Theoretical and empirical relations in forecasting breakers and surf. Eos, Transactions, American Geophysical Union, 27(6), 828-836.

Thomson, D. J. (1982). Spectrum estimation and harmonic analysis. Proceedings of the IEEE, 70(9), 1055-1096. https://doi.org/10.1109/PROC.1982.12433

Turner, I. L., Russell, P. E., \& Butt, T. (2008). Measurement of wave-by-wave bed-levels in the swash zone. Coastal Engineering, 55(12), 1237-1242. https://doi.org/10.1016/j.coastaleng.2008.09.009

Verheyen, B., Gruwez, V., Zimmermann, N., Bolle, A., \& Wauters, P. (2014). Medium term time-dependent morphodynamic modelling of beach profile evolution in Ada, Ghana (pp. 701-708). Presented at the 11th International Conference on Hydroscience \& Engineering, Hamburg, Germany: Henry Hydraulic Engineer Respository.

Vousdoukas, \& Almeida, L. P. (2011). Modelling storm-induced beach morphological change in a meso-tidal, reflective beach using XBeach. Journal of Coastal Research, (64), 1916-1920.

Vousdoukas, M. I., Almeida, L. P. M., \& Ferreira, Ó. (2012). Beach erosion and recovery during consecutive storms at a steep-sloping, meso-tidal beach: Beach Erosion/Recovery During Consecutive Storms. Earth Surface 
Processes and Landforms, 37(6), 583-593.

https://doi.org/10.1002/esp.2264

Welch, P. D. (1967). The use of Fast Fourier Transform for the estimation of power spectra: A method based on time averaging over short, modified periodograms. IEEE Transactions on Audio and Electroacoustics, 15(2), 70-73.

Whitfield, A., \& Elliott, M. (2011). Ecosystem and Biotic Classifications of Estuaries and Coasts. In Treatise on Estuarine and Coastal Science (pp. 99-124). Elsevier. https://doi.org/10.1016/B978-0-12-374711-2.00108-X

Wood, F. J. (1982). Tidal Dynamics: Coastal Flooding and Cycles of Gravitational Force. Dordrecht, Holland: Reidel.

Wright, L. D. (1980). Beach Cut in Relation to Surf Zone Morphodynamics (pp. 978-996). Coastal Engineering.

Wright, L. D., \& Short, A. D. (1984). Morphodynamic Variability of Surf Zones and Beaches: A Synthesis. Marine Geology, 56, 93-118.

XBeach Manual. (2018). XBeach Documentation (Manual).

Zhang, K., Douglas, B. C., \& Leatherman, S. P. (2001). Beach Erosion Potential for Severe Nor'easters. Journal of Coastal Research, 17, 13. 